\title{
Integration of Renewable Energy into Present and Future Energy Systems
}

Coordinating Lead Authors:

Ralph Sims (New Zealand), Pedro Mercado (Argentina), Wolfram Krewitt $\dagger$ (Germany)

Lead Authors:

Gouri Bhuyan (Canada), Damian Flynn (Ireland), Hannele Holttinen (Finland), Gilberto Jannuzzi (Brazil), Smail Khennas (Senegal/Algeria), Yongqian Liu (China), Lars J. Nilsson (Sweden), Joan Ogden (USA), Kazuhiko Ogimoto (Japan), Mark O'Malley (Ireland), Hugh Outhred (Australia), Øystein Ulleberg (Norway), Frans van Hulle (Belgium)

\section{Contributing Authors:}

Morgan Bazilian (Austria/USA), Milou Beerepoot (France), Trevor Demayo (USA/Canada), Eleanor Denny (Ireland), David Infield (United Kingdom), Andrew Keane (Ireland), Arthur Lee (USA), Michael Milligan (USA), Andrew Mills (USA), Michael Power (Ireland), Paul Smith (Ireland), Lennart Söder (Sweden), Aidan Tuohy (USA),

Falko Ueckerdt (Germany), Jingjing Zhang (Sweden)

\section{Review Editors:}

Jim Skea (United Kingdom) and Kai Strunz (Germany)

This chapter should be cited as:

Sims, R., P. Mercado, W. Krewitt, G. Bhuyan, D. Flynn, H. Holttinen, G. Jannuzzi, S. Khennas, Y. Liu, M. O'Malley, L. J. Nilsson, J. Ogden, K. Ogimoto, H. Outhred, Ø. Ulleberg, F. van Hulle, 2011: Integration of Renewable Energy into Present and Future Energy Systems. In IPCC Special Report on Renewable Energy Sources and Climate Change Mitigation [0. Edenhofer, R. Pichs-Madruga, Y. Sokona, K. Seyboth, P. Matschoss, S. Kadner, T. Zwickel, P. Eickemeier, G. Hansen, S. Schlömer, C. von Stechow (eds)], Cambridge University Press, Cambridge, United Kingdom and New York, NY, USA. 


\section{Table of Contents}

Executive Summary

8.1 Introduction

8.1.1 Objectives

8.1.2 Structure of the chapter

8.2 Integration of renewable energy into supply systems

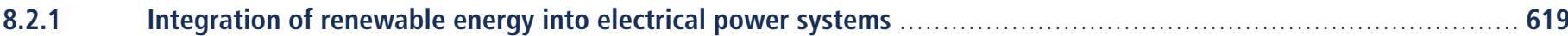

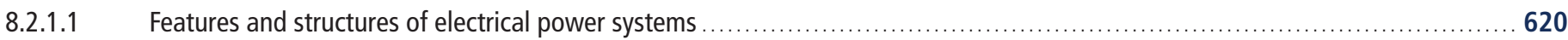

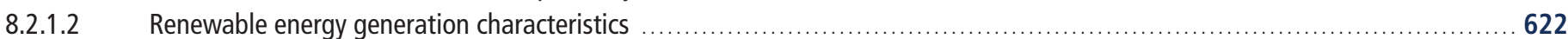

8.2.1.3 Integration of renewable energy into electrical power systems: experiences, studies and options _...........................627

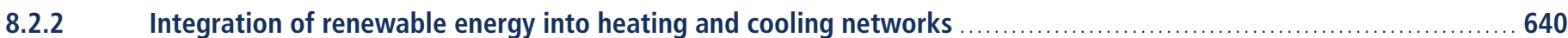

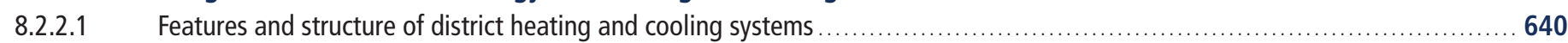

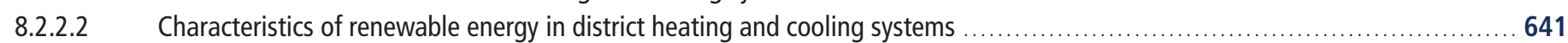

8.2.2.3 Challenges associated with renewable energy integration into district heating and cooling networks ...........................642 642

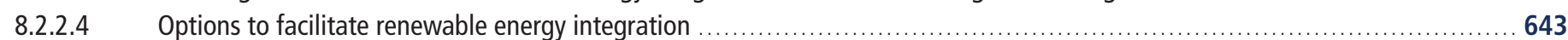

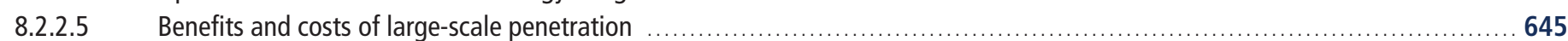

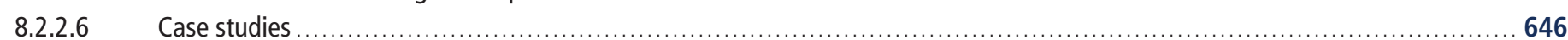

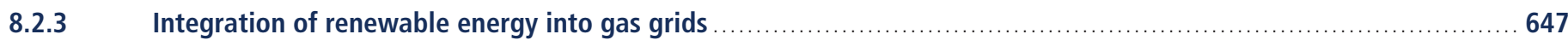

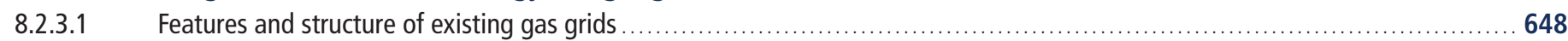

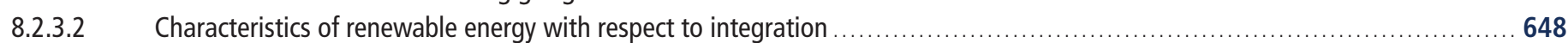

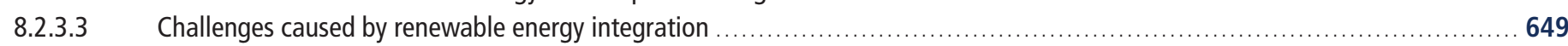

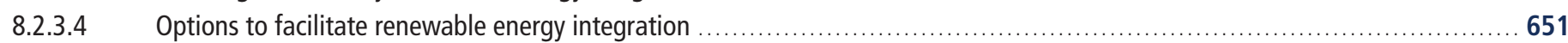

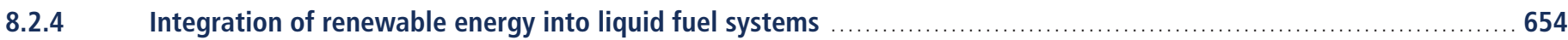

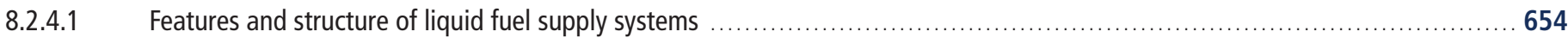

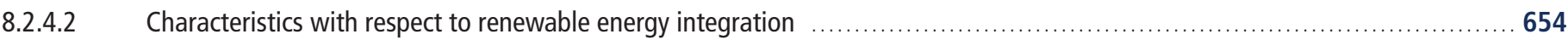

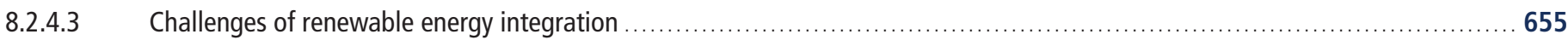

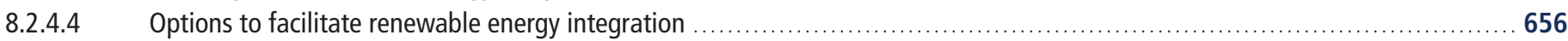

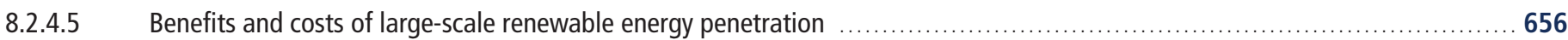

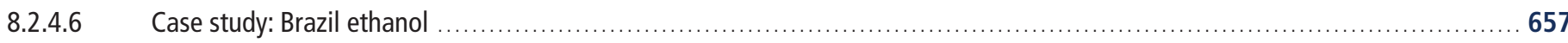

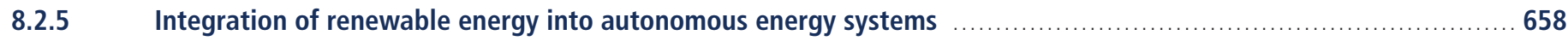

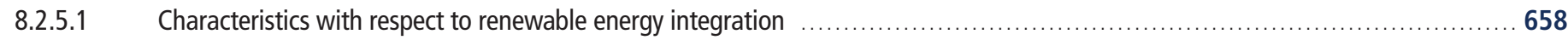

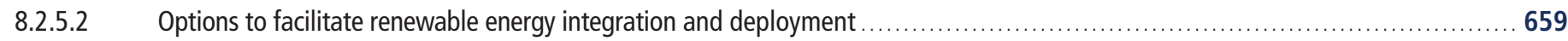

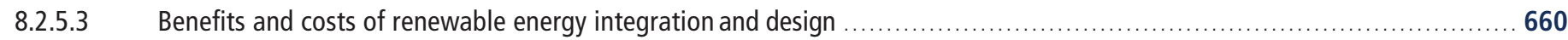

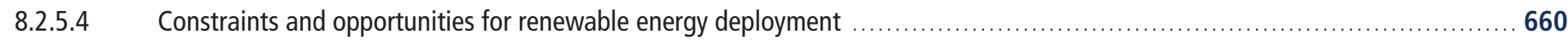

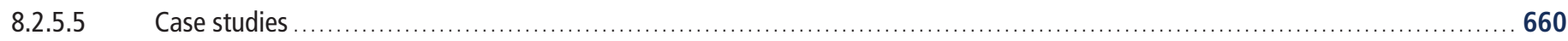




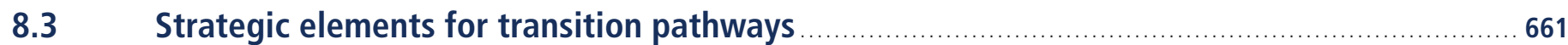

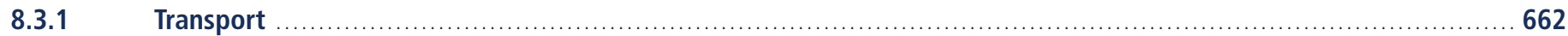

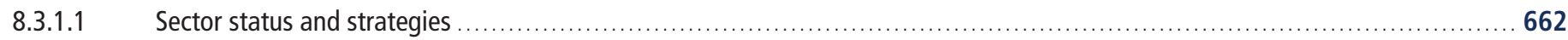

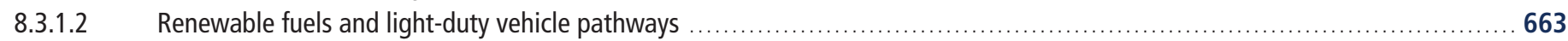

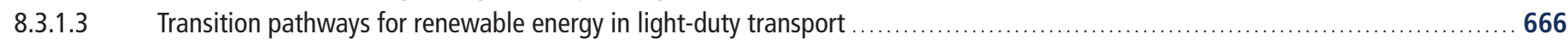

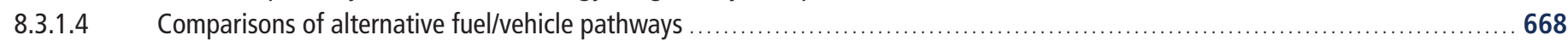

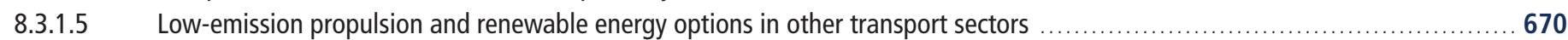

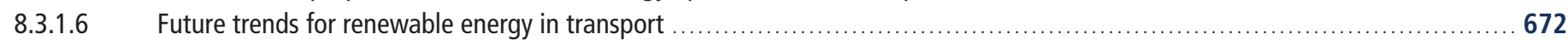

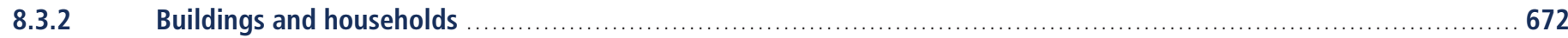

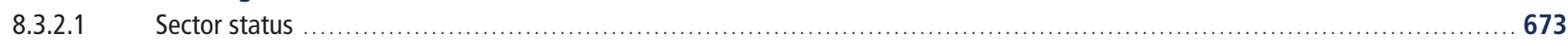

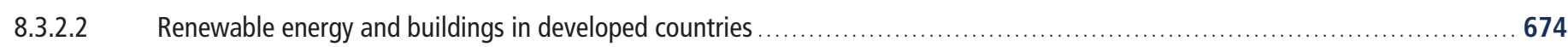

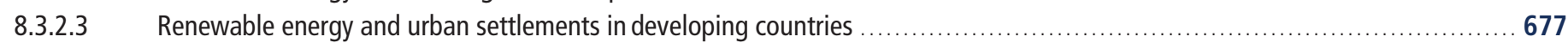

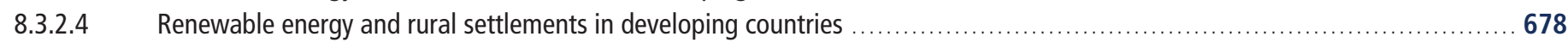

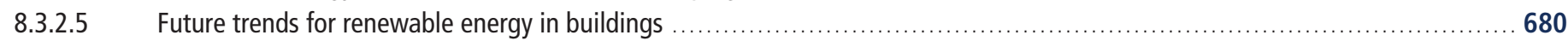

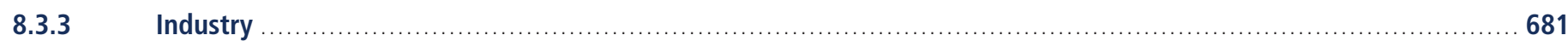

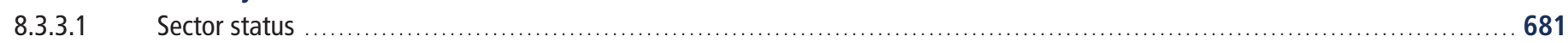

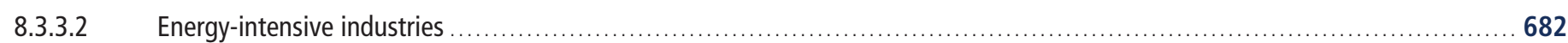

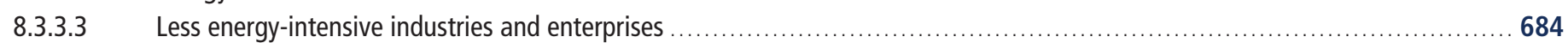

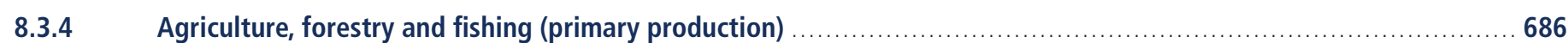

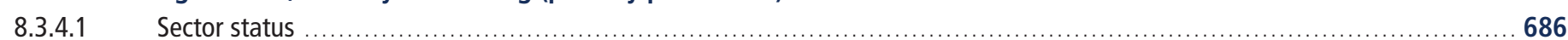

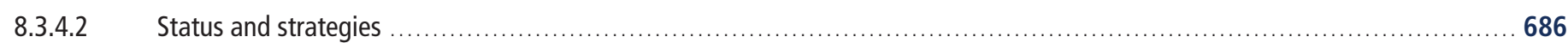

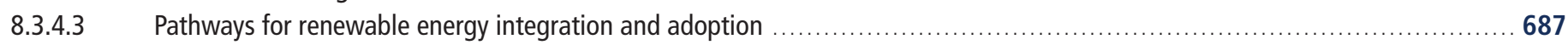

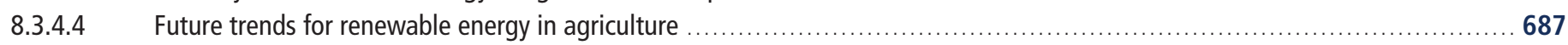

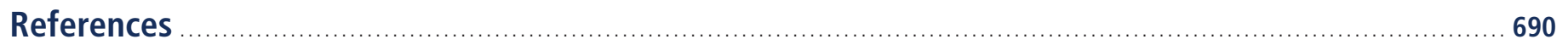




\section{Executive Summary}

To achieve higher renewable energy (RE) shares than the low levels typically found in present energy supply systems will require additional integration efforts starting now and continuing over the longer term. These include improved understanding of the RE resource characteristics and availability, investments in enabling infrastructure and research, development and demonstrations (RD\&D), modifications to institutional and governance frameworks, innovative thinking, attention to social aspects, markets and planning, and capacity building in anticipation of RE growth.

In many countries, sufficient RE resources are available for system integration to meet a major share of energy demands, either by direct input to end-use sectors or indirectly through present and future energy supply systems and energy carriers, whether for large or small communities in Organisation for Economic Co-operation and Development (OECD) or non-OECD countries. At the same time, the characteristics of many RE resources that distinguish them from fossil fuels and nuclear systems include their natural unpredictability and variability over time scales ranging from seconds to years. These can constrain the ease of integration and result in additional system costs, particularly when reaching higher RE shares of electricity, heat or gaseous and liquid fuels.

Existing energy infrastructure, markets and other institutional arrangements may need adapting, but there are few, if any, technical limits to the planned system integration of RE technologies across the very broad range of present energy supply systems worldwide, though other barriers (e.g., economic barriers) may exist. Improved overall system efficiency and higher RE shares can be achieved by the increased integration of a portfolio of RE resources and technologies. This can be enhanced by the flexible cogeneration of electricity, fuels, heating and cooling, as well as the utilization of storage and demand response options across different supply systems. Real-world case studies outlined throughout the chapter exemplify how different approaches to integration within a specific context have successfully achieved RE deployment by means of a combination of technologies, markets, and social and institutional mechanisms. Examples exist of islands, towns and communities achieving high shares of RE, with some approaching $100 \%$ RE electricity penetration and over a $50 \%$ share of liquid fuels for their light duty vehicle fleets.

Several mature RE technologies, including wind turbines, small and large hydropower generators, geothermal systems, bioenergy cogeneration plants, biomethane production, first generation liquid biofuels, and solar water heaters, have already been successfully integrated into the energy systems of some leading countries. Further integration could be encouraged by both national and local government initiatives. Over the longer term, integration of other less mature, pre-commercial technologies, including advanced biofuels, solar fuels, solar coolers, fuel cells, ocean energy technologies, distributed power generation, and electric vehicles, requires continuing investments in RD\&D, infrastructure, capacity building and other supporting measures.

To reach the RE levels being projected in many scenarios over future decades will require integration of RE technologies at a higher rate of deployment than at present in each of the electricity generation, heating/ cooling, gas and liquid fuel distribution, and autonomous energy supply systems.

RE can be integrated into all types of electricity supply systems, from large, interconnected, continental-scale grids to on-site generation and utilization in small, autonomous buildings. Technically and economically feasible levels of RE penetration depend on the unique characteristics of a system. These include the status of infrastructure development and interconnections, mix of generation technologies, control and communication capability, demand pattern and geographic location in relation to the RE resources available, market designs, and institutional rules.

The distribution, location, variability and predictability of the RE resources will also determine the scale of the integration challenge. Short time-variable wind, wave and solar resources can be more difficult to integrate than dispatchable reservoir hydro, bioenergy and geothermal resources, which tend to vary only over longer periods (years and decades). As variable RE penetration levels increase, maintaining system reliability becomes more challenging and costly. Depending on the specifics of a given electricity system, a portfolio of solutions to minimize the risks to the system and the costs of RE integration can include the development of complementary, flexible generation; strengthening and extending the network infrastructure; 
interconnection; electricity demand that can respond in relation to supply availability; energy storage technologies (including hydro reservoirs); and modified institutional arrangements including regulatory and market mechanisms.

District heating $(D H)$ and cooling $(D C)$ systems offer flexibility with regard to the primary energy source, thereby enabling a gradual or rapid transition from the present use of fossil fuel sources to a greater share of RE. DH can use low temperature thermal RE inputs (such as solar or cascaded geothermal heat), or biomass with few competing uses (such as refuse-derived fuels or industrial wastes). DC systems are less common but also offer resource flexibility by being able to use a variety of natural waterways for the source of cold as well as ground source heat pumps. Thermal storage capability (hot or cold) can overcome the challenges of RE variability.

Injecting biomethane or, in the future, RE-derived hydrogen into gas distribution grids can be technically and economically achieved in order to meet a wide range of applications, including for transport, but successful integration requires that appropriate gas quality standards are met.

Liquid fuel systems can integrate biofuels either for cooking (such as ethanol gels and, in the future, dimethyl ether (DME)) or for transport applications when bioethanol or biodiesel esters are usually, but not always, blended with petroleum-based fuels to meet vehicle engine fuel specifications. Advanced biofuels developed in the future to tight specifications may be suitable for direct, unblended use in current and future engine designs used for road, aviation and marine applications.

Autonomous energy supply systems are typically small-scale and are often located in remote areas, small islands, or individual buildings where the provision of commercial energy is not readily available through grids and networks. The viability of autonomous RE systems depends upon the local RE resources available, the costs of RE technologies, future innovation, and the possible avoidance of construction costs for new or expanded infrastructure to service the location.

There are multiple pathways for increasing the share of RE through integration across the transport, building, industry and primary production end-use sectors, but the ease and additional costs of integration vary depending on the specific region, sector and technology.

Being contextual and complex, it is difficult to assess 'typical' system integration costs. These differ widely depending on the characteristics of the available RE resources; the geographic distance between the resource and the location of energy demand; the different integration approaches for large centralized systems versus decentralized, small-scale, local RE systems; the required balancing capacity; and the evolving status of the local and regional energy markets. The few comparative assessments in the literature, mainly for relatively low shares of RE (such as wind electricity in Europe and the USA and biomethane injection into European gas grids), show that the additional costs of integration are wideranging and site-specific.

To achieve higher RE shares across the end-use sectors requires planning, development and implementation of coherent frameworks and strategies. These will vary depending on the diverse range of existing energy supply systems in terms of scale, age and type. RE uptake can be achieved in all end-use sectors by either the direct use of RE (e.g., buildingintegrated solar water heating) or via energy carriers (e.g., blending of biofuels with gasoline or diesel at an oil refinery). Improved end-use energy efficiency and flexibility in the timing of energy use can further facilitate RE integration.

- The transport sector shows good potential for increasing RE shares over the next few decades, but from a low base. Currently the RE shares are mainly from liquid biofuels blended with petroleum products and some electric rail. To obtain higher shares in the future, the RE energy carriers of advanced biofuels, biomethane, hydrogen and electricity could all be produced either onsite or in centralized plants and used to displace fossil fuels. When, and to what extent, flex-fuel, plug-in hybrid, fuel cell or electric vehicles might gain a major share of the current light duty vehicle fleet partly depends on the availability of the energy carriers, the incremental costs of the commercial manufacturing 
of advanced drive trains, development of the supporting infrastructures, and the rate of technological developments of advanced biofuels, fuel cells and batteries. Integration of fuels and technologies for heavy duty vehicles, aviation and marine applications is more challenging. Advanced biofuels could become more fungible with petroleum fuels and distribution systems, but will need to become more cost competitive to gain greater market share. The cost and reliability of fuel cells and the limited range of electric vehicles are current constraints.

- The building sector currently uses RE to meet around $10 \%$ of its total consumer energy demand, excluding traditional biomass. In the future, RE can be integrated more easily into urban environments when combined with energy efficient 'green building' designs that facilitate time- and/or resource-flexible energy consumption. In rural areas in developing countries, many modest dwellings could benefit from the integration of RE technologies, often at the small scale, to provide basic energy services. RE technologies integrated into either new or existing building designs can enable the buildings to become net suppliers of electricity and heat. Individual heating systems using biomass (for cooking and space heating), geothermal (including hydrothermal and ground source heat pumps) and solar thermal (for water and space heating, and, to a lesser extent, for cooling) are already widespread at the domestic, community and district scales.

- For industry, integration of RE is site- and process-specific, whether for very large, energy-intensive 'heavy' industries or for 'light' small- and medium-sized processing enterprises. At the large industrial scale, RE integration can be combined with energy efficiency, materials recycling, and, perhaps in the future, carbon dioxide capture and storage (CCS). Some industries can also provide time-flexible, demand response services that can support enhanced RE integration into electricity supply systems. In the food and fibre processing industries, direct substitution of fossil fuels onsite can be feasible, for example by the use of biomass residues for heat and power. Many such industries (sugar, pulp and paper, rice processing) have the potential to become net suppliers of heat and electricity to adjacent grids. Electro-thermal processes, process hydrogen, and the use of other RE carriers provide good opportunities for increasing the shares of RE for industry in the future.

- Agriculture, ranging from large corporate-owned farms to subsistence peasant farmers, consumes relatively little energy as a sector. (Fertilizer and machinery manufacture is included in the industrial sector). Local RE sources such as wind, solar, crop residues and animal wastes are often abundant for the landowner or manager to utilize locally or to earn additional revenue by generating, then exporting, electricity, heat or biogas off-farm.

Parallel developments in transport (including electric vehicles), heating and cooling (including heat pumps), flexible demand response services (including the use of smart meters with real-time prices and net metering facilities) and more efficient thermal generation may lead to dramatic changes in future electrical power systems. Higher RE penetration levels and greater system flexibility could result (but also depend on nuclear power and CCS developments). Regardless of the present energy system, whether in energy-rich or energy-poor communities, higher shares of RE are technically feasible but require careful and consistent long-term planning and implementation of integration strategies and appropriate investments. 


\subsection{Introduction}

This chapter examines the means by which larger shares of RE could be integrated into the wide range of energy supply systems and also directly into end-user sectors at national and local levels. It outlines how RE resources can be used through integration into energy supply networks that deliver energy to consumers using energy carriers with varying shares of RE embedded (Section 8.2) or directly by the transport, buildings, industry and agriculture end-use sectors (Section 8.3) (Figure 8.1).

Many energy systems exist globally, each with distinct technical, market, financial, and cultural differences. To enable RE to provide a greater share of electricity, heating, cooling and gaseous and liquid fuels than at present will require the adaptation of these existing energy supply and distribution systems so that they can accommodate greater supplies of RE. Integration solutions vary with location, scale and the current design of energy system and related institutions and regulations.

Established energy supply systems are relatively new in terms of human history, with only around 100 years elapsing since the original commercial deployment of internal combustion engines; approximately 90 years for national grid electricity; 80 years for the global oil industry; 50 years for the global gas industry; and only around 30 years for solid state electronic applications. Based upon the rate of development of these historical precedents, under enabling conditions and with societal acceptance, RE systems could conceivably become more prominent components of the global energy supply mix within the next few decades. Energy systems are continuously evolving, with the aims of improving conversion technology efficiencies, reducing losses, and lowering the cost of providing energy services to end users. As part of this evolution, it is technically feasible to continue to increase the shares of RE through integration with existing energy supply systems at national, regional and local scales as well as for individual buildings. To enable RE systems to provide a greater share of heating, cooling, transport fuels and electricity may require modification of current policies, markets and existing energy supply systems over time so that they can accommodate greater supplies of RE at higher rates of deployment than at present.

Regardless of the energy supply system presently in place, whether in energy-rich or energy-poor communities, over the long term and through measured system planning and integration, there are few, if any, technical limits to increasing the shares of RE, but other barriers would need to be overcome (Section 1.4). Specific technical barriers to increased deployment of individual RE technologies are discussed in chapters 2 through 7 . This chapter outlines the more general barriers to integration (including social ones) that cut across all technologies and can therefore constrain achieving relatively high levels of RE integration. Where presented in the literature, solutions to overcoming these barriers are presented.

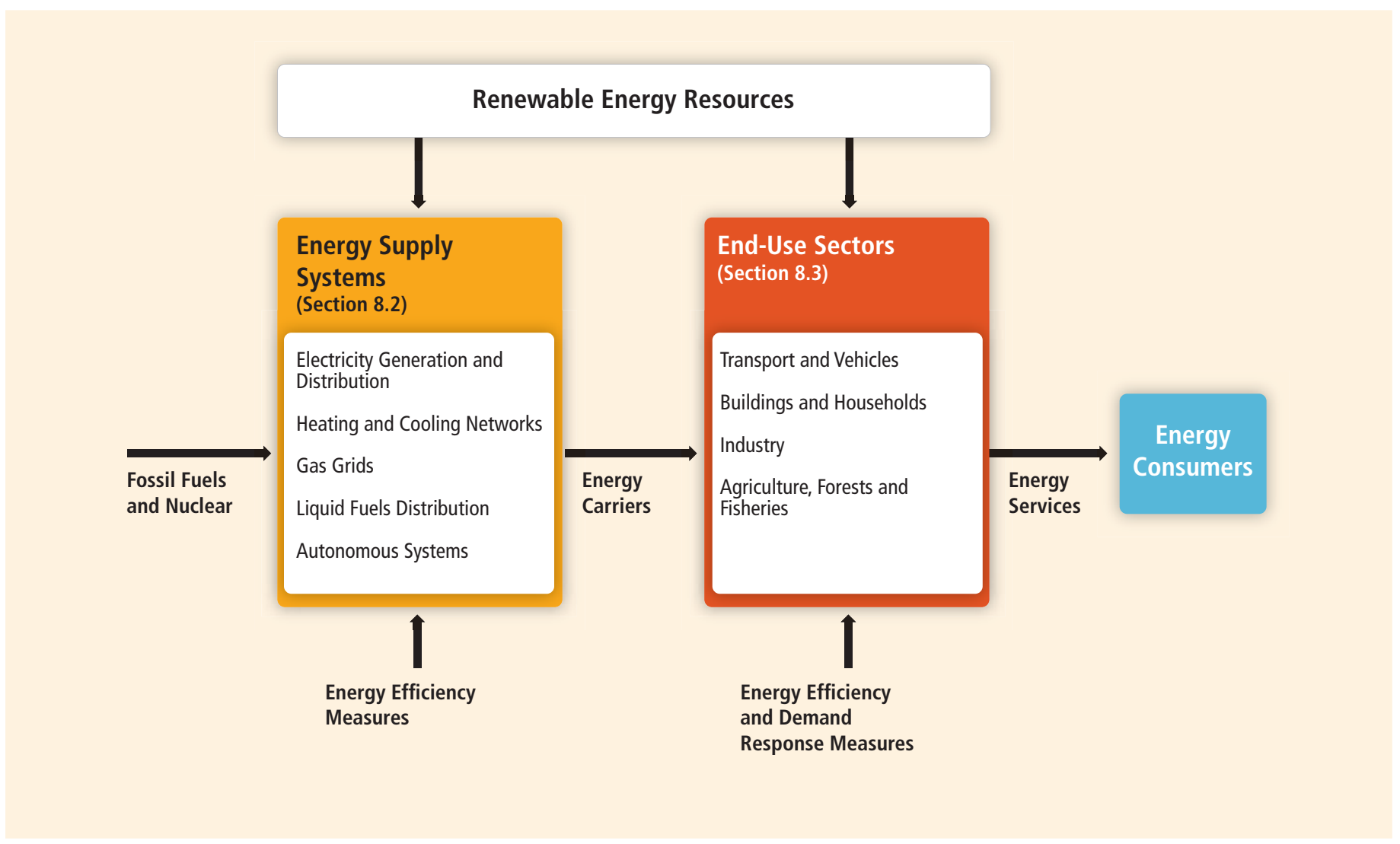

Figure 8.1 | Pathways for RE integration to provide energy services, either into energy supply systems or on-site for use by the end-use sectors. 
Enhanced RE integration can provide a wide range of energy services for large and small communities in both developed and developing countries. The potential shares of RE depend on the scale and type of the existing energy supply system. Transition to low-carbon energy systems that accommodate high shares of RE integration can require considerable investments in new technologies and infrastructure, including more flexible electricity grids, expansion of district heating and cooling schemes, modifying existing distribution systems for incorporating RE-derived gases and liquid fuels, energy storage systems, novel methods of transport, and innovative distributed energy systems in buildings. The potential integration and rate of deployment of RE differs between geographic regions, depending on the current status of the markets and the varying political ambitions of all OECD and non-OECD countries.

All countries have access to some RE resources and in many parts of the world these are abundant. The characteristics of many of these resources distinguish them from fossil fuels and nuclear systems and have an impact on their integration. Some resources, such as solar, are widely distributed, whereas others, such as large hydro, are constrained by geographic location and hence integration options are more centralized. Some RE resources are variable and have limited predictability. Others have lower energy densities and different technical specifications from solid liquid and gaseous fossil fuels. Such RE resource characteristics can constrain their ease of integration and invoke additional system costs, particularly when reaching higher shares of RE.

Alongside RE, nuclear power and CCS linked with coal- or gas-fired power generation plants and industrial applications may well have a role to play in a low-carbon future (IPCC, 2007). However, for a country wishing to diversify its energy supply primarily by increasing domestic RE capacity to meet an increasing share of future energy demand, integrating a portfolio of local RE resources can be beneficial, and also make a positive contribution to improved energy supply security and system reliability (Awerbuch, 2006). Increasing RE integration can also offer a range of other opportunities and benefits (Sections 1.4.5 and 9.3) but carries its own risks, including natural variability (from seconds to years), physical threats to installed technologies from extreme weather events, locational dependence of some RE resources, additional infrastructure requirements, and other additional costs under certain conditions.

The future energy supply transition has been illustrated by many scenarios, the majority of which show increasing shares of RE over the next few decades (Section 10.2). The scenario used here as just one example (Figure 8.2) is based upon the International Energy Agency (IEA) World Energy Outlook 2010 '450 Policy Scenario' out to 2035. It illustrates that achieving high levels of RE penetration' will require a continuation of increasing market shares in all end-use sectors. The average annual RE growth increment required to meet this projection is almost $4 \mathrm{EJ} / \mathrm{yr}$ across all sectors; over three times the current RE growth rate.

\footnotetext{
1 The terms 'shares' and 'penetration levels' of RE are used loosely throughout the text to indicate either the percentage of total installed capacity or total energy that comes from RE technologies.
}

In the 2010 World Energy Outlook (IEA, 2010b), the 22 EJ of final consumption RE (excluding traditional biomass) in 2008 is almost quadrupled in 2035 in the 450 Policy Scenario. This is due mainly to the power sector where the RE share in electricity supply rises from 19 to $32 \%$ over the same period. Government support for RE, projected to rise from USD 44 billion in 2008 to USD 205 billion in 2035, is a key driver along with projected lower RE investment costs and higher fossil fuel prices.

To achieve such increased shares of RE in total energy supply by 2035 and beyond will require overcoming the challenges of integration in each of the transport, building, industry and agriculture sectors. In order to gain greater RE deployment, strategic elements need to be better understood as do the social issues. Transition pathways for increasing the shares of each RE technology through integration should aim to facilitate a smoother integration with energy supply systems but depend on the specific sector, technology and region. Multiple benefits for energy consumers should be the ultimate aim.

Successful integration of high shares of RE with energy systems in recent years has been achieved in both OECD and non-OECD countries, including:

- Brazil, with over $50 \%$ of light duty transport fuels supplied from sugar cane ethanol (Zuurbier and Vooren, 2008) and $80 \%$ of electricity from hydro (BEN, 2010);

- China, where two-thirds of the world's solar water heaters have been installed (REN21, 2010);

- Denmark, with around $20 \%$ (7,180 GWh or 25.84 PJ) of total power supply in 2009 generated from wind turbines (Section 7.4) integrated with other forms of generation (mainly national coal- and gas-fired capacity, but also supported by interconnection to hydrodominated systems) (DEA, 2009);

- Spain, where the 2000 Barcelona Solar Thermal Ordinance resulted in over $40 \%$ of all new and retrofitted buildings in the area having a solar water heating system installed (EC, 2006); and

- New Zealand and Iceland where the majority of electricity supply has been generated from hydro and geothermal power plants for several decades.

It is anticipated that increased urbanization will continue and that the $50 \%$ of the 6.4 billion world population living in cities and towns today will rise by 2030 to $60 \%$ of the then 8.2 billion people (UNDP, 2007). There is potential in many of these growing urban environments to capture local RE resources and thereby help meet an increasing share of future energy demands (MoP, 2006 Droege et al., 2010). The potential exists to integrate RE systems into the buildings and energy infrastructure as well as to convert municipal and industrial organic wastes to energy (Section 2.2.2). However, local government planning regulations 

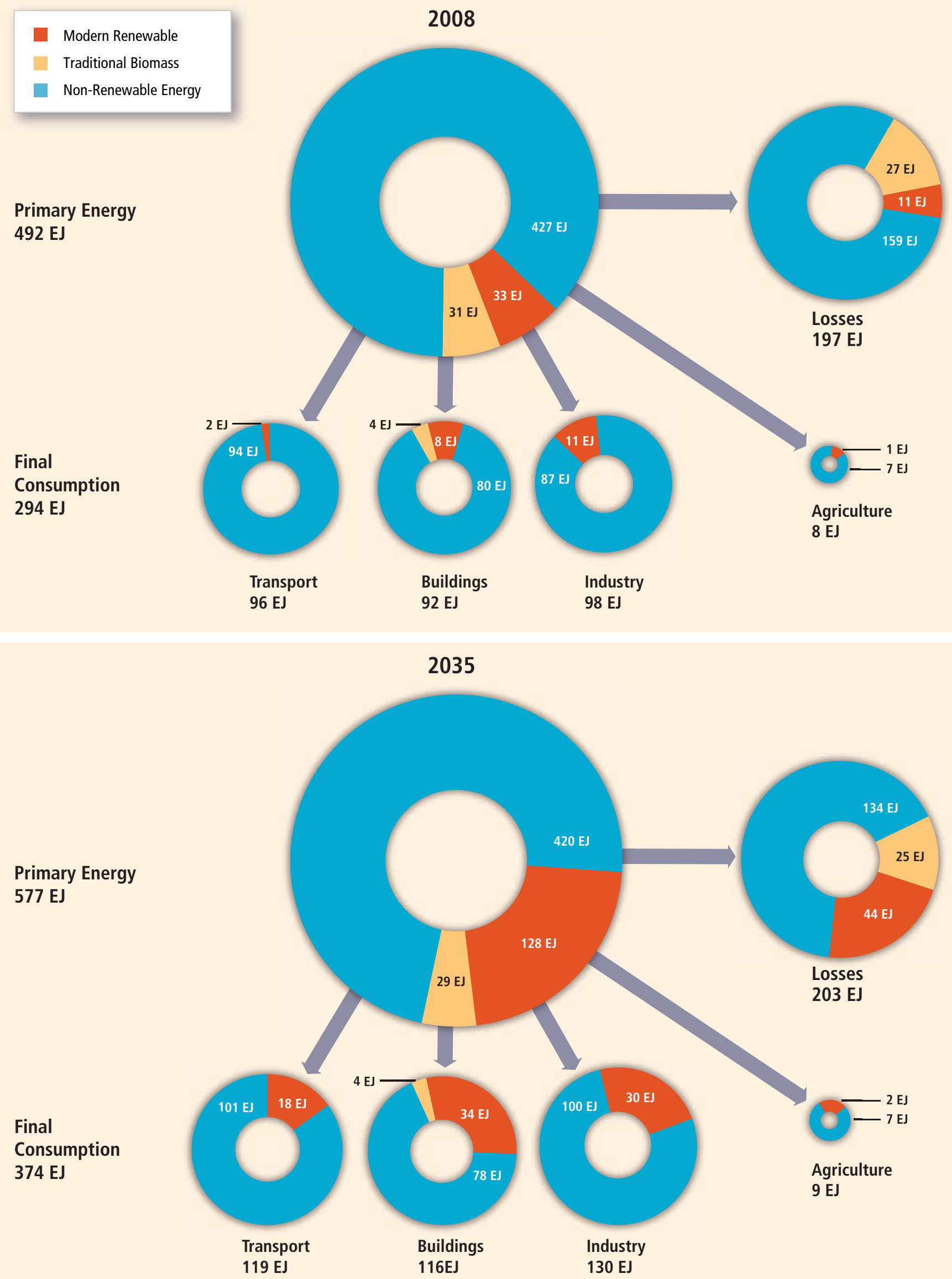
Figure 8.2 | (Preceding page) RE shares (red) of primary and final consumption energy in the transport, buildings (including traditional biomass), industry and agriculture sectors in 2008 and an indication of the projected increased RE shares needed by 2035 in order to be consistent with a 450 ppm CO 2 eq stabilization target.

Notes: Areas of circles are approximately to scale. Energy system losses occur during the conversion, refining and distribution of primary energy sources to produce energy services for final consumption. 'Non-renewable' energy (blue) includes coal, oil, natural gas (with and without CCS by 2035) and nuclear power. This scenario example is based upon data taken from the IEA World Energy Outlook 2010 (IEA 2010d) but converted to direct equivalents (Annex II.4). Energy efficiency improvements above the baseline are included in the 2035 projection. RE in the buildings sector includes traditional solid biomass fuels (yellow) for cooking and heating for 2.7 billion people in developing countries (Section 2.2) along with some coal (UNDP and WHO, 2009). By 2035, some traditional biomass has been partly replaced by modern bioenergy conversion systems. Excluding traditional biomass, the overall RE system efficiency (when converting from primary to consumer energy) remains around $66 \%$ over the period.

may constrain the deployment of some RE technologies in the short term (IEA, 2009b).

Many energy scenarios have incorporated a wide range of energy efficiency initiatives (Sections 1.1.3 and 10.1). These reduce future energy demand baseline projections significantly across the building, industry, transport and energy supply sectors (IPCC, 2007). Lower energy demand reduces the required capacity, and hence cost, of an integrated RE system, which might facilitate having a greater share of RE in a growing energy market (Verbruggen, 2006; Pehnt et al., 2009a). For example, a building owner or developer could be encouraged to initially invest in energy saving measures and energy efficient building design before contemplating the installation of RE systems and hence reduce the installed capacity needed to meet the energy demand of the building occupiers (IEA, 2009b).

Integration of RE into the energy supply and infrastructure system of many OECD countries raises different challenges than those of nonOECD countries. For example, RE integration into dense urban regions that already have high shares of RE, or where cross-border energy supply options are possible, differs markedly from integration of RE into a small autonomous energy system in a remote rural region with limited energy infrastructure. In such districts, small-scale, distributed, RE systems may be able to avoid the high investment costs of constructing infrastructure presently deficient (ARE, 2009).

A technology that is successful in one region may not be so in another, even where RE resource conditions and supportive enabling environments are similar. Successful deployment can depend upon the local RE resources, current energy markets, population density, existing infrastructure, ability to increase supply capacity, financing options and credit availability. For any given location and energy market, issues relating to the integration of a RE project can be complex as there can be impacts on land and water use, adherence to national and local planning and consenting processes, variance due to the maturity of the technology (IEA, 2008b), co-benefits for stakeholders, and acceptance or rejection by the general public (as also would be the case for a fossil fuel, nuclear or CCS project).

\subsubsection{Objectives}

The objectives of this chapter are to

- assess the literature regarding the integration of RE into current and possible future energy systems;

- present the constraints that can exist when integrating RE into current electrical supply systems, heating and cooling networks, gas grids, liquid fuels and autonomous systems, particularly for RE shares that are significantly higher than at present; and

- determine whether increasing RE integration within present energy supply systems and facilitating the increased rate of deployment of RE technologies in the transport, building, industry and agricultural sectors are feasible propositions.

The chapter examines the complex cross-cutting issues that relate to RE integration across centralized, decentralized and autonomous energy supply systems and into the wide range of end-use technologies, buildings and appliances used to provide desirable energy services (heating, cooling, lighting, communication, entertainment, motor drives, mobility, comfort, etc.). These issues include energy distribution and transmission through energy carriers, system reliability and quality, energy supply/ demand balances, system flexibility, storage systems, project ownership and financing, operation of the market, supply security and social acceptance. Regional differences between the integration of various RE systems are highlighted.

Due to the very specific nature of any individual energy supply system, it was not possible to provide general guidance on which policy intervention steps to follow logically in order to increase the share of RE through integration. The unique complexities of energy supply systems, due to their site-specificity, future cost uncertainties, and deficit of analysis in the literature, prohibited a detailed evaluation of the additional costs of RE system integration and deployment (other than for wind power; Section 7.5.4). The inability to determine 'typical' integration costs across the many differing systems and present them as 'representative' 
is a barrier to wider RE deployment and modelling scenarios. Further analysis would be useful.

\subsubsection{Structure of the chapter}

Section 8.2 discusses the integration of RE systems into existing and future centralized supply-side systems for both OECD and non-OECD regions. Where relevant, the benefits of system design and technology components to facilitate integration, operation and maintenance strategies, markets and costs are discussed.

Section 8.3 outlines the strategic elements, including non-technical issues, needed for transition pathways for each of the end-use sectors in order to gain greater RE deployment. The current status, possible pathways to enhance adoption of $\mathrm{RE}$, related transition issues, and future trends are discussed for transport, buildings, industry and primary production.

Both sections endeavour to emphasize that though common solutions to RE integration exist there are sometimes differences between:

- RE integration into centralized, high voltage electricity systems, district heating schemes, and liquid fuel and gas pipelines, and

- RE integration into distributed, small-scale, energy systems such as low voltage electricity grids, heating and cooling of individual buildings, and liquid or gaseous fuel production for local transport use.

The case studies illustrate what has already been achieved, under a given set of circumstances.

\subsection{Integration of renewable energy into supply systems}

Energy supply systems have evolved over many decades to enable the efficient and cost-effective distribution of electricity, gas, heat and transport fuel energy carriers to provide useful energy services to end users. Increasing the deployment of RE systems requires their integration into these existing systems. This section outlines the issues and barriers involved as well as some possible solutions to overcome them in order to achieve increased RE penetration. The complexities of the various electricity supply systems and markets operating around the world result in marked differences in the approach to integration. Prerequisites for efficient and flexible energy conversion, mutual support between energy sectors, and an intelligent control strategy include coherent long-term planning and a holistic approach. Over time this could result in an inter-linked energy system to provide electricity, heating, cooling and mobility rather than having distinct sectors for each as at present. A significant increase in global electricity demand could result from a higher share being substituted for current fossil fuel demands in the heating and transport sectors.

\subsubsection{Integration of renewable energy into electrical power systems}

Modern electrical power systems (the grid) have been developing since the late 19th century and take different forms around the world. Some systems are very advanced and highly reliable but are at different scales, for example the Eastern Interconnection in the USA that serves 228 million consumers across 8.85 million square kilometres contrasts with smaller, more isolated systems such as Ireland serving a population of 6.2 million across 81,638 km² $^{2}$ (NISRA, 2009; CSO, 2010). Other systems are not as well developed but are rapidly evolving. For example, China installed an average of $85 \mathrm{GW}$ of plant per year from 2004 to 2008 and in the same period increased its electricity consumption by over $50 \%$ (J. $\mathrm{Li}, 2009)$. Other systems are not well developed either in terms of access or quality (e.g., many parts of sub-Saharan Africa). Autonomous and/ or micro-scale systems also exist to serve small communities or single buildings or industrial plants (Section 8.2.5). Despite their variations, these systems have a common purpose: the provision of a reliable and cost-effective supply of electricity to loads by appropriate generation and use of network infrastructure.

The versatility of energy in electrical form, the ability to transport it across large distances (nearly) instantaneously, and its necessity for the deployment of modern technology and the advancement of economic and social development has resulted in a dramatic increase in the demand for electricity. This increase is projected to continue in a wide range of scenarios, including some of those that keep greenhouse gas (GHG) concentrations in the atmosphere below 450 ppm (e.g., IEA, 2010d; see also Section 10.2). The provision of modern energy services is recognized as a critical foundation for sustainable development (e.g., DFID, 2002; Modi et al., 2005; UNEA, 2009). This growth of electricity demand coupled with the geographically dispersed nature of many renewable sources makes electricity an attractive energy vector to harness RE where adequate network infrastructure is available. With the development of electric vehicles and heat pumps, electricity is also taking a growing share in the transport and heat markets (Kiviluoma and Meibom, 2010; Sections 8.3.1 and 8.3.2). Additionally, with the development of inexpensive and effective communications systems and technologies as well as smart meters, the electrical power system is experiencing dramatic change. ${ }^{2}$ All these potential developments- $R E$, demand side participation, electric vehicles and any new thermal generation (i.e., fossil fuel or nuclear) — need to be integrated into electrical power systems. They collectively and individually pose common and unique challenges.

This section is comprised of three sub-sections that focus on the integration issues for renewable electricity and begins with a brief description of the basic principles of electrical power systems-how they are designed, planned and operated (Section 8.2.1.1). This is followed by a summary of the pertinent integration characteristics of renewable electricity sources and a high-level description of the integration

2 The term 'smart grid' is often used to refer to this mixture of new technologies but it is not used in this report. 
challenges that result (Section 8.2.1.2). Finally, integration experiences, studies and options for existing and future electrical power systems are provided (Section 8.2.1.3).

\subsubsection{Features and structures of electrical power systems}

The first power plant used direct current (DC) that could transport electricity to consumers living close to the power station. However, a few years after the construction of this first power plant, alternating current (AC) electricity systems were developed (El-Sharkawi, 2009). Alternating currrent systems allow greater flexibility in the transmission of electricity across the various voltage levels in the electricity network and, as such, almost all electrical power systems across the world today use AC. However, DC is still used in the transmission of electricity over long distances, for interconnection of AC systems (sub-sea and over land), and in some very small domestic stand-alone systems. DC technology is developing rapidly and new application domains are being developed (Breuer et al., 2004; EASAC, 2009).

Integration of RE into any electrical power system poses a number of challenges (many shared with other technologies and developments) for the designers and operators of that system. In order to appropriately address these challenges, a basic understanding of the characteristics of electrical power systems is required and some salient elements of planning, design and operation are discussed here (Bergen and Vittal, 2000).

Electricity demand (including losses in the electrical power system) varies with the needs of the user; typically at a minimum at night and increasing to a peak during working hours. In addition, there are normally differences between working days and weekends/holidays and also between seasons; most systems also show an annual growth in consumption from year to year. Therefore, generators on a system must be scheduled (dispatched) to match these variations throughout the year and appropriate network infrastructure to transfer that power must be available. This balancing (of supply and demand) requires complex operational planning from the management of second-tosecond changes in demand to the longer-term investment decisions in generation and transmission assets. The balancing is carried out by the system operator in balancing areas (or control areas), which often are parts of large interconnected AC systems.

In order to maintain an $\mathrm{AC}$ power system at its nominal frequency (e.g., 50 $\mathrm{Hz}$ in Europe and $60 \mathrm{~Hz}$ in North America), the instantaneous power supplied to the system must match the demand. Insufficient power results in a decreased frequency while excess power leads to an increased frequency. Either scenario is a threat to the security of the system, since the generators, interconnectors and loads that constitute the system are physically designed to operate within certain limits, and must be removed from the system once these limits are violated in order to ensure their integrity.

The electrical machines employed in the generation of electricity (and in the conversion of electricity to end-use energy) are an important component within electrical power systems. The traditional machine used for generation is the synchronous machine (El-Sharkawi, 2009). This machine is directly connected and synchronized to the frequency of the system. A synchronous electrical power system consists of (i) a network that connects (ii) synchronous generators to the (iii) demand. The network can further be divided into the transmission network, where large generators and consumers are connected and high voltages are used to transmit power over long distances; and the distribution network, which is used to transmit power to consumers at lower voltage levels and connect distributed generation. Synchronous machines maintain synchronism with one another through restoring forces that act whenever there are forces tending to accelerate or decelerate one or more generators with respect to other machines (Kundur, 2007). As a result of this, synchronous machines can detect and react to events on the system automatically; in particular inertial response to a frequency change. Generators also have governors that detect and react to frequency changes and this coupled with inertial response is of benefit to $A C$ power systems as it allows for the support of frequency on an almost instantaneous basis.

Matching demand and supply (balancing) on a minute-to-minute basis is generally done by control of generation. This is known as regulation/ load following and requires small to medium variations in the output of the power stations. It is usually controlled automatically or by a central electricity system operator, who is responsible for monitoring and operating equipment in the transmission system and in power generating stations. Dispatchable units are those that control their output between a minimum and maximum level. The output of some units such as wind generators cannot be fully controlled. Even here, however, some level of control is possible through a reduction of the output of the units, although such control strategies also lead to lost production. Units such as wind generators are therefore considered partially dispatchable as opposed to dispatchable.

Over slightly longer time periods (e.g., 30 minutes to 6 to 24 hours), decisions must be made regarding which power stations should turn on/turn off or ramp up/ramp down output to ensure the demand is met throughout the day (e.g., to meet low demand at night and high demand during the day). This is usually done using a method known as unit commitment (Wood and Wollenberg, 1996). Unit commitment involves complex optimizations that are conducted, typically one to two days ahead, to create an hourly or half-hourly schedule of generators required to reliably meet the forecasted demand at least cost. These schedules will usually instruct some units to run at their maximum capacity all day (these are known as base load units), some units 
to turn on in the morning and off at night (mid-merit units) and some units to just turn on during times of peak demand (peaking units). The running regime of a unit depends mainly on its operation cost (i.e., fuel used and efficiency), as well as other characteristics such as how long it takes to turn on or off, and the degree to which it can quickly change its output power.

Organized electricity markets have emerged in some countries/regions and they coordinate how the costs of the generators are included in the unit commitment methods. Trading of electricity between producers and consumers can be done in power exchanges (pools) or on a bilateral basis (Schweppe et al., 1988; Stoft, 2002). Sometimes these markets run on very short time horizons, for example, five minutes before the electricity is expected to be needed (Harris, 2006; AEMO, 2010), and in other cases the markets operate days, weeks or even months before the electricity is required. An important market parameter is the gate closure time, which is the time difference between bidding of generators into the market and the actual delivery of power. Properly functioning markets support the long-term financial investment in appropriate generation capacity and network infrastructure to ensure supply meets demand in a reliable manner and at least cost.

It should be noted that the principle of energy balance also applies to the smallest stand-alone autonomous systems. An autonomous electrical power system is one without interconnections to other systems and that cannot access the larger variety of balancing resources available to larger systems. In island systems, or developing economies, a common solution is often to use small autonomous systems in order to avoid the costs of transmission lines to areas with comparatively low consumption. Balancing in many such cases is provided by expensive battery energy storage and/or diesel generators and dump load resistors to absorb surplus energy that cannot be absorbed otherwise (Doolla and Bhatti, 2006). Autonomous systems can be as small as individual homes or groups of homes working on the low voltage distribution grid, sometimes referred to as microgrids (Tsikalakis and Hatziargyriou, 2008). Though the basic principles of electric power system operations do not differ between large interconnected networks and small autonomous systems, the practical implications of those principles can vary. Autonomous systems are addressed to some degree in this section, but are also covered in a more-dedicated fashion in Section 8.2.5.

Over an annual time frame, it is necessary to ensure that the electricity system always has enough generation capacity available to meet the forecasted demand. This means that maintenance schedules must be coordinated to ensure that all generating units and network infrastructure do not shut down for maintenance at the same time, while also considering the fact that units will break down unexpectedly. In addition, planning must also be done over much longer time horizons ( 5 to 20 years). The construction of generators and networks involves long lead times, high capital requirements, and long asset life and payback periods. Therefore, the electricity sector requires significant long-term planning to ensure that generation will continue to meet the demand in the decades ahead and network infrastructure is developed in a timely and economic manner.
A further important planning consideration is the geographic spread of generation. If a generator is located close to a demand centre then less transmission capacity will be required to deliver the electricity to the end user and less electricity will be lost in transmission

Electrical demand cannot always be met and there are many well known reliability metrics that can quantify this (Billinton and Allen, 1988), though the metrics themselves can vary widely among different electric power systems. For example, the value of lost load is different in a modern industrial economy than in a developing one. Electric systems that can accept lower levels of overall reliability may be able to manage the integration of RE into electrical power systems at lower costs than systems that demand higher levels of reliability, creating a trade-off that must be evaluated on a case-by-case basis.

A reliability metric known as the capacity credit ${ }^{3}$ (also known as capacity value) (Keane et al., 2011a) gives an indication of the probability that a particular type of generation will reliably contribute to meeting demand, which generally means that it will be available to generate electricity during the peak demand hours. This is an important metric in the planning of future electricity systems. If a type of generation has a low capacity credit this indicates that its available output tends to be low during high demand periods. The total capacity credit for all generation on the system needs to be sufficient to cover peak demand with a certain level of reliability; usually systems also require an additional margin for reliability purposes (planning reserves). The capacity credit of generation depends on the generator availability (mechanical and fuel source), and the coincidence with electrical power system demand (in particular times of high demand).

To ensure system security and reliability, electrical power systems are designed and operated to withstand specific levels of contingencies. Generation contingencies result from the sudden loss of significant generation capacity; this could be the loss of a large generating unit or loss of a network connection. Reserves are carried by the system operator, usually in the form of other generators operating at reduced output, which rapidly replace the power that was lost during the contingency. Transmission systems are typically designed to withstand the loss of any single critical element, such as a transmission line, such that on the system (i.e., post fault), no other element on the network is overloaded and the system stays within prescribed limits. Faults on electrical power systems are detected and cleared by protection that continuously monitors the system for such events. Electrical power system protection is also critical to the maintenance of system integrity since generators and other critical equipment can be disconnected from the system if a fault on the system is not cleared quickly enough. Many of today's larger power systems use advanced energy management/network management systems to configure their systems in a secure manner, thus allowing them to withstand these contingencies, for example, fault ride through (FRT) capability of generators (and the associated capability

3 Note that capacity credit is different than capacity factor. The capacity factor of a power plant is the average output typically expressed as a percentage of its maximum (rated) output. 
of providing frequency and voltage support during the fault). In order to ensure reliability and proper operability of the network, generators and large consumers connected to the network have to comply with the connection requirements published in the codes of the network operators. These include, for example, grid codes in Ireland (EirGrid, 2009) and Germany (Transmission Code, 2007) and connection standards in the USA (CAISO, 2010).

The power flows on the overhead lines and cables (feeders) of the system require careful management to ensure satisfactory voltage levels throughout the system and to respect the rating limits of individual feeders (El-Sharkawi, 2009). The power must be delivered to the loads via these feeders, and its efficient and reliable delivery is crucial. Key variables in this task are thermal ratings (heating caused by losses), voltage levels and stability limits. These requirements are managed at the planning stage when the network is designed and built and also on a shorter time frame as the network is reconfigured, generator output adjusted to influence the flows, or other control technologies employed to support system voltages (El-Sharkawi, 2009).

The $A C$ nature of the electrical power system results in different voltages throughout the system, in the first instance determined by the demand and generation in the local area. In order to ensure an electricity supply of required quality and reliability, the voltages throughout the system must be maintained within defined limits. This is a challenge to the design and operation of electrical power systems across the world. The voltage levels can be affected by the size and characteristics of generators, transmission lines and consumers, and the design and location of these is one of the key parameters available when designing a reliable and economic electrical power system. Reactive power is a critical component of voltage control. It is distinct from the active power that supplies energy to loads and arises from the AC nature of modern electrical power systems (Taylor, 1994). The effective supply and demand of reactive power is a critical system support service in any AC electrical power system. Network users such as generators supply the different technical services, also called ancillary services, that are needed for proper operation of the network in normal operation (e.g., reactive power supply) and during network faults. Some of these services are delivered on a bilateral commercial basis, though ancillary service markets are emerging in many parts of the world (Cheung, 2008).

\subsubsection{Renewable energy generation characteristics}

Renewable electricity sources depend on energy flows in the natural environment, thus their power generation characteristics are very different in general from other generation based on stockpiles of fuel (with the exception of biomass-fuelled plants). In particular, they reflect the time-varying nature of the energy flows. Here, each of the RE generation technologies is dealt with in turn as it appears in Chapters 2 through 7. This section highlights supply characteristics of the technologies that are of direct relevance to integration into electrical power systems, namely: (a) variability and predictability (uncertainty), which is relevant for scheduling and dispatch in the electrical power system; (b) location, which is a relevant indicator of the need for electrical networks; and (c) capacity factor, capacity credit and power plant characteristics, which are indicators relevant for comparison for example with thermal generation. These particular characteristics are outlined below, and a very brief summary for a selection of the technologies is given in Table 8.1. Further details are available in Chapters 2 through 7.

\section{Bioenergy}

Dedicated biopower plants are similar to fossil-fuel-powered plants in several respects; additionally, bioenergy can be blended with fossil fuels in fossil fuel plants that use co-firing. Biopower plants are powered by storable solid, gaseous or liquid fuel, and use similar types of technology and thermal cycles for the prime mover (e.g., steam turbine, diesel engine; Section 2.3.3). Temporal characteristics and output predictability are thus partly determined by operational decisions, and in part by the plant and biomass fuel availability, which can depend on how the fuel is prepared, stored and supplied to the plant and can exhibit daily, monthly, seasonal and annual variations.

The location of biopower plants is often determined by proximity to the fuel supply or fuel preparation plant. Biopower plant location is not as dependent on resource location as other renewable technologies as fuel can also be transported to the plant. A limitation to transporting fuel over long distances is the relatively low energy content of biomass fuels (in terms of $\mathrm{kWh} / \mathrm{m}^{3}$ or $\mathrm{kWh} / \mathrm{kg}\left(\mathrm{kJ} / \mathrm{m}^{3}\right.$ or $\mathrm{kJ} / \mathrm{kg}$ )). The high transport cost of biomass fuels means that it is generally more economical to locate the plant close to the fuel source (Section 2.3.2). Small biopower plants are very often connected at the distribution level. A single large plant, on the other hand, may be connected at the transmission level. The capacity credit of biopower plants is similar to combined heat and power (CHP) plants and thermal plants.

Biomass electricity production is often operated in CHP plants to achieve better fuel efficiency. As a result, there may be little flexibility in plant dispatch if the operation is heat-load driven. However, when heat storage is available, electricity can be produced in a flexible way (Lund and Münster, 2003; Kiviluoma and Meibom, 2010). Also, control characteristics (power, voltage) of biopower plant are similar to CHP and thermal plants. Plant sizes are mostly in the range from a few hundred kW to 100 MW and larger, particularly when co-fired with fossil fuels.

\section{Direct solar energy}

Direct electricity generation from solar takes two distinct forms: photovoltaic solar power (solar PV) in which sunlight is converted directly to electricity via the photovoltaic effect in a semiconductor; and concentrating solar power (CSP) in which a working fluid is heated to high temperature and used to drive a heat engine (e.g., a Rankine steam cycle or a Stirling cycle) that is connected to an electrical generator (Section 3.3). For both forms of generation the variability of the primary source, the available solar irradiation, is dependent on the level of aerosols in the atmosphere, the position of the sun in the sky, the potential 

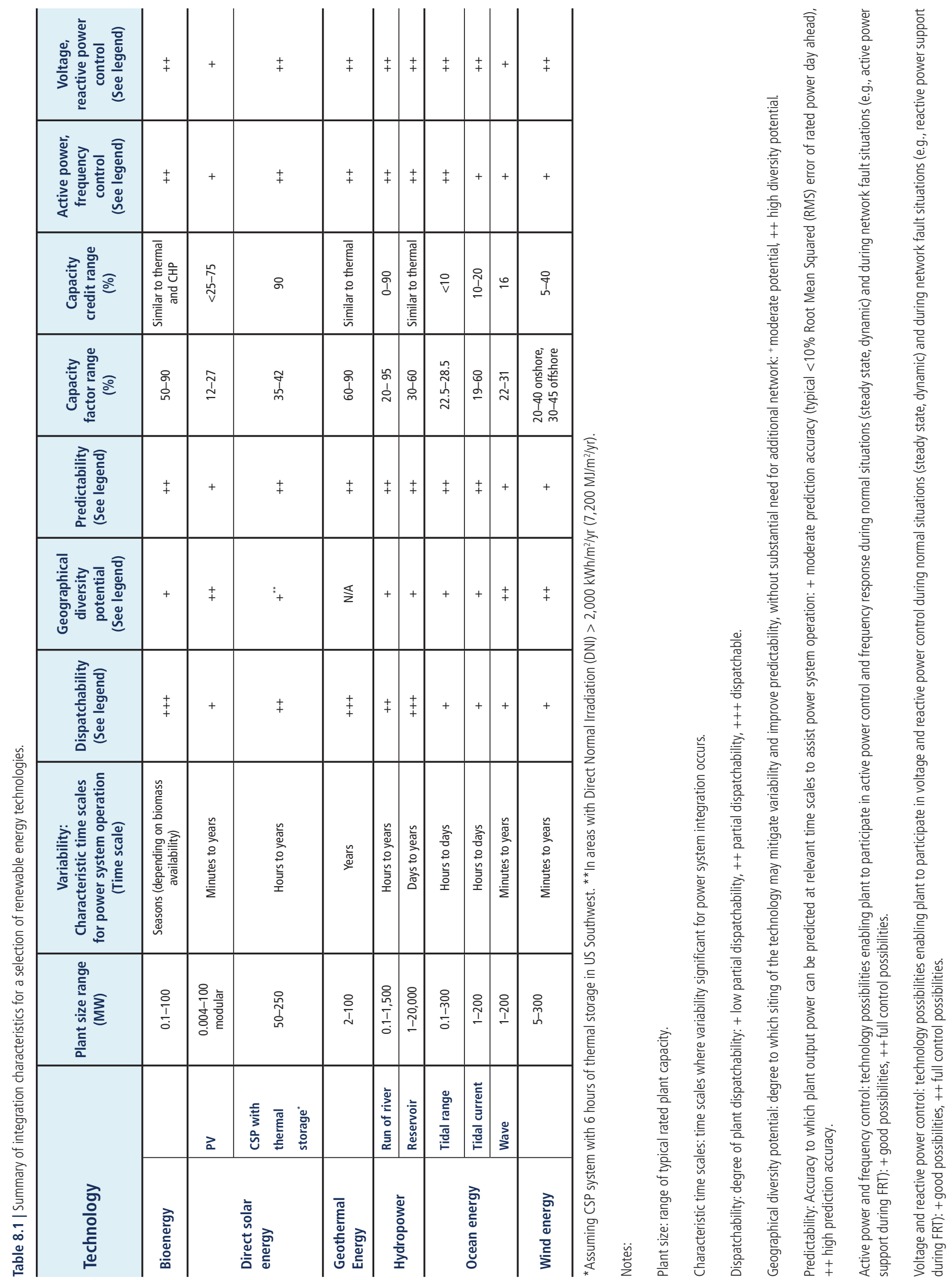
shadowing effect of obstacles (buildings, trees, etc.) and cloud cover. Depending on weather conditions, the latter two can be quite variable over time scales as short as seconds (Woyte et al., 2007). Because of their specific differences, the generation characteristics of solar PV and CSP are discussed separately.

\section{Solar PV}

The electrical output of PV panels changes nearly instantaneously as the solar radiation incident on the panels changes. The variability of a large solar PV plant will to some degree be smoothed due to the footprint of the plant, particularly over very short time scales (roughly less than about 10 minutes for plants of the order of about $100 \mathrm{MW}$ ) (Longhetto et al., 1989; Kawasaki et al., 2006; Curtright and Apt, 2008; Mills et al., 2009a; Marcos et al., 2011). The degree to which the variability and predictability of solar plants is smoothed will depend on the type of solar plants, the size of the individual plants, the geographic dispersion between sites, and prevailing weather patterns.

The aggregate variability of multiple solar plants will be smoothed by geographic diversity because clouds do not shade and un-shade dispersed plants simultaneously. This smoothing effect can substantially reduce the sub-hourly variability of the aggregate of several solar plants (Wiemken et al., 2001; Mills et al., 2009a; Murata et al., 2009; Hoff and Perez, 2010; Mills and Wiser, 2010). It can also lead to lower aggregate short-term forecast errors for multiple solar plants (Lorenz et al., 2009, 2010). This smoothing effect of geographic diversity was shown to lead to comparable variability for similarly sited wind and solar plants in one region of the USA (Mills and Wiser, 2010).

Solar electricity predictions have forecast errors in cloudy weather. There is no production during the night, and the morning and evening ramps as well as the overall diurnal variation are predictable. Locally, for distribution network control, prediction errors can be significant but decrease relatively in larger systems (Lorenz et al., 2009).

Although the solar resource varies from region to region, the sun does shine everywhere. This increases the versatility with which solar PV can be sited in contrast to many other more location-dependent renewable resources. With regard to the impact on network infrastructure, small and medium size solar PV is typically installed near to demand and connected at the distribution level. At low penetrations on distribution feeders (PV capacity $<100 \%$ peak load on feeder), PV may offset the need for distribution upgrades (where peak demand on the feeder occurs in daylight) and reduce losses. Large size PV plants, on the other hand, can be located far from the load centres, which typically requires additional network infrastructure.

Capacity factors of solar PV range between 12 and $27 \%$. The lower capacity factors are for fixed tilt PV systems while the higher capacity factors typically utilize single axis tracking. Estimates of the capacity credit of PV range between 25 and 75\% (Pelland and Abboud, 2008; Xcel Energy, 2009; GE Energy, 2010), though lower values are possible at high levels of solar penetration and in electricity systems where demand patterns and PV output are poorly correlated. Additional analysis indicates the potential for high capacity credit at low solar PV penetration when, as in many cases, there is a high degree of coincidence between solar PV production and demand (Perez et al., 2008). Network-connected PV systems use inverters for grid interfacing, enabling in principle control of electrical characteristics relevant for grid integration (McNutt et al., 2009). With additional controls it is possible for PV to even provide active power control through the plant inverters (Achilles et al., 2008), although this is always at a loss of PV production. Typical plant sizes range from a few $\mathrm{kW}$ to $100 \mathrm{MW}$ but are increasing in size.

\section{Concentrating solar power (CSP)}

The smoothing effects due to geographic diversity for CSP are similar to those of solar PV. CSP, however, includes intrinsic thermal storage in its working fluid and thus can have substantial thermal inertia. Thermal inertia, to a degree, smooths the effects of short-term variations in solar radiation. This thermal inertia can be further enhanced through the storage of additional heated fluid. Adequate thermal storage coupled with an increased size in the solar collector field further smoothes plant output due to passing clouds and allows for extended plant operations into or through the night.

CSP plants can only use the direct-beam portion of solar irradiance. Sites with high direct normal irradiance, greater than approximately 2,000 $\mathrm{kWh} / \mathrm{m}^{2} / \mathrm{yr}\left(7,200 \mathrm{MJ} / \mathrm{m}^{2} / \mathrm{yr}\right)$, are usually found in arid and semi-arid areas with reliably clear skies that typically lie at latitudes from $15^{\circ}$ to $40^{\circ} \mathrm{N}$ or $\mathrm{S}$ and at higher altitudes (IEA, 2010c). The size of the plant in relation to local land availability determines the plant location, which is not necessarily close to load centres and therefore may often require new transmission infrastructure.

Capacity factors of CSP plants range from 22 to $26 \%$ without thermal storage and can reach as high as $74 \%$ with more than 10 hours of thermal storage (DOE and EPRI, 1997; Herrmann et al., 2004). In principle, without storage, the capacity credit of CSP can be similar to solar PV (Xcel Energy, 2009), whereas with storage, CSP's capacity credit could be 89 to $93 \%$, or nearly as high as for thermal plants (GE Energy, 2010). Aside from the increased capacity factor and capacity credit, thermal storage allows CSP plants to provide improved dispatchability (i.e., from partially dispatchable to dispatchable). CSP plants with significant storage have similar electrical power plant characteristics to non-renewable thermal units and thereby enhance the overall grid flexibility to accommodate a larger share of variable energy sources. Plant sizes range from $50 \mathrm{MW}$ to $250 \mathrm{MW}$ and larger.

\section{Geothermal energy}

Geothermal resources can be utilized in a variety of sustainable power generating modes, including continuous low power rates, long-term (decades) cycles of high power rates separated by recovery periods, or uninterrupted high power rates sustained with effective fluid reinjection. Geothermal energy typically provides base load electrical generation, 
but it has also been used for meeting peak demand. Geothermal plants represent major investment and have low variable costs and thus would tend to be operated at maximum, sustainable rated output. Operating in a flexible manner may be possible in some cases but it also may impact efficiency (D.W. Brown, 1996). As a result, while it may be possible to balance demand and/or variable generation with geothermal resources (Bromley et al., 2006), the overall economic effectiveness of this approach requires detailed evaluation at specific sites.

High-temperature hydrothermal-type geothermal reservoirs are geographically specific, and thus power generation will not always be near to population and load centres. Adding new geothermal resources often necessitates extending the transmission network and thus involves infrastructure investments (e.g., Mills et al., 2011). However, in the future enhanced geothermal systems will in principle have the potential of locating closer to demand (Tester et al., 2006). For new geothermal plants, capacity factors of $90 \%$ or higher are typically achieved (DiPippo, 2008), possibly declining over time with ageing. Geothermal plants use heat engines to drive electrical generators and as such they are in general dispatchable to the degree that dispatching the plant does not degrade the geothermal reservoir. In some cases it may be possible for geothermal plants to provide other network services such as frequency response and voltage control similar to thermal generation. The high availability of geothermal plants in California led to an estimated capacity credit of close to $100 \%$ (Shiu et al., 2006). Geothermal plant sizes can vary from small Stirling engine-based generators of a few $\mathrm{kW}$ up to steam plants of over $100 \mathrm{MW}$.

\section{Hydropower (run-of-river, reservoir, pumped storage)}

In addition to hydropower resources providing a source of RE, the generation characteristics of hydro resources further offer flexibility to the power system to manage the variable output of other renewable resources. Through integrated strategies, hydropower can buffer fluctuations in supply and demand, increasing the economic value of the power delivered (US DOE, 2004). Hydropower plants can be classified in three main categories according to operation and type of flow: run-of-river; reservoir based (storage hydropower); and pumped storage.

Run-of-river hydro facilities can exhibit substantial daily, monthly and seasonal variations depending on the precipitation and runoff in the catchment, and are built to operate with this variability. Some runof-river plants may have limited balancing storage (e.g., diurnal) for meeting daily peak demand during periods of low water availability. Variability and predictability can also be influenced by hydrological restrictions, for example from mutual influences of plants operated in cascade along a given river. There can also be limits due to minimum flow in rivers or other similar hydrological factors. Variations in the water availability are in general well predicted at time scales relevant for system operation. In-stream technology using existing facilities like weirs, barrages, canals or falls generates power as per available water flow without any restriction and storage (Section 5.3.1).
For reservoir-based hydropower, when water is available, the electrical output of the plants is highly controllable and can offer significant flexibility for system operation. The reservoir capacity can vary from short term to seasonal to multi-seasonal. The energy storage in the reservoir allows hydro plants to operate in base load mode or as load following plants (Sections 5.3 and 5.5). Just like run-of-river hydro, the hydro plant flexibility can be limited by legally binding restrictions concerning minimum levels in the reservoirs, minimum river flows and other possible restrictions.

Pumped storage plants pump water from a lower reservoir into an upper storage basin using surplus electricity and reverse flow to generate electricity during the daily high demand period or other periods that require additional flexible generation (such as periods with high ramps). Pumped storage is a net consumer of energy due to pumping losses (not an energy source) (Section 5.3.1.3).

The geographic diversity potential of run-of-river hydropower is good; limiting factors are topography and precipitation conditions. The location of reservoir hydropower plants is very much geographically restricted and construction of large plants often requires substantial transmission network investments. Pumped hydro plants are similarly limited by economic constraints to areas that have suitable topography.

Capacity factors for run-of-river systems vary across a wide range (20 to $95 \%$ ) depending on the geographic and climatological conditions, as well as technology and operational characteristics. For reservoir hydro, capacity factors are often in the range of 30 to $60 \%$ (Section 5.3.1.2). The capacity credit of run-of-river and reservoir hydro depends on the correlation of stream flows with periods of high demand and the size of the reservoir, as well as plant operational strategies. Hydro systems with large multi-seasonal reservoirs have capacity credits comparable to thermal plants (i.e., $97 \%$ in British Columbia, Canada; Wangdee et al. 2010). Such high capacity credit does depend on the size of the storage (Haldane and Blackstone, 1955; Billinton and Harrington, 1978) and the availability of other sources of energy during periods of regional drought (Barroso et al., 2003). A survey across a broad range of hydrologic and demand conditions for hydro lacking seasonal storage found capacity credits ranging between roughly 0 and 90\% (Grimsrud et al., 1981). Some reservoir-based hydropower plants may be designed to operate as peaking power plants resulting in a low capacity factor but with a relatively high capacity credit (Section 5.5). The capacity factor and capacity credit for pumped storage are dependent on the energy storage capacity and the operational strategy, but the capacity credit would be expected to be high.

Electrical power plant characteristics of reservoir hydro plants using synchronous generators are similar to thermal generation; in fact, reservoir hydro can often provide rapid power control possibilities in excess of those possible with thermal units. Run-of-river plants use a variety of 
conversion systems, including variable speed systems with power electronic converters. As a consequence, electrical output characteristics of these run-of-river plants in terms of power and voltage control possibilities are comparable to wind power plants. The size of hydropower plants range from a few $\mathrm{kW}$ to over $20 \mathrm{GW}$.

Ocean energy (wave, tidal range, tidal and ocean currents, OTEC, salinity gradient)

Ocean energy comprises several different types of plant: wave energy; tidal range (due to the rise and fall of sea level, i.e., tidal barrages); tidal and ocean currents; Ocean Thermal Energy Conversion (OTEC); and salinity gradient. Virtually all ocean energy technologies are at best at the development or demonstration stage. Therefore, data are scarce in the scientific literature and much of what is available is heavily dependent on simulation studies with little operational field data.

The different forms of ocean energy are driven by very different natural energy flows and have different variability and predictability characteristics. Wave energy is a spatially integrated form of wind energy and daily variability may to some extent be less than wind energy. Seasonal variability has been reported to be similar to wind (Stoutenburg et al., 2010), however this is device dependent. Initial work on wave models and data shows that output can be forecasted and the models perform particularly well during high production situations (ECI, 2006). Forecasting performance for wave energy is reported to be comparable to wind and solar (Reikard, 2009).

Generation from both tidal range and tidal currents is variable in most configurations but production profiles are (almost) completely predictable. Phase differences in tidal currents between different locations within the same electrical power system could be exploited to realize significant power smoothing (Khan et al., 2009). Ocean currents have low variability at power system operational time scales. OTEC derives from thermal gradients that are reasonably well understood and near-continuous base load operations would be expected. Salinity gradient power generation is at an early stage of research and should the technology become commercial it is likely that plants would operate at constant output.

Although all ocean technology requires access to the ocean, the appropriateness of specific locations varies by the type of ocean technology. Wave energy can be collected on or reasonably near to the shore, and perhaps in the future further out into the oceans. Tidal plants and ocean current plants may locate in very specific locations, usually necessitating network infrastructure investments (University of Edinburgh, 2006). Large collections of ocean energy generators will also result in temporal smoothing of the power output (Salter et al., 2002), but are located some way from land and/or load centres.

There are a few studies with indicative values for capacity factors and capacity credit. Radtke et al. (2010) have shown that tidal range can have very low capacity credit (i.e., less than $10 \%$ for the example studied), while the capacity factor of tidal range is expected to be 22.5 to $28.5 \%$ (Section 6.3.3). Bryans et al. (2005) report capacity factors of 19 to $60 \%$ and capacity credit of 10 to $20 \%$ for tidal current. The higher end of the capacity factor and capacity credit range is achieved by downsizing the electrical generator and curtailing output during peak tidal currents. Stoutenburg et al. (2010) report capacity factors of 22 to $29 \%$ and capacity credit of $16 \%$ for wave energy off the coast of California. For Scottish wave energy, a capacity factor of $31 \%$ has been reported (University of Edinburgh, 2006).

Tidal range uses synchronous generators, and has electrical characteristics similar to thermal plants. Wave devices usually make use of power electronic converters for grid connection. Equally, tidal and ocean current turbines tend to be variable speed and thus converter connected. The electrical plant characteristics of wave, tidal current and ocean current may therefore be comparable to wind power plants. Plant sizes are 0.1 to $300 \mathrm{MW}$ for tidal range, and will vary depending on the number of modules for other ocean energy technologies.

\section{Wind energy}

The electrical output of wind power plants varies with the fluctuating wind speed, with variations at all time scales relevant for power system planning, scheduling and operations (Holttinen et al., 2009). The variability of aggregated wind power output diminishes with geographical dispersion and area size, because of the decreasing correlation of wind speeds (Section 7.5.1). Prediction accuracy of wind power plant output decreases with the time span of prediction horizon, and improves with area size considered (Chapter 7). Control systems at the wind turbine, wind plant and area level (e.g., groups of distributed wind power plants) can be used to reduce the power output fluctuations when needed for secure power system operation (e.g., during extreme weather and low load situations), but at the cost of lost production.

In general, wind power plants are distributed over existing networks. However, access to areas of high wind resources, for example offshore or remote onshore, often requires extension of existing transmission networks.

Wind capacity factors depend on wind climate and technology used. Fleetwide wind capacity factors are of the order of $20 \%$ to as high as $40 \%$ for onshore wind depending on the location, and even higher for offshore wind (Section 7.2). The capacity credit of aggregated wind power at low to medium penetrations is around 5 to $40 \%$, depending on location, and diminishes with increasing penetration level (Section 7.5). Electrical power plant characteristics are determined by the type of conversion system and control characteristics of wind power plants. Although many existing wind plants have induction generators, as a general trend, modern wind power plants are connected to the power system via power electronic converters, and can be equipped to provide grid services such as active power, reactive power and voltage control, frequency response (inertial type 
response) FRT and power system support during network faults (Section 7.5.3). Recent onshore wind power plant sizes have typically ranged from 5 to $300 \mathrm{MW}$ and offshore from 20 to $120 \mathrm{MW}$, though smaller and larger plant sizes do exist, including the recently commissioned 500 MW Greater Gabbard offshore plant in the UK. ${ }^{4}$

\section{Challenges with integrating renewable resources into electrical power systems}

Most RE resources are location specific. Therefore, renewable-generated electricity may need to be transported over considerable distances. For example, China's windy regions are often far from population and load centres. Scotland's tidal current resource is a long distance from a significant population. In the USA, the largest high quality wind resource regions and land with significant biomass production are located in the Midwest, a significant distance from the predominantly coastal population. In many of these cases, additional transmission infrastructure can be economically justified (and is often needed) to enable access to higher quality (and therefore lower cost) renewable resource regions by electricity load centres rather than utilizing lower quality renewable resources located closer to load centres. Many renewable sources can also be exploited as embedded generation in distribution networks, which may have benefits for the system when at moderate penetration levels, but also can pose challenges at higher penetration levels (e.g., voltage rise, see Masters (2002)).

Also, as discussed above, certain RE sources lack the flexibility needed to deal with certain aspects of power system operation, in particular balancing supply and demand. This is because they are subject to significant variability across a wide range of time scales important to electrical power systems and also experience more uncertainty in predicted output. Furthermore, renewable plants may displace non-renewable plants that have heretofore provided the required flexibility. Some renewable sources (hydropower with reservoirs and bioenergy) may help to manage this challenge by providing flexibility. However, overall balancing will become more difficult to achieve as partially dispatchable RE penetrations increase. Particular challenges to system balancing are situations where balancing resources are limited (e.g., low load situations with limited operational capacity).

Furthermore, increased penetration of RE production will require renewable generators to become more active participants in maintaining the stability of the grid during power system contingencies. Depending on local system penetration, network faults can trigger the loss of significant amounts of generation if the renewable generation resources are concentrated in a particular section of the power system and connection requirements have not properly accounted for this risk. A solution is to require renewable capacity to participate when possible in transient system voltage control thus supporting recovery from network faults (EirGrid, 2009, 2010b).

4 www.sse.com/PressReleases2011/FirstElectricityGeneratedGreaterGabbardWalney/.
There are also challenges with regard to very short-term system balancing (i.e., frequency response). At high penetration levels the need for frequency response will increase unless supplementary controls are added (Pearmine et al., 2007). Many of the renewable technologies do not lend themselves easily to such service provision. In addition, RE interfaced through power electronics may displace synchronous generators, thereby reducing the overall system inertia and making frequency control more difficult. Research and development is in progress to deliver frequency response from time variable sources such as modern wind turbines, ${ }^{5}$ and some equipment with frequency response and inertial response is already available (Section 7.7). This is a subject of ongoing research (Doherty et al., 2010) and development (Miller et al., 2010).

The output of the different renewable sources is not in general well correlated in time, so if power systems include a wide range of renewable sources, their aggregate output will be smoother thus easing the challenge of electrical power system balancing. Such a portfolio approach to generation should thus be assessed, but as noted above, many of the renewable resources are highly geographically specific so that beneficial combinations of renewable sources may not always be practicable.

Lastly there is the additional challenge of managing the transition from the predominant generation mixes of today to sustainable sources required for the low carbon power systems of the future. Major changes will be required to the generation plant mix, the electrical power systems infrastructure and operational procedures if such a transition is to be made. Specifically, major investments will be needed and will need to be undertaken in such a way, and far enough in advance, so as to not jeopardize the reliability and security of electricity supply.

\subsubsection{Integration of renewable energy into electrical power systems: experiences, studies and options}

As electrical power systems worldwide are different, there cannot be one recipe that fits all when examining the integration of RE. Dispatchable renewable sources (hydro, geothermal, bioenergy, CSP with storage ${ }^{6}$ ) may require network infrastructure but, in many cases, may offer extra flexibility for the system to integrate variable renewable sources (hydropower in particular). Partially dispatchable RE technologies (wind, solar PV, certain forms of ocean energy), on the other hand, will pose additional challenges to electrical power systems at higher penetration levels.

There is already significant experience in operating electrical power systems with large amounts of renewable sources (e.g., 2008 figures on an energy basis are: Iceland 100\%; Norway 99\%; Austria 69\%; New Zealand 64\%; and Canada 60\% (IEA, 2010b)). High percentages of

5 It is worth noting that older wind technologies provided this response inherently, although not as well as synchronous generation (see Mullane and O'Malley, 2005).

6 CSP without additional storage is partially dispatchable and with several hours of storage can be considered dispatchable. 
renewable electricity generation generally involve dispatchable renewable sources, in particular hydropower and geothermal (e.g., 2008 figures on an energy basis are: Norway $99 \%$ hydro; Iceland $75 \%$ hydro and $25 \%$ geothermal (Nordel, 2008)). Large shares of bioenergy are not so common in electrical energy systems, but Finland produces $11 \%$ of its electrical energy from bioenergy (Statistics Finland, 2009). A number of other countries have managed operations with more than $10 \%$ of annual supply coming from wind energy. In addition, integration studies provide insight into possible options for future systems to cope with higher penetration of partially dispatchable renewable sources.

This subsection addresses the integration of RE in three ways. First, it discusses actual operational experience with RE integration. Second, it highlights RE integration studies that have evaluated the potential implications of even higher levels of RE supply. Finally, it discusses the technical and institutional solutions that can be used to help manage RE integration concerns. This section has a focus on the developed world as this is where most experience and studies exist to this point. Autonomous systems are covered here to a degree, while issues associated with such systems are covered in a more dedicated fashion in Section 8.2.5.

\section{Integration experience}

It is useful to distinguish between experience with RE generation plants that can be dispatched (hydro, bioenergy, geothermal, CSP with storage) and variable renewable sources that are only partially dispatchable (wind, solar PV, and certain types of ocean energy).

\section{Dispatchable renewable sources (bioenergy, CSP with storage, geothermal, hydro)}

Experience from biopower plants is similar to that from fossil fuel thermal power plants in power system operation. As the plants are, at least in principal, dispatchable they can also offer flexibility to the power system. Even with CHP plants there are ways to operate the plants so that the electricity production is not totally dependent on the heat load. In Finland, for example, the larger plants use back pressure turbines equipped with auxiliary condensing units making it possible to maintain efficient electricity production even when heat load is low (Alakangas and Flyktman, 2001). Experience from Denmark shows that when operating with thermal storage, small biopower CHP plants can provide electricity according to system needs (market prices) and thus help in providing flexibility (Holttinen et al., 2009).

A renewable integration cost report from California, analyzing real data from CSP plants from 2002 to 2004 shows consistently high generation during peak load periods given the natural tendency of solar generation to track demand that is largely driven by cooling loads. The auxiliary natural gas boilers on some of the CSP plants in the studied region augmented solar generation during the peak demand periods. The variability and ramping of the CSP plants was reported to be of the same (relative) magnitude as for wind power (Shiu et al., 2006).
Adding new geothermal resources has often meant extending the transmission network and thus infrastructure investments. For example, in New Zealand the construction of a $220 \mathrm{kV}$ double circuit is planned to facilitate development of geothermal generation (up to $800 \mathrm{MW}$ ) in the North Island of New Zealand (TransPower, 2008; W. Brown, 2010). Geothermal resources typically produce power (and heat) on a stable basis and there is considerable experience with their use, mostly operating like base load units (Shiu et al., 2006). In California, the existing geothermal generation was assessed for integration impacts based on real output data from the years 2002 to 2004 and was found to impose a very small regulation cost. Because of the very low forced outage rates for geothermal units $(0.66 \%)$ and low maintenance rates $(2.61 \%)$ during the 2002 to 2004 period, geothermal plants were also able to provide more capacity credit to the system than the benchmark units (Shiu et al., 2006).

Adding new hydropower resources has meant extending the transmission network and thus required network investments. Examples include northern Sweden, northern Italy, the USA, and northern Quebec, Canada (Johansson et al., 1993) and more recently in China (X. Yang et al., 2010). The large seasonal and interannual variability of hydropower is usually tackled by building large reservoirs where possible. Aggregation of different regions can help in smoothing hydro resource variability, since the changes over weeks and years are not exactly the same in neighbouring areas. The experience from Nordic countries (Sweden, Norway, Finland, Denmark) shows that the large differences in inflow between a dry and a wet year (up to 86 TWh (309 PJ) when mean yearly hydro production is $200 \mathrm{TWh}(720 \mathrm{PJ})$ ) can be managed with strong interconnections to the large reservoir capacity of 120 TWh (432 PJ) in Norway and Sweden and thermal power availability in Finland and Denmark (Nordel, 1996, 2000). Interconnection to neighbouring systems has been shown to have a large impact on the way hydro is used, since it influences the plant mix and thus changes hydro scheduling (Gorenstin et al., 1992).

The operational cost of hydropower plants is very low; the challenge for scheduling is to use the limited amount of water as efficiently as possible (Sjelvgren et al., 1983). The flexibility of hydropower is often used as an effective balancing option in electrical power systems (PérezDíaz and Wilhelmi, 2010). Switzerland has a flexible hydro system with both reservoirs and pumping facilities, and that system is currently used for daily balancing in the whole interlinked system including Germany, France and Italy (Ochoa and van Ackere, 2009). The flexibility of hydropower can be observed by comparing the changes in the daily prices in different countries. In hydro-dominated systems the price differences are relatively small since water is easily moved from low price periods to high price periods until the price difference is small (Sandsmark and Tennbakk, 2010). Hydropower is a low cost balancing option for daily load following, as can be seen from the Nordic day-ahead market. Sandsmark and Tennbakk (2010) show that the normalized average hourly prices during working days, 2001 to 2003, varied much less in the 
Nordic hydro-dominated system than in Germany where thermal power is used for balancing.

\section{Partially dispatchable renewable sources (solar PV, ocean, wind)} Partially dispatchable renewable sources pose greater challenges to system operators. In essence these sources of generation cannot be fully controlled (dispatched) since they reflect the time-varying nature of the resource. The main way in which they can be controlled is through reduction of the output. This is in contrast to dispatchable generation that can be controlled by increasing or reducing fuel supply.

Solar PV penetration levels remain quite limited despite high growth rates of installed capacity in certain countries. For example, in Germany where active programmes of $\mathrm{PV}$ installation have been successful, about $10 \mathrm{GW}$ of PV were installed by the end of 2009, producing $1.1 \%(6.6$ TWh or 23.76 PJ) of German electrical energy in 2009 (BMU, 2010). Local penetration levels of PV are already higher in southern parts of Germany (Bavaria has the largest concentration of installations), however, and reinforcements have been needed in certain distribution networks, mainly in rural areas with weak grid feeders and high local penetration levels. In strong urban grids there has only been a marginal need for grid reinforcement. There is concern that severe grid disturbances with strong frequency deviations can be worsened by large amounts of PV systems (Strauss, 2009). Due to this, the German guideline for the connection to medium-voltage networks requires a defined frequency/ power drop for frequencies above $50.2 \mathrm{~Hz}$ (BDEW, 2008). Protection systems in distribution grids also have to be adapted to ensure safety (Schäfer et al., 2010). In general, these adaptations and guidelines indicate that it is important that solar PV become a more active participant in electrical networks (Caamano-Martin et al., 2008). In Japan, several demonstration projects have provided experience with technologies related to over-voltage protection through reverse power flow control by generation curtailment and battery control, prevention of islanding (Ueda et al., 2008), and verification of grid stabilization with large-scale solar PV systems (Hara et al., 2009). In the USA, some infrastructure investments have been driven by solar energy. California has approved the Sunrise Powerlink, a $193 \mathrm{~km}, 500 \mathrm{kV}$ line that will connect highquality solar areas in the desert (for both PV and CSP plants), as well as geothermal resources, to the coastal demand centre of San Diego (U.S. Forest Service, 2010).

Some initial reports are also emerging that analyze the variability of groups of PV plants (Wiemken et al., 2001; Murata et al., 2009; Hoff and Perez, 2010; Mills et al., 2011). Local weather situations like clouds, fog and snow are factors that cause variability and challenge short-term forecasting. All of these studies, using data from different regions of the world, indicate that the variability of groups of PV plants is substantially smoothed relative to individual sites, particularly for sub-hourly variability. Day-ahead forecast errors using weather prediction models have been shown to provide forecasts with only slightly lower accuracy (still $<5 \%$ forecast error normalized to installed power) (Lorenz et al., 2010).
Operational ocean energy capacity is effectively in the form of a few individual plants, typically of modest capacity, thus no extensive integration experience with larger installations or collections of plants exists.

The majority of the experience with partially dispatchable RE integration comes from the wind sector (Section 7.5.3.2). West Denmark has a 30\% wind penetration and has hit instantaneous penetration levels of more than $100 \%$ of electricity demand coming from wind power (Söder et al., 2007). But West Denmark is a small control area that is synchronously well connected to the much larger Continental Europe system. Ireland has a small power system with very limited interconnection capacity to Great Britain. Ireland has an $11 \%$ wind energy penetration level (2009) and has coped with instantaneous power penetration levels of up to $50 \%$ (EirGrid, 2010b). Section 7.5.3.2 provides further information on the Danish and Irish systems. Spain and Portugal are medium size control areas with relatively weak synchronous connections to the rest of the Continental Europe system. They both have about $15 \%$ wind energy penetration and have coped, at times, with 54 and $71 \%$ instantaneous power penetration levels, respectively (Estanqueiro et al., 2010). There are also several wind-diesel systems where wind provides a large part of the energy for autonomous systems (e.g., in Alaska, USA, the Cape Verde islands, Chile and Australia (Lundsager and Baring-Gould, 2005)).

Many systems report the need for new grid infrastructure both inside the country/region as well as interconnection to neighbouring countries/ regions. Grid planning includes grid reinforcements as well as new lines (or cables) for targeted wind power. Wind power is normally not the only driving force for the investments but it is a major factor (e.g., Ireland (EirGrid, 2008); Germany (Dena, 2010); Portugal, (REN, 2008); Europe (ENTSO-E, 2010); the USA (MTEP, 2008)). In the USA, a lack of transmission capacity to move the wind energy from the best wind resource areas, most of which are remote, to the distant load centres has been clearly identified. A challenge for transmission planning is to resolve the timing conflict of financing for the wind plants needing transmission access (i.e., wind plants can be permitted and constructed in 2 to 3 years while it may take 5 to 10 years to plan, permit and construct a transmission line). Another related issue is the need for cost recovery certainty (see Chapter 11). At the regional level in the USA, Texas has addressed these issues with the establishment of a Competitive Renewable Energy Zone (CREZ) process, which allows transmission to be built and paid for in advance of the construction of the wind plants. The completed CREZ transmission projects will eventually transmit approximately $18.5 \mathrm{GW}$ of wind power. The estimated time of completion is the end of 2013 (CREZ, 2010). This model is being applied to other parts of the USA and is beginning to be explored in Europe. In Portugal, the investments reported for added transmission capacity to integrate wind production have been USD 2005185 million in the period 2004 to 2009 for increasing wind penetration from 3 to 13\% (Smith et al., 2010a). The network investment plan for the period 2009 to 2019 is another USD $_{2005} 138$ million dedicated to the connection of wind and other (comparatively small) independent producers (REN, 2008). China has rapidly become 
the world's largest market for wind power plant installations, and is therefore also beginning to confront the challenges of transmission and integration. Much of the wind power plant construction is occurring in northern and north-western China, in locations remote from major population centres, and is necessitating significant new transmission infrastructure (e.g., Liao et al., 2010; Liu and Kokko, 2010; Deng et al., 2011). The pace of wind power plant construction has also created a lag between the installation of wind power plants and the connection of those plants to the local grid (e.g., Liao et al., 2010; Deng et al., 2011).

In North Germany, a transitional solution allowing curtailments of wind power was made while waiting for the grid expansion in order to protect grid equipment such as overhead lines or transformers from overloads (Söder et al., 2007). Germany has also changed the standard transmission line rating calculation to increase the utilization of the existing grid. Dynamic line ratings, taking into account the cooling effect of the wind together with ambient temperature in determining the transmission constraints, can increase transmission capacity and/or delay the need for network expansion (Abdelkader et al., 2009; Hur et al., 2010). In the UK, some wind projects accept curtailments in order to lower the connection cost to the (distribution) grid that otherwise would need reinforcements (Jupe and Taylor, 2009; Jupe et al., 2010). Curtailment was particularly high in Texas in 2009 with $17 \%$ of all potential wind energy generation within the Electric Reliability Council of Texas curtailed (Wiser and Bolinger, 2010).

Many countries have already experienced high instantaneous wind penetration during low demand situations. Wind power is usually last to be curtailed. However, when all other units are already at minimum (and some shut down), system operators sometimes need to curtail wind power (Söder et al., 2007) to control frequency. Denmark has solved part of the curtailment issues by increasing flexible operation of CHP and by lowering the minimum production levels used in thermal plants (Holttinen et al., 2009). Experience from both Denmark and Spain shows that when reaching penetration levels of 5 to $10 \%$, an increase in the use of reserves can be required, especially for reserves activated on a 10 to 15 minute time scale although, so far, no new reserve capacity has been built specifically for wind power (Söder et al., 2007; Gil et al., 2010). In Portugal and Spain, new pumped hydro is planned to be built to increase the flexibility of the power system, mainly to avoid curtailment of wind power (Estanqueiro et al., 2010). In small power systems such as those on islands, system balancing is more challenging due to a lack of load aggregation (Katsaprakakis et al., 2007). Power system operators have reported challenging situations for system balancing caused by high ramp rates for wind power production during storms when individual wind power plant production levels can drop from rated power to zero over a short time span, due to wind turbines cutting out. Due to aggregation effects, the impact on the power system/control area is often spread over 5 to 10 hours, however, and these events are rare (once in one to three years) (Holttinen et al., 2009).

In Ireland some curtailments have been due to concerns about low inertia (Dudurych, 2010b) and consequently susceptibility to instability in the system due to high instantaneous wind penetration and low system load. Currently, the issue of low inertia is unique to small systems like Ireland and possible solutions are being investigated (EirGrid, 2010b). In order to allow higher instantaneous penetration levels, the capability of wind power plants to provide (some) ancillary services must be improved. Equally, flexible balancing plants that can operate at low output levels and deliver stabilizing services would facilitate high instantaneous penetrations.

Low inertia has not, as yet, caused a problem for larger power systems but is being investigated (Vittal et al., 2009; Eto et al., 2010). Concerns about frequency regulation and stability have resulted in instantaneous penetration limits in the range of 30 to $40 \%$ for wind power on some Greek islands, including Crete (Caralis and Zervos, 2007a; Katsaprakakis et al., 2007; RAE, 2007). Frequency control and frequency response requirements associated with integration of Danish wind generation are reported to be virtually nonexistent (Eto et al., 2010) because the contribution of Danish wind generation is comparatively small in the large interconnected Continental Europe and Nordic systems (Denmark is connected to both). Experiences reported by the system operators in the Iberian Peninsula (Spain and Portugal) are consistent with those in Denmark in that no significant frequency impacts have been observed that are the result of wind power variation (Eto et al., 2010).

Formal forecasting methodologies are now implemented by system operators in many countries with high wind penetration (e.g., Denmark, Spain and Germany), with user acceptance/demonstration trials taking place in countries elsewhere (Ackermann et al., 2009; Grant et al., 2009). In Australia, the experience from a real-time, security-constrained, fiveminute dispatch spot market, associated derivative and frequency control ancillary services markets, and a fully integrated wind energy forecasting system show that markets can in principle be designed to manage variable renewable sources (MacGill, 2010). Managing the variability and limited predictability of wind power output in China is made more complex by (1) China's reliance on coal-fired generation and the relatively low capacity of more flexible generation sources, especially in the regions where wind development is most rapid; (2) the still-developing structure of China's electricity and ancillary services markets; (3) the limited historical electricity trade among different regions of China; and (4) grid code requirements for wind plant installations that, historically, have been somewhat lenient (e.g., Yu et al. 2011). As a result of some of these factors, wind power plant curtailment has become common, especially in northern China. In Japan, the low flexibility of the power system has led to the development of certain options, such as requiring batteries in wind farms to reduce the night time variability (Morozumi et al., 2008).

There are short- and longer-term impacts of wind energy on wholesale electricity prices (Section 7.5.3.1). In Denmark, the Nordic electricity market is used for balancing wind power. The system operator balances the system net imbalance during the hour and passes this cost to all generators that have contributed to the imbalance, as balancing costs. Balancing costs for wind power are incurred when there are 
differences between the wind generation bid into the market (according to forecasts) and the actual production. The balancing cost of Danish wind power from the Nordic market has been approximately $\mathrm{USD}_{2005} 1.37$ to 2.98 per MWh (0.38 to $0.82 \mathrm{USD}_{2005} / \mathrm{GJ}$ ) of wind energy (Holttinen et al., 2009). The Danish case also shows how interconnection benefits the balancing task: when Denmark is separated from the Nordic market area due to transmission constraints, the prices become very volatile with day-ahead market prices going to zero during windy low-load periods and with balancing prices also being affected (Ackermann and Morthorst, 2005; see also Section 7.5.3.2). There is already some initial experience in Germany and in the Denmark/Nordic market about how wind power impacts day-ahead electricity market prices-during hours with a lot of wind, the market prices are lowered (Munksgaard and Morthorst, 2008; Sensfuß et al., 2008). Other experience shows that wind power will increase the volatility in market prices when there is a high wind penetration in the market (Jónsson et al., 2010). Chapter 7 discusses the short- and longer-term impacts of wind energy on wholesale electricity prices (Section 7.5.3.1).

In Spain, the reliability impact of wind generation of greatest concern has been when network faults (for example short circuits) occur (Smith et al., 2010a). This concern is in part due to the older wind turbines deployed in Spain not being capable of FRT. Large amounts of wind power can therefore trip off the grid because of a short-lived transient disturbance of the grid (voltage drop). This problem has been addressed by new grid code requirements for wind power that have been adopted in many systems (Tsili and Papathanassiou, 2009) (Section 7.5.2.2). Germany has also changed the grid code to require FRT capability from wind turbines as simulated cases showed the possibility of losing more than $3,000 \mathrm{MW}$ of wind power in a rather limited area in North Germany (Dena, 2005; Holttinen et al., 2009). The USA has also adopted a FRT requirement in FERC Order 661-A (FERC, 2005) as have a number of other jurisdictions (see Section 7.5.2.2 for more detail on grid codes for wind energy). The grid codes also require wind turbines to provide reactive power and in some regions also to take part in voltage and frequency control (Söder et al., 2007). Work in Spain has shown that wind power plants can contribute to voltage support in the network (Morales et al., 2008).

In Germany, wind and solar power have already created problematic flows through neighbouring systems (mainly the Netherlands and Poland; Ernst et al. (2010)).

Also of some concern is the possibility of low wind power production at times of high load. However, so far wind power has been built as additional generation and thus no problems with capacity adequacy were reported at least until 2007 (Söder et al., 2007).

Events in Germany in 2006 (UCTE, 2006) suggest that more and better information is needed in the control rooms of system operators, and also at the regional level (Section 7.5.3.2). Indeed, experiences from Denmark, Germany, Spain, Portugal and the USA show that system operators need to have on-line real-time variable renewable generation data together with forecasts of expected production (Holttinen et al., 2009). This can be challenging as variable renewable generation is sometimes from small units and is often connected to the distribution system. In Spain and Portugal, decentralized control centres have been established to collect on-line data and possibly to control smaller variable renewable power plants (Morales et al., 2008; J. Rodriguez et al., 2008). Experience from the USA shows that when most of the generation is connected to the transmission system, this is not as much of a problem, due to the requirement that wind plants provide supervisory control and data acquisition (SCADA) capability to transmit data and receive instructions from the transmission provider to protect system reliability (FERC, 2005).

Experience of a more institutional nature is the processing of large numbers of grid-connection applications that has led to group processing procedures in Ireland and Portugal (Holttinen et al., 2009; EirGrid, 2010a). Also the assessment of grid stability has required model development for wind turbines and wind power plants (Section 7.5.2.1). One high level experience that applies to integrating any form of generation into electrical power systems is the public opposition to overhead network infrastructure (Devine-Wright et al., 2010; Buijs et al., 2011). Evidence of this can be seen in Ireland and Denmark where needed transmission investment (not necessarily related to RE integration) is being opposed vigorously and burial options are being considered (Ecofys, 2008; Energinet.DK, 2008). Burying low voltage distribution networks is common practice, technically not challenging, but is more expensive. Burying high voltage transmission is rare, technically challenging and can be very costly (EASAC, 2009). The related issue of planning and permitting $\mathrm{RE}$ technologies is dealt with in detail in Section 11.6.4.

\section{Results from integration studies for variable renewable sources} Numerous studies of RE integration have been undertaken over recent decades. It should be reiterated that integration issues are highly system specific and resource related and consequently there is a wide diversity of results and conclusions. To date most integration studies have focused on increasing levels of wind energy (typically above existing experience). Some recent large-scale studies look at both wind power and other renewable sources like solar and wave energy. There are very few dedicated and comprehensive solar or ocean integration studies, but there are some smaller-scale studies. Some of the results obtained from wind integration studies can also be applied to solar and wave integration.

The specific issues investigated in the wind integration studies vary and the methods applied have evolved over time, with studies building upon the experience gained in previous efforts (Section 7.5.4). Best practices are emerging and models are being improved (Smith et al., 2007; Söder and Holttinen, 2008; Holttinen et al., 2009). The main issues studied are the feasibility of integrating high levels of wind energy, the impact on the reliability and efficiency of the power system and the measures required to facilitate the increased levels of wind energy. Impacts typically considered include: effects on balancing at different time scales (e.g., any increase needed in reserves or ramping 
requirements); effects on the scheduling and efficiency of other power plants; impacts on grid reinforcement needs and stability; and impacts on generation adequacy and therefore long-term reliability. The largescale studies briefly outlined below have been selected to illustrate key issues arising from wind integration into electrical power systems. ${ }^{7}$ More detail on wind integration at low to medium penetration levels (i.e., $<20 \%$ ) can be found in Section 7.5.4.

A Danish analysis concluded that integration of a $50 \%$ penetration of wind power into the electricity system in Denmark by 2025 is technically possible without threatening security of supply (EA Energy Analyses, 2007). To do so would require new power system architectures that integrate local grids and consumers into system operation, coupling power generation, district heating (Section 8.2.2) and transport (Section 8.3.1), together with improved wind power forecasts and optimal reserve allocation. A strong transmission grid with connections to international markets will be needed, supported by a framework for improved international cooperation and harmonized operational procedures. In particular, the international electricity market must efficiently handle balancing and system reserve provisions across borders. Also, demand response would have to play a greater role as wind power penetrations increase (Energinet.DK, 2007; Eriksen and Orths, 2008).

The European Wind Integration Study (EWIS) and TradeWind are the first studies that examined wind integration at a European continental level. EWIS was led by a system operator consortium, and analyzed up to 185 GW of wind in 2015 (EWIS, 2010). TradeWind was led by a wind industry representative organization, the European Wind Energy Association, and analyzed up to $350 \mathrm{GW}$ of wind in 2030 (TradeWind, 2009). Both studies identified the main interconnection upgrades needed (a total of 29 lines for 2015 by EWIS and a total of 42 lines for 2030 by TradeWind) and concluded that those interconnections would bring technical and economical benefits for the system in the short and long term. EWIS results pointed out that significant changes are needed in dispatch and interconnectors will be used more extensively. Additional measures needed to maintain system security include faster protection schemes, more reactive power compensation devices, faster ramping of other plants, and additional protection measures when using dynamic line rating for increasing network capacity. Future wind plants need to be equipped with state-of-the art FRT capability. The joint operation of the European network needs to be better coordinated, and dedicated control centres for renewable sources should be implemented similar to those in Spain (Morales et al., 2008; J. Rodriguez et al., 2008). Large-scale storage and demand side management were not found to bring significant benefits. The costs for upgrading the network for $185 \mathrm{GW}$ wind by 2015 were found to be approximately $5.6 \mathrm{USD} / \mathrm{MWh}^{8}$ (approximately $1.6 \mathrm{USD} / \mathrm{GJ}$ ), while the additional deployment of reserves were estimated at $3.6 \mathrm{USD} /$ $\mathrm{MWh}^{8}$ (approximately 1.0 USD/GJ) (EWIS, 2010). TradeWind calculated

7 Some of the studies also investigate other renewable sources but are dominated by wind.

8 Conversion to 2005 dollars is not possible given the range of study-specific assumptions. the economic benefits of an offshore meshed transmission grid in the North Sea that could connect $100 \mathrm{GW}$ wind power and improve electricity trade across the countries around the North Sea. Finally, the wind power capacity credit was found to be significantly higher when cross border transmission capacity in Europe was increased (TradeWind, 2009).

The U.S. Eastern Wind Integration and Transmission Study (EnerNex Corporation, 2010) examined three scenarios representing alternative build-outs of $20 \%$ wind energy, and a single build-out of $30 \%$ wind energy. The study found that new transmission would be required for all scenarios to avoid significant wind curtailment. In spite of the diverse locations of wind energy in the various scenarios, there is a common core of transmission that is required in each scenario. The study found that large regional control areas and significant changes in markets, tariffs and operations would be required. New transmission was found to enlarge the potential operating footprint, which decreases loss of load expectation and increases wind capacity credits. The wind capacity credit ranged from 16 to $23 \%$ in the lowest of three years, to 20 to $31 \%$ in the highest year. Adding new transmission increased the capacity credit of wind power by about 2 to 10 percentage points, depending on the year, scenario build-out and transmission additions.

The US Western Wind and Solar Integration Study (GE Energy, 2010) looks at a large regional electrical power system and finds that 30\% wind and $5 \%$ "solar energy penetration is operationally feasible provided significant changes to current operating practice are made" (GE Energy, 2010). The changes include greater control area cooperation and sub-hourly generation and interchange scheduling. At penetration levels of $30 \%$ all available flexibility from coal and hydropower plants was found to be crucial for the operation of the power system. Up to a $20 \%$ penetration level relatively few new long distance interstate transmission additions were required assuming full utilization of existing transmission capacity. Wind was found to have a capacity credit of 10 to $15 \%$, solar PV was 25 to $30 \%$ and CSP with six hours of thermal energy storage was 90 to $95 \%$.

High system RE penetrations in the limited capacity and weakly interconnected Irish electricity system are anticipated to give rise to demanding integration challenges. Studies (AIGS, 2008; EirGrid, 2010b) have shown that $42 \%$ renewable sources including $34 \%$ wind is technically feasible at modest additional cost. Nonetheless, there will be a need for extensive transmission infrastructure development and a complementary flexible generation plant portfolio. Dynamic studies were also identified as a need, and the first stage of these was completed in 2010 (EirGrid, 2010b). It was confirmed that the technical performance of renewable and non-renewable generation to support high levels of renewable generation (mainly wind) is important. Operational limitations for non-synchronous generation, which may alter the fundamental characteristics of the electrical power system, may result in some curtailment of renewable generation but these operational restrictions will not prevent achievement of national targets for RE penetration (i.e., 40\% electrical energy). However, these limitations will result in significant 
curtailment if higher targets are set (assuming non-synchronous generation technology) and the economic barriers could be very significant. Similar operational limitations have also been reported for other island systems (Papathanassiou and Boulaxis, 2006).

The Hawaii Clean Energy Initiative (NREL, 2010) specifically identifies up to $400 \mathrm{MW}$ of wind energy capacity offshore from Molokai and Lanai that could be brought by undersea cables ( $\mathrm{AC}$ and/or DC) to Oahu as part of a diversified portfolio of RE technologies. The goal is $40 \%$ renewable electrical energy penetration. To accommodate the expected very high instantaneous penetration levels, the thermal generation minimum online level may need to be lowered and ramping capabilities increased. State-of-the-art wind and solar forecasting were also recommended.

There are also some studies on integration of wind in autonomous systems. On some islands, the maximum allowed wind power penetration has been restricted (Weisser and Garcia, 2005). Several studies have shown that this fixed limit does not guarantee system security and in some instances is not necessary. It has also been shown that it is possible to operate the power system of Crete with a high level of wind penetration while maintaining a high level of security when adequate and appropriate frequency and voltage control response from the other units are available (Karapidakis, 2007). Caralis and Zervos (2007b) investigate the use of storage in small autonomous Greek island systems where wind penetration is restricted for operational and dynamic reasons. They found that storage may reduce operational costs.

Many studies have specifically looked at the cost effectiveness of electricity storage to assist in integrating wind (Ummels et al., 2008; Denholm et al., 2010; Holttinen et al., 2011; Tuohy and O'Malley, 2011). Outside of autonomous energy systems, where storage may be more essential (Section 8.2.5), these studies have found that for wind penetration levels of as much as $50 \%$, the cost effectiveness of building new electricity storage is still low when considering the need for wind integration alone due to the relatively higher cost of storage in comparison to other balancing options (excluding hydropower with large reservoirs and some pumped hydro). As and if storage costs decline, a greater role for storage in managing RE variability can be expected.

In general, the higher penetration studies have often been from island systems (Hawaii, Ireland). In such cases, the studies can be and need to be more detailed (AIGS, 2008; EirGrid, 2010b; NREL, 2010). Moreover, island systems (Hawaii, Ireland, Greek islands) are interesting as they can hit large penetrations faster, providing important early lessons for larger electric systems, and frequency control is more challenging. Another important trend, however, has been to study even larger areas in order to capture the impacts of variable renewable sources on a system wide basis, taking into account potentially valuable exchange possibilities (TradeWind, 2009; EnerNex Corporation, 2010; EWIS, 2010; GE Energy, 2010).

A useful attempt has been made to summarize the results of a number of recent wind integration studies (Holttinen et al., 2009). The studies cover different penetrations and systems and exhibit a wide range of results. Important conclusions include:

- Required increase in short-term reserve of 1 to $15 \%$ of installed wind power capacity at $10 \%$ penetration and 4 to $18 \%$ of installed wind power capacity at $20 \%$ penetration. The increased reserve requirement was calculated for the worst case (static, not dynamic) and does not necessarily require new investments for reserve capacity; rather generators that were formerly used to provide energy could now be used to provide reserves. The reserve requirements will be lower if shorter time scales are used in operation (gate closure time in markets).

- Increase in balancing costs at wind penetrations of up to $20 \%$ amounted to roughly 0.14 to 0.56 US cents $/ \mathrm{kWh}^{9}$ (roughly 0.4 to 1.6 USD/GJ) of wind power produced (see also Section 7.5.4.2). Balancing costs reflect increased use of reserves and less efficient scheduling of power plants. Though there is an increase in balancing costs and less efficient scheduling of power plants, the studies show a significant overall reduction of operational costs (fuel usage and costs) due to wind power even at higher penetration levels. Wind power is still found to lead to emission savings even with the increased integration effort (Denny and O'Malley, 2006; Mills et al., 2009b; Section 7.6.1.3).

- Capacity credit of wind is in the range of 5 to $40 \%$ of installed capacity depending on penetration, wind regime and correlation between wind and load (Keane et al., 2011a).

- The cost of grid reinforcements due to wind power is very dependent on where the wind power plants are located relative to load and grid infrastructure. Grid reinforcement costs roughly vary from 0 USD/kW to 378 USD/kW, ${ }^{9}$ reflecting different systems, countries, grid infrastructure and calculation methodologies. The costs are not continuous; there can be single very high cost reinforcements. There can also be differences in how the costs are allocated to wind power.

While no large-scale and comprehensive studies have been conducted solely on the integration of solar there is a substantial body of work on the topic appearing in the literature. As PVs are installed predominantly locally, there is the possibility of reducing grid losses to the extent that the production coincides with demand (Wenger et al., 1994; Chowdhury and Sawab, 1996). At higher penetration, however, upgrades may be required to enable power to flow from the distribution feeder back to the transmission system without incurring large losses (Paatero and Lund, 2007; Liu and Bebic, 2008). In addition, voltage rise in distribution grids is an issue for PV integration (Widén et al., 2009). Thomson and Infield (2007), however, show that in a typical urban UK network with a very high PV penetration level (2,160 Wpeak on half of all houses), only small increases in average network voltages occur. Different studies propose solutions in order to avoid grid reinforcement such as

9 Conversion to 2005 dollars is not possible given the range of study-specific assumptions. 
decentralized voltage control with reactive power (Braun et al., 2009). This could be performed by the PV inverters themselves (Stetz et al., 2010) or by other measures used for smart voltage control. Besides supporting frequency control and performing decentralized voltage control, other ancillary services could be provided by smart PV inverters. Such inverters can perform filtering/compensation of harmonics and support the fault behaviour of the power system with appropriate FRT capabilities (Notholt, 2008). In Japan, the target for PV is 28 GW in 2020 and 53 GW in 2030, which would supply around 3 and $6 \%$ of the total demand, respectively. Several demonstration projects in Japan addressed grid stabilization with large-scale PV systems by controlling PV generation and local demand (Kobayashi and Kurihara, 2009).

In some locations, adding solar PV to the system near demand centres may avoid the need to expand the transmission network. Kahn et al. (2008) illustrates a case in California where adding PV near coastal load centres would negate the need for significant transmission investments when compared with other renewable sources, in particular the transmission built to access solar PV, CSP, and geothermal in the desert described in the previous section. This benefit is likely to depend on local conditions and therefore vary greatly from region to region.

The capacity credit of solar varies in different parts of the world and by solar technology. In some electrical power systems due to high cooling demand at the peak load period, CSP with thermal energy storage can provide a capacity credit comparable to a thermal generator (GE Energy, 2010). The capacity credit for PV and CSP without thermal storage is much more dependent on the correlation of peak demand and the position of the sun (Pelland and Abboud, 2008; Perez et al., 2008; Xcel Energy, 2009; GE Energy 2010). The capacity credit of solar PV will drop as deployment increases (a similar characteristic to wind, see Section 7.5.2.4) due to the high degree of correlation between solar PV plants from the deterministic change of the position of the sun (Perez et al., 2008).

Managing the short-term variability of solar PV will be somewhat similar to that of wind power. The variability of solar PV systems can be considerable in partly cloudy weather and also with fog or snow (Lorenz et al., 2009; Mills et al., 2011). The ramping up and down during morning and evening of solar output, even if highly predictable and sometimes coinciding with load ramping, can also impose a large variation for electrical power systems with large amounts of solar PV energy (Denholm et al., 2009).

At increasingly high penetrations of solar PV and CSP without thermal storage ( $>10 \%$ annual energy production), the net demand (demand less solar production) will become increasingly low during the middle of the day when the sun is shining, while the night time net demand will not be reduced by these solar resources. Power systems with inflexible power plants may find it challenging to provide energy through the night, ramp down during daylight hours and then ramp back up at night. Inflexible electrical power systems are expected to therefore find integrating high levels of PV and CSP without thermal storage difficult without curtailing a significant amount of solar energy production (Denholm and Margolis, 2007).

Limited research exists in the published literature about ocean energy integration, but one review compared the integration of ocean energy with wind energy (Khan et al., 2009). Since there is little or no operational experience with ocean energy, the results are based only on simulations with little real data to validate the results. At an overall system level, however, the variability of ocean energy output is not expected to pose any greater challenges than the variability from wind power. However, short-term output fluctuations of wave energy plants could be greater than those from wind plants. Ocean wave resources are expected to have greater predictability than wind power because estimation of wave characteristics involves reduced uncertainties when compared to wind owing to its slower frequency of variation and direct dependence on wind conditions.

Bryans et al. (2005) explore methods of deployment and control of tidal current, including the down rating of the generator relative to turbine size and operational output reduction, to reduce the capital cost increase capacity factor and reduce the impact on the grid system. The capacity credit (10 to $20 \%$ ) and capacity factor (19 to $60 \%$ ) of tidal current were also quantified. Denny (2009) used an electricity market model to determine the impact of tidal current generation on the operating schedules of the other units on the system and on the resulting cycling costs, emissions and fuel savings. It is found that for tidal current generation to produce positive net benefits for the case study, the capital costs would have to be less than USD ${ }_{2005} 560 / \mathrm{kW}$ installed, which is currently an order of magnitude lower than the estimated capital cost of tidal current (Section 6.7).

Studies show that combining different variable renewable sources will be beneficial in smoothing the variability and decreasing overall uncertainty. A study undertaken in California, where the system load peak is driven by space cooling demand, shows that the average solar and wind plant profiles when considered in aggregate can be a good match to the load profile and hence improve the resulting composite capacity credit for variable generation (GE Energy Consulting, 2007). It should be noted that the negative correlation between wind and solar in California is not universal; there are many sites where positive correlation exists (e.g., Ireland, where the wind tends to peak in the late afternoon (Hasche et al., 2010). The combination of wind and hydro in British Columbia, Canada, was shown to lead to an improved capacity credit for hydro by using wind power to conserve water stored in the reservoir (Wangdee et al., 2010). Likewise, the independence of wind power and stream flows can reduce the risk of energy deficits in hydro-dominated systems (Denault et al., 2009). Additional analysis specifically on wind-hydro coordination is part of the ongoing IEA Wind Task $24 .{ }^{10}$

An analysis of high penetrations of RE in Denmark found that a mixture of wind, wave and solar power minimizes excess generation of RE. Wind

10 http://www.ieawind.org/Annex_XXIV.shtml 
energy consistently contributed $50 \%$ of the RE mixture. The wave and solar share changed depending on the overall RE fraction (H. Lund, 2006). The potentials for reductions in variability when combining wave and wind energy have been reported for Scotland (University of Edinburgh, 2006), Ireland (Fusco et al., 2010) and California (Stoutenburg et al., 2010). How much of the reduction in variability is associated with the geographic diversity as opposed to the different resources remains an open question. Similarly, any benefits of technology diversity should be compared to the costs of diversifying the RE mix relative to the cost of a less diverse portfolio.

In summary, the results of integration studies for variable renewable sources vary depending on the system being analyzed, the level and type of renewable sources being considered and the methods and available data used in the analysis. However, some general messages can be drawn from the results. Studies show clearly that combining different variable renewable sources, and resources from larger geographical areas, will be beneficial in smoothing the variability and decreasing overall uncertainty for the power systems. The key issue is the importance of network infrastructure, both to deliver power from the generation plant to the consumer as well as to enable larger regions to be balanced; the options described below all need to be considered using a portfolio approach. There is a need for advanced techniques to optimize the infrastructure capacity required for variable renewable sources that have low capacity factors (Burke and O'Malley, 2010). The requirement to balance supply and demand over all time scales raises the need for access to flexible balancing resources (flexible generation, demand response, storage; NERC, 2010b) as well as the need to use advanced techniques for demand and supply forecasting and plant scheduling (NERC, 2010a). There is also a need for market or other mechanisms to ensure that all the complementary services necessary to balance supply and demand over all time scales are provided at a reasonable cost (Smith et al., 2010b; Vandezande et al., 2010).

\section{Integration Options}

The general form of the solutions required to accommodate a high penetration of renewable sources is largely known today. There is already considerable experience operating power systems with large amounts of renewable sources, and integration studies have also offered valuable insights into how high penetrations of renewable sources can be successfully achieved. This section examines in more detail the most important options identified to date. This should not be taken as a complete or definitive list since the future will no doubt open up new options and strategies. In addition, these options should not be viewed as competing in all circumstances, or that focussing on a single option will resolve all issues. Instead, for most electrical power systems, many, if not all of the options considered will be required, although the degree to which each is important may vary from one electrical power system to the next and over time (see Section 8.2.5 for a discussion of the autonomous systems and which of these options may be most appropriate in those circumstances).

\section{Improving network infrastructure}

Strengthening connections within an electrical power system, and introducing additional interconnections to other systems, can directly mitigate the impact of variable and uncertain RE sources. With strengthened connections, electrical energy can more easily be transmitted from where it is generated to where it can be consumed, without being constrained by bottlenecks or operational concerns. This argument also holds true for other generation and distributed loads, such that additional transmission may be viewed as of value to the entire system, rather than an integration cost associated with renewable generation. However, with much of this renewable generation being connected at the distribution level in some countries, greater cooperation and transparency will be required between distribution system operators and transmission system operators (Sebastian et al., 2008). Network expansion and refurbishment is an ongoing process to ensure security of supply and economic efficiency and to realize internal energy markets (ENTSO-E, 2010). Operating as part of a larger balancing area, or sharing balancing requirements across electrical power systems, reduces the integration cost associated with renewable generation and reduces the technical and operational challenges. The opportunity then also exists to exploit the geographical diversity of supply from RE sources to reduce net variability and uncertainty. This may also enable a wider range of renewable sources to be accessed, bringing further potential aggregation benefits due to the imperfect correlation between different renewable sources: for example, the concept of bringing together the solar-rich regions of northern Africa and the Middle East with the windy regions of mainland Europe (Pihl, 2009).

While power systems have traditionally employed $A C$ connections to link dispersed generation to dispersed loads, there can be advantages to using DC connections instead (Meah and Ula, 2007). For example, for long point to point transmission lines ( $>500 \mathrm{~km}$ approximately) there will be a capital cost saving, while for underground or sub-sea connections, issues surrounding reactive power requirements are drastically reduced (Velasco et al., 2011). Consequently, DC connections are increasingly seen as attractive for capturing energy from offshore renewable sources, and for creating sub-sea interconnections between neighbouring countries/regions. However, issues surrounding meshed (rather than point-to-point) high voltage DC (HVDC) grids remain to be resolved (Henry et al., 2010). The investments required to put in place such infrastructure will be substantial and the value they add to the system needs to be carefully assessed (EASAC, 2009).

Employing communications technology to monitor and control larger electrical power system areas will enable more efficient use of the network infrastructure and reduce the likelihood of bottlenecks and other constraints. The cost of implementation of a secure and reliable communications and network infrastructure, however, could well be high, depending on previous investment in the networks and the geographical location of potential renewable generator sites relative to the existing network. The variability and uncertainty of some 
renewable sources may result in local network constraints, but such concerns may be solvable if the renewable (or embedded) generation can provide network support services such as reactive power (Keane et al., 2011b). This capability exists for modern wind generators, although incentives to exploit it are generally lacking (Martinez et al., 2008). Opportunities to realize the potential of flexible AC transmission system (FACTS) devices (which already exist, but have only been installed in small numbers) and other power flow control devices may also develop, as and when system stability issues arise (X.-P. Zhang et al., 2006; Hingorani, 2007; Tyll and Schettler, 2009).

Delivering new network infrastructure will face institutional challenges, in particular to provide incentives for the required transmission investments and to ensure social acceptance of new overhead lines or underground or sub-sea cables (see also Sections 11.6.4, 11.6.5 and 8.2.1.3). Investment in new transmission is, for example in Europe, the business of transmission system operators who recover their costs through transmission usage system charges. In some situations it is possible to divide the costs between different stakeholders. An effective framework should anticipate the need for transmission upgrades, so as not to inhibit investment in desirable new generation capacity (renewable or otherwise). Public opposition to new transmission lines can develop, traditionally linked with visual impacts (Devine-Wright et al., 2010), environmental concerns and the perceived impacts of electromagnetic fields on human health (Buijs et al., 2011). Underground cables are an available, but not necessarily preferable, option to alleviate such problems: cable reliability and maintenance concerns are potentially higher, and the investment cost will be much higher. With long underground connection distances (i.e., over $50 \mathrm{~km}$ approximately), DC will be the preferred technology (Schultz, 2007).

\section{Increased generation flexibility}

Thermal generation provides most of a power system's existing flexibility to cope with variability and uncertainty, through its collective ability to ramp up, turn down and cycle as needed (Troy et al., 2010). An increasing penetration of variable renewable sources implies a greater need to manage variability and uncertainty, and so greater flexibility is required from the generation mix. This can imply either investment in new flexible generation or improvements to existing power plants to enable them to operate in a more flexible manner. Retirement of existing inflexible generation may further accelerate this process, whereas the use of storage hydropower has been found to facilitate operational integration. Thermal power plants can be designed or retrofitted to ramp up and down faster and more frequently, but this will in general have a cost, both in capital and operational terms (Carraretto, 2006). A challenge is to achieve all of these aims in such a way that unit efficiency is not lowered so much that costs and emissions are significantly increased (Denny and O'Malley, 2006). Variable renewable generators can also be a focus for a degree of flexibility, for example limiting the rate at which they increase their output, and providing local voltage support for the network. Such capabilities are increasingly standard for wind generation (Z. Chen et al., 2009), but much less so for other variable renewable technologies. Increasing the flexibility of the generation fleet can occur progressively as power plants are modernized and investors see the need for more flexible operation to better respond to system or market needs. A significant future issue will be that as more variable generation comes online, dispatchable generation may be displaced thus reducing the amount of flexibility available. Ensuring that future power plants can maintain stable and profitable operation at output levels lower than at present will help to address this concern, but system operators will need to carefully monitor the dynamic stability of the power system to ensure safe and secure system operation.

In parallel with increasing targets for RE sources in electrical power systems across the world, it should also be noted that non-renewable options for low carbon generation, such as nuclear and fossil fuel with CCS are also in active development. With technology choices being made for economic, technical, social and political reasons, RE generation must recognize factors that may help, or in some cases hinder, future growth. For example, deployment of newer technologies such as integrated gasification combined cycle (IGCC) with carbon capture and sequestration and further deployment of nuclear technology (fission and also possibly fusion in the distant future) could have impacts on RE integration. These technologies may, for example, lack the required flexibility to help integrate variable renewable sources (Q. Chen et al., 2010), meaning that high penetrations of both RE and IGCC/CCS or nuclear may pose special integration challenges.

Synergies and connections also exist between the electricity sector and other energy sectors, so, for example, combining electricity and heat allows for greater flexibility in the electricity side as thermal storage options are already cost effective (Kiviluoma and Meibom, 2010). RE will also have impacts on the dispatch of gas deliveries in the systems where it is mainly gas power plants that react to increasing flexibility needs (Qadrdan et al., 2010).

\section{Demand side measures}

Flexible elements of demand, such as remotely switched night storage heating (Fox et al., 1998), have long been used, and often with good cost efficiency (Buckingham, 1965), to aid system operation. However, implementations tend to be proprietary in nature, installed over small geographical areas and with limited demand controllability actually offered. The development of advanced communications technology, with smart electricity meters linked to control centres, offers the potential to access much greater levels of flexibility from demand. One of the key opportunities is to make domestic demand flexible. Through pricing electricity differently at different times, and in particular higher prices during higher load periods, electricity users can be provided with incentives to modify and/or reduce their consumption. Such demand side management schemes, in which individual discretionary loads respond to price signals and/or external response 'request' signals, are seen as having a large potential (Brattle Group et al., 2009; Centolella, 2010). Thermal loads are ideal and include air conditioning, water heating, heat pumps and refrigeration, since the appliance can be temporarily switched on/off without significant impacts on service supply due to 
intrinsic energy storage (Stadler, 2008). Water desalination, aluminium smelting, ice production, production line inventory, oil extraction from tar sands and shale deposits etc. can offer a similar flexibility (Kirby, 2007; Kirby and Milligan, 2010). Commercial entities may be particularly attractive, as installations will tend to be larger (load served), they are more likely to participate in schemes that deliver cost savings and they may be more willing to invest in necessary equipment. Electric vehicles represent an emerging load, but uncertainty exists about public uptake, battery performance and daily charging patterns. Vehicle battery charging, or even vehicle battery discharging, is potentially a further example of a discretionary load that can be controlled to assist in daily electrical power system operation (Kempton and Tomic, 2005).

All forms of demand side management require consumer engagement, in terms of changes in behavioural patterns, social acceptance and privacy/security issues. The implications of these various factors are not fully understood at present and more research is required. In addition, the amount of peaking plant that can be replaced by demand side measures is not fully understood (Earle et al., 2009; Cappers et al., 2010). Furthermore, a market or incentive system is required. Real-time electricity pricing (or some approximation) may be more widely adopted, whereby the electricity cost to the user more accurately reflects the cost of supply. However, demand side schemes are required that not only enable consumers to participate but actively encourage such behaviour, and correctly allocate charges and payments where required.

Although demand side measures have historically been implemented to reduce average demand or demand during peak load periods, demand side measures may potentially contribute to meeting electrical power system needs resulting from increased variable renewable generation. The low capacity credit of some types of variable generation, for instance, can be mitigated through demand side measures that reduce demand during peak load periods (Moura and de Almeida, 2010). Additionally, demand that can quickly be curtailed without notice during any time of the year can provide reserves (Huang et al., 2009), which have the potential to reduce electrical power system costs and emissions associated with short-term balancing of variable generation (Strbac, 2008; GE Energy, 2010). Demand that is flexible and can be met at anytime of the day can also participate in intra-day balancing, which mitigates dayahead forecast errors for variable generation (Klobasa, 2010). Demand that responds to real-time electricity prices, on the other hand, may mitigate operational challenges for thermal plants that are expected to become increasingly difficult with variable generation, including minimum generation constraints and ramp rate limits (Sioshansi and Short, 2009). Challenges with managing electrical power systems during times with high wind generation and low demand, meanwhile, may be mitigated to a degree with demand resources that can provide frequency regulation (Kondoh, 2010). Off-peak electrical vehicle charging increases electrical demand and may reduce curtailment of variable renewable generation in high penetration scenarios (Lund and Kempton, 2008; Kiviluoma and Meibom, 2011).
The economic viability of any of these demand side measures should be evaluated relative to meeting the system needs with other resources, including renewable resources. Ultimately, however, accessing the flexibility of demand to mitigate variable renewable resources will depend on the integration of the demand side into system planning, markets and operations along with adequate communication infrastructure between power system operators and load aggregators/ customers. It will also be necessary to engage, inform and provide incentives to users to participate in such schemes.

Demand side participation may have a particular role in small autonomous systems where there is limited access to other balancing resources.

\section{Energy storage}

At any given time, the amount of energy stored at plants in the form of fossil fuels or water reservoirs is large (Wilson et al., 2010). The amount of energy that can be converted into electricity and then converted back into stored energy, called electricity energy storage, is currently much more modest. The most common form of large-scale electrical energy storage is the mature technology of pumped hydro storage. Since the first pumped hydro storage plant was built in the late 1920s, over 300 plants with approximately $95 \mathrm{GW}$ of pumped hydro capacity have been built in the world (Deane et al., 2010). Additionally, two large-scale commercial compressed air energy storage plants have been operating in Germany and the USA since 1978 and 1991, respectively, and a number of additional facilities are being planned or are under construction (H. Chen et al., 2009). Electrical energy storage is used in power systems to store energy at times when demand/price is low (i.e., off peak during the night /weekend) and generate when demand/price is high (i.e., at peak times during the afternoon). In addition, energy storage units can be very flexible resources for an electrical power system, and if correctly designed can respond quickly when needed (Mandle, 1988; Strunz and Louie, 2009). Technologies such as batteries or flywheels that store smaller amounts of energy (minutes to hours) can in theory be used to provide power in the intra-hour timeframe to regulate the balance between supply and demand in microgrids or in the internal network of the energy user (behind the electricity meter). Whether such technologies will be widely deployed will depend on capital costs, cycle efficiency and likely utilization (H. Chen et al., 2009; Ekman and Jensen, 2010). However, coupled with demonstration programs, market rules and tariffs are gradually being introduced to provide incentives for the participation of new technologies (Lazarewicz and Ryan, 2010; G. Rodriguez, 2010). Battery technology is an area of active research, with costs, efficiencies and other factors such as lifetime being improved continuously.

By storing electrical energy when renewable output is high and the demand low, and generating when renewable output is low and the demand high, the curtailment of RE will be reduced, and the base load units on the system will operate more efficiently (DeCarolis and Keith, 2006; Ummels et al., 2008; Lund and Salgi, 2009; Denholm et al., 2010; Loisel et al., 2010; Tuohy and O'Malley, 2011). Storage can 
also reduce transmission congestion and may reduce the need for, or delay, transmission upgrades (Denholm and Sioshansi, 2009). In autonomous systems, in particular, storage can play a particularly important role (Section 8.2.5).

When using storage to assist the integration of variable generation, storage should be viewed as a system asset to balance all forms of variability, including demand variations, as opposed to dedicating a storage unit to a single variable source. It is generally not cost effective to provide dedicated balancing capacity for variable generation in large power systems where the variability of all loads and generators is effectively reduced by aggregation, in the same way as it is not effective to have dedicated storage for outages of a certain thermal power plant, or to have specific plants following the variation of a certain load.

Market prices or system costs should determine how the storage asset is best used. The value of storage depends on the characteristics of the power system in question: its generation mix; its demand profile; connectivity to other systems; and the characteristics of the variable renewable generation plant (Tuohy and O'Malley, 2011). This is true for all power systems, including small autonomous systems (Caralis and Zervos, 2007a; Katsaprakakis et al., 2007). Storage must ultimately compete against increased interconnection to other electrical power systems, greater use of demand side measures, and the other options outlined here (Denny et al., 2010). The most effective choice is likely to be system specific and the economics will be affected by any specific electricity market incentives. Large-scale development of energy storage at the present time, however, remains questionable due to the generally high capital cost and inherent inefficiency in operation, unless these costs and inefficiencies can be justified through a reduction in curtailment, better use of other flexible resources or more efficient operation of the system more generally (DeCarolis and Keith, 2006; Ummels et al., 2008; GE Energy, 2010; Nyamdash et al., 2010; Tuohy and O'Malley, 2011). At the same time, storage technologies have attributes that have not, to this point, been fully valued in all electricity markets. For example, storage technologies that can provide ancillary services and very fast injections of energy for short periods of time may be able to provide virtual inertia particularly on isolated or weakly connected power systems (Wu et al., 2008; Delille et al., 2010). As these additional benefits are valued and as storage costs decline, the role of electrical storage in balancing supply and demand and assisting in RE integration is likely to increase.

\section{Improved operational/market and planning methods}

Existing operational, planning and electricity market procedures are largely based around dispatchable generation and predictable load patterns. The software tools that support these activities are largely deterministic in nature. In order to cope with increased penetrations of variable and uncertain generation, however, there is a greater need to identify sources of flexibility in operating the system, to develop probabilistic (rather than deterministic) operations and planning tools
(Bayem et al., 2009; Papaefthymiou and Kurowicka, 2009) and to develop more advanced methods to maintain the electrical stability of the electrical systems. More fundamentally, real-time operations and long-term planning have traditionally been viewed as separate, decoupled activities. With high renewable penetrations, the two processes must come closer together such that a system is planned that can actually be operated in an economic and reliable manner (Swider and Weber, 2007).

To help cope with the variability and uncertainty associated with variable generation sources, forecasts of their output can be combined with stochastic unit commitment methods to determine both the required reserve to maintain the demand-generation balance, and also the expected optimal unit commitment (Meibom et al., 2011). This ensures less costly, more reliable operation of the system than conventional techniques. Wind (generation) forecasting systems have been developed that include ensemble probabilistic forecasting, and the technology is reaching maturity, with high forecast accuracies now achievable (NERC, 2010a Giebel et al., 2011). Forecasting systems for other variable RE sources (e.g., wave and solar) will need to be developed in parallel with commercial implementation of the devices. In addition, future forecasting systems, for all renewable sources, must include the ability to adequately predict extreme conditions, persistent high or low resource availability and exceptional power ramp rates (Greaves et al., 2009; Larsen and Mann, 2009).

Moving to larger balancing areas, or shared balancing between areas, is also desirable with large amounts of variable generation, due to the aggregation benefits of multiple, dispersed renewable sources (Milligan et al., 2009). Institutional changes may be required to enable such interaction with neighbouring systems and electricity markets (e.g., policies on transmission pricing), with the underlying assumption that adequate interconnection capacity is in place. The creation of the European Network of Transmission System Operators for Electricity as the first continental transmission system operators association with legal obligations to establish binding rules for cross-border network management and a pan-European grid plan follows this principle. Similarly, by making decisions closer to real time (i.e., shorter gate closure time in markets) and more frequently, a power system can use newer, more accurate information and thus dispatch generating units more economically (TradeWind, 2009; EWIS, 2010; Weber, 2010). Using a higher time resolution (intra-day, with resolutions of five minutes or less) provides a better representation of variability and the required balancing (Milligan et al., 2009), and so also enables more optimal decisions to be made closer to real time. In addition, institutional or electricity market structures must evolve such that they can quantify the flexibility requirements of the power system, and put measures in place to reward it (Arroyo and Galiana, 2005). In addition, reduced utilization of thermal generation may require an examination of market mechanisms to reduce investor risk (e.g., capacity payments, longer-term contracts) (Newbery, 2005, 2010). 
Advanced planning methods are also required to optimally plan the upgrade and expansion of the electrical networks to ensure that variable generation can be connected in an efficient manner, especially considering the large geographical and remote areas that will sometimes be involved. Methods should ensure best usage of the existing transmission and distribution networks, as well as the best locations for upgrades or extensions (Keane and O'Malley, 2005). Planning methods should also move from 'snapshot' type studies, where the times of greatest system risk are well known, towards studies that consider the variable nature of renewable generation, recognizing correlations between different renewable sources and daily/seasonal patterns, and how this can cause risk at different times throughout the year (Burke and O'Malley, 2010). New metrics, similar to those already used in long-term resource planning, also need to be developed to ensure that sufficient short-term flexibility is planned for (NERC, 2009; Lannoye et al., 2010). This will require an understanding of the variability and uncertainty that variable renewable sources bring to different time scales, and how these increase the existing load variability and uncertainty in the short and long term (capacity adequacy). Detailed modelling of all sources of flexibility will be required, including generation and demand response, such that planning studies reflect the operational potential (NERC, 2010b,c).

On-line stability analysis tools must also be developed to ensure that the electrical power system is secure and robust against plausible eventualities (Dudurych, 2010a; P. Zhang et al., 2010), with optimal network configurations determined, and system recovery strategies identified in advance. Effective operation and management of the potentially large numbers of generation units will be very challenging and require a sophisticated information and communication infrastructure (J. Rodriguez et al., 2008). The emergence of more sophisticated network monitoring and control, coupled with demand side management and storage options, will ease the integration of RE sources into electrical power systems, but the control systems and decision-making systems required to monitor and manage the resulting complexity at both the distribution network level and transmission network level remain to be developed.

\section{Summary and knowledge gaps:}

RE can be integrated into all types of electrical power systems, from large interconnected continental-scale systems to small autonomous systems. System characteristics including the network infrastructure, demand pattern and its geographic location, generation mix, control and communication capability combined with the location, geographical footprint, and variability and predictability of the renewable resources determine the scale of the integration challenge. As the amounts of RE resources increase, additional electricity network infrastructure (transmission and/or distribution) will generally have to be constructed. Time variable renewable sources, such as wind, can be more difficult to integrate than non-variable renewable sources, such as bioenergy, and with increasing levels maintaining reliability becomes more challenging and costly. These challenges and costs can be minimized by deploying a portfolio of options including electrical network interconnection, the development of complementary flexible generation, larger balancing areas, subhourly markets, storage technologies and better forecasting and system operating and planning tools.

Parallel developments such as a move towards the use of electric vehicles, an increase in electric heating (including heat pumps), demand side control through the use of smart meters and thermal generation are providing complementary physical flexibility and together with the expansion of renewable power generation are driving dramatic changes in electrical power systems. These changes also include altered institutional arrangements including regulatory and market mechanisms (where markets exist), in particular those required to facilitate demand response and that reward the desired electrical power system portfolio. In addition, should variable RE penetration levels increase, deployment could increase in both developed and developing countries and the range of technologies could become more diverse (for example, if ocean energy technologies become competitive).These changes and developments lead to several gaps in our knowledge related to integration options that may become important in the future, including:

- Fundamental characteristics of future power systems due to wide spread deployment of non-synchronous generation, aspects of which were explored in EirGrid (2010b);

- Protection and interoperability of meshed HVDC networks, relevant for the connection of offshore wind and ocean energy (Henry et al., 2010);

- Changes to protective relaying to ensure system reliability and safety (Jenkins et al., 2010);

- New probabilistic methods for planning in the context of high proportions of variable stochastic generation (Bayem et al., 2009);

- Greater understanding of inter-area constraints and operational challenges (GE Energy, 2010);

- Changes in the non-renewable generation portfolio (e.g., impact of retirements, flexibility characteristics and the value of possible fleet additions or upgrades) (Doherty et al., 2006);

- Quantification of the potential for load participation or demand response (McDonough and Kraus, 2007) to provide the grid services needed to integrate RE (Sioshansi and Short, 2009; Klobasa, 2010);

- Impacts of the integration of the electricity sector with other energy sectors (Lund and Kempton, 2008); 
- Integration needs in new and emerging markets that differ from those in which variable renewable sources have been integrated in the past (e.g., China);

- Benefits and costs of combining multiple RE resources in a complementary fashion (H. Lund, 2006); and

- Better market arrangements for variable renewable and flexible sources (Glanchant and Finon, 2010; Smith et al. 2010b).

\subsubsection{Integration of renewable energy into heating and cooling networks}

Heating, cooling and hot water account for a large share of energy use, particularly in the building and industry sectors. These energy services can be provided by using a range of fuels and technologies at the individual building level (Section 8.3.2) as can process heat and refrigeration for individual industries (Sections 8.3.3 and 8.3.4). District heating and cooling (DHC) is the alternative approach and this section deals with RE integration into such distribution networks.

\subsubsection{Features and structure of district heating and cooling systems}

DHC networks enable the carrying of energy from one or several production units, using multiple energy sources, to many energy users. The energy carrier, usually hot or cold water or steam, is typically pumped through underground insulated pipelines to the point of end use and then back to the production unit through return pipes. The temperatures in district heating $(\mathrm{DH})$ outward pipes typically average 80 to $90^{\circ} \mathrm{C}$, dropping to 45 to $60^{\circ} \mathrm{C}$ in return pipes after heat extraction. Heat exchangers are normally used to transfer the heat from the network to a hydronic heating system with radiators or to a hot water system (Werner, 2004).

Heat and CHP production have historically been dominated by oil and coal but, after the oil crises in the 1970s, oil was replaced by other fuels in most systems. In Western Europe, where DH systems commonly occur, the most popular fuels are natural gas and coal, although oil and biomass (Section 2.4; Figure 2.8) are also used. Coal still dominates in China and Eastern Europe. Waste heat from industrial processes, heat from waste incineration, geothermal heat and solar heat are feasible alternatives but less commonly used (Oliver-Solà et al., 2009).

Large DHC systems offer relatively high flexibility with respect to the energy source. Centralized heat production in DHC facilities can use low quality fuels often unsuitable for individual boilers and furnaces in buildings. ${ }^{11}$ They also require pollution control equipment. Improved

11 An example is a DHC in Kalundborg, Denmark (Section 2.4.3) that has several bioenergy components, including a pilot lignocellulosic ethanol plant. urban air quality and the possibility to cogenerate heat and electricity at low cost were, and still are, important motivations for DH (IEA, 2009c).

A good example of a central DHC plant is in Lillestrøm, Norway (Figure 8.3). It uses several energy sources, including a heat pump based on sewage effluent, to deliver heat and cold to commercial and domestic buildings. This system, and other DHC systems generally, includes an accumulator tank for hot water storage to even out fluctuations in demand over the day(s) to facilitate more stable production conditions (Section 8.2.2.4). The total investment is estimated to be around USD $_{2005} 25$ million with completion planned in 2011.

Different production units dispatch heat in optimal ways to meet the varying demand (including the use of dedicated fast-response boilers and storage to meet peak demand). Higher overall system efficiencies can be obtained by combining the production of heat, cold and electricity and by using diurnal and seasonal storage of heat and cold. Using heat and cold sources in the same distribution network is possible and the selection of conversion technologies depends strongly on local conditions, including demand patterns. As a result, the energy supply mix varies widely between different countries and systems (Werner, 2006a).

DHC systems can be most economically viable in more densely populated urban areas where the concentration of heating and cooling demand is high. DHC schemes have typically been developed where strong planning powers exist and where a centralized planning body can build the necessary infrastructure, such as centrally planned economies, American university campuses, countries with utilities providing multiple services as in Scandinavia, and urban areas controlled by local municipalities. Urbanization creates opportunities for new or expanded DHC systems, as demonstrated on a large scale in China (Section 8.2.2.6). Development of DHC systems in less dense or rural areas has been restricted by the relatively high costs of distribution and higher heat distribution losses (Oliver-Solà et al., 2009).

Development and expansion of most DHC systems took place after 1950 in countries with cold winters, but earlier examples exist, such as New York in 1882 and Dresden in 1900. World annual district heat deliveries have been estimated at nearly $11 \mathrm{EJ}$ (Werner, 2004) (around 10\% of total world heat demand; IEA, 2010b) but the data are uncertain. Several high-latitude countries have a DH market penetration of 30 to $50 \%$, and in Iceland, with abundant geothermal resources, the share has reached $96 \%$ (Figure 8.4).

District cooling $(D C)$ is becoming increasingly popular through the distribution of chilled or naturally cold water through pipelines, possibly using the pipes of a DH network in higher latitudes to carry water to buildings where it is passed through a heat exchanger system. The supply source, normally around 6 to $7^{\circ} \mathrm{C}$, is returned at 12 to $17^{\circ} \mathrm{C}$ (Werner, 2004). Alternatively, heat from a DH scheme can be used during summer to run heat-driven absorption chillers. 
Integrated Renewable Energy District Heating \& Cooling System

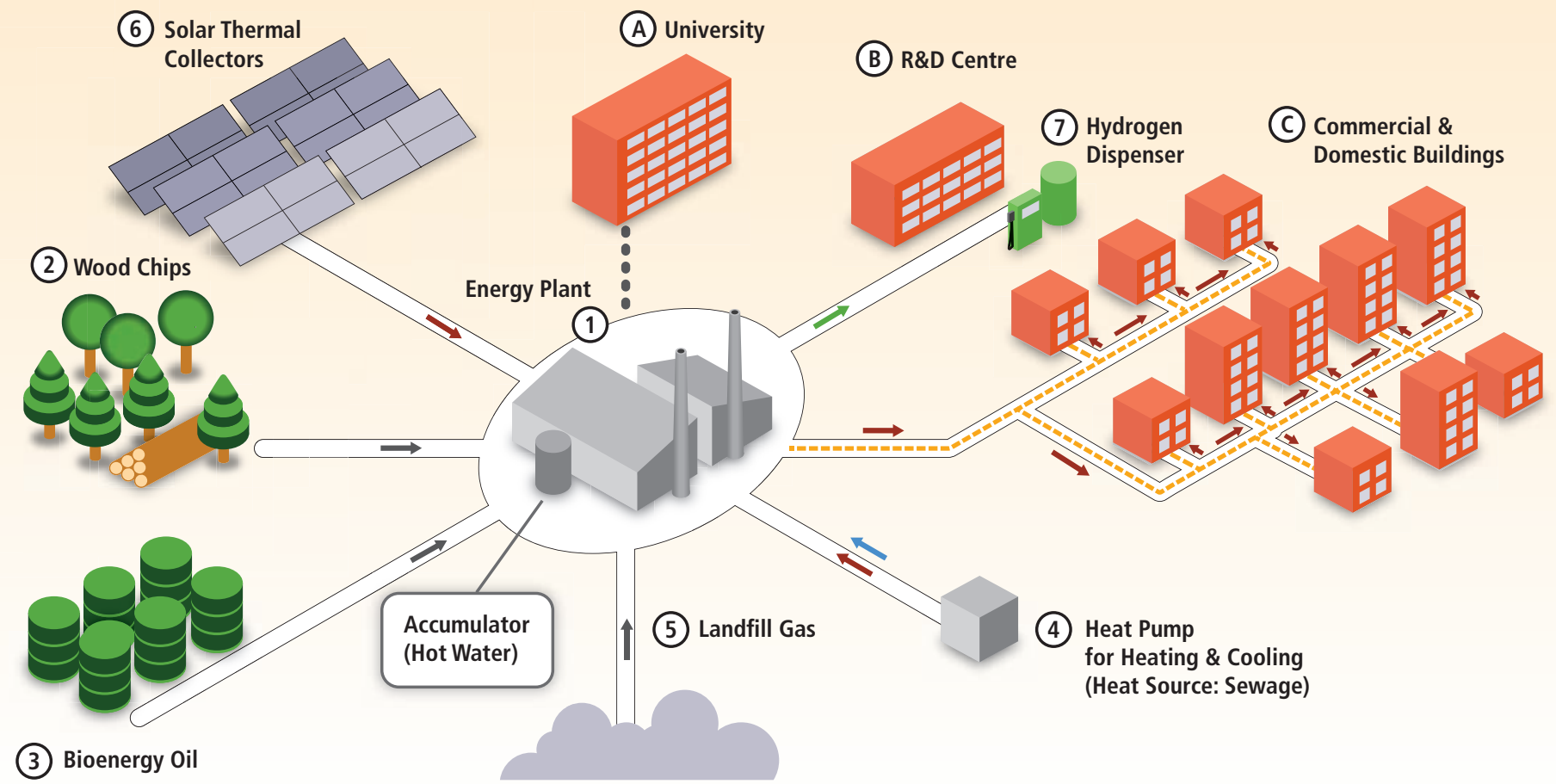

Figure 8.3 An integrated RE-based energy plant in Lillestrøm, Norway, supplying the University, R\&D Centre and a range of commercial and domestic buildings using a district heating and cooling system that incorporates a range of RE heat sources, thermal storage and a hydrogen production and distribution system (Akershus Energi, 2010).

Notes: (1) Central energy system with 1,200 $\mathrm{m}^{3}$ accumulator tank; (2) $20 \mathrm{MW}_{\text {th }}$ wood burner system (with flue gas heat recovery); (3) $40 \mathrm{MW}_{\text {th }}$ bio-oil burner; (4) $4.5 \mathrm{MW}_{\text {th }}$ heat pump; (5) $1.5 \mathrm{MW}_{\text {th }}$ landfill gas burner and a $5 \mathrm{~km}$ pipeline; (6) 10,000 $\mathrm{m}^{2}$ solar thermal collector system (planned for completion in 2012); and (7) demonstration of RE-based hydrogen production (using water electrolysis and sorption-enhanced steam methane reforming of landfill gas) and fuel cell vehicle dispensing system planned for 2011.

Cooling demands in buildings are tending to grow because of increased internal heat loads from computers and other appliances, more stringent personal comfort levels and modern building designs having greater glazed areas that increase the incoming heat levels (IEA, 2007c). Recent warmer summers in many areas have also increased the global cooling demand, particularly to provide greater comfort for people living in many low-latitude, developing countries as their economies grow. Several modern DC systems, from 5 to $300 \mathrm{MW}_{\text {th }}$ capacity, have been operating successfully for many years including in Paris, Amsterdam, Lisbon, Stockholm and Barcelona (IEA, 2007d).

\subsubsection{Characteristics of renewable energy in district heating and cooling systems}

Over the past two decades, many DHC systems have been switched from fossil fuels to RE resources, initially in the 1980s to reduce oil dependence, but since then, to reduce carbon dioxide $\left(\mathrm{CO}_{2}\right)$ emissions. Centralized heat production can facilitate the use of low cost and/or low grade RE heat sources that are not suitable for use in individual heating systems. These include refuse-derived fuels, wood process residues and waste heat from CHP generation, industrial processes or biofuel production (Egeskog et al., 2009). In this regard, DHC systems can provide an enabling infrastructure for increased RE deployment.

The potential contribution and mix of RE in DHC systems depends strongly on local conditions, including the availability of RE resources. For biomass or geothermal systems it is not a technical problem to achieve high penetration levels as they can have high capacity factors. Hence many geothermal and biomass heating or CHP plants have been successfully integrated into $\mathrm{DH}$ systems operating under commercial conditions.

- Woody biomass, crop residues, pellets and solid organic wastes can be more efficiently used in a DH-integrated CHP plant than in individual small-scale burners (Table 2.6). Biomass fuels are important sources of district heat in several European countries where biomass is readily available, notably Sweden and Finland (Euroheat\&Power, 2007). In Sweden, nearly half of the DH fuel share now comes from biomass (Box 11.11).

- Near-surface and low temperature geothermal resources are well suited to DH applications. Due to the often lower costs of competing fuels, however, the use of geothermal heat in DH schemes is 


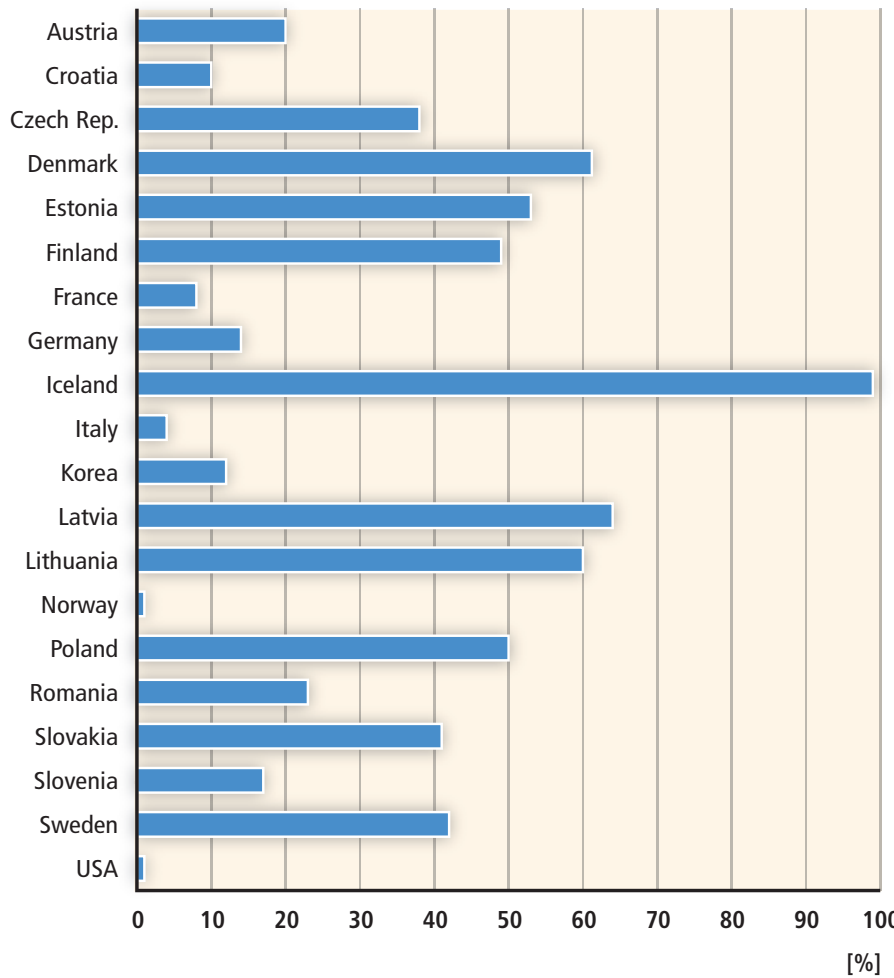

Figure 8.4 | Share of total heat demand in buildings supplied by district heating schemes for selected countries (Euroheat\&Power, 2007).

low (with the exception of Iceland), even though the global technical potential of the resource is high (Section 4.2).

- The global installed capacity of solar thermal collectors in 2009 was $180 \mathrm{GW}_{\text {th }}$ (Section 3.4.1) but only a small fraction was used for DH (Weiss et al., 2009). Solar thermal DH plants are found mainly in Germany, Sweden, Austria and Denmark (Dalenbäck, 2010). In Denmark, several have large-scale collector areas of around $10,000 \mathrm{~m}^{2}$ (Epp, 2009). At solar shares of up to $20 \%$, the large number of customers connected to the DH system ensures a sufficiently large demand for hot water even in summer, so that high solar heat yields $\left(\sim 1,800 \mathrm{MJ} / \mathrm{m}^{2}\right)$ can be achieved. Higher solar shares can be achieved by using seasonal thermal storage systems, for which integration into a DH system with a sufficiently high heat demand is an economic prerequisite. Pilot plants with a solar share of more than $50 \%$ equipped with seasonal heat storage have demonstrated the technical feasibility of such systems (Section 8.2.2.6).

Using RE through electricity sources in DH systems in situations with low or even negative electricity prices is possible through heat pumps and electric boilers, with thermal storage also an option (Lund et al., 2010). Through CHP plants, DH systems can also export electricity to the grid as well as provide demand response services that facilitate increased integration of RE into the local power system. Thermodynamically, using electricity to produce low grade heat may seem inefficient, but under some circumstances it can be a better economic option than spilling potential electricity from variable RE resources (Section 8.2.1).
DC systems that utilize natural aquifers, waterways, the sea or deep lakes as the source of cold can be classed as a RE resource. The potential for such cooling is difficult to estimate but many cities are located close to good water supplies that could easily provide a source of cold. Deep water cooling allows relatively high thermodynamic efficiency by utilizing water at a significantly lower heat rejection temperature than ambient temperature (Section 8.2.2.6). Often lake or sea water is sufficiently cold to cool buildings directly, which can, at times, enable the refrigeration portion of associated air-conditioning heat pump systems to be only operated to provide additional cooling when needed. All the excess building interior heat is transferred directly to the water heat sink.

To use RE cooling most efficiently in buildings from a quality perspective, a merit order of preferred cooling can be set up (as can also be done for heating) (IEA, 2007c). The order will differ due to specific local conditions and costs, but a typical example could be to supplement energy efficiency and passive cooling options by including active compression cooling and refrigeration powered by RE electricity; solar thermal, concentrating solar power, or shallow geothermal heat to drive active cooling systems (Section 3.7.2); and biomass-integrated systems to produce cold, possibly as tri-generation. The Swedish town of Växjö, for example, uses excess heat in summer from its biomassfired CHP plant for absorption cooling in one district, and an additional $2 \mathrm{MW}$ chiller is also planned (IEA, 2009b).

Ground source heat pumps can be used in summer for space cooling (air-to-ground) at virtually any location, as well as in winter for space heating (ground-to-air). They use the heat storage capacity of the ground as an earth-heat sink since the temperature at depths between 15 and $20 \mathrm{~m}$ remains fairly constant all year round, being around 12 to $14^{\circ} \mathrm{C}$. They are commercially available at small to medium scales between 10 and $200 \mathrm{~kW}$ capacity.

\subsubsection{Challenges associated with renewable energy integration into district heating and cooling networks}

To meet growth in demand for heat or cold, and goals for integrating additional RE into energy systems, expansion of existing networks may be required. A DHC piping network involves up-front capital investment costs that are subject to large variations per kilometre depending on the local heat density and site conditions for constructing the underground, insulated pipes. Network capital investment costs and distribution losses per unit of delivered heat (or cold) are lower in areas with high annual demand (expressed as $\mathrm{MJ} / \mathrm{m}^{2} / \mathrm{yr} \mathrm{MW}_{\text {peak }} / \mathrm{km}^{2}$ or $\mathrm{GJ} / \mathrm{m}$ of pipe length/yr). Area heat densities can range up to 1,000 $\mathrm{MJ} / \mathrm{m}^{2}$ in dense urban, commercial and industrial areas down to below $70 \mathrm{MJ} / \mathrm{m}^{2}$ in areas with dispersed, single family houses. Corresponding heat distribution losses can range from less than $5 \%$ in the former to more than $30 \%$ in the latter. The extent to which losses and network costs are considered an economic constraint depends on the cost and source of the heat. Under certain conditions, areas with either a heat 
density as low as $40 \mathrm{MJ} / \mathrm{m}^{2} / \mathrm{yr}$, or a heat demand of $1.2 \mathrm{GJ} / \mathrm{m}$ of pipeline/ yr, can be economically served by district heating (Zinco et al., 2008).

Energy efficiency measures in buildings and new building designs that meet high energy efficiency standards will reduce the demand for heating or cooling. As more buildings are built or retrofitted with lowenergy and energy efficient designs, the total energy demand or density for existing DHC systems may decrease over time. Energy efficiency measures can also flatten the load demand profile by reducing peak heating or cooling demands. In these cases, the profitability of supplying district heat from either new DH plants or extending existing networks would be reduced (Thyholt and Hestnes, 2008). In Norway, Germany and Sweden the competition between low-energy building standards and $\mathrm{DH}$ development has received attention by policymakers working to design local or national energy policies (Thyholt and Hestnes, 2008). At the same time, while energy efficiency may be a challenge to the general economic viability of DH due to lower heating densities in the network, it may also facilitate higher shares of RE energy in individual heating systems (Verbruggen, 2006; IEA, 2009b).

The technical and economic challenges of heating and cooling using RE sources are not necessarily associated with the integration of the heat or cold into existing DHC networks that can be injected into a system for few additional costs. The challenges are instead primarily associated with assuring a consistent and reliable resource base from which the heat and cold can be produced.

- Combustion of wood residues or straw fuels can be challenging due to the varying composition of the fuel, the associated additional plant costs for storage and handling, fuel purchase costs and the need for a logistical supply chain to provide reliable supplies of biomass (Section 2.3.2).

- Extraction of geothermal heat is reliable but may entail local environmental impacts (Section 4.5).

- The variable nature of solar energy can be a challenge (Section 3.2) but is partly overcome by thermal storage. If used for $D C$, the need for diurnal and seasonal storage can be low because peak cooling demands often correlate relatively well with peak solar radiation levels.

In terms of cooling, the distance away from demand of the water to be used as the source of cold may also need costly infrastructure investment in order to integrate with DC systems. When using solar energy or biomass for absorption cooling, the challenges closely reflect those for heating.

In less densely populated areas, or those without a strong, centralized planning body, institutional barriers may pose challenges to developing or increasing the use of DHC, thereby posing indirect challenges to increasing the share of RE in the DHC networks. Constructing new capacity or expanding existing DHC networks usually requires planning consents and coordination of stakeholders and institutions.

\subsubsection{Options to facilitate renewable energy integration}

RE sources can be integrated into existing systems by replacing and retrofitting older production units or incorporating them into the designs of new DHC systems. DHC networks can be constructed or extended where a growing number of customers seek RE supply sources. These can be more cheaply integrated into existing systems at the slow natural rate of capital building stock turnover, or dedicated policies can speed up the grid connection process.

\section{New technological options for heating}

As new RE technologies are developed, additional technical options for increasing the shares of RE in DH systems are presented. Fuel switching and co-firing of biomass in existing fossil fuel-fired heat-only or CHP boilers present an option in the near term. The suitability of biomass fuels, their moisture contents, and whether they need to be pulverized or not, depend on the existing boiler design (whether grate, circulating or bubbling fluidized bed).

Heat from geothermal and solar thermal sources can be more readily integrated into existing DH systems. Enhanced geothermal systems (EGS) could be operated in CHP mode coupled with DH networks. The commercial exploitation of large heat flows is necessary to compensate for the high drilling costs of these deep geothermal systems (Thorsteinsson and Tester, 2010). Such a large heat demand is usually only available through $\mathrm{DH}$ networks or to supply major industries directly (Hotson, 1997).

\section{Storage options}

Heat storage systems can bridge the gap between variable and unsynchronized heat supply and demand. The capacity of a thermal storage system can range from a few $\mathrm{MJ}$ up to several $\mathrm{TJ}$; the storage time from hours to months; and the temperature from $20^{\circ} \mathrm{C}$ up to $1,000^{\circ} \mathrm{C}$. These wide ranges are made possible by choosing between solids, water, oil or salt as different thermal storage materials together with their corresponding storage mechanisms.

A hot water storage system design depends on the local geological and hydro-geological conditions, and the supply and demand characteristics of the DHC system. For short-term storage (hours and days) the thermal capacity of the distribution system itself can act as storage (Figure 8.5). Longer-term seasonal storage, usually between winter and summer, is less common. In this case, the main storage options include underground tanks, pits, boreholes and aquifers (Heidemann and MüllerSteinhagen, 2006). With geological storage, relatively small temperature differences are employed. In aquifers, heat may be injected during the 


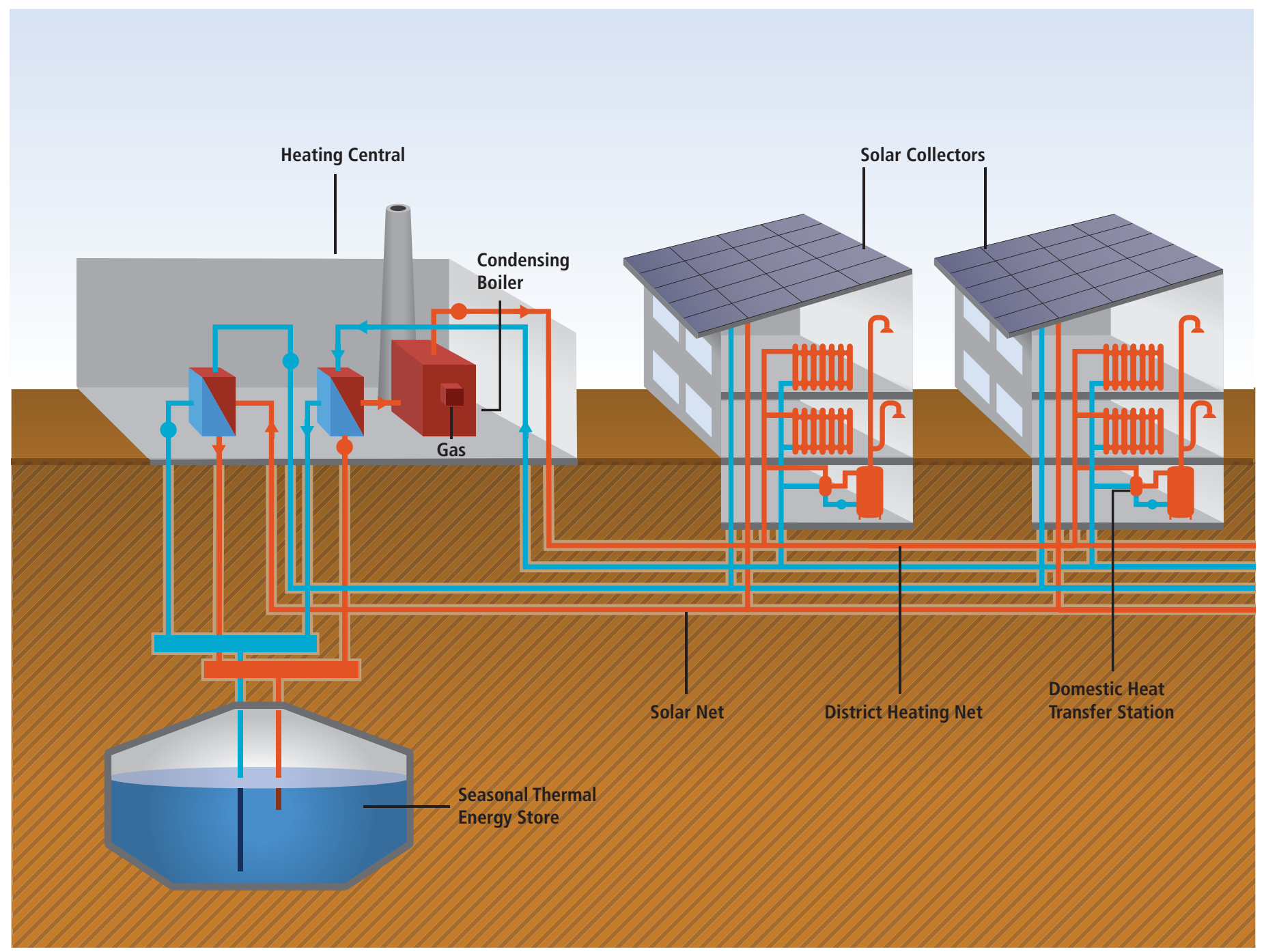

Figure 8.5 | Solar-supported centralized heating plant with seasonal tank storage connected to a district heating system (modified from Bodmann et al., 2005).

summer to increase the temperature and then be extracted during the winter. Seasonal storage is likely to become more important where high shares of solar thermal energy are used in DHC systems due to the seasonal and daily variability of the solar resource. In order to integrate large-scale solar systems into DH networks, the development of systems for seasonal heat storage (Figure 8.5 ) has made progress and several demonstration plants have been realized (Bauer et al., 2010).

Heat and cold storage systems using latent heat of fusion or evaporation, based on phase-change materials or the heat of sorption, offer relatively high thermal storage densities (Bajnóczy et al., 1999; Anant et al., 2008). Sorptive and thermo-chemical processes allow thermal storage for an almost unlimited period of time since heat supply or removal occurs only when the two physical or chemical reaction components are brought back into contact. However, both latent and sorptive heat storage technologies are in a relatively early phase of development.

\section{Technological options for cooling}

Cooling demands located remotely from a natural cold water source could be met using thermo-chemical sorption processes including chiller/heat pumps, absorption chillers or compression chillers (IEA, 2009b). Such active cooling systems can be used for centralized or decentralized conditioning and involve a range of technologies to produce cooling from a RE resource.

Solar-assisted cooling has been demonstrated in plants up to $3.6 \mathrm{MW}_{\text {th }}$ at Munich airport, but these technologies, being in their early stage of commercialization, tend to be relatively costly although the costs continue to decline with experience (IEA, 2007c). One main advantage of 
solar-assisted cooling technologies is that peak cooling demands often correlate with peak solar radiation levels and hence can offset peak electricity loads for conventional air conditioners.

\section{Institutional and policy aspects}

CHP as well as DHC developments do not always need financial incentives to compete in the marketplace, although government measures to address non-financial barriers, such as planning constraints, could aid greater deployment (IEA, 2008a) (Section 11.5.4). Some governments support investments in DH networks as well as provide incentives for using heat from deep geothermal and biomass CHP. In Germany, for example, if the share of RE is above $50 \%$, a market incentive programme supports new DH schemes through investment grants in existing settlement areas, as well as for new development areas (BMU, 2009). In addition, the DH system operator receives a grant for each consumer connected to the new system.

In Sweden, high carbon taxes have provided strong incentives to switch to RE heating options (see case studies in Section 8.2.2.6 and Box 11.11). Targeted support under a climate investment programme has motivated investment in DH networks as well as new heating and CHP plants. Biomass CHP has also benefited from a quota obligation scheme (Section 11.5.3). DH, where available, is often competitive with alternative heating systems as a result of the carbon tax and other policy instruments (Figure 8.6). Similarly, under Danish conditions of high energy costs and carbon taxes, the integration of solar collectors into existing DH systems can be economically viable without additional targeted subsidies.

In the former centrally planned economies, DH prices were regulated because of a social policy to sell heat below the cost of supplying it. Today, in several countries with large DH schemes, an independent regulatory body ensures appropriate pricing where natural monopolies exist. In Denmark, for instance, the ownership of DH grids and the sale of heat as a monopoly are recognized, and hence the pricing and conditions of sale are regulated. The regulatory authority oversees the formation of prices and resolves disputes between consumers and utilities (Euroheat\&Power, 2007).

In theory, third party access to DHC networks could lead to a more competitive market for heating services, stimulate independent producers of RE heating and cooling, and result in decreased heat prices for consumers. However, DHC plants operate and compete in markets that, by nature, are local, unlike national and regional electricity and natural gas markets. If a new competitor invests in a more efficient and less expensive production plant and is allowed to use the network of the existing DHC utility, then the incumbent utility may be unable to compete, the only choices then being to reduce the price and accept lost revenue. In this case, stranded asset costs could be higher than the customer benefits obtained from having a new third party producer, therefore resulting in the risk of a net overall loss. More pronounced competition could be obtained if several producers operate in the

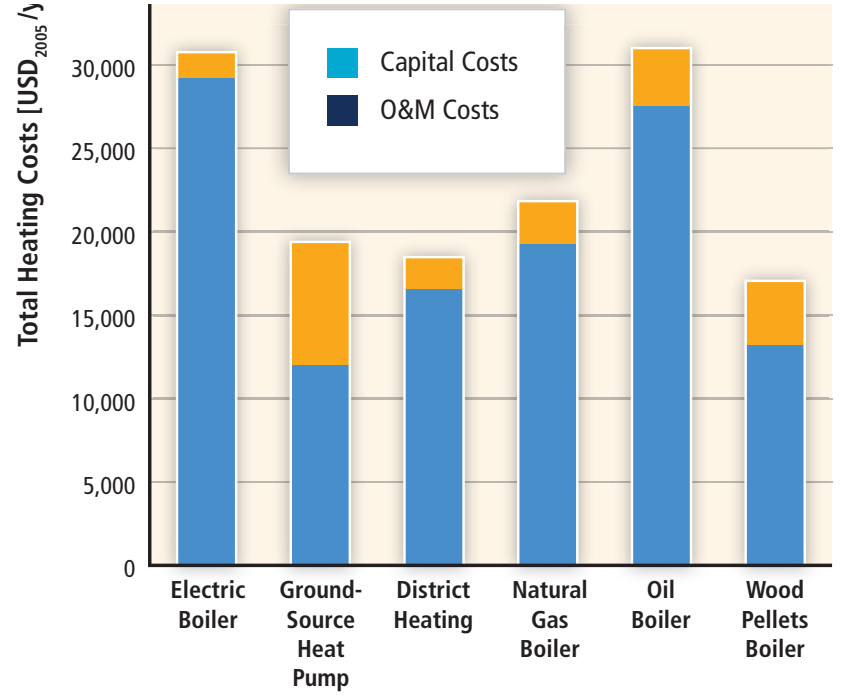

Figure 8.6 $\mid$ Comparative average annual heating and unit costs $\left(\mathrm{USD}_{2005}\right)$, including climate, energy and carbon taxes, as seen by the end user in a typical Swedish 1,000 $\mathrm{m}^{2}$ multi-family building with a heat demand around $700 \mathrm{GJ} / \mathrm{yr}$.

Notes: Capital investment costs are for the end-user investment in the grid connection terminal, heat exchanger, boiler, heat pump etc. O\&M costs are the end-user payments for electricity, district heat or fuel (including system capital costs, fuel, taxes, profit etc). For district heat, distribution cost is typically about $25 \%$ of total production and distribution costs and the distribution capital cost is about $35 \%$ of the total system capital cost. Data adapted from the Swedish Energy Markets Inspectorate (Ericsson, 2009). For the fuel mix of Swedish DH systems, see Figure 11.11.

same network. However, most DHC systems are too small to host several producers. Thus, third party access into an existing DHC system must be evaluated on a case by case basis to ensure it is financially sustainable and beneficial for the customer.

\subsubsection{Benefits and costs of large-scale penetration}

The benefits and costs of increasing the contribution of RE sources in a DHC system depend on site-specific conditions such as the heating and cooling demand density, the availability of RE resources, and appropriate infrastructure. A Danish analysis of a future energy system, based upon achieving $100 \%$ RE by 2060 , concluded that a gradual expansion of DH systems (using mainly heat pumps and biomass CHP), together with a switch to electric heat pumps for buildings that could not be connected to DH, would be the most efficient and least cost strategy for decarbonizing the heating of space and domestic water (Lund et al., 2010).

Large DHC systems offer benefits such as high overall system efficiencies (potentially obtained by combining the production of heat, cold and electricity and by using diurnal and seasonal storage of heat and cold) and relatively high flexibility with respect to energy source (as different production units can dispatch heat in an optimal way to meet varying demand). The incorporation of RE into DHC systems may provide 
additional benefits such as improved urban air quality, and the provision of heating and cooling at low or zero $\mathrm{CO}_{2}$ emissions. (For a full discussion of these benefits of RE, see Chapter 9.)

DH networks represent a relatively mature technology. Expected reductions in heat network costs through improved design and reduced losses suggest that the expansion of $\mathrm{DH}$ will remain economically feasible in many locations, even in areas with relatively low heat densities (Bruus and Kristjansson, 2004). Improved designs include the co-insulation of paired, small diameter outward and return flow distribution pipes.

The total costs of a RE-based DHC system are highly contextual and site specific. The onsite heating of buildings using natural gas from grids in condensing boilers, small-scale heat pumps, biomass boilers, solar thermal systems or geothermal heat pumps can be strong competitors to DH in many locations. However, the ability of DHC systems to provide reliable supplies, avoid the need for maintenance of individual appliances, as well as integrate a broad spectrum of energy sources, facilitates competition among various heating/cooling sources, fuels and technologies (Gronheit and Mortensen, 2003). RE integration in itself does not lead to significant additional costs, except in the case where heat storage is necessary for high shares of solar thermal.

\subsubsection{Case studies}

\section{Solar-assisted district heating system in Germany}

As a demonstration project of proof-of-concept, a new residential area in Crailsheim with 260 houses, a school and sports hall has been designed for solar energy to displace about half the potential heat demand from a highly efficient, fossil fuel heating plant linked to the existing DH network. As a result, GHG emissions have been reduced by more than $1,000 \mathrm{t} \mathrm{CO}_{2}$ per year (Wagner, 2009). Apartment blocks, new single houses and community buildings connected to the scheme are equipped with $3,800 \mathrm{~m}^{2}$ of solar collectors with a further $3,500 \mathrm{~m}^{2}$ installed on a noise protection wall that separates the residential and commercial areas. In 2010, a total annual heat demand of around $15 \mathrm{TJ}$ is expected to be met by the solar collectors (Dalenbäck, 2010). Achieving such a high solar share was made possible by the use of a seasonal heat storage facility and a $100 \mathrm{~m}^{3}$ buffer tank used to directly meet instantaneous peak heat demands. Seasonal storage is provided by $7555-\mathrm{m}$ deep boreholes and a second $480 \mathrm{~m}^{3}$ buffer tank. The integration of a $350 \mathrm{~kW}$ heat pump allows the discharge of the borehole storage system down to a temperature of $20^{\circ} \mathrm{C}$. This reduces the heat losses in the storage system and leads to a higher efficiency of the solar collectors due to lower return temperatures. The borehole storage system is designed to heat to $65^{\circ} \mathrm{C}$ by the end of summer and, at the end of the winter heating period, the lowest temperature is $20^{\circ} \mathrm{C}$. Maximum temperatures during heat recharging will be above $90^{\circ} \mathrm{C}$. In the second phase of the project, the heated residential area will be extended by 210 additional accommodation units, requiring an additional collector area of 2,200 $\mathrm{m}^{2}$ and the seasonal storage system will need to be expanded to 160 boreholes (Mangold and Schmitt, 2006). Solar heat costs in this advanced proof-of-concept system are estimated to be around USD $_{2005} 67 / \mathrm{GJ}$ (Mangold et al., 2007). In less advanced systems without seasonal storage, the solar heat cost under northern European conditions is typically USD $_{2005} 14$ to 28/GJ (Dalenbäck, 2010).

\section{Biomass CHP district heating plant in Sweden}

District heating in Sweden expanded rapidly between 1965 and 1985. Sweden used to be dependent on oil for the production of heat but after the 1979 oil crisis the fuel mix changed considerably. Since 2007, biomass has accounted for nearly half of total fuel supply in $\mathrm{DH}^{12}$ (IEA, 2009c). The Enköping CHP plant is an illustrative case of this transition, driven by national $\mathrm{CO}_{2}$ taxes, other policy instruments (Section 11.5.5, Box 11.8) and a local council decision to avoid fossil fuels (McKormick and Kåberger, 2005). The oil-fired DH system, constructed in the early 1970s, was converted after 1979 to use a mix of oil, solid biomass, coal, electric boilers and liquefied petroleum gas (LPG), until the construction in 1995 of a $45 \mathrm{MW}_{\text {th }} 24 \mathrm{MW}_{\mathrm{e}}$ biomass-fired CHP plant enabled a transition to nearly $100 \%$ biomass by 1998 .

The Enköping plant demonstrates an innovative approach to RE integration as a result of cooperation begun in 2000 among the local energy company, the nearby sewage treatment plant and a local landowner. The energy company wished to diversify fuel supply for the CHP plant fearing that there would not be enough forest residue biomass in the region to meet future heat and power demands. At the same time, the neighbouring municipal sewage plant was obligated to reduce its nitrogen discharges by $50 \%$. The use of land treatment of the sewage effluent on to willow (Salix) was identified as a cost-effective solution. An 80 ha willow plantation acting as a 'nitrogen filter' was established on farmland adjacent to the sewage plant and close to the CHP plant. The farmer was remunerated for receiving the wastewater and sewage sludge on the land as well as by the market price for delivering biomass to the CHP plant. The success of this cooperation can be attributed to all parties being proactive and open to new solutions. Advisors worked as liaisons between parties, the regional and local authorities were positive and interested, and the risks were divided between the three main parties (Börjesson and Berndes, 2006). In 2008, the local area of willow plantations was increased to 860 ha and it is now the ambition of the energy company to further increase the biomass fuel share from the Salix to above the current 15\%.

\section{District heating in China}

In China, the floor area of buildings served by DH has increased steadily from 277 million $\mathrm{m}^{2}$ in 1991 to 3,489 million $\mathrm{m}^{2}$ in 2008 (Figure 8.7), corresponding to an increase in heat deliveries from $0.4 \mathrm{EJ}$ to nearly 2.6 EJ. About half of all Chinese cities, essentially those with colder winters, have DH systems (Kang and Zhang, 2008).

More than $95 \%$ of DH production in 2000 was based on coal. Nevertheless, the use of CHP results in lower emissions compared to the alternative of using individual boilers and coal-condensing power

12 The remaining heat production was based on $18 \%$ (35 PJ) from municipal solid waste, $10 \%$ industrial waste heat, $5 \%$ coal, $4 \%$ oil, $4 \%$ natural gas, $5 \%$ peat and $10 \%$ from heat pumps (Box 11.11). 


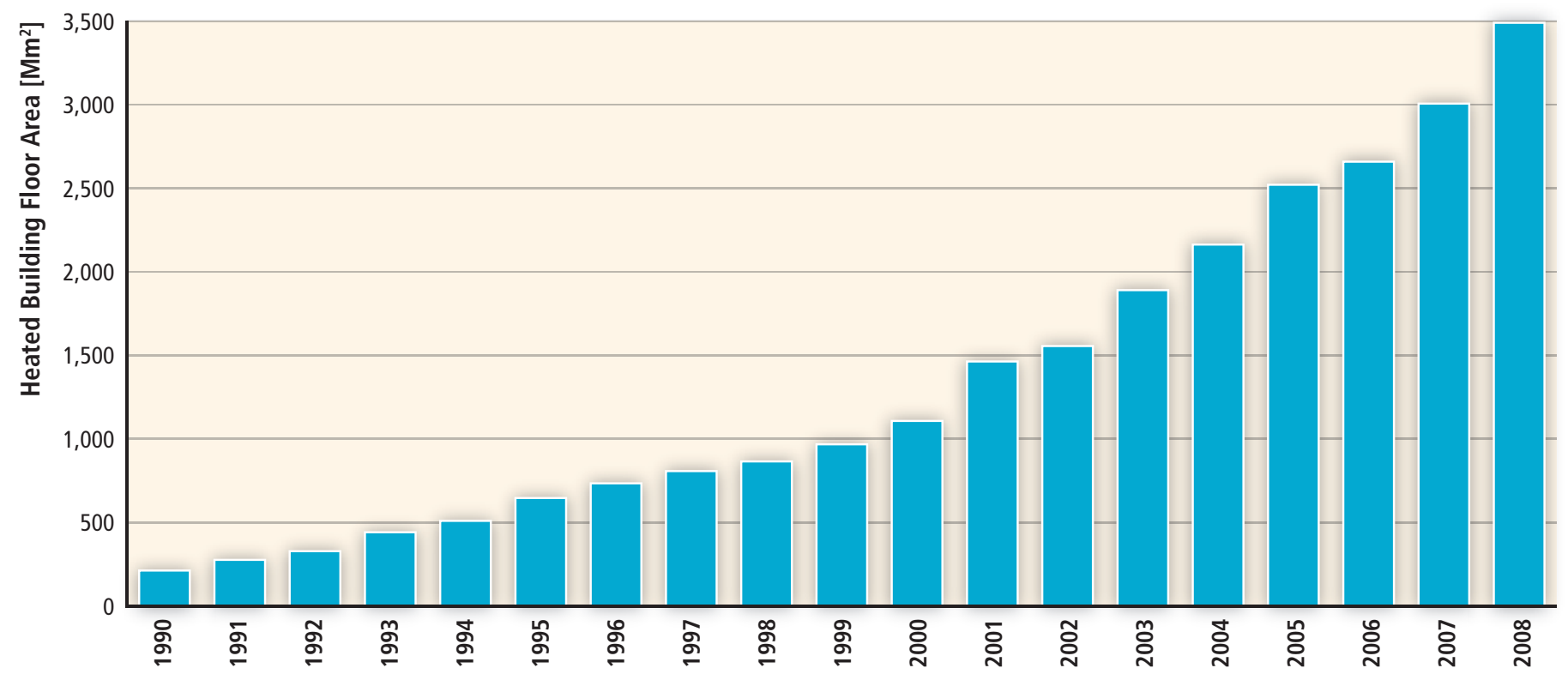

Figure 8.7 Total area of building floor space served by district heating in China increased over twelve fold from 1990 through 2008 (adapted from Kang and Zhang (2008), updated with 2006-2008 data from the National Bureau of Statistics China, 2010).

generation plants. In the case of the city of Harbin, the result of installing a DH system was improved air quality in addition to $0.5 \mathrm{Mt} / \mathrm{yr} \mathrm{CO}_{2}$ emission reductions (WBCSD, 2008). Local air pollution concerns, as in Beijing and Tianjin, have motivated a shift from coal to natural gas in recent years, but interest in the integration of geothermal, biomass and solar thermal applications is now growing. For example, Shenyang, a leading city in the application of geothermal heat pumps, is meeting nearly one quarter of its $200 \mathrm{Mm}^{2}$ heated building floor area by taking water at 12 to $14^{\circ} \mathrm{C}$ from 80 to $160 \mathrm{~m}$ depths (Shenyang, 2006; Jiang and Hai, 2010). Eco-city developments, such as Caofeidian in Tangshan, are also fuelling a growing interest in RE for DHC systems.

\section{District cooling in North America}

Successful examples of DC installations include $51 \mathrm{MW}$ of cooling at Cornell University, Ithaca, USA. Around $1,200 \mathrm{~m}^{3} / \mathrm{hr}$ of $4^{\circ} \mathrm{C}$ water is pumped from the bottom of nearby Cayuga Lake through a heat exchanger before it is stored in a $20,000 \mathrm{~m}^{3}$ stratified thermal storage tank (Zogg et al., 2008). A separate water loop runs back $2 \mathrm{~km}$ before passing through the air-conditioning systems of the 75 campus buildings and Ithaca High School. In this USD 200568 million scheme, the cooling water is discharged back to the lake at around 8 to $10^{\circ} \mathrm{C}$ and mixed with the surface water by 38 injection nozzles to maintain stable water temperatures. The $1.6 \mathrm{~m}$ diameter intake pipe has a screen at $76 \mathrm{~m}$ depth and this, and the discharge nozzles, were carefully designed to minimize maintenance and environmental problems.

Compared with the original refrigeration-based cooling system, since the project started in 1999, GHG emissions have been reduced significantly due to both reducing the power demand for cooling by around 80 to $90 \%$ of the previous $25 \mathrm{GWh} / \mathrm{yr}(90 \mathrm{TJ} / \mathrm{yr})$ and by avoiding the 12 to $13 \mathrm{t}$ of chlorofluorocarbons (CFCs) that were used in the six chillers (Cornell, 2005).
The ecology, hydro-dynamics, temperature strata and geophysics of the lake have been closely monitored. There remain some concerns about bringing up phosphorus-rich sediments from the bed of the lake and discharging them near to the surface, which could possibly encourage algal growth.

In another example, Toronto, Canada, has pumped cold water drawn from nearby Lake Ontario to a $207 \mathrm{MW}$ cooling plant since 2004. The DC system cools 3.2 million $\mathrm{m}^{2}$ of office floor area in the financial district. The lake water intake pipe at $86 \mathrm{~m}$ depth runs $5 \mathrm{~km}$ out into the lake to ensure clean water is extracted, since this is also the supply for the city's domestic water system. No warm water return discharge impacts to the lake therefore result. Stockholm has a similar but smaller district cooling system based on extracting sea water from the harbour.

\subsubsection{Integration of renewable energy into gas grids}

The main objective of a gas grid is to transport gas from producers to consumers. The overall system consists of gas productions plants, main transmission and local distribution pipelines, storage tanks, and industrial or domestic gas consumers. The design of a gas system depends on the type and source of gas, location of the gas supply in relation to the consumers, and the supply volumes needed to meet peak demand. This section shows that replacing the combustion of some natural gas with biogas or biomass synthesis gas ${ }^{13}$ to provide heat is relatively straightforward in the short term. Upgrading of biogas to biomethane (by removing carbon dioxide and hydrogen sulphide gases) and the cleaning of biomass synthesis gas (by removing tars) are necessary where the

13 Synthesis gas or syngas is a mixture of carbon monoxide, hydrogen, methane, higher hydrocarbon gases, and carbon dioxide also known as town gas or producer gas. It can be manufactured by gasification of coal or biomass (Section 2.2). 
gas is to be injected into a natural gas grid or used to fuel an internal combustion engine in a vehicle or to power an electricity generator. In the longer term, demand for RE-produced hydrogen may expand but could need high capital investment in infrastructure.

\subsubsection{Features and structure of existing gas grids}

A gas distribution system is primarily designed to deliver adequate amounts of gas at a certain quality (heating value, pressure and purity) to downstream users. Existing gas processing, delivery and storage systems are quite complex. New designs depend on the existing energy system in the region where the gas grid is being considered. Consisting of different types of pipelines, some designs have been built just to supply local users with 'town gas'. Large grids, first developed in the 1960s, now traverse continents in order to distribute large volumes of gas from natural gas fields. For example, the natural gas grid in the USA is highly integrated, with more than 210 pipeline systems, $480,000 \mathrm{~km}$ of inter- and intra-state transmission pipelines and 394 underground storage facilities (EIA, 2007). Europe (EU27) has 1.8 million km of pipelines and 127 storage facilities to supply more than 110 million customers (Eurogas, 2008). To balance supply and demand, gas storage, usually in steel tanks, can be incorporated at various levels in the system. The capacity depends on how the gas is produced, how it can be integrated into the gas grid and the end-use applications. The volume of gas stored is normally minimized to reduce costs and safety hazards.

The gas flow rate depends on the scale and physical attributes of the gas (molecular weight, viscosity, specific heat) and the friction in the pipe (which depends on pipe layout, design and type). A pipeline designed with a large diameter and a high pressure drop can move more gas over a given distance than a smaller pipe at lower pressure (Mohitpour and Murray, 2000). There is an economic trade-off between increasing the diameter of the pipeline versus increasing the gas pressure.

The materials used in gas pipelines depend on the type of pipeline (transmission or distribution), location (sub-sea, overland, underground), operating conditions (pressure, temperature, moisture), and type and quality of gas or gases to be sent through the pipeline. Metallic materials are mainly used in larger transmission pipelines as they are tolerant to higher pressures and temperatures, but have the potential for internal and external corrosion problems (Castello et al., 2005). Plastics can be used in distribution gas grids operating at lower temperatures $\left(<100^{\circ} \mathrm{C}\right)$ and pressures $(<1,000 \mathrm{kPa})$.

Natural gas extraction points are normally connected to the pipeline head stations via trunk lines (at 7,000 to 10,000 $\mathrm{kPa}$ pressure). The gas is then pumped into long distance transmission pipelines (at 6,000 to $9,000 \mathrm{kPa}$ ) and sent to the takeoff stations from where it is transported to the control station of the regional distribution system (at 800 to 4,000 $\mathrm{kPa}$ ), before it finally reaches industrial and household customers (at 5 to $10 \mathrm{kPa}$ ) (Castello et al., 2005). Distribution pipelines, including main feeders, station connections, valves and meters are contained on the property of the customer at the end-use point (EIGA, 2004).

Hydrogen pipelines are currently limited to a very few geographical areas that have large hydrogen consumers such as chemical and petrochemical industries (Castello et al., 2005). Blending of hydrogen (up to $20 \%$ ) with natural gas on a large scale, and transporting this gas mix long distances in existing or new natural gas grids, could be a future option for the large-scale distribution of hydrogen (NATURALHY, 2009).

Once the energy feedstock for producing biogas or syngas has been established, the end-use application, whether for heating, combined heat and power (CHP), raw feedstock for the chemical industry, or transport fuels, needs to be determined. Local gas distribution systems have traditionally used gas-burning appliances to provide cooking, space and water heating. Using existing commercial internal combustion engine (ICE) and micro-turbine technologies, biomethane and syngas can also be used to fuel small- to large-scale CHP systems. The commercialization of highly efficient, small-scale fuel-cell-based CHP systems (with 80 to $90 \%$ overall efficiency) could contribute to a more energy efficient and cost effective use of existing and new gas grids in the longer term (DeValve and Olsommer, 2006; Zabalza et al., 2007).

\subsubsection{Characteristics of renewable energy with respect to integration}

Over the past decade there has been an increasing interest in 'greening' existing natural gas grids. In Europe the EU Directive 2003/55/EC of the European Parliament opened up the existing grid to carry alternative gases such as 'hythane' (a blend of hydrogen and natural gas), hydrogen and biogas (Persson et al., 2006; NATURALHY, 2009). Furthermore, an EU directive ${ }^{14}$ included measures for increasing the share of biogas and enabling access to the gas grid. As a result, in Germany, for example, the target for 2020 is to substitute 20\% (by volume; around $1.12 \mathrm{PJ} /$ year) of compressed natural gas (CNG) used for transport with biomethane and a 2030 target is to substitute $10 \%$ of natural gas in all sectors with biomethane (382 PJ/year) (Müller-Langer et al., 2009). Similar proposals have been made for the natural gas grid running along the West Coast of North America, with a Bioenergy Action Plan having been introduced by the Governor of California (CEC, 2006).

Until recently, most of the raw biogas produced around the world (from landfills, urban sewage and industrial and agricultural wastes) has been used onsite or distributed in dedicated local gas systems, primarily for heating purposes. Biogas can be upgraded to biomethane of natural gas quality and suitable for blending with natural gas for transporting via gas grids. In a few cases biomethane has been transported via trucks to filling stations to supply gas-fuelled vehicles (Hagen et al., 2001; Persson et al., 2006). The biogas business is growing rapidly and is currently being commercialized by larger industrial players (Biogasmax, 2009).

14 Promotion of the use of energy from renewable sources. EU Directive 2009/28/EC. 
These include major gas companies that are planning to upgrade and inject large quantities of biogas into national/regional transmission gas pipelines (NationalGrid, 2009) to offset some of the demand for natural gas in existing and future markets.

Synthesis gas can be produced via gasification (partial oxidation) of coal or biomass feedstocks (Section 2.2). The Lebon gasification process has been used since the beginning of the 19th century and the gas is already used for cooking, heating and power generation, especially in areas where natural gas is unavailable.

Hydrogen is today mainly produced from natural gas but it can also be produced from RE sources. The main current use is by industry (Section 8.3.3), but it can also be used as a transport fuel (Section 8.3.1). To establish a RE-based hydrogen economy, it will be necessary to develop more efficient small-scale distributed hydrogen production technologies such as water electrolyzers and steam methane reformers (Riis et al., 2006; NRC, 2008; Ogden and Yang, 2009). Small- to medium-scale hydrogen production based on wind (Section 8.3.4), solar or biomass has been evaluated favourably in some regions such as North Rhine-Westphalia, Germany (CEP, 2010) and the North American Great Plains (Leighty et al., 2006). Such RE technologies could conceivably provide the basis for large-scale hydrogen production in the future (IEA-HIA, 2006).

Several different options are available for hydrogen delivery, including road or rail transport of gaseous hydrogen compressed in cylinders of various sizes, trucking of cryogenic liquid hydrogen, and transmission by pipelines. The technical and economic competitiveness of each delivery option depends on the geographical area and gas volume demand. For small consumers, transport of liquefied or compressed hydrogen by trucks is the most viable option, while pipeline delivery can only be justified for a very high flow rate of hundreds of tonnes per day (Castello et al., 2005). The building of hydrogen production and distribution infrastructure over the next few decades could be a mix of centralized and decentralized systems (Bonhoff et al., 2009). Initially, hydrogen will mainly be distributed by trucks, while pipelines will only become important at a later stage as demand increases. For example, in North Rhine-Westphalia, a region with existing gas pipelines supplying industry, there are progressive plans to construct a hydrogen transport infrastructure based initially on the existing gas grid. Dedicated hydrogen pipelines could be needed after 2025 (Pastowski and Grube, 2009) and by 2050 , about $80 \%$ of all hydrogen produced centrally in Germany could be transported by pipeline (Bonhoff et al., 2009).

Local gas distribution grids can complement heating and cooling networks (Section 8.2.2). At the national and regional scales, electricity and gas transmission grids can complement each other in the long-distance transport of energy carriers. The design of a future hydrogen infrastructure, for example, could depend strongly on its interaction with the electricity system (Sherif et al., 2005; C. Yang, 2008), which over time is expected to gain an increasing share of RE. Using surplus RE power to produce hydrogen by electrolysis is an example, possibly combining this with $\mathrm{CO}_{2}$ (arising from biogas, fossil fuel combustion or extracted from the atmosphere) using the process of methanation to produce methane as an energy store and carrier (Sterner, 2009). Currently this process is not commercially viable.

\subsubsection{Challenges caused by renewable energy integration}

A few technical challenges exist related to gas source, composition and quality. The composition and specifications of fuel gases from different carbon-based sources vary widely (Table 8.2). Gas composition and heating values depend on the biomass source, gasification agent utilized in the process and reactor pressure. Such variations in quality may constitute a significant barrier to gas pipeline integration. Landfill gas or biogas from anaerobic digestion can be upgraded to reach a similar methane composition standard as natural gas (80 to $90 \%$ methane) by stripping out the $\mathrm{CO}_{2}$ content before it is fed into a gas grid and/or used as a fuel in ICEs or high-temperature fuel cells. The composition of biomass-derived syngas depends on the type and moisture content of the organic feedstock and on the production method (e.g., using bubbling versus circulating fluidized bed gasifier designs).

Gas companies and/or authorities define the standard gas composition for injection into a gas grid on the basis of minimizing the risks associated with the infrastructure, the quality of combustion in industrial processes and domestic appliances, health, and emissions to the environment. In small-scale systems for stand-alone operations, the standards are mainly defined to minimize risks associated with the equipment and the processes themselves. Since only gases of a specific quality can be injected directly into a gas grid, meeting these standards can create market barriers for biogas and landfill gas producers (more than for syngas, which is relatively clean (Table 8.2) assuming tars can be avoided during gasification).

- $\mathrm{CO}_{2}$ can be removed by several methods, but each have operational and cost issues (Persson et al., 2006).

- Absorption (water scrubbing) requires large amounts of water. Blockage of the equipment by organic growth can also be a problem.

- Absorption by organic solvents such as polyethylene glycols or alcohol amines requires large amounts of energy for regenerat ing the solvent.

- Pressure swing adsorption requires dry gas.

- Separation membranes, dry (gas-gas) or wet (gas-liquid) require handling of the methane in the permeate stream (which increases with high methane flow rates in the gas stream).

- Cryogenic separation requires removal of water vapour and hydrogen sulphide $\left(\mathrm{H}_{2} \mathrm{~S}\right)$ prior to liquefaction of $\mathrm{CO}_{2}$.

- Removal of corrosive $\mathrm{H}_{2} \mathrm{~S}$ from biogas is necessary to protect downstream metal pipelines, gas storage and end-use equipment. Micro-organisms 
can be used to reduce the concentration of $\mathrm{H}_{2} \mathrm{~S}$ by adding stoichiometric amounts of oxygen to the process (around $5 \%$ air to a digester or biofilter). Alternatively, simple vessels containing iron oxides can be used as they react with $\mathrm{H}_{2} \mathrm{~S}$ and can be easily regenerated once saturated by oxidation when placed in contact with air.

- Small volumes of siloxanes and organic silicon compounds (not shown in Table 8.2) can form extremely abrasive deposits on engine pistons, cylinder heads and turbine sections and cause damage to the internal components of an engine if not removed (Hagen et al., 2001; Persson et al., 2006).

- Other particulates and condensates may also need removal as there are normally low tolerances for impurities.

A community-scale biogas plant in Linköping, Sweden exemplifies an economically viable system for local use (IEA Bioenergy, 2010a). Multiple organic wastes are treated and processed in an anaerobic digester to produce biogas with similar properties to those shown in Table 8.2. The gas mixture is then upgraded to remove $\mathrm{CO}_{2}$ and $\mathrm{H}_{2} \mathrm{~S}$ before the residual biomethane gas is distributed through a local grid to supply a slow overnight filling station for buses, 12 public refuelling stations for cars, taxis and fleet vehicles, and a refuelling system for a converted diesel train with $600 \mathrm{~km}$ range (IEA, 2010a). The system payback time is sensitive to the estimated long-term gas production and price, which in turn is affected by taxation and carbon values, the future end-use demands for the gas and the clean-up costs. The economic payback time to integrate 'scrubbed' biomethane into a gas grid depends on the location of injection. If injection is at the end of a pipeline as incremental capacity, then the cost can be relatively low. Local and regional differences in existing infrastructure make it difficult to make specific recommendations for planning and integration costs at a national and regional level.

Hydrogen transported via existing natural gas grids may first require some upgrading of the pipelines and components (Mohitpour and Murray, 2000; Huttenrauch and Muller-Syring, 2006). Since pure hydrogen has a lower volumetric density compared to natural gas, hydrogen pipelines will require either operation at higher pressures or around three times larger diameter pipes in order to carry the same amount of energy per unit time as a natural gas pipeline. In a dedicated hydrogen gas grid, depending on the hydrogen pathway but particularly if used with fuel cells rather than for direct combustion, the hydrogen needs to be purified and dried before it is stored and distributed. For

Table 8.2 Examples of composition and parameters of gases from a range of carbon-based sources, using typical data for landfill gas, biogas from anaerobic digestion (AD), (Persson et al., 2006) and biomass-based syngas (Ciferno and Marano, 2002), and compared with natural gas.

\begin{tabular}{|c|c|c|c|c|c|}
\hline Parameter & Unit & Landfill Gas & Biogas from $A D^{1}$ & Syngas from biomass ${ }^{2}$ & North Sea natural gas \\
\hline Density & $\mathrm{kg} / \mathrm{Nm}^{3}$ & 1.3 & 1.2 & - & 0.84 \\
\hline Methane number & & $>130$ & $>135$ & - & 70 \\
\hline Methane, typical & vol- $\%$ & 45 & 63 & 10 & 87 \\
\hline Hydrogen & vol- $\%$ & $0-3$ & - & $5-43$ & - \\
\hline Carbon monoxide, typical & vol- $\%$ & - & - & 30 & - \\
\hline Carbon monoxide, variation & vol- $\%$ & - & - & $9-47$ & - \\
\hline Carbon dioxide, typical & vol- $\%$ & 40 & 47 & 25 & 1.2 \\
\hline Carbon dioxide, variation & vol- $\%$ & $15-50$ & $30-37$ & $11-40$ & - \\
\hline Oxygen, variation & vol- $\%$ & $0-5$ & - & - & - \\
\hline Hydrogen sulphide, typical & $\mathrm{ppm}$ & $<100$ & $<1,000$ & $\sim 0$ & 1.5 \\
\hline Hydrogen sulphide, variation & ppm & $0-100$ & $0-10,000$ & - & $1-2$ \\
\hline Ammonia & ppm & 5 & $<100$ & - & - \\
\hline Total chlorine (as $\mathrm{Cl}$ ) & $\mathrm{mg} / \mathrm{Nm}^{3}$ & $20-200$ & $0-5$ & - & - \\
\hline Tars & vol- $\%$ & - & - & $<1$ & - \\
\hline
\end{tabular}

Notes: 1. Anaerobic digestion. 2. From gasification using bubbling or circulating fluidized beds with direct or indirect heating. Syngas followed by methanation can produce 83 to $97 \%$ methane and 1 to $8 \%$ hydrogen. $\mathrm{Nm}^{3}$ is an uncompressed 'normal' cubic metre of gas at standard conditions of $0^{\circ} \mathrm{C}$ temperature and atmospheric pressure. 
example, for fuel cell vehicles (Section 8.3.1), the hydrogen needs to be of a very high purity $\left(>99.9995 \% \mathrm{H}_{2}\right.$ and $\left.<1 \mathrm{ppm} \mathrm{CO}\right)$. Industrial hydrogen with lower purity can be transported in dedicated transmission and distribution pipelines so long as there is no risk of water vapour building up, or any other substances that could lead to internal corrosion. Regular checking for corrosion and material embrittlement in pipelines, seals and storage equipment is important when dealing with hydrogen (EIGA, 2004).

\subsubsection{Options to facilitate renewable energy integration}

\section{Technical options}

Pipeline compatibility and gas storage are the two main technical challenges when integrating RE-based gases into existing gas systems. For variable RE-based systems, a constant stream of gas may not be produced so some storage may be essential to balance supply with demand. Since RE-based gases can be produced regionally and locally, storage is likely to be located close to the demand of the end user. Hence, the size and shape of a storage facility will depend on the primary energy source and the end use. In small applications, pressure variations in the pipeline (Section 8.3.4) could act as storage depending on the varying rates of production and use (Gardiner et al., 2008). In cases where there are several complementary end users for the gas, infrastructure and storage costs can be shared.

Simpler system designs enable RE-derived gases with a lower volumetric energy density to be distributed locally in relatively cheap polymer pipelines. Such dedicated distribution gas pipelines can be operated at relatively low pressures but will then need a larger diameter to provide similar volume flow rates and energy delivery. After a RE gas has been upgraded, purified, dried, brought up to the prescribed gas quality, then safely injected into a distribution grid, the main operational challenge is to avoid leaks and regulate the pressure and flow rate so that it complies with the pipeline specifications. Continuously available compressors, safety pressure relief systems and gas buffer storage systems are used to maintain the optimum pressures and flow rates.

Small- to medium-sized gas buffer storage such as inflatable rubber or vinyl bags (normally with four or five days of gas demand capacity) can be used to collect and store biogas, biomethane or syngas produced from variable RE feedstocks to help balance supply and local demand. The options for large-scale storage of biomethane are similar to those of CNG or liquefied natural gas (LNG). In large landfill gas or industrialized biogas plants, upgraded biomethane gas can be stored at high pressures in steel storage cylinders (as used for $\mathrm{CNG}$ ). These can be connected to a local dispenser, to a gas pipeline, or transported by truck to the place of demand. Liquefaction before transport is possible, as used for LNG, but this is likely to add significant cost and complexity to a system. Producing LNG requires a large amount of energy and is therefore mainly an option for gas transport by boat or truck over thousands of kilometres when it can compete with constructing new gas pipelines.
Small-scale storage of hydrogen can be achieved in steel cylinders at pressures around 20,000 to 45,000 kPa Commercial composite-based hydrogen gas cylinders can withstand pressures up to $70,000 \mathrm{kPa}^{15}$ and hydrogen stations with gas pipelines and tanks that can withstand pressures up to $100,000 \mathrm{kPa}$ already exist (www.zeroregio.com). In integrated gas grids, it is suitable to use low pressure $(1,200$ to $1,600 \mathrm{kPa}$ spherical containers that can store relatively large amounts $\left(>30,000 \mathrm{~m}^{3}\right)$ of hydrogen above ground (Sherif et al., 2005). For safety reasons, such storage is normally situated in industrial areas away from densely populated and residential areas. Hydrogen can also be stored at low pressure in stationary metal hydrides, but these are relatively costly and can only be justified for small volumes of hydrogen or if compact storage is needed.

Large-scale hydrogen storage is normally as compressed gas, or cryogenically in liquid form. Liquefaction of hydrogen is more costly than liquefaction of biomethane due to its lower volumetric density and boiling temperature $\left(-253^{\circ} \mathrm{C}\right)$. In practice, about 15 to $20 \%$ of the hydrogen energy content is required to compress it from atmospheric pressure to 20000 to $70000 \mathrm{kPa}$ while around 30 to $40 \%$ is required to produce liquid cryogenic hydrogen (Riis et al., 2006). Natural underground storage options, such as caverns or aquifers, for large-scale seasonal storage can be found in various parts of the world, but their viability and safety must be evaluated on a case-by-case basis.

\section{Institutional options}

The main institutional challenges to integrating RE gases into existing gas systems are adequacy of supply, quality standards, pipeline security and safety issues (McCarthy et al., 2007).

- Adequacy of supply can be influenced by the variable and seasonal nature of some RE resources, while the capacity of the gas distribution system also needs to be able to meet demand.

- Meeting gas quality standards poses a barrier, but is not fundamentally technically challenging. For biomethane, this can often be achieved at relatively low additional costs. However, gas quality standards vary: Sweden and Germany, for example, have developed their own national standards for biomethane that differ widely (Persson et al., 2006) (Table 8.3). There is as yet no single international gas standard for pipeline quality RE-based gases.

- The security of a gas pipeline system involves assuring a primary supply and building robust networks that can withstand either natural or physical events. In order to enhance supply security, pipeline networks often include some degree of duplication and multiple pathways between suppliers and end users so that a disruption in a network cannot shut down the entire system. Assessing vulnerability to malicious attacks on an extensive pipeline system over thousands of kilometres is a daunting task, and may require technological solutions such as intelligent sensors that report back pipeline conditions

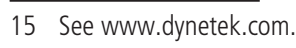


Table 8.3 National standards for biomethane to be met before allowing injection into Swedish and German natural gas grids (Persson et al., 2006).

\begin{tabular}{|c|c|c|}
\hline Parameter & Unit & Demand in Standard \\
\hline \multicolumn{3}{|l|}{ Sweden } \\
\hline Lower Wobbe index & $\mathrm{MJ} / \mathrm{Nm}^{3}$ & $43.9-47.3$ (i.e., 95-99\% methane) \\
\hline MON (motor octane number) & - & $>130$ (calculated according to ISO 15403) \\
\hline Water dew point & ${ }^{\circ} \mathrm{C}$ & $<\mathrm{T}_{\text {ambient }}-5$ \\
\hline $\mathrm{CO}_{2}+\mathrm{O}_{2}+\mathrm{N}_{2}$ & vol \% & $<5$ \\
\hline $\mathrm{O}_{2}$ & vol \% & $<1$ \\
\hline Total sulphur & $\mathrm{mg} / \mathrm{Nm}^{3}$ & $<23$ \\
\hline $\mathrm{NH}_{2}$ & $\mathrm{mg} / \mathrm{Nm}^{3}$ & 20 \\
\hline \multicolumn{3}{|l|}{ Germany } \\
\hline \multirow[t]{2}{*}{ Higher Wobbe index } & $\mathrm{MJ} / \mathrm{Nm}^{3}$ & 46.1-56.5 (>97.5\% HHV' methane) \\
\hline & $\mathrm{MJ} / \mathrm{Nm}^{3}$ & 37.8-46.8 (i.e., 87-98.5\% LHV² methane) \\
\hline Relative density & - & $0.55-0.75$ \\
\hline Dust & - & Technically zero \\
\hline Water dew point & ${ }^{\circ} \mathrm{C}$ & $<$ Ground temperature $\mathrm{T}_{\text {ground }}$ \\
\hline $\mathrm{CO}_{2}$ & vol \% & $<6$ \\
\hline $\mathrm{O}_{2}$ & vol \% & $<3$ (in dry distribution grids) \\
\hline $\mathrm{s}$ & $\mathrm{mg} / \mathrm{Nm}^{3}$ & $<30$ \\
\hline
\end{tabular}

Notes: $1 . \mathrm{HHV}=$ higher heat value. $2 . \mathrm{LHV}=$ lower heat value.

via Global Positioning System (GPS) technology to allow rapid location of a problem and corrective action. Diverse local or regional RE resources used for gas production can offer more secure supply than a single source of imported gas.

- Safety procedures and regulations for hydrogen used in the chemical and petroleum refining industries are already in place. Industrial hydrogen pipeline standards and regulations for on-road transport of liquid and compressed hydrogen have also been established. However, there is a lack of safety information on components and systems, which poses a challenge to the commercialization of hydrogen energy technologies. Codes and standards are necessary to gain the confidence of local, regional and national officials involved in the planning of hydrogen and fuel cell projects, hence, several organizations are developing safety and operational standards.

Given relative costs, policy support for the integration of RE gases may be needed if higher rates of deployment are sought. For example, feed-in regulations could enable the injection of biomethane into natural gas grids, similary to how RE power is fed into electricity grids (Section 11.5.2).

\section{Benefits and costs of large-scale penetration of RE gases}

Benefits and costs can be assessed using both economic (capital expenditure, operation and maintenance costs) and environmental (GHG emissions, local air pollution, energy input ratio, air pollution) indicators. The relevant parameters are significantly affected by the type of RE source, gas production technology, storage and distribution system, and end-use application being either transport (Section 8.3.1) or stationary (Sections 8.3.2 and 8.3.3).
The compatibility of biomethane for distribution in natural gas grids can facilitate the widespread production and use of biogas and landfill gas. The costs of distribution are similar to existing gas systems, which enables a straightforward transition path for integration. Biomethane is already well established for heating, cooking, power generation, CHP and transport fuels. The latter is mainly for vehicle fleets of only a few hundred associated with water treatment plants and some agricultural usage (Matic, 2006). By comparison, more than 9 million CNG and LNG vehicles are operating worldwide (Åhman, 2010).

The market for hydrogen-fuelled vehicles is presently limited to applications such as forklift trucks (that operate indoors and hence require zero emissions) and demonstration cars and buses. Several leading automobile manufacturers anticipate that hydrogen fuel cell vehicles will be commercially introduced from 2015 (Pastowski and Grube, 2009) (Section 8.3.1). Hydrogen distribution demonstration projects are currently being introduced. For example, in California, 7 new hydrogen stations are due for completion by 2011, resulting in 11 stations in two clusters around Los Angeles (Dunwoody, 2010). Germany plans to increase the number of hydrogen stations from around 10 in 2009 to more than 140 in 2015 (Bonhoff et al., 2009). Similar initiatives in Japan are described in the Hydrogen and Fuel Cells Demonstration Project (Uchida, 2010).

GHG emissions related to producing and upgrading a RE-based gas should be assessed before a system is implemented. Vehicles fuelled with landfill gas can reduce GHG emissions by around 75\% compared to using CNG, or even more if using biogas produced from the anaerobic digestion of animal manure (NSCA, 2006). Methane leakage to the atmosphere during biogas upgrading, storage, distribution and vehicle filling processes, as well as GHG emissions from any heat and power consumed during the upgrading process, will affect the overall energy efficiency and total GHG emissions as assessed on a life cycle basis (Figure 8.8) (Pehnt et al., 2009b). For example, if biogas produced from animal manure is used to fuel a $500 \mathrm{~kW}_{\mathrm{e}}$ CHP system, assuming $20 \%$ utilization of the

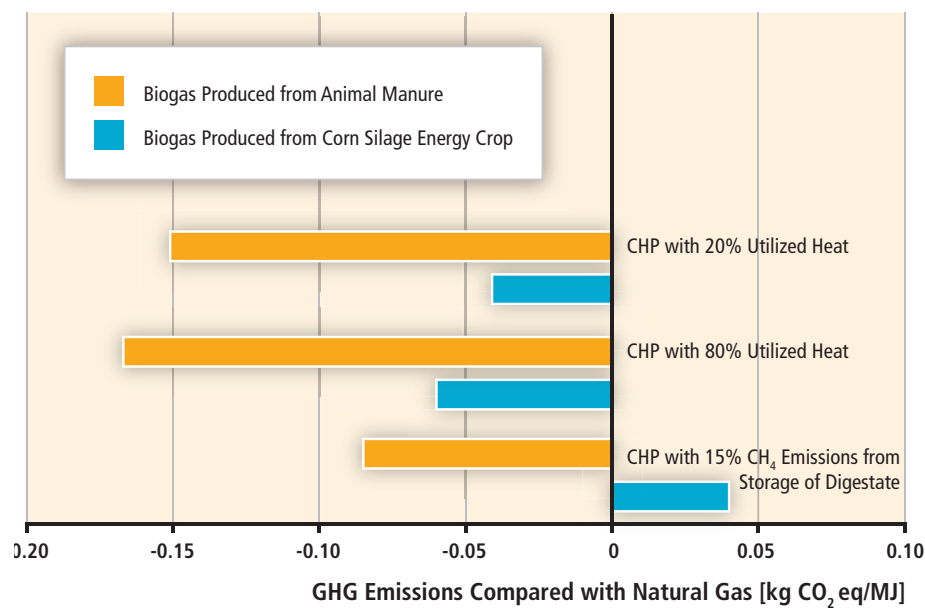

Figure 8.8 | For a $500 \mathrm{~kW}_{\mathrm{e}}$ CHP plant fuelled by biogas produced from either the anaerobic digestion of animal manure slurry or a corn silage energy crop, the potential reductions of GHG emissions can be compared with using natural gas to fuel the CHP plant. Methane leaks to atmosphere reduce the GHG reduction benefits (Pehnt et al., 2009b). 
available useful heat, a $0.15 \mathrm{~kg} \mathrm{CO}$ eq reduction in $\mathrm{GHG}$ emissions per MJ of energy output results, compared with a natural gas-fired CHP plant. If the biogas is produced from corn silage, only a $0.04 \mathrm{~kg} \mathrm{CO}$ eq/ MJ reduction would be achieved. If more heat can be utilized, the benefits increase, but should some methane leak to atmosphere, for example during storage of the process digestate, the GHG reduction benefits are considerably reduced (Figure 8.9).

To compete with other energy carriers, the cost of producing and upgrading biogas to the quality required for injection into an existing gas grid should be minimized. A comprehensive study of several biogas plants in Sweden showed that the electricity required to upgrade biogas is about 3 to $6 \%$ of the energy content of the cleaned gas, and the cost for upgrading is about USD 20050.005 to $0.02 / \mathrm{MJ}$ (Persson, 2003).

The cost per unit of energy delivered using a gas pipeline depends on the economies of scale and gas flow rate. The main cost is the pipe itself plus costs for installation, permits and rights of way. The cost of a local distribution pipeline is similar to that for district heating (Section 8.2.2) and depends mainly on the density of the urban demand. More dense systems yield a lower cost per unit of energy delivered. When designing a new gas grid, planning for anticipated future expansions is recommended because adding new pipes can be a costly option. Increasing the pressure to provide additional gas flow may be cheaper than adding larger diameter pipelines. The cost for distribution and dispensing of compressed biomethane at the medium scale is around USD $_{2005} 15 / \mathrm{GJ}$ when transported by truck (Figure 8.9), which is substantially higher than by pipeline or as liquefied methane (Åhman, 2010).

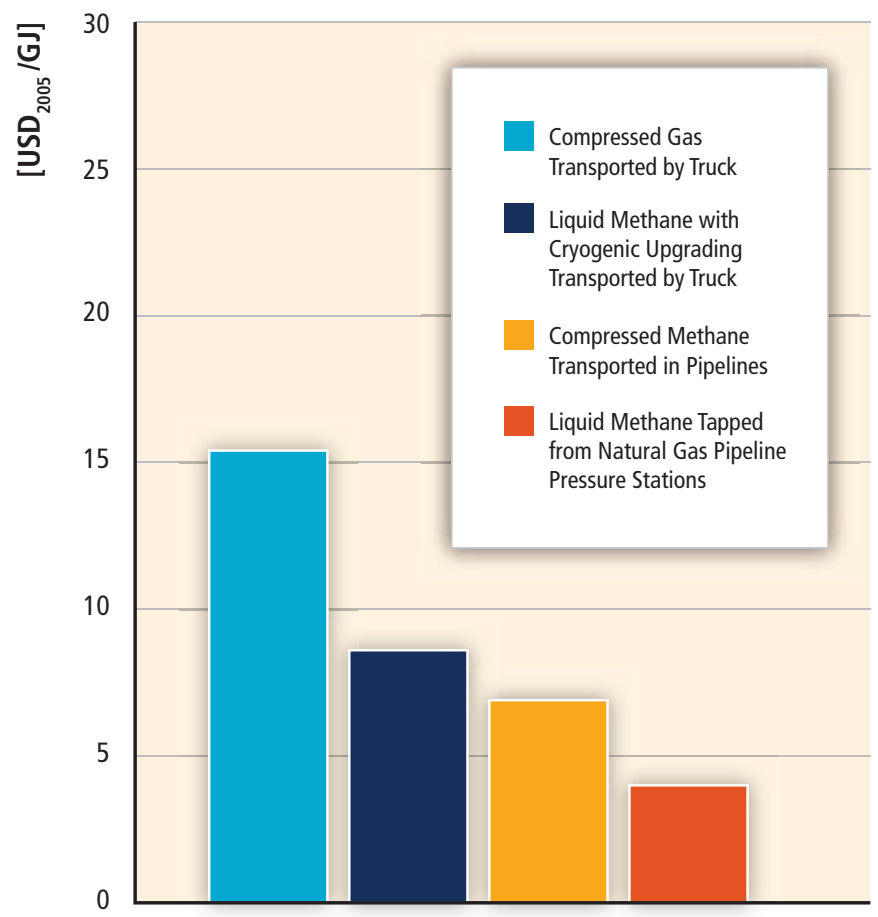

Figure 8.9 | Relative costs for distributing and dispensing biomethane (either compressed or liquefied) at the medium scale by truck or pipeline (Åhman, 2010).
In order to blend RE gases into a gas grid, the gas source needs to be located near the existing system to avoid high connection costs. More remotely located plants should ideally use the biomethane or hydrogen onsite to avoid the cost of gas distribution. Blending syngas or hydrogen into a natural gas system may require changes to the natural gas distribution and end-use equipment. Local networks in urban areas that currently carry fossil fuel-derived syngas (town gas) may also be suitable for biomass-derived syngas.

The limiting factors for hydrogen distribution are likely to be capital costs and the time involved to build a new infrastructure. In Germany, the cost for hydrogen production and distribution to supply some 7 million fuel cell light duty vehicles in 2030 is estimated to be around USD 200540 billion (Bonhoff et al., 2009). In the USA, for refuelling 200 million fuel cell vehicles, several hundred billion dollars would need to be invested over four decades (NRC, 2008). Incorporating variable RE sources would add to the cost due to the additional need for hydrogen storage.

In Europe, biomethane has been estimated to have the possibility of replacing 17.4 EJ of natural gas ${ }^{16}$ in 2020 (Figure 8.10) (Müller-Langer

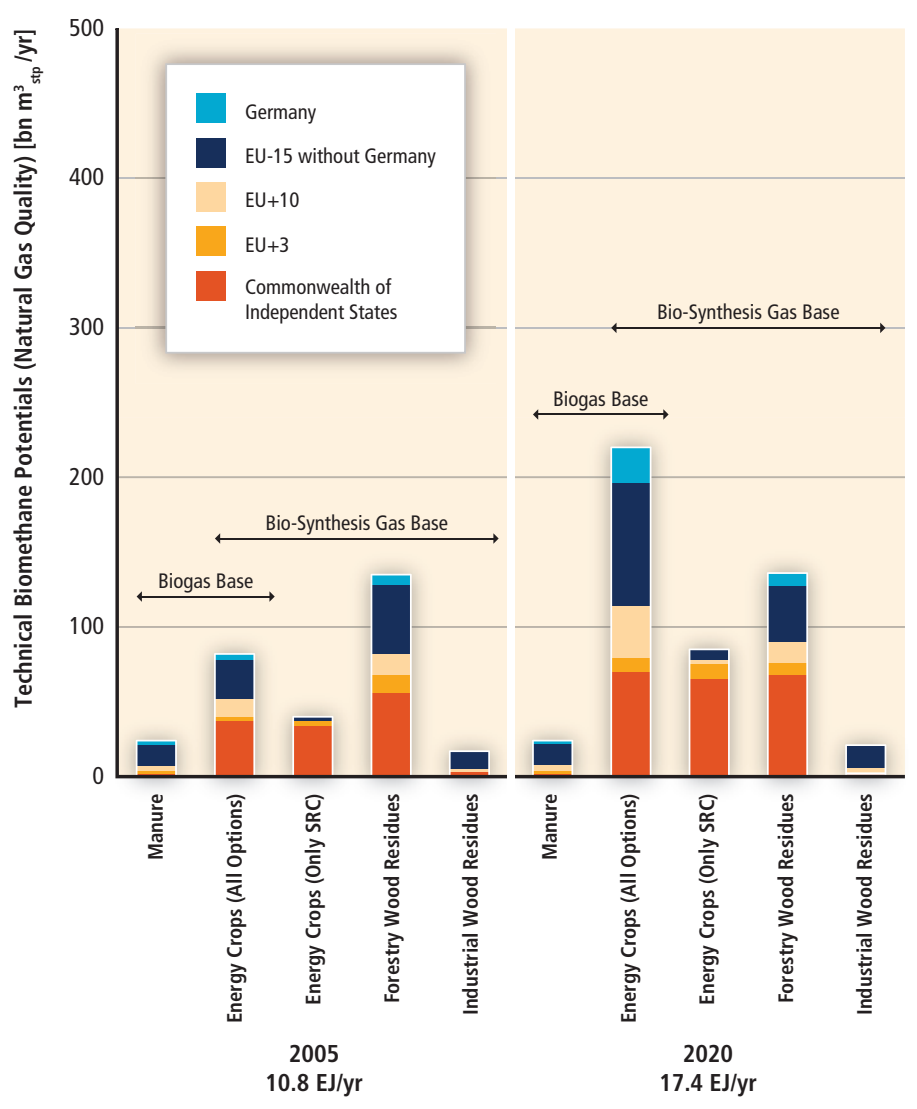

Figure 8.10 | Technical annual potentials of biomethane at standard temperature and pressure (STP) as produced from a range of biomass feedstocks in the EU region in 2005 and 2020 (Müller-Langer et al., 2009).

Note: $S R C=$ short rotation coppice; $b n=$ billion $=10^{9}$

16 Total natural gas consumption in OECD Europe (EU27) in 2008 was $19.1 \mathrm{EJ}, 25 \%$ of total primary energy (IEA, 2010d). 
et al., 2009), but this partly depends on the competition for the available biomass resources (Eurogas, 2008).

\subsubsection{Integration of renewable energy into liquid fuel systems}

\subsubsection{Features and structure of liquid fuel supply systems}

Renewable liquid fuels can take advantage of existing infrastructure components (storage, blending, transportation and dispensing) already used by petroleum-based fuels, with some adaptations. Integration issues may therefore be less problematic as compared to electricity or gas systems. The structure of a biomass-to-liquid fuel system for first generation biofuels is well understood (Figure 8.11) but sustainable production and land use remain controversial (Fritsche et al., 2010) (Sections 2.5.4 and 9.3.4.1).

The transport of bulky, low energy density biomass feedstocks to a biorefinery by road can be costly and normally produces $\mathrm{GHGs}$. Rail transport can be a more efficient and cost effective delivery mode (Reynolds, 2000).

Biofuels can be blended with gasoline or diesel at oil refineries or blend centres during the distribution of petroleum fuels to vehicle refilling stations. Biofuels and blends can be stored at their production sites, alongside oil refineries or in underground storage tank facilities at service stations. As for petroleum products, similar care needs to be taken regarding safety and environmental protection. Due to the seasonality of agricultural crops grown specifically as biomass feedstocks, storage of the feedstock and/ or the biofuel is crucial if the goal is to meet year-round demand (NAS, 2009), but this adds to the production costs. International trade can also play a role to provide a stable year-round supply (IEA, 2007a) (Section 2.4). Biodiesel is prone to variation in composition during storage due to the action of micro-organisms that can lead to rises in acidity and hence engine corrosion. Ethanol is more biologically stable.

\subsubsection{Characteristics with respect to renewable energy integration}

Currently most liquid biofuels are produced from sugar, carbohydrate and vegetable oil crops and integrated into existing fuel supplies by using blends, typically up to $25 \%$ (in volumetric terms) with gasoline and diesel (Sections 2.3.3 and 2.6.3). However, ethanol can be blended in any proportion with gasoline for use in flex-fuel vehicles (Section 8.3.1) and biodiesel can be used in compression ignition engines either neat $(100 \%$ or B100) or blended with regular diesel. Modified diesel engines may also run on almost neat alcohol (E95) with an ignition improver (Scania, 2010). Several manufacturers produce trucks and agricultural machinery with engines certified for use with B20 and B100 fuels (NBB, 2010; New Holland Information Center, 2010; Power-Gen, 2009).

Solid lignocellulosic biomass sources can be converted to liquid fuels by means of biochemical processes such as enzymatic or acid hydrolysis, or by thermo-chemical processes to produce synthesis gas (mainly carbon monoxide $(\mathrm{CO})$ and hydrogen $\left(\mathrm{H}_{2}\right)$ ) followed by Fischer-Tropsch conversion

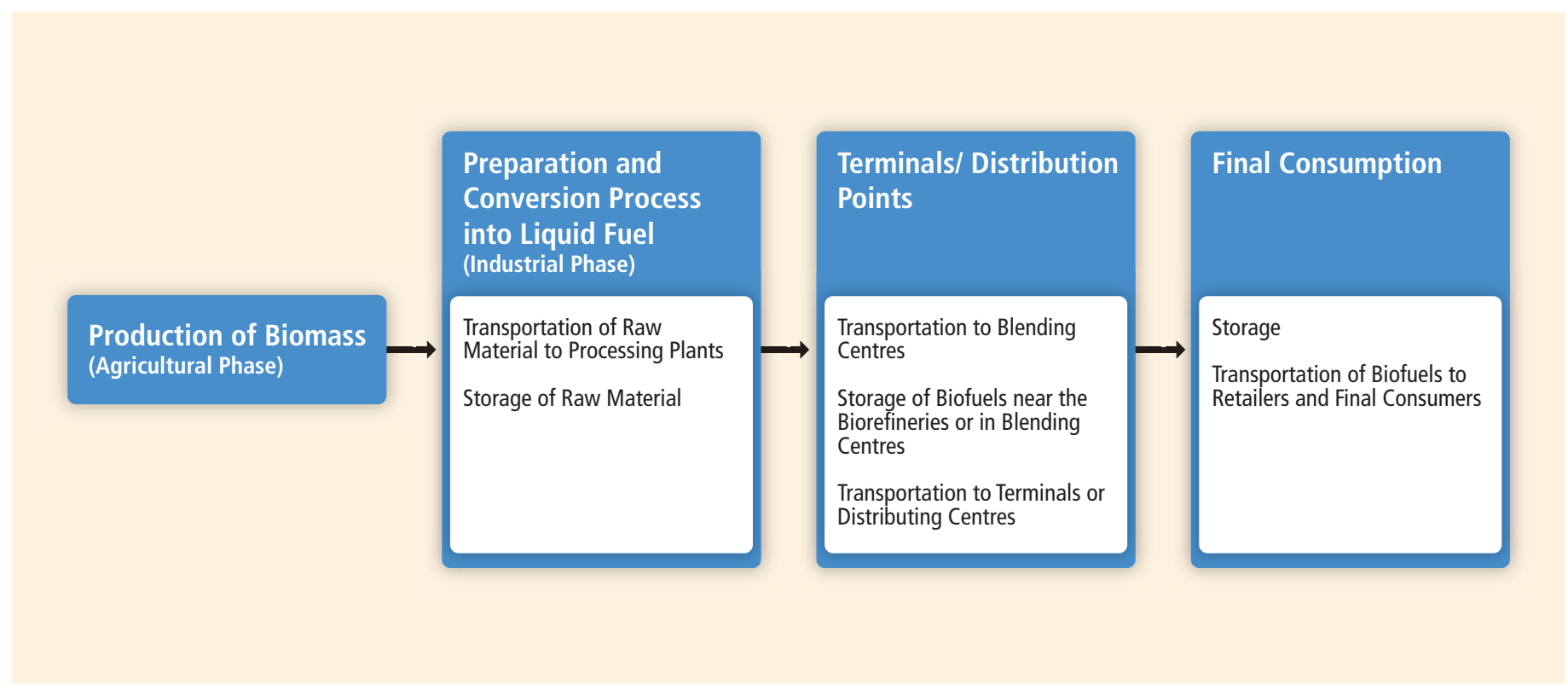

Figure 8.11 The various phases in a typical biofuel production, blending and distribution system for transport fuel. 
to produce a range of synthetic liquid fuels suitable for road transport, aviation, marine and other applications (Sims et al., 2008; Section 2.3.3). Fuel quality issues are important because they can affect the performance of vehicle engines and transport emissions (Section 8.3.1.2). Biomethane, if it meets appropriate specifications (Section 8.2.3), can also be combusted directly in spark-ignition ICEs as for compressed natural gas (CNG).

Most of the projected demand for liquid biofuels is for transport, though industrial demand for bio-lubricants, and chemicals such as methanol for use in chemical industries, could also increase (Section 2.6.3.5). Some biofuels are also used in stationary CHP engines as a substitute for petroleum fuels. The demand for large amounts of traditional solid biomass primarily in developing countries for cooking and heating could be replaced by more convenient gaseous fuels such as LPG, but also by liquid fuels produced from biomass such as ethanol gels (Utria, 2004; Rajvanshi et al., 2007) or dimethyl ether (DME) (Sims et al., 2008).

Liquid biofuels can be integrated into the existing oil product distribution infrastructure. Transition barriers are relatively low as biofuel blends could be introduced without costly modifications to existing petroleum storage and delivery systems, and could take advantage of existing infrastructure components (NAS, 2009). Some related costs could eventuate for blending and for additional technical modifications of fuel storage tanks and fuel pumps, or provision of new installations. The type of fuel storage and delivery system will vary depending on the properties of the biofuel and its compatibility with the existing petroleum-based fuel system. Most common biofuels have similar properties to gasoline and diesel so can be blended reasonably easily with these. Cold temperature conditions can represent difficulties, during transport and storage and in engines, especially for some biodiesels that may form polymer gels that restrict fuel flow. Overcoming these constraints is imperative if biofuels are to be used as aviation fuels.

Transport and delivery modes from refineries to terminals include trucks, barges, tankers and pipelines. From the terminals, trucks or distribution pipelines can supply the retail outlets depending on the distances and volume of biofuels involved. Storage and distribution costs would be similar to petroleum-based fuels.

Bio-refineries that produce biofuels and other co-products are generally much smaller in capacity than oil refineries and could be widely located in geographic regions where the resource exists. For example, numerous ethanol processing plants are situated throughout the mid-western and south-eastern corn belt of the USA, whereas a few oil refineries are concentrated along the coasts. Brazil already has many bio-refineries in operation producing sugar, ethanol, biodiesel, animal fodder, electricity, steam and heat.

Although the cost of fuel delivery is a small fraction of the overall production cost, the logistics and capital requirements for widespread expansion and integration could present hurdles if not well planned.
Technical issues regarding ethanol and gasoline blends (gasohol) during storage and transport can arise if water is absorbed by anhydrous ethanol in the pipelines (Section 8.2.4.3). However, in Brazil, ethanol produced from sugar cane has been successfully transported in pipelines also used for oil products for over 20 years, though the clean-up and maintenance procedures have increased. Since ethanol has around two-thirds the volumetric energy density of gasoline, larger storage systems, more rail cars or vessels, and larger capacity pipelines would be needed to store and transport a similar amount of energy and hence would increase the fuel storage and delivery costs compared to oil-based products.

The possibility exists to use by-products of biofuel production as raw materials for biogas production or electricity generation, for example from bagasse, the sugarcane residue. Integration with the existing electricity grid system has been successfully achieved in Brazil and elsewhere in cogeneration schemes after the energy demands of the processing plant have been met (Rodrigues et al., 2003; Pacca and Moreira, 2009). Anaerobic digestion of the by-products from bioethanol and biodiesel processing has the potential to be integrated with various existing bio-refinery models. The biogas can either be used for heat and electricity generation, as a vehicle fuel (Börjesson and Mattiasson, 2008), or injected into gas grids (Section 8.2.3).

\subsubsection{Challenges of renewable energy integration}

Although renewable liquid fuels can take advantage of the existing infrastructure components (storage, blending, transportation and dispensing) already used by the petroleum industry, some issues need to be addressed. Most biofuels have fairly similar properties to gasoline and diesel so can be blended reasonably easily with these fuels. Cold weather conditions can produce engine difficulties from higher viscosity and gel formation when using some biodiesels, and also produce difficulties for their storage and transport (NAS, 2009).

Sharing oil-product infrastructure with biofuels may lead to possible water contamination from hydrous ethanol, and the resulting corrosion may require using new materials to preserve the working life of the pipeline and equipment. Moisture resulting from condensation in oil-product pipelines can increase the water content of ethanol if being transported in the same lines. If it exceeds the technical specification for the bioethanol, additional distillation after delivery may then be required. Ethanol and biodiesel can also dissolve and carry any impurities present inside multi-product pipeline systems and these are potentially harmful to ICEs. Therefore a dedicated pipeline may be preferable if improved cleanup procedures between products being sent through multi-product pipelines are not successful. Moisture absorption and phase separation during pipeline shipment of ethanol can be avoided by shipping some hydrous ethanol first, which is then used directly by end users or distilled, followed by anhydrous ethanol that then remains suitable for direct blending with gasoline. An alternative 
strategy is to send a 'sacrificial buffer' of neat ethanol down a pipeline to absorb any moisture ahead of sending the primary batches of ethanol or blends. The buffer shot is discarded or re-distilled.

Ethanol in high concentrations can lead to accelerated stress corrosion cracking $(\mathrm{SCC})$ in steel pipelines and storage tanks, especially at weld joints and bends (NAS, 2009). This can be avoided by adding tank liners, using selective post-weld heat treatments, and coating internal critical zones (at pipeline weld points, for example). However, these all increase system costs. Ethanol may degrade certain elastomers and polymers found in seals and valves in pipelines and terminals as well as some engines, so these may need replacement. New pipelines could be constructed with ethanol-compatible polymers in valves, gaskets and seals and be designed to minimize SCC (NAS, 2009).

\subsubsection{Options to facilitate renewable energy integration}

\section{Technical options}

Technologies will continue to evolve to produce biofuels that are more compatible with the existing petroleum infrastructure (Sims et al., 2008). Advanced biofuels in the future may need to meet stringent quality specifications in order to match the fuels with existing and new engine designs installed in heavy transport, marine and aviation applications. In some countries, the development of codes and standards for biofuels has been slow and delayed their integration into the supply system. Quality control procedures also need to be implemented to ensure that biofuels meet all applicable product specifications (Hoekman, 2009) and hence facilitate integration.

The facilitation of international trade in biofuels instigated a need for more homogeneous international standards to be developed. A comparison was made of existing biofuel standards (NCEP, 2007). The standards for biodiesel in Brazil and USA reflect its use only as a blending component in conventional mineral diesel fuel, whereas the European standard allows for its use either as a blend or as neat fuel. Variations also exist in current standards for regulating the quality of biodiesel reaching the market due to the different oil and fat feedstocks available. This translates to variations in the performance characteristics of each biofuel, less so for ethanol, which is a simple chemical compound compared with longchain biodiesels. Bioethanol technical specifications differ with respect to the water content but do not constitute an impediment to international trade (NIST, 2007). Blending levels of biofuels need to account for regional differences in the predominant age and type of vehicle engines, ambient temperatures and local emission regulations.

\section{Institutional aspects}

Policy support has played an important role in creating a market for biofuels. For example, the mandatory blending of biodiesel and ethanol in diesel and gasoline respectively has been used in several countries (Section 11.5.5). Agencies in charge of regulating oil product markets could also include biofuels under their jurisdiction. These agencies are the most appropriate to deal with issues such as security of biofuel supplies, safety and technical specifications (or standards) and quality control at both the production and retail levels. This is currently the case for Brazil where the regulator for the oil sector also regulates biofuels (TN Petróleo, 2010).

Environmental agencies and related regulations (for example, low-carbon fuel standards and air quality controls), can facilitate greater penetration of biofuels and their integration into the existing energy system. National energy planning organizations can evaluate any impacts and additional costs associated with the large-scale integration of biofuel systems with existing and future energy production and delivery systems.

\subsubsection{Benefits and costs of large-scale renewable energy penetration}

Achieving a high share of biofuels should be relatively easy where unit production costs are similar to imported oil product costs since additional storage and transport costs are a relatively small portion of total costs. Existing infrastructure for oil distribution can be adapted and used for biofuels, especially at low blend levels. For large-scale penetration of biofuels, or where the use of E100 or B100 is envisaged, special provisions may need to be made.

Specialist equipment is needed at collection terminals at ports and oil refineries receiving biofuel shipments for blending of ethanol or biodiesel, and for loading the blended product on to barge, rail or road tankers (Reynolds, 2000). Existing transport, storage and dispensing equipment at vehicle refuelling stations need to be modified to handle biofuel blends, as has been successfully achieved in the USA, Brazil, Germany, Sweden and elsewhere. Underground storage tank systems, pumps and dispensers may need to be converted to be compatible with higher biofuel blends and to meet safety requirements. Issues relating to the retrofitting of existing facilities are similar to those associated with pipeline transport (Section 8.2.4.3) and include phase separation, $\mathrm{SCC}$ and the degradation of incompatible materials (NAS, 2009).

Ethanol terminals usually have one or more storage tanks ranging from 750 to $15,000 \mathrm{~m}^{3}$ capacity. New ethanol storage tanks cost around USD $_{2005} 180 / \mathrm{m}^{3}$ capacity for small tanks up to $\mathrm{USD}_{2005} 60 / \mathrm{m}^{3}$ for large ones (Reynolds, 2000). It may be possible to refurbish gasoline tanks to suit ethanol storage for lower costs than investing in new tanks.

In the USA, most ethanol is transported by rail, road tanker and barge (NCEP, 2007), but since 2008, batches in Florida have also been sent through gasoline pipelines (KinderMorgan, 2010). Capacities and costs vary for ethanol storage and delivery equipment (Table 8.4). As a point of reference, ethanol plants in the USA each produce 300 to $1,200 \mathrm{~m}^{3} /$ day, while the ethanol demand for 1 million cars using E10 would be about 400 to $800 \mathrm{~m}^{3} / \mathrm{day}$, and storage facilities typically hold between 4,000 and $12,000 \mathrm{~m}^{3}$ for local and regional demands respectively. 
Table 8.4 | Capacities and costs of a range of equipment suitable for ethanol storage and long-distance transport.

\begin{tabular}{|c|c|c|c|}
\hline & Capacity & Cost $\left(\right.$ USD $\left._{2005}\right)$ & Reference \\
\hline Truck/trailer & $25 \mathrm{~m}^{3}$ & $\begin{array}{l}103,000 \\
141,000\end{array}$ & EPA (2007) Reynolds (2000) \\
\hline Rail car & $90 \mathrm{~m}^{3}$ & 85,000 & EPA (2007) \\
\hline River barge & Several linked units of $1,200 \mathrm{~m}^{3} / \mathrm{unit}$ & 5 million for one unit & EPA (2007) \\
\hline Ocean ship & $3,000-30,000 \mathrm{~m}^{3}$ & Not known & Reynolds (2000) \\
\hline Pipeline (300 mm diameter) & $12,000 \mathrm{~m}^{3} /$ day & 0.34-0.85 million/km & \\
\hline Terminal storage tank & $\begin{array}{l}3,000 \mathrm{~m}^{3} \\
6,000 \mathrm{~m}^{3}\end{array}$ & $\begin{array}{l}360,000 \\
540,000\end{array}$ & $\begin{array}{l}\text { Reynolds (2000) } \\
\text { Reynolds (2000) }\end{array}$ \\
\hline Retrofit a gasoline storage tank & $1,200 \mathrm{~m}^{3}$ & 18,800 & EPA (2007) \\
\hline Blending equipment & & $170,000-450,000$ & Reynolds (2000) \\
\hline Total terminal refit & $6,000 \mathrm{~m}^{3}$ & 1.13 million & Reynolds (2000) \\
\hline
\end{tabular}

Rail shipment is generally the most cost effective delivery system for medium and longer distances (500 to 3,000 km) and to destinations without port facilities (Reynolds, 2000). Rail shipments require more handling at the terminals because of the greater number and smaller volumes of units compared to barges, as well as the more labour-intensive efforts for cargo loading, unloading and inspection, Trains containing up to 75 railcars have been proposed for ethanol as an alternative to pipeline development (Reynolds, 2000).

Barges are used for long distance transport when biofuel production plants have access to waterways. In the USA, for example, barges travel down the Mississippi River from ethanol plants in the Midwest to ports at the Gulf of Mexico where the ethanol is stored before being transferred to ships for transport to overseas or national coastal destination terminals for blending.

Estimates for the costs of transporting large ethanol volumes over long distances (Reynolds, 2000) (Section 2.6.2) range from USD ${ }_{2005} 6$ to $10 / \mathrm{m}^{3}$ for ocean shipping, USD 2005 to $90 / \mathrm{m}^{3}$ for barge, USD ${ }_{2005} 10$ to $40 / \mathrm{m}^{3}$ for rail and, over shorter haul distances, USD ${ }_{2005} 10$ to $20 / \mathrm{m}^{3}$ for trucks (Section 2.6.2). In Brazil, depending on the origin of the biofuel, the costs of transporting ethanol from the producing regions to the export ports is around USD ${ }_{2005} 35$ to $64 / \mathrm{m}^{3}$, which also includes storage costs at the terminal (Scandiffio and Leal, 2008). More pipelines are being planned to connect main rural ethanol producing centres to coastal export ports with the expected costs ranging from USD ${ }_{2005} 20$ to $29 / \mathrm{m}^{3} ; 70 \%$ less than by road and $45 \%$ less than by rail (CGEE, 2009).

\subsubsection{Case study: Brazil ethanol}

After a relatively slow start, the ethanol distribution system, retailing of biofuel blends and manufacture of flex-fuel engines in Brazil have all proven successful in the past decade, so that in 2010, Brazil was the world's second largest producer of ethanol, after the USA (REN21, 2010). Integration of liquid biofuels with the oil distribution system began after the first global oil crisis when the government promoted sugarcane ethanol as a gasoline alternative (Box 11.9). The state oil company,
Petrobras, was obliged to purchase all domestically produced ethanol, blend it with gasoline, and distribute it nationwide (Walter, 2006). In 1979 , vehicles with engines designed to run on E100 were produced, so existing infrastructure was adapted for delivery of $100 \%$ ethanol nationwide, though production was regionally concentrated. Significant gains in sugarcane yields per hectare have since helped to increase ethanol output per unit of land area so that in 2008 , ethanol production was $495 \mathrm{PJ}$, equivalent in energy terms to $85 \%$ of the gasoline consumed in Brazil that year (EPE, 2009).

About $60 \%$ of ethanol distilleries in Brazil are dual-purpose, producing sugar when world sugar prices are high, and converting it to ethanol at other times (Ministry for Agriculture Livestock and Supply, 2010). When world sugar prices rose in the 1990s, ethanol production declined and hence owners of dedicated E100 vehicles experienced fuel shortages. Vehicles with flexible fuel engines (Section 8.3.1.3) capable of using bioethanol blends ranging from E20 to E100 were therefore developed (de Moraes and Rodrigues, 2006) and have now largely replaced the dedicated E100 fleet. All present gasoline has a blended content of 20 to $25 \%$ anhydrous ethanol (by volume) and therefore, since their commercial introduction in 2003, the majority of new light duty vehicles sold today have 'flex-fuel' engines (Goldemberg, 2009).

Over the last 30 years, a country-wide ethanol storage and distribution system was implemented so that several biofuel blends up to E100 are available in practically all refuelling stations. All subsidies were removed in the 1990s (Box 11.9), but ethanol prices continued to decline steadily and remain competitive with gasoline when oil prices fluctuate around USD $_{2005}$ 70/barrel.

Since 1990, electricity and heat have been generated in sugar/ethanol plants by combusting the bagasse co-product in CHP systems (Cerri et al., 2007). Where the electricity grid is located nearby, any electricity that is surplus to onsite demand can be sold and fed into the national grid (Azevedo and Galiana, 2009). Technological improvements, better energy management and cogeneration schemes have enabled optimal use of the bagasse. Government programmes (PROINFA, 2010), regulatory changes and public auctions for electricity contracts were 
introduced to enable the electricity to be sold to local utilities or monitored and dispatched by the national transmission system operator (Section 8.2.1). Since the sugar cane harvesting period coincides with the dry season in Brazil, generation of electricity from bagasse complements the country's hydroelectric system. In 2009, the total installed capacity of bagasse-fuelled CHP was $5.6 \mathrm{GW}_{\mathrm{e}}$ and generated around $4.75 \%$ of total electricity (BEN, 2010).

Brazil's experience suggests that the integration of high shares of biofuels can be successfully achieved by implementing blending mandates in combination with other policies to address economic, social and environmental barriers (Section 11.5).

\subsubsection{Integration of renewable energy into autonomous energy systems}

Not all buildings, communities or business enterprises are connected to electricity grids, district heating or cooling systems or gas grids, nor have easy access to liquid fuels. This section covers such autonomous energy supply systems, which are typically small scale and are often located in off-grid remote areas, on small islands or in individual buildings where the provision of commercial energy is not readily available through grids and networks. There is also growing interest by industry in the future potential for connecting decentralized energy supply systems ${ }^{17}$ that could utilize advanced control systems and integrate numerous small heat and power generation technologies through smart meters and time-of-use and price-responsive appliances (Cheung and Wilshire, 2010). Overall system costs, benefits and constraints are uncertain, so RD\&D, monitoring and evaluation have been undertaken by several governments in association with several leading electricity and information technology industries. Demonstration projects based on small, autonomous community micro-grids have been established in the USA, Japan, Denmark and elsewhere.

In principle, RE integration issues for autonomous systems are similar to large electrical power systems, for example for supply/demand balancing of electricity supply systems (Section 8.2.1), selection of heating and cooling options (Section 8.2.2), production of RE gases (Section 8.2.3) and liquid biofuel production for local use (Section 8.2.4). Autonomous systems also involve building-integrated RE technologies (Section 8.3.2).

Planning an autonomous system, often remotely located and with low energy demand, involves considering future fossil fuel supply options for the location, the local RE resources available, the costs of RE technologies, future technology innovation prospects and the possible avoidance of construction costs should new or expanded infrastructure be an option for the location (Nema et al., 2009).

17 Various terms are used in the literature to describe a possible future paradigm shift in energy supply such as 'distributed energy systems', 'digital energy', 'intelligent grids' and 'smart grids', but none are as yet clearly defined.

\subsubsection{Characteristics with respect to renewable energy integration}

Several types of autonomous systems exist and can make use of either single energy carriers (electricity, heat, liquid, gaseous or solid fuels) or a combination. A full range of energy services can usually be provided, including heating, lighting, drying, space cooling, refrigeration, desalination, water pumping (Bouzidi et al., 2009) and telecommunications.

Unlike large electrical power systems, smaller autonomous systems often have fewer RE supply options that are readily available at a local scale. Additionally, some of the technical and institutional options for managing integration within large electrical power systems, including sophisticated RE supply forecasting, stochastic unit commitment procedures, stringent fuel quality standards and benefiting from the smoothing effects of geographical and technical diversity, become more difficult or even implausible for smaller autonomous systems.

RE integration solutions typically become more restricted as supply systems become smaller, particularly where there are high shares of variable RE sources. Autonomous systems will naturally have a tendency to focus on storage, various types of demand response and highly flexible generation to help match supply and demand. RE supply options that better match local load profiles or that are dispatchable may be chosen over lower-cost RE supply options that do not have as strong a match with load patterns or that are variable. Managing RE integration within autonomous systems can, all else being equal, be more costly than in larger electrical power systems. One implication of this observation is that autonomous systems face harder tradeoffs between a desire for reliable/continuous supply and a desire to minimize overall supply costs than do larger networks. For those without ready access to electricity, cost comparisons with larger electrical power systems may be irrelevant and standards of reliability may vary.

For electricity generation in small to medium-sized autonomous systems, fossil fuels such as diesel, gasoline or LPG have been commonly used in stationary engines that drive generator sets (gensets). Due to the potential supply constraints and costs of delivering fossil fuel supplies to remote locations in developing countries, there is a growing trend towards using local RE resources where available. Supply/demand balancing problems associated with variable RE sources may emerge for autonomous electrical power systems, similarly as for larger centralized systems but perhaps more acutely. Discussion of the variability and predictability of different RE technologies and their effect on the reliability of electrical power system supply can be found in Section 8.2.1.2. In rural communities with small electric distribution networks, in small villages using simple, low voltage DC mini-grids, or in individual buildings, limited deployment of a single type of RE generation technology such as solar PV or micro-hydro is possible. However, in such cases, variable RE supplies will need to be coupled with other options such as demand side measures, energy storage and increasing generation flexibility to ensure reliability (Section 8.2.5.2). 
Heating and cooling of off-grid autonomous buildings, often in rural locations, can use RE technologies, particularly where good solar, geothermal or biomass resources are available (IEA, 2007c). Variability again may be of some concern where solar thermal is used, but typically it can be addressed through the addition of thermal storage.

Domestic and commercial buildings in urban areas are normally connected to the network energy supply, though interest is growing in the possibility of more existing and new buildings becoming energy generators by installing integrated RE technologies (IEA, 2009b). Building-integrated solar PV (Bloem, 2008), off-grid system operation (Dalton et al., 2008), and distributed energy systems that include solar thermal, small bioenergy CHP plants, micro-hydro and small wind turbines (IEA, 2009a) have all been demonstrated with many successful technology examples surpassing the pre-commercial phase of development. Buildings can be designed to be energy efficient as well as using RE to generate as much energy as they consume. For example, the Net-Zero Energy Commercial Building Initiative of the US Department of Energy (USDOE, 2008a) aims to achieve marketable low-carbon building designs by 2025 . Low-rise buildings can also become autonomous energy systems through the combination of energy efficiency (air-tight structure, high heat insulation, efficient ventilation, air conditioning, lighting, water heating etc.) and integration of RE technologies (Section 8.3.2).

\subsubsection{Options to facilitate renewable energy integration and deployment}

The integration of RE conversion technologies, balancing options and end-use technologies in an autonomous energy system depends on the site-specific availability of RE resources and the local energy demand, which can vary with local climate and lifestyles. The balance between cost and reliability is critical when designing and deploying autonomous power systems, particularly for rural areas of developing economies because, as noted earlier, the additional cost of providing continuous and reliable supply may be greater as autonomous systems grow smaller. The balancing options available to larger electrical power systems are also, in principle, available to autonomous electrical power systems, and are discussed extensively in Section 8.2.1.3. These include improving network infrastructure, increasing generation flexibility, demand side measures, electrical energy storage and improving operational/market and planning methods.

Prioritization among the available options for integrating variable RE into these systems will depend on a variety of factors including but not limited to the type of system, geographic location and expectations of reliability. As already discussed, however, as autonomous systems become smaller, several of the options for managing variability become impractical, and storage, flexible thermal generation and demand response often take precedence.

In terms of demand side measures, autonomous RE systems can be integrated with selected end-use technologies that use surplus electricity only when available. These include solar stills, humidifiers and dehumidifiers, membrane distillers, reverse osmosis or electro-dialysis water desalinators (Mathioulakis et al., 2007), water pumps using solar PV and an AC or DC motor (Delgado-Torres and Garcia-Rodriguez, 2007), solar adsorption refrigerators (Lemmini and Errougani, 2007) and oilseed presses (Mpagalile et al., 2005). Various other forms of load management may also be important for balancing autonomous systems that feature significant amounts of supply and demand variability.

Electrical energy storage technologies (Section 8.2.1.3) may often be the more attractive option for autonomous RE systems, despite their relatively high cost. Where, for example, pumped hydro is not an option, battery storage can be employed with installed capacity sufficient to meet two to three days of electricity demand. The cost of such storage options should be carefully evaluated against the level of reliability desired during the design and planning stages, alongside capital investment and operational costs of the system. Several simulation analyses, demonstration assessments and commercial operations of the application of energy storage technologies to autonomous systems have been reported. These include solar PV plus wind with hydrogen storage in Greece (Ipsakis et al., 2009), wind/hydrogen in Norway (Ulleberg et al., 2010; Section 8.2.5.5), pumped hydro systems plus wind integration on three Greek islands (Caralis and Zervos, 2007b, 2010) and a wind/solar/ pumped hydro demonstration on the Spanish Canary Islands (Bueno and Carta, 2006; Section 8.2.5.5). Small PV systems coupled with battery storage are already in widespread use in many countries.

Alternatively, a portfolio of RE and non-RE technologies could be integrated to enhance system reliability. For example, small diesel- or gasoline-powered gensets and dump load (usually a resistance heater to use any excess electricity generated above the demand) could be cheaper to operate than having batteries for short periods when wind or solar resources are not available (Doolla and Bhatti, 2006).

Gaseous or liquid biofuels that are produced locally from biomass (Section 2.2.2) could be an option for heating or the fuelling of gensets or vehicles (Section 8.3.1). To maintain the desired supply reliability and flexibility of autonomous electricity system operation (Section 8.2.1), the present use of gasoline or diesel to fuel small gensets could, in future, be totally displaced by RE gases and biofuels. RE gases are easy to store under low or medium pressure in butyl containers or cylinders (Section 8.2.3) and liquid biofuels can be stored in steel or butyl rubber tanks (Section 8.2.4).

For many autonomous RE systems (with the possible exception of bioenergy CHP and certain run-of-river micro-hydro schemes), energy storage and low-energy utilization technologies are integral (Lone and Mufti, 2008). Autonomous micro-hydro schemes are popular in hilly regions, particularly in developing countries such as Nepal, to provide a resourcedependent continuous power supply (except possibly in dry seasons). For run-of-river hydro, a cost efficient solution for system balancing (Section 8.2.1) has been to use load control instead of controlling the power generation output (Paish, 2002). 
Providing system reliability in a cost effective manner can prove difficult for autonomous systems, but possible future designs of autonomous heat and power supply systems based on the development of innovative system controls, smart meters and appliances that offer demand response services (Meenual, 2010) could provide solutions and enhance RE integration. Whether such technological solutions are appropriate for use in remote areas of less-developed countries, however, is unclear.

\subsubsection{Benefits and costs of renewable energy integration and design}

For remote rural areas, it is widely recognized that energy supplies can contribute to rural development through increased productivity per capita; enhanced social and business services such as education, establishment of markets and supply of water for drinking and irrigation; improved security due to street lighting; decreased poverty; and improved health and environmental conditions (Goldemberg, 2000; Johansson and Goldemberg, 2005; Takada and Charles, 2006; Takada and Fracchia, 2007). Issues of energy access are addressed in Section 9.3.2.

In developing countries, where suitable and sustainable biomass supplies are available, including organic wastes, their use can often be the least-cost option to provide basic services for cooking, water heating, small-scale power generation and lighting. In China, solar thermal water heating for isolated rural dwellings has brought environmental, social and economic benefits (Z. Li et al., 2007).

Electricity generated by an autonomous system is usually more expensive than using electricity where a grid connection is available. Therefore autonomous RE buildings have been uncommon in urban environments, though some interest in micro-grids and others concepts has been expressed. In remote areas, RE-based electricity autonomous systems may be the only or least-cost option, at least until a connection to external grids becomes available.

\subsubsection{Constraints and opportunities for renewable energy deployment}

Beyond those barriers already addressed, constraints to integration can arise from the wide-ranging RE technology specifications and the difficulties of their appropriate design, construction and maintenance. These can lead to capital investment and operational cost increases or inadequate maintenance. Should a technical failure occur, poor public perception of the technology could arise. Establishing standards, certifying products, integrating planning tools, training maintenance workers and developing a knowledge database could help avoid technology reliability problems (Kaldellis et al., 2009). Local capacity building, training, good planning and careful market establishment could result in lower operational and maintenance costs, an enhanced reputation, employment opportunities and other social benefits (Meah et al., 2008).
For each type of autonomous RE system, appropriate planning methods could assist developers to build projects (Giatrakos et al., 2009), though the variety of possible RE technologies that could be deployed and integrated makes development of broad planning guidelines difficult to achieve. To improve planning methodology, databases could be established from RD\&D projects as well as from commercial experiences to enable comparisons between sustainability criteria (Igarashi et al., 2009), lifestyles (Amigun et al., 2008; Himri et al., 2008) and various combinations of technologies under specific site conditions.

The integration of RE into autonomous systems on a broad scale may also require policy measures to help cover the additional costs and to provide an enabling environment (Section 11.6). Even where an autonomous, RE-integrated system is assessed to be economically feasible over its lifetime, appropriate financial schemes to remove the barrier of high capital investment costs could be warranted.

\subsubsection{Case studies}

\section{Seawater desalination in a rural area of Mexico}

Baja California Sur is an arid, sparsely populated coastal state where underground aquifers are over-exploited due to population growth, agricultural irrigation demands and tourism. Around 70 seawater desalination plants are therefore operating using fossil fuel electricity and there are plans to construct more.

Small-scale desalination using solar PV is an alternative water supply option for the smaller, more remote communities in the state. Installed solar PV-powered seawater reverse osmosis plants can each produce $19 \mathrm{~m}^{3}$ of fresh water per day with a total dissolved solids content of $<250 \mathrm{ppm}$ while consuming as little as $2.6 \mathrm{kWh} / \mathrm{m}^{3}\left(\sim 9.4 \mathrm{MJ} / \mathrm{m}^{3}\right)$ of water (Contreras et al., 2007). The plants use an energy recovery device and integrate a battery bank to enable 24-hour operation. The balance between continuous, smooth operation and cost minimization depends on optimizing the integration and capacity of this battery bank. In the future, further integration of desalination plants and rural electrification could be beneficial to provide both clean water and sustainable energy supplies.

\section{Wind/hydrogen demonstration, Utsira, Norway}

An autonomous wind/hydrogen energy demonstration system located on the island of Utsira, Norway was officially launched by Norsk Hydro (now Statoil) and Enercon (a German wind turbine manufacturer) in July 2004. The main components of the system are a $600 \mathrm{~kW}_{\mathrm{e}}$ rated wind turbine, a water electrolyzer to produce $10 \mathrm{Nm}^{3} / \mathrm{h}$ of hydrogen, 2,400 $\mathrm{Nm}^{3}$ of hydrogen storage (at 20,000 $\mathrm{kPa}$ ), a hydrogen-powered internal combustion engine driving a $55 \mathrm{~kW}_{\mathrm{e}}$ generator, and a $10 \mathrm{~kW}_{\mathrm{e}}$ proton exchange membrane (PEM) fuel cell. ${ }^{18}$ This innovative demonstration

$18 \mathrm{Nm}^{3}$ is an uncompressed 'normal' cubic metre of gas at standard conditions of $0^{\circ} \mathrm{C}$ temperature and atmospheric pressure. 
system supplies 10 households on the island providing two to three days of full energy autonomy (Ulleberg et al., 2010).

Operational experience and data collected from the plant over four to five years showed the electrical energy consumption for the hydrogen production system (electrolyzer, compressor, inverter, transformer, and auxiliary power system) under nominal operating conditions is about $6.5 \mathrm{kWh} / \mathrm{Nm}^{3}\left(\sim 23.4 \mathrm{MJ} / \mathrm{Nm}^{3}\right)$, equivalent to an efficiency of about $45 \%$ (based on lower heat value). The efficiency of the hydrogen engine/generator system is about $25 \%$. Hence, the overall efficiency of the wind to AC-electricity to hydrogen to AC-electricity system, assuming no storage losses, is only about $10 \%$. If the hydrogen engine was to be replaced by a $50 \mathrm{~kW}_{\mathrm{e}}$ PEM fuel cell, the overall efficiency would increase to 16 to $18 \%$. Replacing the present electrolyzer with a more efficient unit (such as a PEM or a more advanced alkaline design), would increase the overall system efficiency to around 20\% (Ulleberg et al., 2010).

The relatively low efficiency of the system illustrates the challenge for commercial hydrogen developments. More compact hydrogen storage systems and more robust and less costly fuel cells need to be developed before autonomous wind/hydrogen systems can become technically and economically viable (Gardiner et al., 2008). Nevertheless, this project has demonstrated that it is possible to supply remote area communities with wind power using hydrogen as the energy storage medium, but that further technical improvements and cost reductions need to be made to compete with a wind/diesel hybrid. The overall wind energy utilization of only $20 \%$ could be improved by installing more suitable and efficient load-following electrolyzers that allow for continuous and dynamic operation. Surplus wind power could also be used to meet local heating demands, both at the plant and in the households. In addition, the hydrogen could conceivably be utilized in other local applications, such as fuel for local vehicles and boats. The overall costs of the system are not known but are likely to be relatively high.

\section{El Hierro - the Spanish Canary Islands}

This, the smallest of the Canary Islands, used to meet the electricity demand of its 10,600 population (plus 60,000 tourists a year) with a 10 MWe diesel generating set, $100 \mathrm{~kW}_{\mathrm{e}}$ and $180 \mathrm{~kW}_{\mathrm{e}}$ wind turbines and a small, low voltage distribution grid going around the $276 \mathrm{~km}^{2}$ island (IEA, 2009b). The annual imported diesel fuel costs were around USD $_{2005} 3$ million per year. In 2005, the local government implemented a $100 \%$ RE electricity programme with a budget for wind of approximately USD ${ }_{2005} 20$ million, for hydro approximately USD ${ }_{2005} 50$ million, and for solar approximately USD $_{2005} 10$ million. Energy saving is a key part of the project, which includes local government incentives to encourage solar water heating installations. The demonstration programme has a simple payback period of around 30 years, so is supported by a consortium of seven partners including the European Commission under its ALTENER programme.

The utility company Unelco-Endesa is developing the wind/hydro plant expected to be commissioned in 2011. The local government has a $70 \%$ stake in the project and the islanders can also purchase shares.
Five 2.2 MW turbines have been installed and surplus wind power will be used to pump water up a $3 \mathrm{~km}$ long, $0.5 \mathrm{~m}$ diameter pipe to the upper storage system, which is a lined volcanic crater giving $200,000 \mathrm{~m}^{3}$ storage capacity and a $700 \mathrm{~m}$ head potential. This reservoir will be used to run a hydro plant to meet peak power demands and also act as balancing reserve during calm periods of up to seven days. Any surplus water could be used for irrigation purposes along with water from a desalination plant used to top up the system. The existing diesel generating plant remains for system balancing (and also as backup under extreme conditions) and is anticipated to initially meet around $20 \%$ of the annual total electricity demand.

Solar PV is used for street lighting and is also to be installed on 10 public buildings. Each $5 \mathrm{~kW}$ capacity system will feed any surplus power into the low voltage grid. Local, sustainably produced woody biomass is already used to meet a share of the heat demand. Biogas, produced from a range of feedstocks, is used to power a hybrid bus and could also be used for heat and power generation in the future (Insula, 2010). Electric vehicles are planned and the potential for ocean energy development is being assessed (Iglesias and Carballo, 2010). Successful initiation of the project resulted from major awareness campaigns undertaken for the islanders in 2005. Training sessions were also provided for locals so as to create a workforce of installers and maintenance personnel from within the population (de Angelis et al., 2010).

\subsection{Strategic elements for transition pathways}

For each of the transport, buildings, industry and primary production sectors, in order to increase the contribution of RE (Figure 8.2), possible strategies to overcome barriers and non-technical issues need to be better understood. Preparing transition pathways for each specific strategic element in a region can enable the effective integration of $\mathrm{RE}$ with existing energy supply systems to occur.

In the IPCC 4th Assessment Report (IPCC, 2007) the economic mitigation potentials for each of the sectors were analyzed at various carbon prices (Figure $8.12^{19}$ ). The substitution of fossil fuels by RE sources for heat and electricity generation was included in the energy supply sector (together with fuel switching, nuclear power and CCS). Integration of biofuels for transport, RE for heating/cooling of buildings, RE for process heat for industry and RE in food and fibre production were considered only to a limited degree.

The IPCC 4th Assessment Report was based mainly on information and data collected from 2004 or earlier as published in the latest literature at the time. Since then, RE technologies have continued to evolve and there has been increased deployment due to improved cost

19 In this chapter the 'Energy Supply' sector is covered in Section 8.2 and the 'Waste' sector discussion on biogas, landfill gas and municipal solid waste (MSW) incineration has been distributed between Sections 8.2.2, 8.2.3 and 8.3.4. 

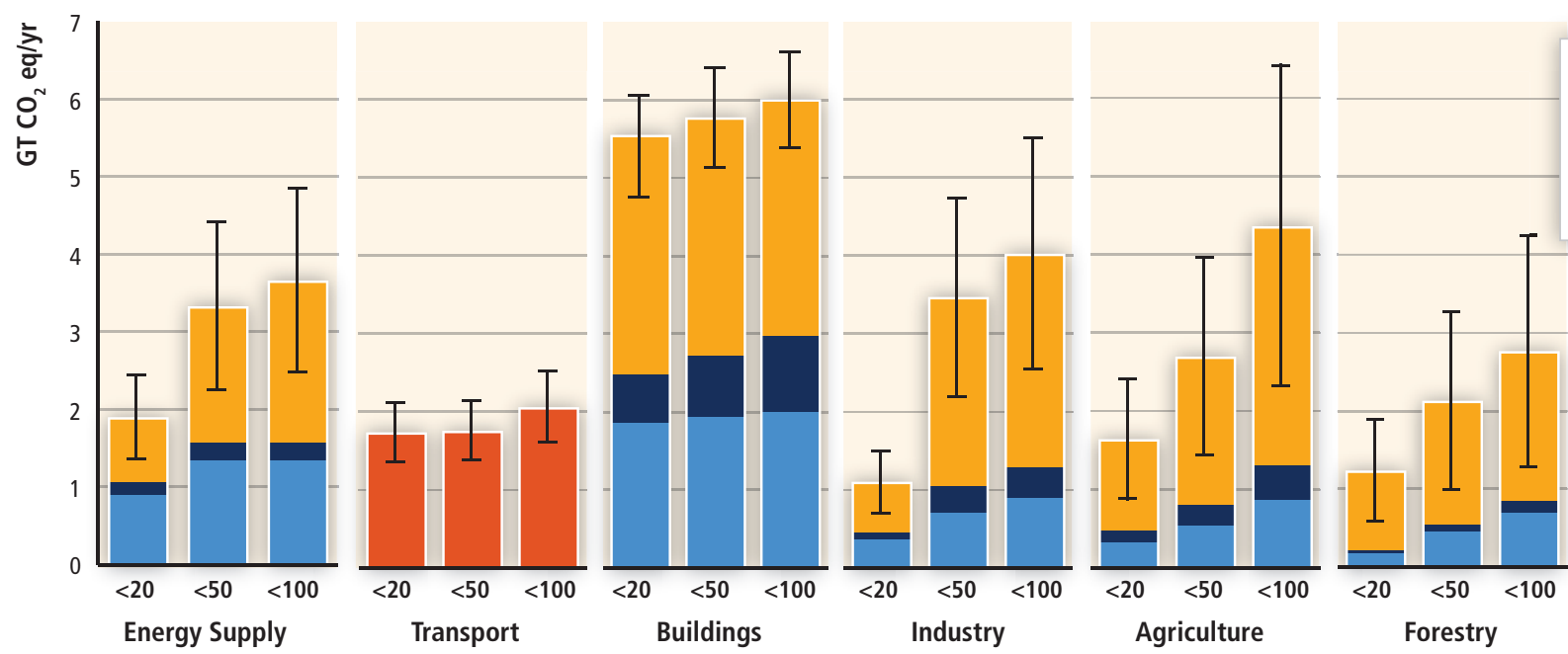

Non-OECD/EIT

EIT

OECD

World total

Figure $\mathbf{8 . 1 2}$ | Estimated economic potential ranges for GHG mitigation in the energy supply and end-use sectors, above the assumed baseline for different regions, as a function of the carbon price in 2030, and based on end-use allocations of emissions including from electricity generation (IPCC, 2007). Regional categories presented here include the entire world, member countries of the Organisation for Economic Co-operation and Development (OECD), Economy In Transition (EIT) countries, and Non-OECD/EIT countries.

competitiveness, more support policies and increased public concerns about the threats of an insecure energy supply and climate change. In the following sections, for each of the transport, residential and commercial building, industry and agriculture/forestry sectors, the current status of RE use, possible pathways to enhance increased adoption, the barriers to integration yet to be overcome, possible future trends and regional variations are discussed.

Ideally, the sectors need to be flexible enough to cope with future integration of the full range of RE systems as these continue to evolve. As market shares increase, competition between RE technologies, as well as with other low-carbon technologies, could result. For example, if domestic solar and geothermal heating systems for individual buildings become more cost competitive, an existing bioenergy district heating scheme supported by the local municipality could become a stranded asset as building owners disconnect. Similarly, at the larger scale, should a new large nuclear or coal-fired power plant with CCS be developed in a region to provide enough capacity to meet the future electricity demands of an energy-intensive industry, then this could compete with investment capital from the industry for developing a local geothermal, bioenergy or hydropower plant and potentially constrain such development for several decades, even where good RE resources exist. Failure to recognize future competition can result in an overestimation of the potential for integration of any single RE technology. Similarly, for road transport, it is uncertain how much investment in infrastructure for biofuel distribution, electric vehicle recharging or hydrogen production and storage will be required, or indeed how these technologies will compete.

\subsubsection{Transport}

Demand for mobility is growing rapidly, with the number of motorized vehicles projected to triple by 2050 (IEA, 2009c). Globally, about 94\% of transport fuels come from petroleum sources, about $70 \%$ of which is traded (EIA, 2010). Decarbonizing and improving the efficiency of the transport sector will be critical for achieving long-term, deep cuts in carbon emissions. The potential exists for a transition by using larger quantities of RE as fuels (IEA, 2009c).

\subsubsection{Sector status and strategies}

In 2008, the direct combustion of oil products for transport accounted for around $18 \%$ of global primary energy use and produced approximately $22 \%{ }^{20}$ of energy-related GHG emissions (IEA, 2009d) and between 5 and $70 \%$ of air pollutant emissions, (varying with the pollutant and region). Of the total transport fuel consumption worldwide in 2008 (around 96 EJ, Figure 8.2), light duty vehicles (LDVs) consumed about half, with heavy duty vehicles (HDVs) accounting for $24 \%$, aviation $11 \%$, shipping $10 \%$ and rail $3 \%$ (IEA, 2009d). Future energy supply security is a serious concern for the sector.

To help meet future goals for both energy supply security and GHG reduction, oil use would need to be substantially reduced over a period of several decades. Many mitigation scenarios (Section 10.2) and other recent studies (C. Yang, 2008; IEA, 2008c; NRC, 2008) suggest that, other than diversifying the primary energy supply, a combination of

$2023 \%$ in 2005 on a well-to-wheel basis. 
approaches will be needed to accomplish 50 to $80 \%$ reductions in transport-related GHG emissions by 2050 (compared to current values) whilst meeting the projected growth in demand (IEA, 2009c). ${ }^{21}$

- Reduction of travel demand. Less total vehicle kilometres travelled might be best achieved by encouraging greater use of car-pooling, cycling and walking, combining trips, or telecommuting. City and regional 'smart growth' practices could reduce GHG emissions as much as $25 \%$ by planning cities so that people do not have to travel as far to work, shop and socialize (Johnston, 2007; PCGCC, 2010).

- Shift to more energy efficient modes (in terms of reduced MJ per kilometre). For example, people could move from LDVs to mass transit (bus or rail) ${ }^{22}$ or freight could be moved from trucks to rail or ships ${ }^{23}$ (IEA, 2009c).

- Improved energy efficiency of vehicles. Reducing vehicle weight, aerodynamic streamlining, and improving the designs of engines, transmissions and drive-trains will continue. Examples include hybrid electric vehicles (HEVs), turbo-charging of internal combustion engines (ICES) and down-sizing of installed vehicle engine power. Electric drive vehicles, employing either batteries or fuel cells, can be more efficient than their ICE counterparts, but the full wellto-wheel efficiency will depend on the source of the electricity or hydrogen (Kromer and Heywood, 2007; NRC, 2008; Section 8.3.1.3). Consumer acceptance of high efficiency drive-trains and lighter cars will depend on a host of factors including vehicle performance and purchase price, fuel price, and advancements in materials and safety. For light commercial trucks where high speeds are not needed, smaller, more efficient engines may be sufficient and could result in lower GHG emissions. In the HDV sub-sector for freight movement, and in aviation, there are also potentially significant energy efficiency improvements (Section 8.3.1.6).

- Replacing petroleum-based fuels with low or near-zero carbon fuels. These include biofuels, electricity or hydrogen produced from lowcarbon sources such as RE, fossil energy with CCS or nuclear power. Other than biofuels, which provided around $2 \%$ of global road transport fuels in 2008 mostly as blends (Section 2.2), alternatives to petroleum-based fuels have had limited success thus far since

21 In IEA scenarios, vehicles become about twice as efficient by 2050. In the Energy Technology Perspectives 'Blue Map' scenario (50\% GHG reduction by 2050), conventional gasoline and diesel-powered LDVs are largely replaced by a portfolio of vehicle drive trains (IEA 2010c). At least half of GHG emission reductions come from a mix of improved efficiency measures and alternative fuels (biofuels, electricity and hydrogen). These account for 25 to $50 \%$ of total transport fuel use in 2050, with liquid biofuels used more extensively in HDVs, aviation and marine applications.

22 Assuming that mass transit is operating at relatively high capacity. On a passenger$\mathrm{km}$ basis, the transport modes with the lowest GHG intensity are rail, bus and twowheel motor bikes, and the highest are LDVs and aviation.

23 For freight, shipping is the lowest $\mathrm{GHG}$ intensity mode on a $\mathrm{tCO}_{2}-\mathrm{km}$ basis, followed by rail, and then HDVs and aviation by at least an order of magnitude higher. the total number of internal combustion engine passenger vehicles (ICEVs) is currently more than $99 \%$ of the global on-road vehicle fleet (IEA, 2009c). Alternative fuels, including electricity for rail, presently represent about 5 to $6 \%$ of total transport energy use (IEA, 2009c). Exceptions include:

- Brazil, where sugar cane bioethanol and some biodiesel supply around $50 \%$ (by energy content) of total transport fuels used for LDVs (IEA, 2007b), representing about $15 \%$ of total energy use (EIA, 2010);

- Sweden, where imported ethanol is being encouraged through taxation policy; and

- The USA where ethanol, derived from corn or imported from Brazil, is currently blended with gasoline up to $10 \%$ by volume in some regions, although it still only accounts for about $3 \%$ of total US transport energy use (EIA, 2010).

Compressed natural gas (CNG) is widely used in LDV fleets mainly in Pakistan, Argentina, Iran, Brazil and India (IANGV, 2009). Liquefied petroleum gas (LPG) is also used in several countries while Sweden is encouraging the use of biomethane for vehicles (IEA Bioenergy, 2010b). ${ }^{24}$ Electricity also makes a contribution to the transport sector in many countries, mostly limited to rail. ${ }^{25}$ The context for alternative fuels is rapidly changing due to secure energy supply, oil price volatility and climate change concerns, and a host of policy initiatives in Europe, North America and Asia are driving towards lower carbon fuels and zero-emission vehicles.

\subsubsection{Renewable fuels and light-duty vehicle pathways}

A variety of more efficient vehicles and/or compatible alternative fuels have been proposed including gasoline and diesel plug-in hybrid electric vehicles (PHEVs), battery electric vehicles (EVs), hydrogen fuel cell electric vehicles (HFCVs) and liquid and gaseous biofuels. Possible fuel/vehicle pathways (Figure 8.13) begin with the primary energy source, its conversion to an energy carrier (or fuel), and then the end use in a vehicle drive train.

This section focuses on how the different RE pathways (including for liquid and gaseous biofuels; Sections 8.2.3, 8.2.4, and 2.6.3) can be integrated into the present transport system. Metrics include cost, GHG emissions from wellto-wheel (WTW), ${ }^{26}$ energy use and air pollutant emissions (Section 9.3.4).

24 In Sweden, 19\% of biogas produced in 2006 was upgraded to biomethane and used in vehicles, but only represented about $1 \%$ of total domestic transport energy use.

25 For Germany as an example, in 2008, surface passenger transport amounted to 1,042 billion person- $\mathrm{km}$ of which roughly $8 \%$ was electric rail transport (DPG, 2010). Several regional rail networks purchase only RE electricity. This includes S-Bahn Hamburg that consequently avoids $60,000 \mathrm{t}$ of $\mathrm{CO}_{2} / \mathrm{yr}$ (www.s-bahn-hamburg.de/s_hamburg/view/aktuell/presse/2009_12_04.shtml).

26 Made up of 'well-to-tank' emissions upstream of the vehicle, plus 'tank-to-wheels' tail-pipe vehicle emissions. 


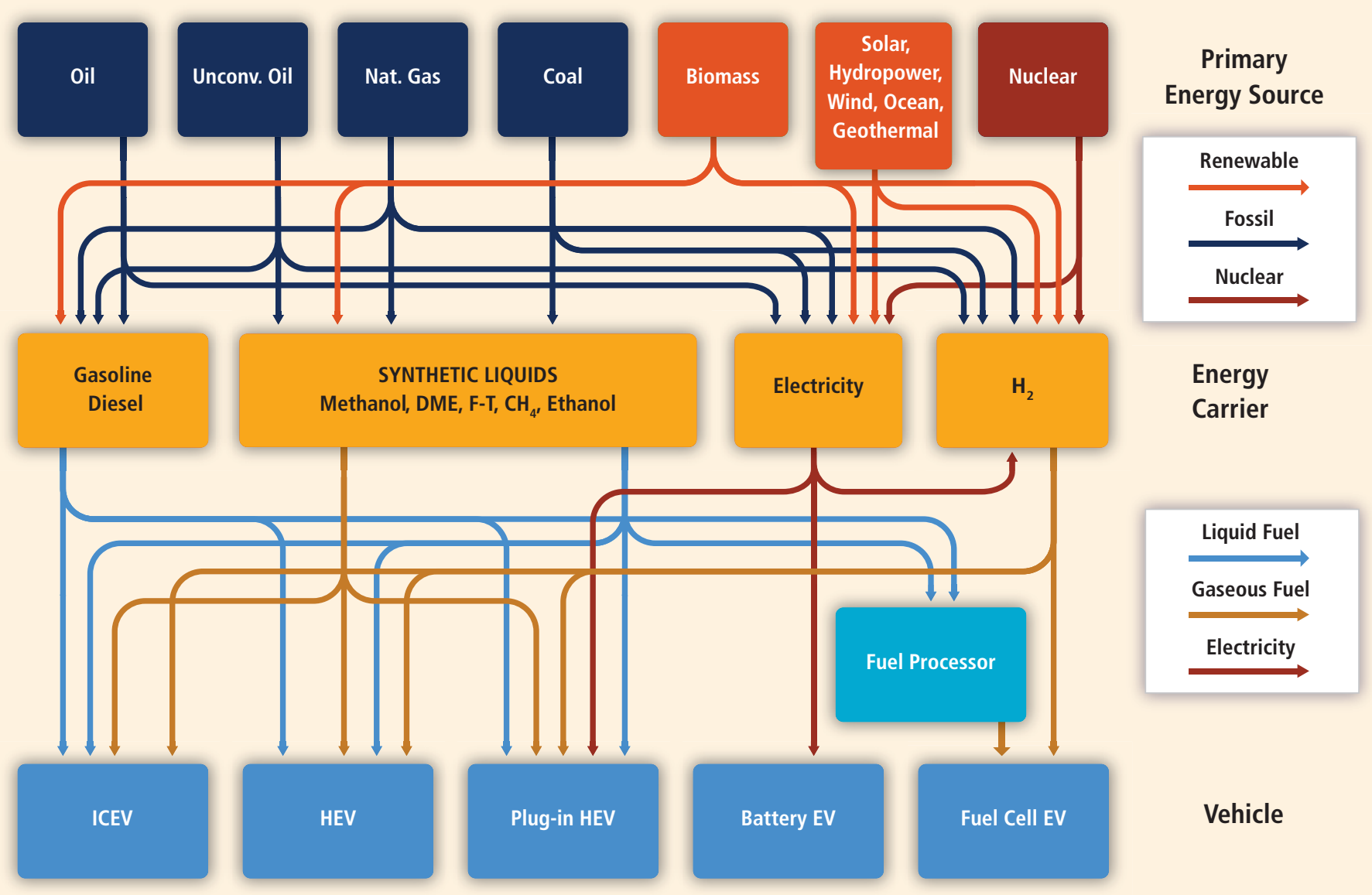

Figure 8.13 | Possible fuel/vehicle pathways from primary energy sources, through energy carriers (yellow, to vehicle end-use drive-train options (with RE resources highlighted in orange).

Notes: F-T= Fischer-Tropsch process. 'Unconventional oil' refers to oil sands, oil shale and other heavy crudes.

Each fuel/vehicle pathway has different environmental impacts, costs and benefits from a life-cycle perspective. WTW analyses (MacLean and Lave, 2003; CONCAWE, 2007; Bandivadekar et al., 2008; L. Wang, 2008) account for all emissions including those associated with primary resource extraction, processing, delivery, conversion to a useful fuel, distribution and dispensing, and vehicle use. Composite sustainable fuel indicators for future transport pathways include a variety of factors in addition to GHG emissions (Zah et al., 2007) such as air quality and a secure energy supply. Sustainability issues, such as land use and water (Section 2.5) may impose further constraints as well as the use of materials. Commercializing new vehicle drive technologies could require large amounts of scarce, hard to access mineral resources. For example, automotive fuel cells require platinum, electric motors require powerful lightweight magnets that may use neodymium and lanthanum (Delucchi and Jacobson, 2009; Margonelli, 2009; Mintzer, 2009), and the most likely next generation of advanced, lightweight, high-energy-density batteries will require lithium. Land use change impacts from biofuel feedstock production are sometimes but not always included (Fritsche et al., 2010; Section 2.5.3). Complementary discussions of these issues are provided in Chapters 2 and 9.

\section{Status and prospects - vehicle technology}

A variety of alternative vehicle drive-trains could use RE-based fuels, including advanced ICEVs using spark-ignition or compression-ignition engines, HEVs, PHEVs, EVs and HFCVs. Several recent studies have assessed the performance, technical status and cost of different vehicle types (CONCAWE, 2007; Kromer and Heywood, 2007; Bandivadekar et al., 2008; IEA, 2009c; Plotkin and Singh, 2009). Fuel economy and incremental costs of alternative-fuelled vehicles based upon these studies have been compared (Figures 8.14 and 8.15 ). Since each study employed different criteria and assumptions for vehicle design, technology status and development time frames (varying between 2010 and 2035), and since not all possible vehicle/fuel pathways were covered in all studies, the results have been normalized to those for an advanced gasoline ICEV, as defined in each study. The relative energy efficiency assumptions for 


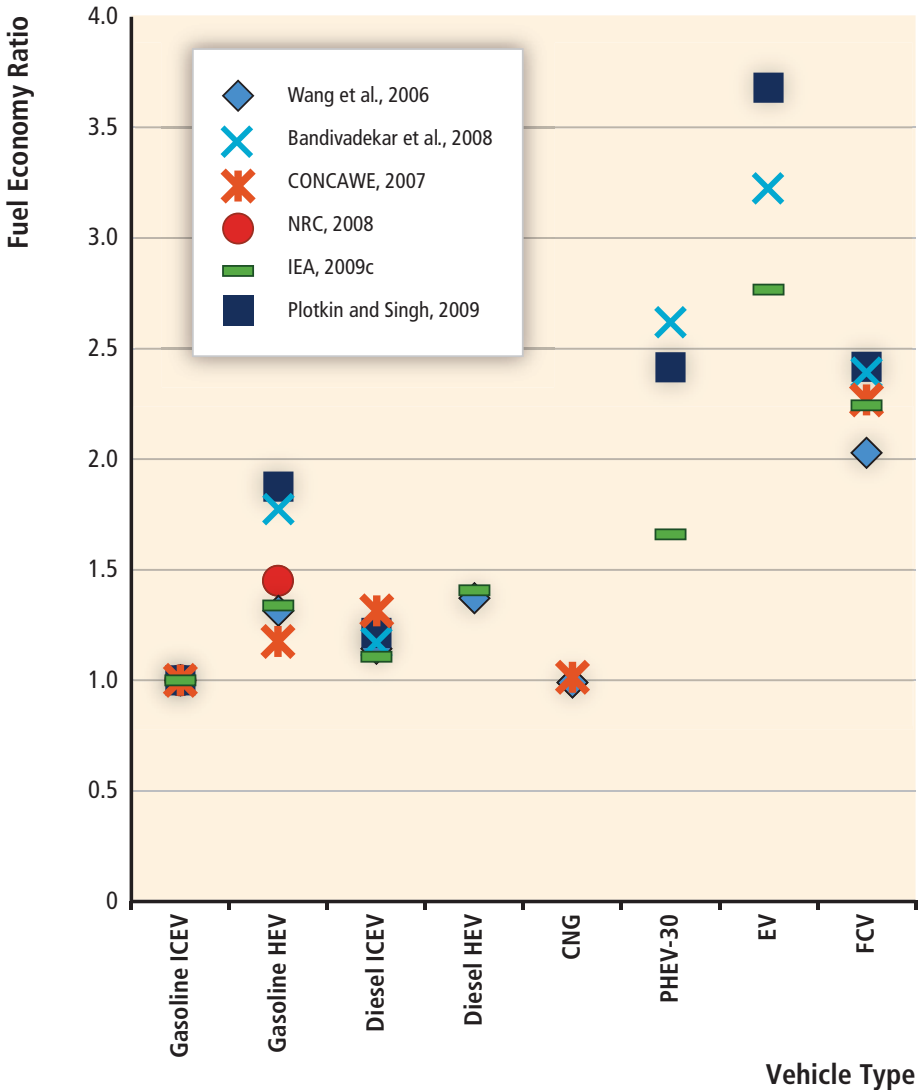

Figure 8.14 | Relative fuel economies of future alternative drive train light duty vehicles compared to advanced spark ignition, gasoline-fuelled, internal-combustion engine vehicles, based on several selected studies.

Notes: The comparative ratios only represent tank-to-wheel energy use. In a full analysis, wellto-tank energy use should also be considered (Section 8.3.1.2) with overall system losses typically 5 to $15 \%$ for gasoline and diesel extraction, refining and delivery; 20 to $80 \%$ for biofuels depending on the type and biomass feedstock; 40 to $80 \%$ for electricity; and 40 to $90 \%$ for hydrogen (M. Wang et al., 2006). Biofuels can be used in gasoline, diesel and hybrid drive train and biomethane in CNG engines. PHEV30 implies a 30 mile all-electric range (also termed PHEV 50km).

different vehicle types also varied, especially for less mature technologies, although the overall findings of all studies were fairly consistent.

Several trends are apparent in fuel consumption of light-duty vehicles:

- There is significant potential to improve fuel economy by adopting new fuels and drivetrains and more advanced engines, improving aerodynamic design of the vehicle and employing lighter weight materials.

- HEVs increase efficiency and improve tank-to-wheel fuel economy of the vehicle by 15 to $70 \%$ over advanced conventional gasoline ICEVs.

- Although still under development and in the demonstration phase, HFCVs may be 2 to 2.5 times more efficient on a tank-to-wheel basis than non-hybrid gasoline ICEVs.

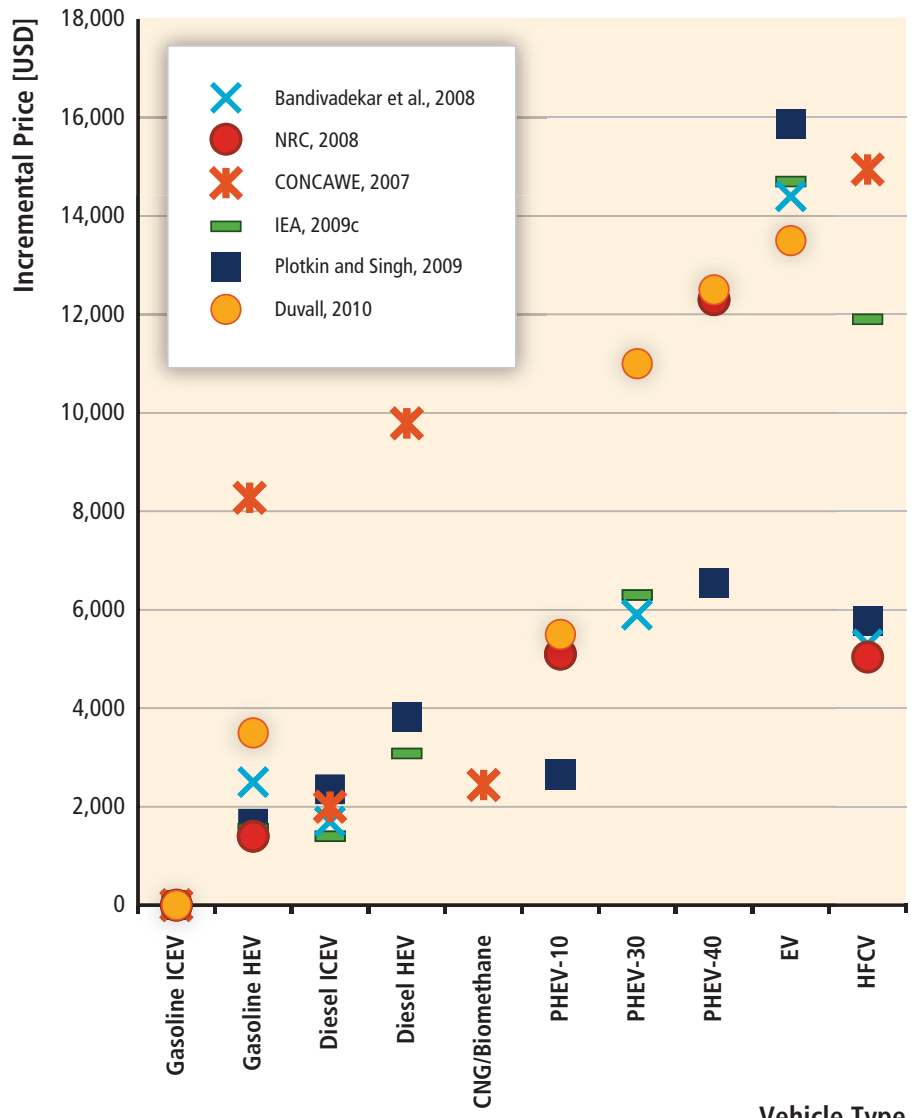

Figure 8.15 | Relative incremental retail price for future mid-sized alternative drive light duty vehicles compared to advanced gasoline, spark ignition, internal combustion engine vehicles as the reference price $(=\$ 0)$.

Notes: The reference gasoline ICEV had a price range of USD 200521,000 to 24,000 as quoted in the various studies. Bandivadekar et al. (2008) gave projections for 2035. NRC (2008) assumed mature technologies with cost reductions due to experience learning and mass production post-2025. CONCAWE (2007) was for 2010 technologies; IEA (2009c) and Plotkin and Singh (2009) were for 2030 technology projections. The pure battery EVs in these studies had an assumed shorter range (typically $320 \mathrm{~km}$ ) compared to the reference gasoline car because of imposed battery weight and cost limits. PHEV-10, -30 and -40 imply the range in miles on electricity only. Biofuels can be used in all gasoline and diesel vehicles.

- EVs could operate around 3 to 4 times as efficiently as gasoline ICEVs on a tank-to-wheel basis, not including electric power generation or oil extraction and processing inefficiencies.

- On a total WTW fuel cycle basis, the relative efficiency improvements for HFCVs and EVs are considerably less when electricity generation and hydrogen production losses are included.

- Losses related to electricity generation, transmission and distribution range between 40 and $80 \%$, depending on the source of power and transmission distance. A similar loss range occurs for hydrogen production, depending on the 
primary energy source, conversion technology and distribution infrastructure.

- In general, the higher the fuel economy, the higher the vehicle price (assuming similar size and performance).

- There is uncertainty in the fuel economy and cost projections, particularly for HFCVs and EVs that are not yet commercially produced at high volumes.

\subsubsection{Transition pathways for renewable energy in} light-duty transport

Historically, major changes in transport systems, such as building canals and railroads, paving highways and adopting gasoline cars, have taken many decades to complete for several reasons.

- Passenger vehicles have relatively long lifetimes: 15 years average in the USA (Davis et al., 2010), 10 to 13 years in EU countries (Christidis et al., 2003), 11 to 13 years in Japan (M. Wang et al., 2006) and 16 years in China (M. Wang et al., 2006). Even if a new technology rapidly moved to $100 \%$ of new vehicle sales, it would take many years for the present vehicle stock to 'turn over'. In practice, adoption of new vehicle technologies occurs slowly and can take 25 to 60 years for an innovation to be used in 35\% of the on-road fleet (Kromer and Heywood, 2007). For example, research into gasoline HEVs in the 1970s and 1980s led to a decision to commercialize only in 1993 with the first vehicle becoming available for sale in 1997 in Japan. More than 13 years later, HEVs still represent only about $1 \%$ of new car sales ${ }^{27}$ and less than $0.5 \%$ of the worldwide fleet (although low oil prices during part of this period were a possible factor). This slow turnover rate is also true for relatively modest technology changes such as the adoption of automatic transmissions, intermittent windscreen wipers and direct fuel injection (Kromer and Heywood, 2007; Bandivadekar et al., 2008). The time frame for new technologies relying on batteries, fuel cells or advanced biofuels could be even longer since they all need further RD\&D investment and international standardization before they can become fully commercialized. Further cost reductions may also be needed to achieve wide customer acceptance.

- Changing fuel supply infrastructure, especially if switching on a major scale from liquids to gaseous fuels or electricity, will require a substantial amount of capital and take many decades to complete (IEA, 2009c; Plotkin and Singh, 2009). Developing new supply chains for RE and replacing existing fossil fuel systems will take time and require close coordination among fuel suppliers, vehicle manufacturers and policymakers.

27 In Japan adoption has been more rapid, with roughly $8 \%$ of the new car market in 2009 captured by HEVs.
Each fuel/vehicle pathway faces its own transition challenges that can vary by region. In terms of technology readiness of fuels and vehicles, challenges include infrastructure compatibility, consumer acceptance (costs, travel range, refuelling times, reliability and safety concerns), primary resource availability for fuel production, life-cycle GHG emissions, and environmental and sustainability issues including air pollutant emissions and competing demands for water, land and materials.

Millions of vehicles capable of running on liquid biofuels or biomethane are already commercially available in the global fleet. The cost, weight and life of present battery technologies are the main barriers to both EVs and PHEVs but the vehicles are undergoing rapid development, spurred by recent policy initiatives worldwide. Several companies have announced plans to commercialize them within the next few years, albeit in relatively small numbers initially (tens of thousands of vehicles per year) and at higher retail prices than comparable vehicles, even with proposed subsidies. Electric two-wheel motor-bikes and scooters are a large and fast-growing market in the developing world, especially in China with 20 million annual sales in 2007 (Kamakaté and Gordon, 2009). They have significant potential for fuel efficiency improvements and GHG reductions. HFCVs have been demonstrated, but are unlikely to be fully commercialized until at least 2015 to 2020 due to barriers of fuel cell durability and cost, on-board hydrogen storage and hydrogen infrastructure availability and cost. The timing for commercializing each technology is discussed in Section 8.3.1.4.

\section{Liquid biofuel pathways}

Biofuels are generally compatible with ICEV technologies and many vehicle owners already regularly choose liquid biofuels and blends, whereas only a small fraction of vehicles are adapted to run on gaseous fuels (CNG, LPG or hydrogen). Most of the existing gasoline and diesel ICEV and HEV fleet, however, can only operate on relatively low fraction biofuel blends. Blends above $10 \%$ by volume of ethanol or $5 \%$ of biodiesel risk possible adverse effects on some engine designs and in some cases, higher air pollution levels. Over 22 million flexible fuel vehicles (FFVs), including motor bikes, have been designed to use either $100 \%$ gasoline or blends of ethanol between E20 and E100 in Brazil (Section 8.2.4.6), up to E85 in the USA and Canada, and up to E75 in Sweden under winter conditions. The incremental cost to produce an FFV is estimated to be only USD ${ }_{2005} 50$ to 100 per vehicle, so in many cases, manufacturers offer these vehicles at the same price as a comparable gasoline ICEV (EPA, 2010).

Biomass can be converted into liquid fuels using many different routes (Section 2.3.3). First generation processes are commercially available and second generation and more advanced processes, aiming to convert non-food, cellulosic materials and algae, are under development (Section 8.2.4). Advanced biofuels have potential for lower WTW GHG emissions than some first generation and petroleum-derived fuels, but these technologies are still several years from market (Sims et al., 2008) (Section 2.6.3). 
An advantage of liquid biofuels is their relative compatibility with the existing liquid fuel infrastructure and ease of blending with petroleumderived fuels (Section 8.2.4.1). In Brazil, for example, FFV users select their fuel blend based on price. Reduced vehicle range and fuel economy when using ethanol and, to a lesser extent, biodiesel, can also be a factor in consumer acceptance.

Primary biomass resource availability from sustainable production (Fritsche et al., 2010) can be a serious issue for biofuels. Recent studies (IEA, 2009c; Plotkin and Singh, 2009) have assessed the potential for biofuels to displace petroleum products. Environmental and land use concerns could limit production to 20 to $30 \%$ of total transport energy demand or about 35 to $50 \mathrm{EJ} / \mathrm{yr}$ of biofuel in 2050 (IEA, 2008e) though this remains under debate (Section 2.6.3). Given that certain transport sub-sectors such as aviation and marine require liquid fuels, it may be that biofuels will be used primarily for these applications (IEA, 2008c), whilst electric drive train vehicles (EVs, PHEVs or HFCVs), if successfully developed and cost effective, might eventually dominate the LDV sector.

\section{Biomethane pathways}

Biogas and landfill gas produced from organic wastes and green crops (Section 2.3.3) can be purified by stripping out the $\mathrm{CO}_{2}$ (to give greater range per storage cylinder refill) and any $\mathrm{H}_{2} \mathrm{~S}$ (to reduce risk of engine corrosion) (Section 8.2.3.3) to provide biomethane. Various pathways include injection into existing natural gas distribution systems (Section 8.2.3) or direct use in ICEVs, mainly with spark-ignition engines designed or converted to run on biomethane using similar modifications as for CNG.

\section{Hydrogen/fuel cell pathways}

Hydrogen is a versatile energy carrier that can be produced in several ways (Section 8.2.3). WTW GHG emissions vary for different hydrogen fuel/vehicle pathways, but both RE and fossil hydrogen pathways can offer reductions compared to gasoline vehicles (Section 8.3.1.4).

Although hydrogen can be burned in a converted ICEV, more efficient HFCV s are attracting greater RD\&D investment by engine manufacturers. Many of the world's major automakers have developed prototype HFCVs, and several hundred of these vehicles, including cars and buses, are being demonstrated worldwide. HFCVs are currently very costly, in part because they are not yet mass produced. Fuel cell lifetimes are also relatively short. It is projected that the costs of HFCVs will fall with further improvements resulting from $R \& D$, economies of scale from mass production, and learning experience (NRC, 2008).

HFCVs could match current gasoline ICEVs in terms of vehicle performance and refuelling times. The maximum range of present HFCV designs of LDVs is acceptable at around $500 \mathrm{~km}^{28}$ but hydrogen refilling

28 Some demonstration HFCVs have significantly higher ranges. The latest demonstration Toyota HFCV has 70 MPa compressed gas storage and achieves a range of 790 km under optimum conditions (www.cleanenergypartnership.de). availability and the high cost of both vehicle and fuel remain key barriers to consumer acceptance. Hydrogen is not yet widely distributed to consumers in the same way as gasoline, diesel and, depending on the market, electricity, natural gas and biofuels. Bringing hydrogen to large numbers of vehicle owners would require building a new refuelling infrastructure over several decades (Section 8.2.3.5). Hydrogen and fuel cells exhibit the 'chicken and egg' problem that vehicle makers will not introduce hydrogen cars until refuelling stations are in place, and fuel providers will not build refuelling stations until there are enough cars to use them. A solution is to introduce the first hydrogen vehicles and stations in a coordinated fashion in a series of demonstration projects (Gronich, 2006; CAFCP, 2009; Nicholas and Ogden, 2010).

Hydrogen can be produced regionally in industrial plants or locally onsite at vehicle refuelling stations or in buildings. The first steps to supply hydrogen to HFCV test fleets and demonstrate refuelling technologies in mini-networks have been constructed in Iceland, California, Germany and elsewhere. ${ }^{29}$ System-level learning from these programmes is valuable and necessary, including development of safety codes and standards. In the longer term, in the USA for example, a mix of low-carbon resources including natural gas, coal (with CCS), biomass and wind power could supply ample hydrogen (NRC, 2008). The primary resources required to provide sufficient fuel for 100 million passenger vehicles in the USA using various gasoline and hydrogen pathways have been assessed (Ogden and Yang, 2009). Enough hydrogen could be produced from wind-powered electrolysis using about $13 \%$ of the technically available wind resource. However, the combined inefficiencies of producing the hydrogen via electrolysis from primary electricity sources, then converting it back into electricity on a vehicle via a fuel cell, loses more than $60 \%$ of the original RE inputs. Electricity would be used more efficiently in an EV or PHEV but hydrogen might be preferred in large vehicles requiring a longer range and faster refuelling times.

Hydrogen production and delivery pathways have a significant impact on the cost to the consumer. In addition, compared to industrial uses, fuel cell grade hydrogen needs to be $>99.99 \%$ pure and generally compressed to 35 to $70 \mathrm{MPa}$ before dispensing. Using optimistic assumptions in the near-term, hydrogen at the pump might cost around USD $_{2005} 7$ to $12 / \mathrm{kg}$ excluding taxes, potentially decreasing to USD $_{2005}$ 3 to $4 / \mathrm{kg}^{30}$ over time (NRC, 2008). However, estimates range from about USD 8 to $10 / \mathrm{kg}$ for dispensed hydrogen produced from natural gas reforming and about USD 10 to 13/kg for hydrogen from electrolysis using grid electricity (NREL, 2009). RE electricity may increase the electrolyzed hydrogen cost. Given the potential higher efficiency of fuel cell vehicles, the fuel cost per kilometre could eventually become competitive with ICEVs (Kromer and Heywood, 2007; NRC, 2008).

29 These include the GermanHy project (Bonhoff et al., 2009), Norway's Hynor project (www.hynor.no), the California Fuel Cell Partnership (www.fuelcellpartnership.org), Japan's Hydrogen and Fuel Cell Demonstration Project (www.nedo.go.jp), the European Clean Energy Partnership (www.cleanenergypartnership.de) and the EU Fuel Cells and Hydrogen - Joint Undertaking (ec.europa.eu/research/fch).

$301 \mathrm{~kg}$ of hydrogen at $120.2 \mathrm{MJ}$ (lower heat value) has a similar energy content to 1 US gallon (3.78 litres) of gasoline. 
Several studies (Gielen and Simbolotti, 2005; Gronich, 2006; Greene et al., 2007; NRC, 2008) indicated that cost reductions were needed to bring down fuel cell vehicles to market clearing prices (through technological learning and mass production). In addition, to build the associated infrastructure over several decades could cost hundreds of billions of dollars (Section 8.2.3.5). The majority of this cost would be for the incremental costs of early hydrogen vehicles, with a lesser amount needed for early infrastructure. Even at high oil prices, government support policies may most likely be needed to subsidize these technologies in order to reach cost-competitive levels and gain customer acceptance.

\section{Electric and hybrid vehicle pathways}

$\mathrm{EV}$ drive trains are relatively efficient as is battery recharging as a way to store and use RE electricity. Combined EV efficiencies (motor/controller 90 to $95 \%$; battery charge/discharge efficiencies $~ 90 \%$ ) for electric plugto-battery output-to-motor, are of the order of 81 to $86 \%$ (Kromer and Heywood, 2007), although electricity generation from primary energy sources including transmission and distribution losses is typically only 20 to $60 \%$ efficient (Graus et al., 2007; IEA, 2008c).

EV use is currently limited to neighbourhood and niche fleet vehicles, from golf carts to buses. There are also a limited number of operating passenger and light truck EVs that were sold by GM, Ford, Toyota, Honda and others during the 1990s and early 2000s. Limited commercialization of new designs of EVs and PHEVs is underway partly in response to policy measures (Kalhammer et al., 2007) with several automobile manufacturers making niche initial offerings. In Japan, Mitsubishi Motors and Fuji Heavy Industry launched EVs in 2009 and Nissan launched a model in 2010. GM has launched a PHEV in the USA and Toyota began road testing pre-commercial Prius PHEVs in 2010.

Today's lithium batteries cost USD 700 to 1,000/kWh (194 to 278 USD/ $\mathrm{MJ})$, three to five times the goal needed for an EV to compete with gasoline vehicles on a life cycle cost basis. The main transition issue is to bring down the cost and improve the performance of advanced batteries. Demonstrated lifetimes for advanced lithium battery technologies are presently only 3 to 5 years, whereas, ideally, a 10-year minimum life is required for automotive applications (Nelson et al., 2009).

For RE electricity to effectively serve growing EV markets, several innovations would need to occur, such as having flexibility in the charging schedule to reflect varying RE generation outputs (and possibly by encouraging off-peak charging at night) and optimizing peak-time charging loads. Additional power generation and distribution capacity would then not necessarily be needed and there may be an adequate temporal match with wind, solar or hydropower resources. Flexible grids, interconnections, energy storage etc. (Section 8.2.1) may also be ways to help control and balance vehicle recharging demands when using variable RE resources. In addition, upgrading the distribution grid to include smart meters and RE technologies could manage the added load (IEA, 2009b).
Public acceptance of EVs is yet to be demonstrated, but one attraction is that they can often be recharged at home, thereby avoiding trips to the refuelling station. However, home recharging would require new equipment that only 30 to $50 \%$ of households and apartments in the USA would be able to conveniently install (Kurani et al., 2009). Therefore a public recharging point infrastructure would need to be developed in some areas. Recharger technology costs vary with different levels.

- 'Level 1' home overnight charging, using a standard domestic plug socket at $110 \mathrm{~V}$ (e.g., in the USA) or $240 \mathrm{~V}$ (e.g., in Europe), could take several hours, compared with the quick refill time possible with liquid or gaseous fuels and the recharging system might cost USD ${ }_{2005}$ 700 to 1,300 to install (USDOE, 2008b).

- 'Level 2' charging could take less time but would require a specialized higher power outlet and cost USD 800 to 1,900 to install.

- 'Level 3' fast-charge outlets at publicly accessible recharging stations might bring batteries to near full charge after only 10 to 15 minutes, faster than level 1 or 2 charging technologies, but taking more time than refilling an ICEV. They would costs tens of thousands of dollars for each recharging point.

An EV can have a range of 200 to $300 \mathrm{~km}$ under good conditions compared with a similar size ICEV of 500 to $900 \mathrm{~km}$ (Bandivadekar et al. 2008). While this range is adequate for $80 \%$ of car trips in urban/suburban areas, long distance EV travel would be less practical. This could be overcome by owners of small commuter EVs using rental or community cooperative car share HEVs or PHEVs ${ }^{31}$ for longer journeys (IEA, 2009b).

The added vehicle cost for PHEVs, while still significant, is less than for a similar size EV and the range is comparable to a gasoline HEV. One strategy could be to introduce PHEVs initially while developing and scaling up battery technologies for EVs. This could help lead to more costcompetitive EVs. However, HEVs will always be cheaper to manufacture than PHEVs due to their smaller battery capacity. Any advances in battery technologies will apply to HEVs as well as to PHEVs and EVs.

\subsubsection{Comparisons of alternative fuel/vehicle pathways}

WTW GHG emissions differ, depending on the fuel/vehicle pathway. For petroleum fuels, most of the emissions are 'tank-to-wheels' and take place at the vehicles. The GHG emissions and environmental benefits of EVs depend on the marginal grid mix and the source of electricity used for vehicle charging. For PHEVs the source of electricity also impacts the life cycle GHG emissions (Figure 8.16) but to a lesser degree. With the current US grid being $45 \%$ dependent on coal, WTW emissions from

31 Community car sharing cooperatives exist in many cities in Europe, having started in Switzerland and Germany in 1987, and are now growing in North America (www. carsharing.net and www.cooperativeauto.net/). 


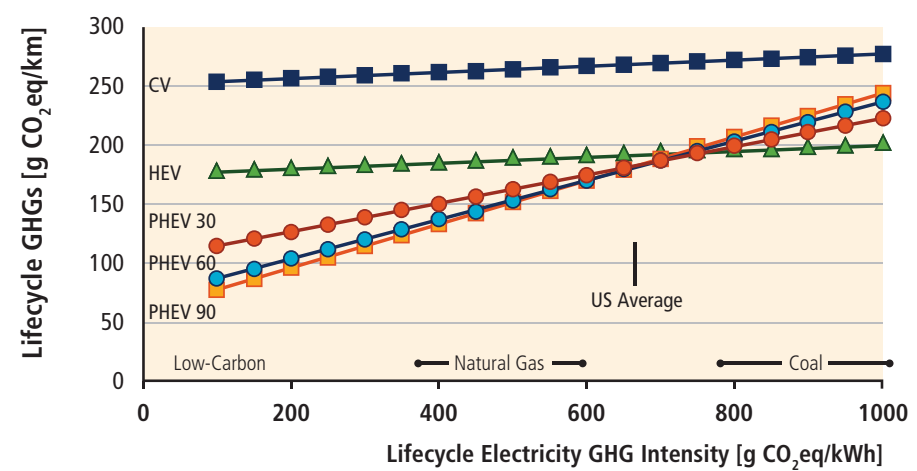

Figure 8.16 | Life cycle GHG emissions (excluding land use change) from a range of light duty vehicle types as a function of the GHG emission intensity of electricity generation systems using coal, natural gas or low-carbon technologies including nuclear and RE (Samaras and Meisterling, 2008).

Notes: The slight slopes of the conventional gasoline vehicle (CV) and HEV lines reflect the GHG emission intensity of the electricity used during production of the vehicles. Generation options correspond to various GHG intensities and provide insight into the impact of different generation mixes. For example, a 'low-carbon' portfolio could include nuclear, wind and coal with CCS. The vertical line at $670 \mathrm{~g} \mathrm{CO}_{2}$ eq/ $/ \mathrm{kWh}\left(186 \mathrm{CO}_{2}\right.$ eq/MJ) indicates the current US average life cycle GHG intensity. PHEV-30, -60, and -90 imply all-electric vehicle range in miles.
EVs would give only around 20 to $40 \%$ GHG emission reduction over efficient gasoline vehicles (Figure 8.17). By way of contrast, the French electric grid with a major share from nuclear power, or the Norwegian system dependent on hydropower, would give relatively low-carbon WTW emissions (Zgheib and Clodic, 2009).

For electricity and hydrogen, all emissions are 'well-to-tank' and the vehicle itself has zero GHG emissions except in the manufacturing process. For RE biofuel pathways, carbon emissions at the vehicle are partially offset by carbon uptake from the atmosphere by future biomass feedstocks. The degree of this offset is uncertain because of indirect land use issues (Searchinger et al., 2008; Fritsche et al., 2010; Section 2.5).

Various studies have developed scenarios for decarbonizing electricity grids over the next few decades (Sections 8.2.1 and 10.2), which would result in reduced WTW emissions for EVs, HEVs and PHEVs (EPRI, 2007; IEA, 2009c). Using larger fractions of RE or other low-carbon electricity, WTW emissions would, over time, become smaller than they are in many regions at present. EVs, having zero tailpipe emissions, can also reduce urban air pollution. However, if the electricity is produced

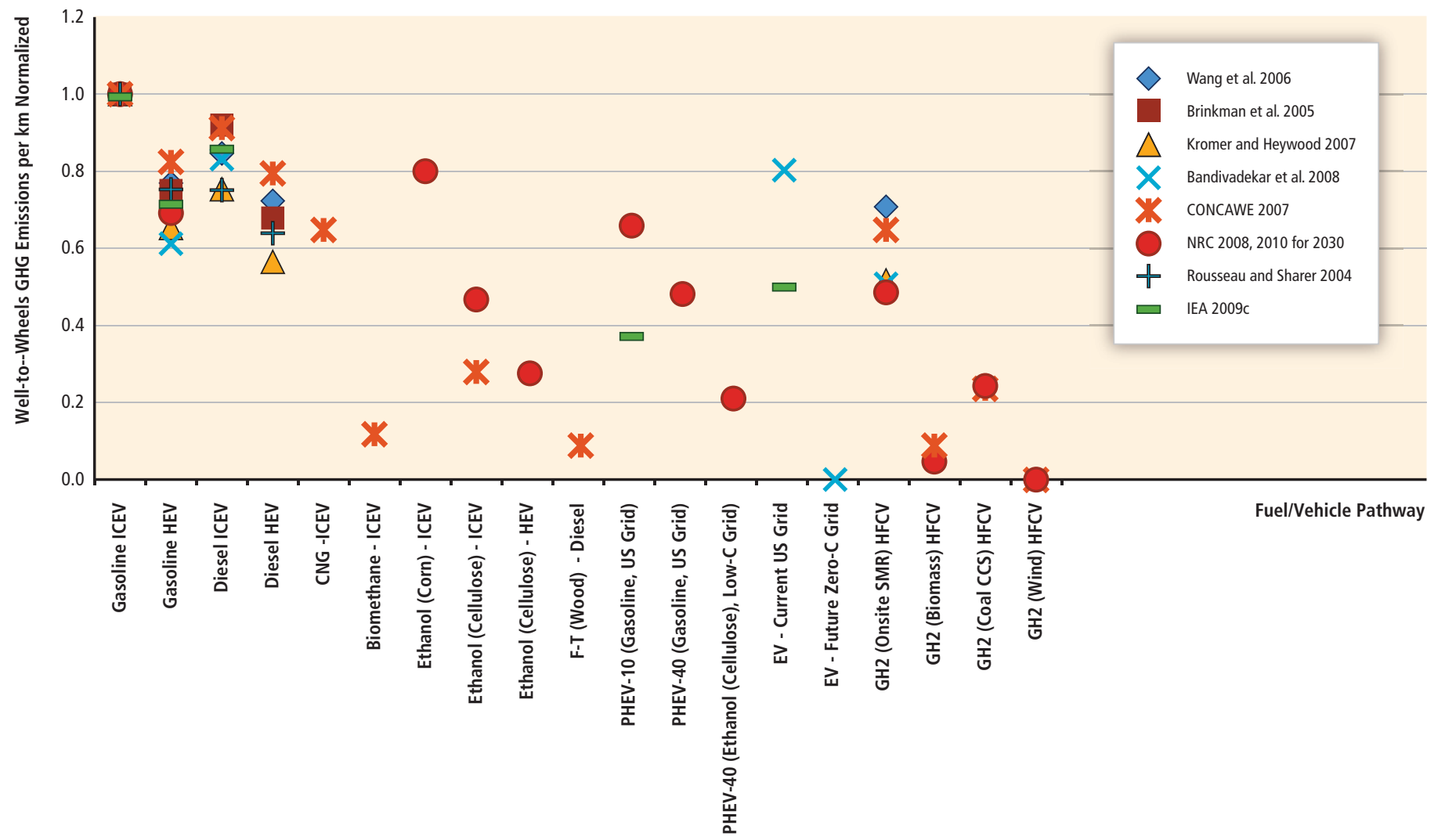

Figure 8.17 Well-to-wheels GHG emissions per kilometre travelled from selected studies of alternative light duty fuel/vehicle pathways, normalized to the GHG emissions value of a gasoline internal combustion engine light duty vehicle (ICEV) but excluding land use change, vehicle manufacturing, and fuel supply equipment manufacturing impacts.

Notes:WTW GHG emissions per kilometre for the gasoline ICEV reference vehicle ('Gasoline ICEV' = 1 on the y-axis) were normalized to the average emissions taken from the gasoline ICEV in each study, which ranged from 170 to $394 \mathrm{gCO}_{2} / \mathrm{km}$. For all hydrogen pathways, hydrogen is stored onboard the vehicle as a compressed gas $\left(\mathrm{GH}_{2}\right)$.

SMR = steam methane reformer. 
from an uncontrolled source (such as coal plants without particulate scrubbers), one source of pollution might simply be substituted for another but in a different location (Kromer and Heywood, 2007; Bandivadekar et al., 2008).

Making a transition to new fuels and types of vehicles is a complex process involving technology, cost, infrastructure, consumer acceptance and environmental and resource impacts. Transition issues vary for biofuels, hydrogen and electric vehicles. Biofuels have a clear start and could grow rapidly over the next decade (Section 2.8), but over the longer term, no one option is seen to be a clear 'winner' and all will take several decades to achieve large RE shares of the transport market.

\subsubsection{Low-emission propulsion and renewable energy} options in other transport sectors

\section{Heavy duty vehicles}

Globally, HDVs, consisting mainly of freight trucks and long-haul tractortrailers, account for about $24 \%$ of transport-related energy use and a similar fraction of GHGs (IEA, 2009c). Other HDVs include buses and off-highway vehicles such as agriculture and construction equipment. As is the case for LDVs, several strategies can reduce fuel consumption and GHG emissions such as by:

- Partially switching to lower carbon fuels;

- Switching freight from trucks to more energy efficient modes such as rail and inland waterways;

- Streamlining operational logistics for handling freight and using GPS routing technology to avoid empty return trips; and

- Further increasing vehicle efficiency, perhaps by up to 30 to $40 \%$ by 2030 (IEA, 2009c), through more advanced engines, exhaust gas energy recovery (via advanced turbo-charging or turbo-compounding), hybrid vehicles (which may include either electric or hydraulic motors), weight reduction, lower rolling resistance tyres, use of aerodynamic technologies on the tractor and trailer, longer trains of more than one trailer, more efficient driving behaviour, optimized automatic gear shifting, speed reduction, and use of more efficient auxiliary power units (APUs) used when decoupled from the power train.

Presently, about $85 \%$ of freight-truck fuel is diesel, with the remainder being gasoline. Integrating biofuels into the fuel mix would be the most straightforward RE option. Second generation biofuels could become a more significant blend component in diesel fuel for trucks, possibly reaching as high as 20 to $30 \%$ by 2050 (IEA, 2008c). Due to the range and resulting fuel storage requirements for long-haul HDVs, the use of other lower-carbon fuel options such as CNG, LPG, compressed biomethane, hydrogen (for either HFCVs or ICEVs) or electricity would likely be limited to urban or short-haul HDVs, such as refuse trucks, delivery trucks and buses. ${ }^{32}$ LNG might become an option for freight transport though it faces the key hurdles of limited driving range and lack of refuelling infrastructure. For example, an LNG truck could travel around $600 \mathrm{~km}$ between refuelling, only around half the range of some diesel trucks. The additional weight of onboard LNG tanks can pose constraints for vehicle payloads. For urban fleets where more stringent air pollution controls and a common refuelling site exist, LNG may be viable for applications such as refuse trucks (EIA, 2010). Another potential use of low-carbon hydrogen or electricity might be to power onboard fuel cell APUs or charge batteries, although neither of these options is yet cost effective. Trucks could also plug into an electrical energy source at a truck stop to run their accessories, but the GHG reduction benefit would depend on the carbon footprint of the local electricity source.

The reduction of fuel consumption and GHG emissions in HDVs may be more difficult than for LDVs due to more limited weight reduction potential, slower vehicle turnover, faster growth in vehicle kilometres travelled (VKT), less discretionary freight movement, and inherent economic drivers that continuously aim to minimize HDV operating costs. Many HDVs are purchased for fleet operations, so there could be an opportunity to integrate alternative fuels and vehicles by providing fleet-wide support for new fuelling infrastructure, technology maintenance and, if needed, driver training. According to the IEA's baseline scenario (IEA, 2008c), HDV energy use by 2050, even with improved energy efficiency of about $20 \%$, is projected to increase by $50 \%$ due to double the current quantity of worldwide freight moved by trucks, mostly in non-OECD countries.

\section{Aviation}

Aviation energy demand accounts for about $11 \%$ of all transport energy and this could double or triple by 2050 (IEA, 2009c). Rapid growth of aviation emissions is due to the increase of air traffic volumes for both passenger and freight, with aviation usually having the highest energy and GHG intensity of all transport modes. About $90 \%$ of fuel use and GHG emissions occur in flight, mostly at cruising altitude (TRB, 2009). Efficiency improvements can play an important role in reducing aviation energy use by 30 to $50 \%$ in future aircraft designs compared with 2005 models (IEA, 2009c). These include improved aerodynamics, airframe weight reduction, higher engine efficiency, as well as improvements in operation and air traffic control management to give higher load factors, improved routing, and more efficient ground operations at airports (including gate electrification and use of low carbon-fuelled service vehicles) (TRB, 2009). A slow average fleet turnover of around 30 years (IEA, 2009c; TRB, 2009) will delay the penetration of advanced aircraft designs. Although reductions in energy use per passenger-km or per cargo tonne-km can be substantial, they are unlikely to be able to completely offset the expected increase in GHG emissions arising from higher demand for air freight and passenger transport.

32 An electric bus with a range of $200 \mathrm{~km}$ and recharged daily from $50 \mathrm{kWe}$ of solar PV panels installed on the roof of the bus station, has been operating in Adelaide since 2009 (IEA, 2009b) 
Aircraft will continue to rely mainly on liquid fuels due to the need for high energy density fuels in order to minimize fuel weight and volume. In addition, due to safety, the fuels need to meet more stringent requirements than for other transport modes, including thermal stability (to assure fuel integrity at high engine temperatures and to avoid freezing or gelling at low temperatures), specific viscosity, surface tension, ignition properties and compatibility with aircraft materials. Compared to other transport sectors, aviation has less potential for switching to lower carbon footprint fuels due to these special fuel requirements. In terms of $R E$, various aircraft have already flown test flights using various biofuel blends, but significantly more processing is needed than for road fuels to ensure that stringent aviation fuel specifications are met. Standards to allow greater biofuel blend fractions into conventional aviation fuel are currently under development. Industry and policy views on biofuels as a share of total aviation fuels by 2050 range from a few percent up to $30 \%$ (IEA, 2009c).

Liquid hydrogen is another long-term option, but faces significant hurdles due to its low volumetric energy density. Fundamental aircraft design changes would be needed to accommodate cryogenic storage, and airports would have to construct a hydrogen distribution and refuelling infrastructure. The most likely fuel alternatives to conventional jet fuel are therefore synthetic jet fuels (from natural gas, coal or biomass) since they have similar characteristics. Net carbon emissions will vary depending on the fuel source.

\section{Maritime}

Marine transport, the most efficient mode for moving freight, currently consumes about $9 \%$ of total transport fuel, $90 \%$ of which is used by international shipping (IEA, 2009c). Ships rely mainly on heavy fuel ('bunker') oil, but lighter marine diesel oil is also used. Heavy fuel oil accounts for nearly $80 \%$ of all marine fuels (IEA, 2009c). Its combustion releases sulphates that in turn create aerosols that may actually mitigate GHG impact by creating a cooling effect, though this will decline as ever more stringent air quality regulations aimed at reducing particulate emissions through cleaner fuels will require lower-sulphur marine fuels in the future. An expected doubling to tripling of shipping transport by 2050 will lead to greater GHG emissions from this sector.

Due to a fragmented industry where ship ownership and operation can occur in different countries, as well as a slow fleet turnover with typical ship replacement occurring about every 30 years (IEA, 2009c), energy efficiency across the shipping industry has not improved at the same rate as in the HDV and aviation sectors. Hence, significant opportunities exist to reduce fuel consumption through a range of technical and operational efficiency measures (IEA, 2009d; TRB, 2009) including improvements in:

- Vessel design (e.g., larger, lighter, more hydro-dynamic, lower drag hull coatings);

- Engine efficiency (e.g., diesel-electric drives, waste heat recovery, engine derating);
- Propulsion systems (e.g., optimized propeller design and operation, use of sails or kites);

- More efficient and lower GHG APUs; and

- Operation (e.g., speed reduction, routing optimization, better fleet utilization, reduced ballast).

These measures could potentially reduce energy intensity by as much as 50 to $70 \%$ for certain ship types (IEA, 2009c).

The key application of RE in marine transport could be through the use of biofuels. Existing ships could run on a range of fuels, including blends of biodiesel or lower quality fuels such as unrefined bio-crude oil produced from pyrolysis of biomass (Section 2.3.3). Engines would probably need to be modified in a manner similar to HDV road vehicles in order to operate reliably on high (80 to $100 \%$ ) biofuel blends. Other RE and low-carbon options could include the use of on-deck hybrid solar PV and micro-wind systems to generate auxiliary power; solar thermal systems to provide hot water, space heating or cooling; wind kites for propulsion; and electric APU systems plugged into a RE grid source while at port. Although nuclear power has been used for decades by some navies, as well as ice breakers and a handful of other ships, widespread marine use would require large investments, demand for specialized crews and the need to deal with complex legal and security concerns. As a result, onboard nuclear marine power appears to be an unlikely and limited alternative for commercial ship propulsion (TRB, 2009).

\section{Rail}

Rail transport accounts for only about 3\% of global transport energy use, but by 2050 , rail freight volume is expected to increase by up to $50 \%$ with most of this growth occurring in non-OECD countries (IEA, 2009d). Rail moves more freight and uses an order of magnitude less energy per tonne-kilometre than road HDVs due to its much higher efficiency (IEA, 2009c). Rail transport is primarily powered by diesel fuel, especially for freight transport. However, electrification is increasing and accounted for $31 \%$ of global rail sector energy use, including both freight and passenger transport, in 2006 (IEA, 2009c). In certain economies including OECD Europe, the Former Soviet Union and Japan, over $50 \%$ of the rail sector is electric. Growth in high-speed electric rail technology continues rapidly in Europe, Japan, China and elsewhere. As with shipping, the use of high-sulphur fuels has helped to mitigate net GHG emissions due to the negative radiative forcing effect of sulphates, but this trend has other negative environmental consequences and will likely decline with stricter clean fuel regulations.

Rail sector efficiency increases of up to 20 to $25 \%$ are possible (IEA, 2009c; TRB, 2009) including:

- Upgrading locomotives to more efficient diesel engines, hybrids and APUs;

- Increasing load factors by reducing the empty weight of the rolling stock, lengthening trains and using double-stacked containers; and 
- Operational improvements such as operator training, optimized logistics and reduced idling.

The two primary pathways for RE penetration in rail transport are through increased use of biodiesel, which may account for 2 to $20 \%$ of rail fuel use in 2050 (IEA, 2009d) and a further shift towards electrification. Compared to their diesel counterparts, all-electric locomotives can improve life cycle efficiency by up to $15 \%$, (though less improvement if compared to a diesel hybrid-electric drive system that includes battery storage). GHG emissions can be further reduced as electricity generation switches to RE, nuclear power and fossil fuels with CCS. Although the use of hydrogen fuel cells may be limited due to range, energy storage and cost issues, the challenges for installing fuel cells on locomotives appear to be fewer than for passenger HFCVs. Compared with LDVs, a rail system provides more room for hydrogen storage, offers economies of scale for larger fuel cell systems and uses the electric traction motors already installed in diesel-electric locomotives.

\subsubsection{Future trends for renewable energy in transport}

The most important single trend facing the transport sector is the projected high growth of the road vehicle fleet worldwide, which is expected to triple from today's 700 million LDVs by 2050 (IEA, 2008c). Achieving a low-carbon, sustainable and secure transport sector will require substantial vehicle technology advancements and public acceptance of these new vehicles and alternative fuels, strong policy initiatives, monetary incentives, and possibly the willingness of customers to pay additional costs for fuels and vehicles. There is scope for RE transport fuel use to grow significantly over the next several decades, playing a major role in this transition.

In the future, a wider diversity of transport fuels and vehicle types is likely. These could vary by geographic region and transport sub-sector. For applications such as air and marine, liquid fuels are currently the only practical large-scale option. In the LDV sector, increased use of electric drive-train technologies has already begun, beginning with HEVs, and potentially progressing to PHEVs and EVs as well as possibly to HFCVs (IEA, 2008c). Historically, the electric and transport sectors have been developed separately, but, through grid-connected $E V s$, they are likely to interact in new ways by charging battery vehicles, or possibly 'vehicle-to-grid' electricity supply (Section 8.2.1; McCarthy et al., 2007).

Environmental and secure energy supply concerns are important motivations for new transport systems but sustainability issues may impose constraints on the use of alternative fuels or new vehicle drive trains. Understanding these issues will be necessary if a sustainable, low-carbon future transport system is to be achieved. Meeting future goals for GHG emissions and secure energy supplies will mean displacing today's ICEVs, planes, trains and ships with higher efficiency, lower
GHG emission designs, switching to more efficient modes of transport and ultimately adopting new low- or zero- carbon fuels that can be produced cleanly and efficiently from diverse primary sources. There is considerable uncertainty in the various technology pathways, and further RD\&D investment is needed for key technologies (including batteries, fuel cells and hydrogen storage) and for RE and low-carbon production methods for the energy carriers of biofuels, hydrogen and electricity.

Recent studies (IEA, 2008b, 2009d) see a major role for RE transport fuels in meeting future societal goals, assuming that strict carbon limits are put in place. Given uncertainties and the long timeline for change, however, it may be important to maintain a portfolio approach that includes behavioural changes (to reduce VKT), more efficient vehicles and a variety of low-carbon fuels. This approach may help recognize that people ultimately make vehicle purchase decisions, and that different technologies and fuel options will need to fit their various situations and preferences.

Present transport fuels and vehicle engine technologies represent sunk investments that, with experience and economies of scale, have progressed down their respective technological learning curves over the past century. Therefore, new alternative fuels and technologies are naturally disadvantaged (Section 11.11). Making the hydrogen, biofuel or electricity energy carriers more cost effective, efficient and reliable is one condition for providing RE for transport. Subsidies, tax exemptions and fuel standard exemptions for alternative fuel vehicles all have an impact on future market shares. To enable electricity or hydrogen from RE fuels to power transport vehicles, incentives such as low electricity prices relative to gasoline, carbon charges, subsidized low-carbon electricity and first-cost vehicle subsidies could be necessary to make EVs, PHEVs and HFCVs viable options (Avadikyan and Llerenaa, 2010). Policies could specifically provide incentives for infrastructure development that might enable biofuel production, trade and blending at high levels, public recharging of $\mathrm{EVs}$, and hydrogen production and distribution. However, at this stage, it is not possible to determine which of these options will become dominant and should therefore receive the bulk of such incentives.

\subsubsection{Buildings and households}

Decarbonization of the building sector ${ }^{33}$ can result from integration of RE in electric power systems (Section 8.2.1), heating and cooling networks (Section 8.2.2) and gas grids (Section 8.2.3) or by installing RE technologies onsite directly integrated into the building structure (Figure 8.1). RE deployment in a building can be combined with energy efficiency measures and encouraging energy conservation through education and behavioural change of the occupants (Pehnt et al., 2009a).

33 The 'building sector' is defined here as the combination of the 'residential' sector, the 'commercial and public services' sector and the 'non-specified' sector as segregated for IEA data. 


\subsubsection{Sector status}

The building sector in 2008 accounted for about $92 \mathrm{EJ}$, or $32 \%$ of total global final energy consumption (IEA, 2010b; Figure 8.2). Around 4 EJ $( \pm 15 \%)$ of this total consumer energy was from combustion of around $31 \mathrm{EJ}$ of traditional biomass for cooking and heating, assuming efficiency of combustion was around 15\% (Section 2.1). Excluding this biomass, the residential sector consumed over half the total building energy demand followed by the commercial and public service buildings that slightly increased their share of the total since 1990 (IEA, 2010b). GHG emissions from the building sector, including through electricity use, were about $8.6 \mathrm{Gt} \mathrm{CO}_{2}$ in 2004 with scope for significant reduction potential mainly from energy efficiency ${ }^{34}$ (IPCC, 2007; IEA, 2009b).

Projections of energy demand for the building sector by region can vary considerably as a result of different assumptions of population growth rates, household numbers and service sector activity in each country. In OECD countries, decreasing energy use for heating buildings in $O E C D$ countries is expected as a result of energy efficiency and other policies (IEA, 2010b). For example, the EU Energy Performance of Buildings Directive, May 2010, demands that "member states shall ensure that by 2020, all new buildings are nearly zero-energy buildings" (EC, 2010). By contrast, non-OECD countries, as a result of significantly faster growing populations and increased average standard of building stock, will be faced with a potentially very large growth in energy demand, particularly for cooling. However, assuming stringent energy efficiency policies under the IEA 450 Policy Scenario, by 2035 the total sector demand could rise by only $25 \%$ above current levels to 116 EJ (Figure 8.2).

\section{A broad typology of the building sector includes}

- Commercial buildings and high-rise apartment buildings in mega-cities;

- Small towns of mainly attached and detached dwellings;

- Historic quarters;

- New urban subdivision developments;

- Wealthy suburbs;

- Poor urban areas; and

- Small village settlements in developing countries that have limited access to energy services.

The composition of age class of the building stock of a country influences its future energy demand, especially for heating and cooling. Many buildings in developed countries have average life spans of 120 years and above, hence energy efficiency measures and the integration and deployment of RE technologies will need to result mainly from the retrofitting of existing buildings. Developing countries currently have stock turnover rates of 25 to 35 years on average with relatively high new building construction growth (IEA, 2010d), therefore offering good opportunities to integrate RE technologies through new building designs.

34 Full details of the potential for energy efficiency and RE in the building sector were provided in Chapter 6 of the IPCC 4th Assessment Report - Mitigation (Levine et al., 2007).
Energy service delivery systems for residential and commercial buildings vary depending on the energy carriers available, local characteristics of a region and its wealth. To support the basic human requirements, livelihoods and well-being of the people living and working in buildings in both developed and developing countries, the appliances used in these buildings provide a variety of basic energy services including for:

- Space heating, water heating, cooking;

- Cooling, refrigeration;

- Lighting, electronic and electrical appliances;

- Water pumping and waste treatment.

For both residential and commercial buildings, RE energy carriers and service delivery systems vary depending on the local characteristics of a region and its wealth (Section 9.3). In order to curb GHG emissions from the sector a combination of approaches are likely to be needed.

\section{Reducing energy demand for heating and cooling}

Whereas heating loads are generally large in OECD countries and economies in transition, in most developing countries, energy for cooling is often a higher demand. For both heating and cooling, the design of a building can contribute to lowering the energy demand. A UK regulation that began in the London Borough of Merton (IEA, 2009b) requires new building developers to integrate RE technologies to meet $10 \%$ of total energy demand. This has resulted in energy efficient building designs being constructed in order to minimize the additional costs of RE to meet the regulation and exemplifies the links between RE and efficiency. Where heat loads dominate, passive designs (that receive natural solar heat gain in winter and/or avoid excessive heating in summer), optimization of window surfaces, and insulation levels can contribute to reducing the demand for heating as well as facilitating natural lighting (see Chapter 3). In warm climates where cooling loads dominate, adapting bio-climatic principles of traditional designs to new building stock, such as extensive shading and natural ventilation, can contribute to decreasing energy demand.

\section{Improving efficiency of appliances}

Improved energy efficient designs of systems and appliances, such as gas condensing boilers, heat pumps, district heating from CHP plants (Section 8.2.2), electronic appliances when on standby, light-emitting diodes (LEDs) and compact fluorescent light bulbs (CFLs), can contribute to reduced energy demand. Since the life span of such technologies is relatively small compared with the building itself, policies to encourage uptake of energy efficient appliance designs can be key to achieving $\mathrm{CO}_{2}$ reductions in the short term. In dwellings currently without access to electricity even for basic lighting (Lighting Africa, 2010), installing RE technologies such as small PV systems or micro-hydropower can be relatively expensive. So electricity demand should be minimized by use of energy efficient appliances such as LEDs and CFLs. Improved energy use and energy management systems in residential and commercial buildings continue to be found through R\&D investment (Figure 8.18). For example, smart appliances that use less energy, and operate 


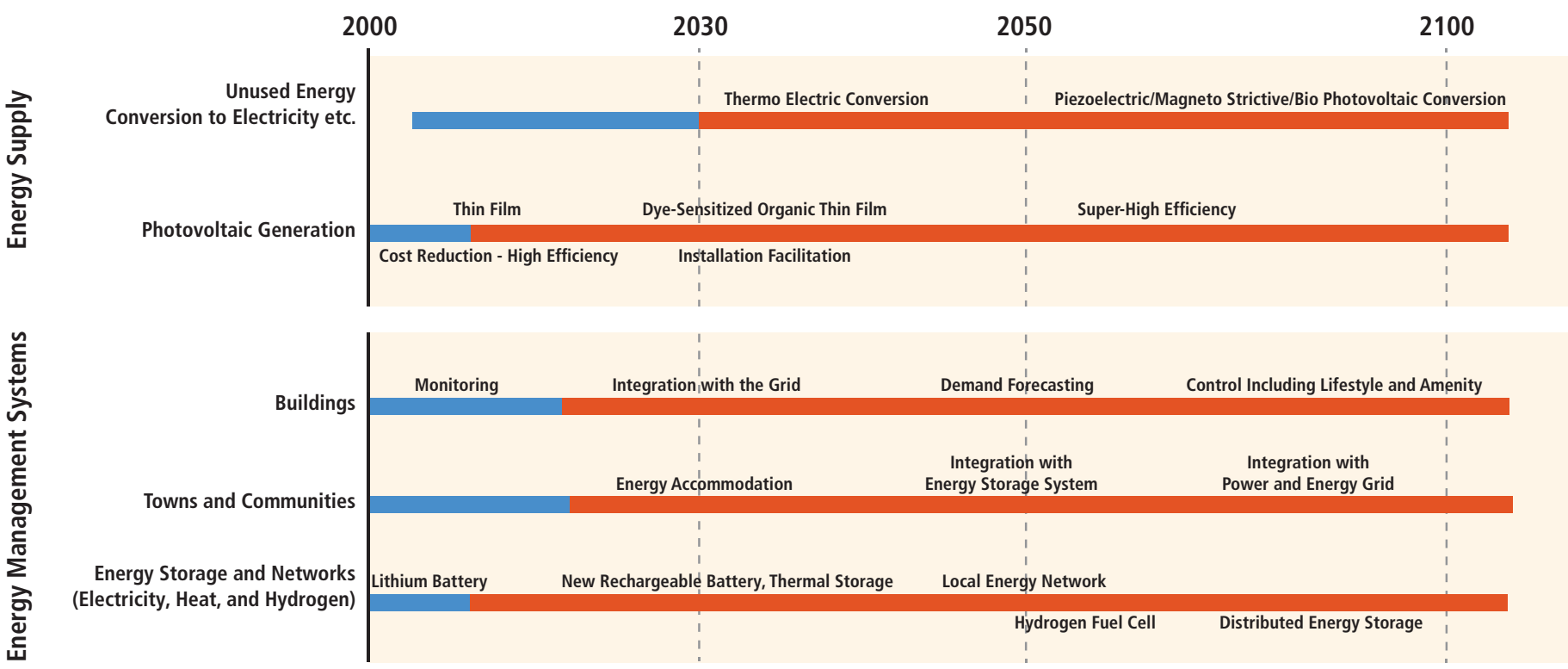

Figure 8.18 | Technology development pathways in Japan for future energy efficiency and RE technologies for use in residential and commercial buildings (METI, 2005).

automatically at off-peak times for use with future 'intelligent' electricity networks (Cheung and Wilshire, 2010), are beginning to reach the market.

\section{Building management}

An energy manager of a commercial or multi-unit apartment building is usually responsible for multiple objectives including the integration of RE as well as managing energy use, providing comfort for those living or working in the building, and reducing environmental impacts, all for minimal cost. Various building energy management systems and controls have been developed to balance these multiple objectives (Dounis and Caraiscos, 2009). Measuring and monitoring both energy use and the building environment are usually required (Figure 8.18) (Wei et al., 2009). Monitoring techniques can also be deployed in apartment buildings with home energy management standard technologies installed to control and actuate appliances as part of a distributed energy network.

\section{RE technology deployment}

Low or near-zero carbon fuels from modern biomass, geothermal and solar thermal currently supply around 3.5 to $4.5 \mathrm{EJ} / \mathrm{yr}$, or about 6 to $8 \%$ of the total global heating demand for buildings (excluding traditional biomass) (IEA, 2007c). The share of RE for heating and cooling building space has the potential to be significantly increased in many regions using a range of new and improved RE technologies including cost-competitive and efficient enclosed pellet and other biomass stoves, heat pumps using low temperature heat available from ambient energy sources ${ }^{35}$ (IEA, 2007c), solar thermal and PV systems, solar cooling systems and hybrid technologies such as combining solar thermal with biogas boilers, heat pumps or PV systems.

Policies to encourage the greater deployment of RE heating/cooling systems are not common, but several successful national and municipal

35 Ambient heat energy can be extracted from air, surface water or the ground (also referred to as shallow geothermal energy). approaches are in place (IEA, 2007c; Section 11.5.4). Electricity generated from RE sources is already widely utilized by the building sector. Increasing shares (Sections 8.2.1 and 10.3) could result in reduced sector GHG emissions (as could the use of electricity from the increased uptake of nuclear and CCS low-carbon supply side technologies). For air-tight, single-residential, multi-residential or commercial building designs, high energy demands for forced ventilation can be reduced through appropriate selection and hybridization of RE power generation, solar chimneys and wind cowls (Antvorskov, 2007). An innovative transition pathway to help decarbonize heat demand consists of using thermal storage systems that can also aid the balancing of variable electricity supplies (Hughes, 2010).

\subsubsection{Renewable energy and buildings in developed countries}

For any building class category in any given region, RE strategies and associated RE technical options can be developed based on the characteristics of the present or planned buildings, the building energy demand as a result of climatic conditions, and the RE resources available. This section examines the options to integrate RE into the built environment of developed countries. Following are options for urban (Section 8.3.2.3) and rural (Section 8.3.2.4) areas of developing countries. These contrasting situations face very different opportunities and challenges when endeavouring to accelerate RE uptake.

In the OECD and other major economies, most urban buildings are connected to electricity, water and sewage distribution schemes, and some to DHC schemes (Section 8.2.2). Many also use electricity, natural gas or LPG for heating and cooking, giving greater convenience to residents than using coal or oil products to provide these services. Woody biomass is also used for space and water heating, normally in efficient enclosed 
stoves more than open fires, but the fuel requires more handling and storage space than coal or oil with greater energy densities. Wood pellet stoves are therefore becoming popular, in part due to their operating convenience and the greater energy density of pellets compared to firewood logs (Section 2.3.2.1). Other RE conversion technologies such as solar water heaters and ground source heat pumps often have simple economic payback periods of five years or longer. Nevertheless, their integration in buildings is expanding in order to improve the quality of life of the residents whilst simultaneously realizing low carbon emission ambitions and security of future energy supplies (IEA, 2009b).

\section{Challenges caused by RE integration}

Greater integration of RE into the built environment is directly dependent on how urban planning, architectural design, engineering and a combination of technologies can be integrated. Tools and methods to assess and support strategic decisions for planning new building construction and retrofits are available (Doukas et al., 2008), including computer simulations to project the outcomes of a planning strategy (Dimoudi and Kostarela, 2008; Larsen et al., 2008). Therefore, to achieve more rapid RE deployment in the building sector of a city, town or municipality in an OECD country:

- A new vision for urban planning could be produced, based on the available RE energy resources;

- New buildings could be designed to accommodate the RE technologies for them to generate heat and electricity onsite rather than be consumers of imported energy as at present; and

- Assessments of the economic and non-economic barriers to RE technology deployment could be made and the need for supporting policies considered.

A transition from a fossil fuel-based, centralized energy supply system to a more distributed energy system with increased RE integration would need a comprehensive revision of how urban space has been traditionally planned and occupied. Changes in land and resource use, as well as modifying planning regulations to better accommodate RE technologies with the existing energy supply, are major strategic amendments that could be made to shape their integration.

The greater deployment of RE resources in an urban environment (IEA, 2009b) may require innovative use of roof and wall surfaces of the buildings to facilitate the uptake of RE technologies. This would affect the orientation and height of buildings in order to gain better access to solar radiation and wind resources without shading or sheltering neighbouring installations. Local seasonal storage of excess heat using ground source heat pumps may also contribute, along with more efficient bioenergy systems such as novel small-scale CHP systems that can run on natural gas or biogas (NZVCC, 2008; Aliabadi et al., 2010).

The technical challenges of integrating variable and distributed RE power and heat generation (Sections 8.2.1 and 8.2.2) can be partly resolved by the smart use of appliances in buildings. Technological advances can assist the integration of RE into the built environment, including energy storage technologies, real-time smart meters, demand side management and more efficient systems. Advanced electricity meters with bi-directional communication capability and the use of related information technologies interfacing with intelligent technology for appliances are expected to be widely deployed to gain the benefits of demand response and energy storage (possibly including electric vehicles in the future) in combination with distributed generation (NETL, 2008) (Section 8.2.5). If properly managed, appliances could contribute to maintaining the supply/demand balance of the energy system especially at higher penetration levels of variable RE sources. For some cities and towns, this could also require adaptation of the local electricity (Section 8.2.1) and/ or heating/cooling distribution (Section 8.2.2) grids.

Without regulatory policies, efforts to improve energy efficiency and utilize RE sources are largely dependent on the motivation of building owners and occupiers. Institutional and financial measures such as energy auditing, appliance labelling, grants, regulations, incentives and automatic billing systems can lead to increased deployment (Section 11.5). Many buildings are leased to their occupiers, leading to the conundrum of owner/tenant benefits, also known as the 'split-incentive' (IEA, 2007d). Investing in energy efficiency or RE integration by the building owner usually benefits the tenants so that return on investment has to be recouped through higher rents.

\section{Options to facilitate RE integration}

New buildings in both hot and cold regions have demonstrated that 'importing' energy for heating or cooling can be minimized by innovative passive heating/cooling building designs, adequate insulation and thermal sinks. Building codes are steadily being improved to encourage the uptake of such technologies, so that new, well-designed buildings in future will require little, if any, heating or cooling using imported energy (EC, 2010). Many new building designs already demonstrate these passive solar concepts, but they remain a minority due to slow stock turnover.

Due to long life spans and low turnover rates, existing buildings can be retrofitted to significantly reduce their heating and cooling demand using energy efficient technologies such as triple glazing, cavity wall and ceiling insulation, shading and white painted roofs (Akbari et al., 2009; Oleson et al., 2010). The lower the energy consumption that the inhabitants of a building require to meet comfort standards and other energy services, then the more likely that RE can be employed to fully meet those demands (IEA, 2009b). RE tends to have a low energy density and often high capital investment costs, so reducing the energy demand by efficiency measures can help reduce the initial investment needed to meet the total energy demand of the building (Section 8.3.2.1).

Solar thermal and solar PV technologies can be integrated into building designs as components (such as roof tiles, wall facades, windows, balcony rails etc.). Innovative architects are beginning to incorporate such concepts into their designs. Integration of solar PV panels into 
roofs, window overhangs, and walls during construction can replace the function of traditional building materials and possibly improve building aesthetics relative to non-building-integrated solutions. Losses occurring during electricity distribution from centralized power stations can also be avoided.

In future, distributed energy systems could supply clusters of buildings on industrial estates or new residential developments using locally generated RE heat and power or RE-produced hydrogen for use in fuel cells at small to medium urban scales (Liu and Riffat, 2009). If sufficient heat and power is produced to meet local demands, any excess electricity or heat can be 'exported' off-site to gain revenue (IEA, 2009b). Bioenergy CHP combustion linked with steam engines, gas turbines and other conversion technologies is being undertaken at both medium ( $>50 \mathrm{MWe}$ ) and small $(<5 \mathrm{kWe})$ scales, with ongoing research into fuel cells and other micro-CHP systems (Leilei et al., 2009).

\section{Case study: RE house in Bruxelles, Belgium.}

Among many buildings that have been retrofitted to enable high RE penetration levels for meeting their heating, cooling and electricity demands, the 'Renewable Energy House' in Bruxelles is a good example (EREC, 2008). Opened in 2006, it now houses the headquarters of the European
Renewable Energy Council and fifteen RE industry associations. The aims of refurbishing the meeting facilities and offices of this historic, 120-yearold, 2,800- $\mathrm{m}^{2}$ building were to reduce the annual energy consumption for heating, ventilation and air conditioning by $50 \%$ compared to a similar size reference building, and to meet the remaining energy demand for heating and cooling using solely RE sources (Figure 8.19). Key elements of the heating system are two biomass wood pellet boilers of $85 \mathrm{~kW}$ and $15 \mathrm{~kW}, 60 \mathrm{~m}^{2}$ of solar thermal collectors (half being evacuated tubes and half flat plates), and four $115 \mathrm{~m}$ deep geothermal borehole loops in the courtyard connected to a $24 \mathrm{~kW}$ ground source heat pump (GSHP) also used in summer for cooling. Most cooling, however, comes from a 35 kW capacity (at 7 to $12^{\circ} \mathrm{C}$ ) solar absorption cooler driven by relatively low-temperature solar heat $\left(85^{\circ} \mathrm{C}\right)$ and a little electrical power for the controls and pumps.

In winter, the heating system mainly relies on the GSHP and the pellet boilers since the solar contribution is low. However, when available, any solar heat reduces the pellet fuel consumption since both are used to heat the same water storage tank. The GSHP operates on a separate circuit with borehole loops that absorb any excess low-grade summer heat and thus serve as a seasonal heat storage system. In summer, since high solar radiation levels usually coincide with cooling demands, the solar

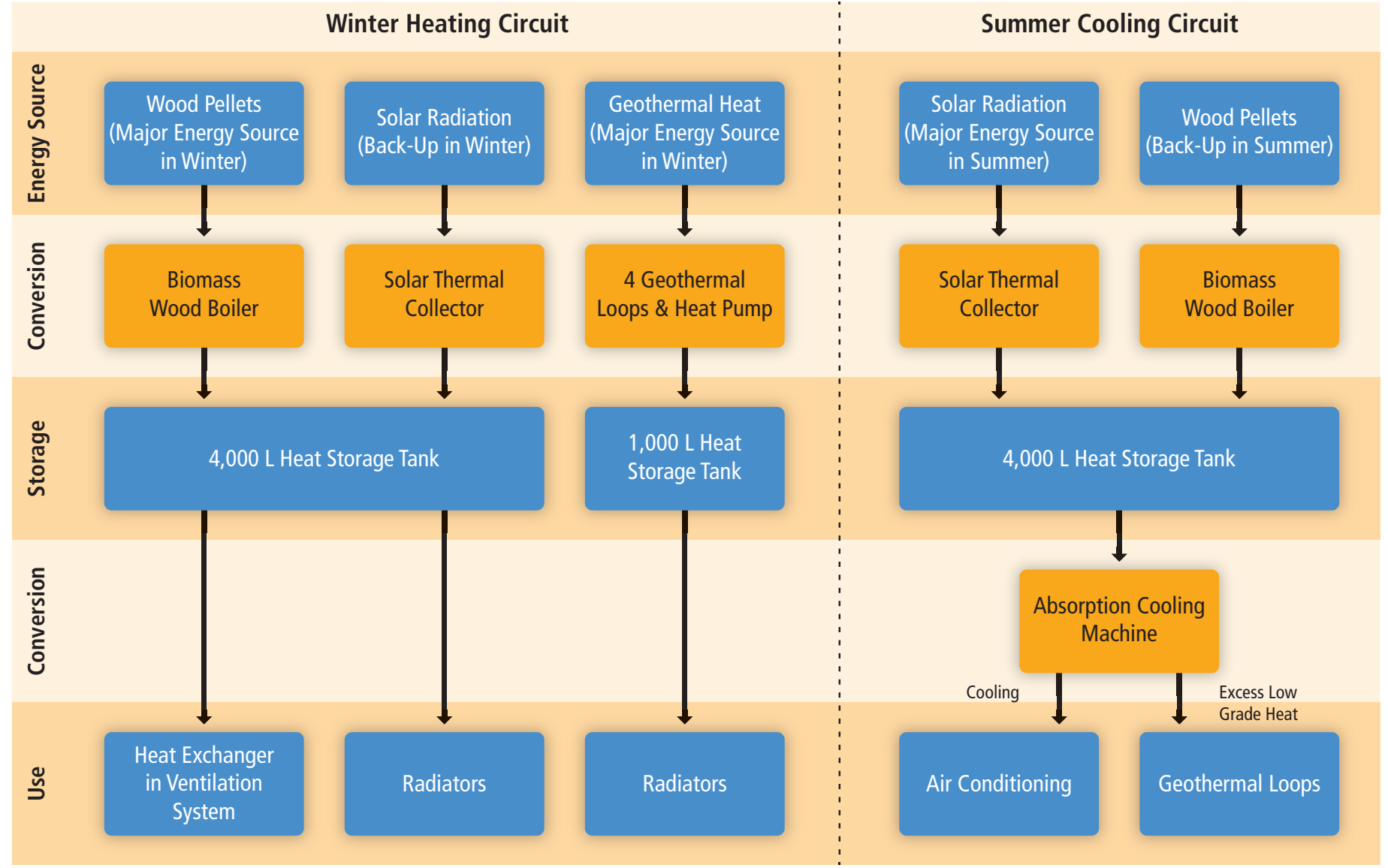

Figure 8.19|RE integrated heating and cooling systems installed in a 120-year-old urban building in Bruxelles converted to commercial offices prior to the retrofit (EREC, 2008). 
absorption cooler provides most of the cooling (backed up on cloudy days by heat from the biomass boiler). The thermally driven process of solarassisted cooling is complex, being based on a thermo-chemical sorption process or a thermally driven open cooling cycle (IEA, 2009b). The technologies have not been widely applied and need more RD\&D investment to gain reliability and sufficient cost reductions in order that they might compete with other cooling technologies such as heat pumps.

\subsubsection{Renewable energy and urban settlements in developing countries}

Urban energy consumption patterns of the more wealthy households in many developing countries resemble those of developed countries (Section 8.3.2.1). However, many poor urban households in low-income countries still rely mainly on collecting or purchasing traditional biomass that for many will probably remain their common fuel source for many years. In sub-Saharan Africa and elsewhere, many urban areas are experiencing a transition from burning fuelwood on open fires and small stoves to cleaner-burning charcoal for health reasons, though this trend can impact negatively on deforestation in the rural areas where charcoal is produced, given the growing demand and the very low energy conversion efficiency of traditional kilns used in the carbonization process (Section 2.3.2.2). Furthermore, the transport of charcoal from forest areas to urban demand centres often uses old and inefficient diesel trucks that contribute to GHG emissions. Modern RE technologies could provide an alternative option.

\section{Challenges and options for RE integration}

Biomass used by urban communities and households should be supplied from sustainably produced plantation forests. In a few places, community plantations have been grown to provide local biomass resources. To ensure the sustainability of such resources, a holistic approach to policy development would be useful that encompasses plantation biomass supplies, natural forest management as well as the demand side, such as fuel switching and the uptake of improved stoves and kilns (Figure 8.20). Such an approach may need fiscal policies (CILSS, 2008) in order to provide financial incentives to ensure the biomass is supplied from sustainable sources or to encourage the deployment of other RE technologies in the building sector such as small biogas digesters. In Nepal, for example, more than 200,000 domestic biogas plants had been installed as of December 2009 and 17 biogas appliance manufacturing businesses established as a result of recent supporting policies (Bajgain and Shakya, 2005).

In the majority of urban areas, grid electricity is available, although in some regions it can be unreliable, relatively expensive, and therefore often limited to providing basic needs. Along with small gasoline- or diesel-fuelled generating sets and coupled with energy storage, there is scope for increased penetration of independent, small-scale RE systems as backup support for when outages of the main grid electricity supply occur, but at additional costs.
Solar water heating (SWH) is considered to be a good RE option in gridconnected urban areas of many countries (as well as in off-grid rural areas without modern water heating services such as in China where over half the global SWH installations exist). Large-scale implementation can benefit both the customer and the utility. Where centralized switching (such as using ripple control communication over the power line) is used to manage electric water heater loads, the impact of solar water heaters is limited to energy savings. For utilities without this facility, the installation of a large number of solar water heaters may have the additional benefit of reducing peak electricity demand loads on the grid, especially in high sunshine regions where demand savings from using solar water heaters can correspond with high summer electrical demand for cooling. Hence there is a capacity benefit from load displacement of electric water heaters, particularly when used as a hybrid technology integrated with PV modules (Dubey and Tiwari, 2010). Markets for SWHs are apparent in the service sector such as hotels and lodges, in middle and high income households and for buildings not connected to the grid. Regulations and incentives could be necessary to reach a critical mass of installations in many urban areas (IEA, 2009b) and hence gain economies from greater dissemination.

Cooling demand in warmer climates has tended to rise where an increase in affluence occurs. Heat pump penetration rates in most developing countries are still low, but where coupled with high annual cooling degree days, could result in a future rapidly growing cooling demand as economies expand. This could cause peak power demand during periods of hot weather that, if exceeding the available supply capacity, could result in power outages. Offsetting cooling demand can be achieved by energy efficiency options such as reducing surface to volume ratios of new building designs, passive solar building designs and cooling towers (Chan et al., 2010). Active RE technologies for cooling include ground source heat pumps, district cooling using cold water sources (Section 8.2.3) and solar-assisted coolers (R. Wang et al., 2009). The latter technology offers the matching of peak cooling demand with peak solar radiation and hence with peak electricity demand for conventional air conditioners (air-to-air heat pumps). Another option is to use RE electricity to power conventional refrigeration appliances or air-toair heat pumps (also known as 'air conditioners').

\section{Case Study: Urban settlements in Brazil.}

The rapid urbanization process in many developing countries has created peri-urban settlements near to central metropolitan areas. In Brazil, all major cities and a third of municipalities have a significant fraction of their population living in 'favelas'. Dwellings are usually precarious, fragile and temporary and frequently lack basic water, sanitation, gas and electricity distribution infrastructures (IBGE, 2008). Access to modern energy services is a challenge for many local governments and utilities. Energy planning is complex. Where an electricity distribution grid is available, it often does not comply with safety and regulatory standards of the utility. Furthermore, illegal connections with no meters are common practice. New integration of RE technologies could provide opportunities for improvements. 


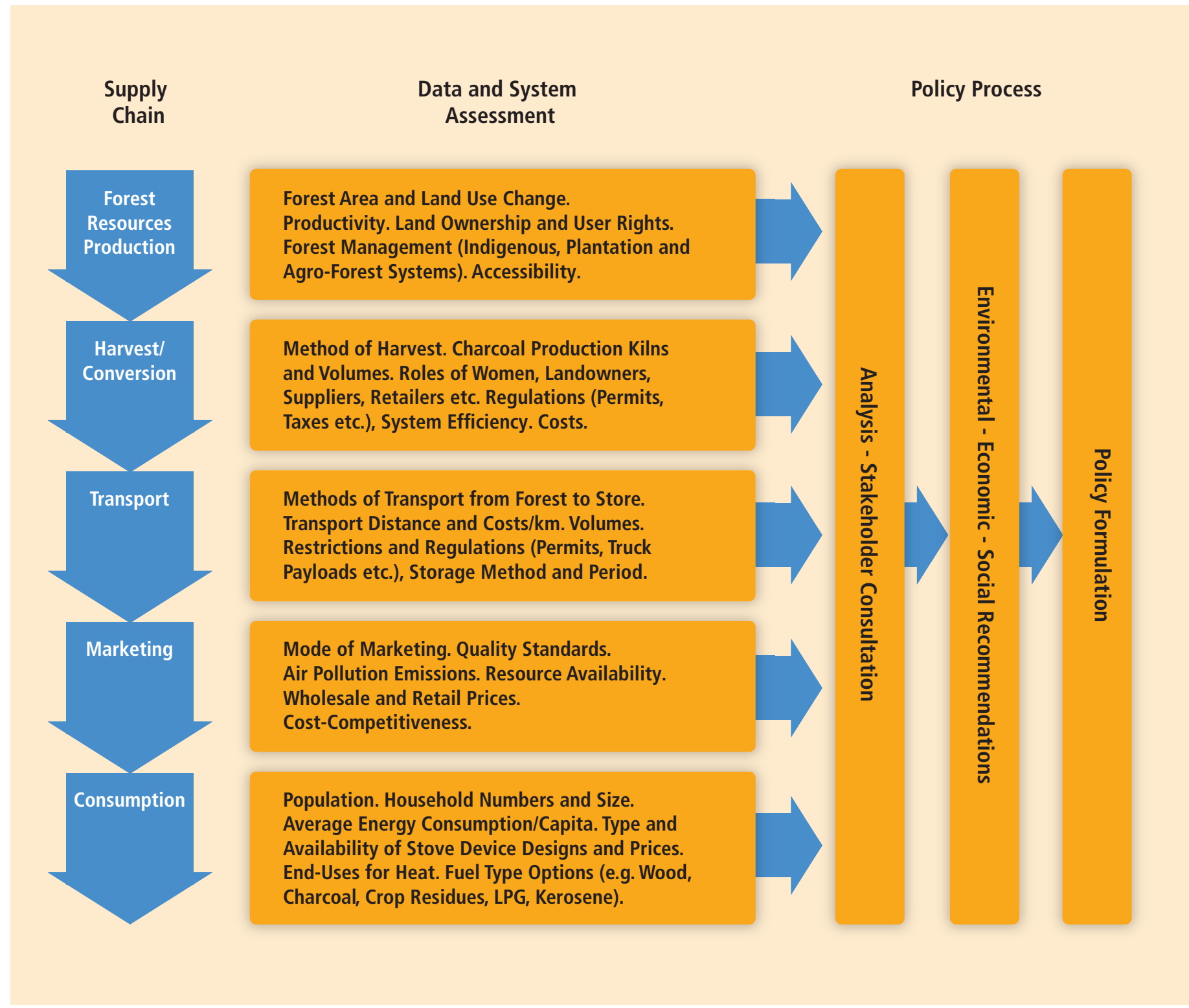

Figure $8.20 \mid$ A holistic approach using supply chain analysis for local or national policy development for the sustainable supply of biomass for domestic consumption in developing countries (Khennas et al., 2009). The formulation of policies can impact on the supply chain resulting in a continuous learning-by-doing feedback loop.

Under current regulations, Brazil's electricity utilities invest annually about $\mathrm{USD}_{2005} 80 \mathrm{M}$ (half of their compulsory social investment) in energy efficiency programmes for low-income end users living in favelas. Complex issues still needing to be tackled include enforcing legal regulations, developing more creative and technical solutions to reduce theft of electricity and fraud, and improving the economic situation of the poor inhabitants. A pilot case study in one favela in São Paulo indicated that, as a result of promoting energy efficiency and solar water heating programmes, average household electricity consumption was reduced from $250 \mathrm{kWh} /$ month to $151 \mathrm{kWh} /$ month ( 900 to $540 \mathrm{MJ} / \mathrm{month})$ with a payback period of only 1.36 years (ICA, 2009). In addition there was opportunity for the uptake of stateof-the-art technologies including remote metering, real-time demand monitoring, more efficient transformers, new cabling systems and improved materials. The financial analysis identified a reduction in commercial and technical losses. Increased revenue resulted for the utility from a reduction in arrears and non-payments.

\subsubsection{Renewable energy and rural settlements in developing countries}

Rural households in developing countries relying on fuelwood, noncommercial crop residues and animal dung for their basic energy needs, and with zero or only limited access to modern energy services, are a constraint to eradicating poverty and improving health, education and social and economic development (Section 9.3.1). In several sub-Saharan Africa and other developing countries, traditional 
biomass accounts for more than $75 \%$ of total primary energy. The inefficiency of the whole supply chain, together with indoor air pollution problems, affect a large proportion of the population, particularly the many women who still rely on gathering fuelwood for their basic cooking and heating needs. Solutions to fuelwood scavenging include developing local forest plantations to be harvested sustainably, and improved natural forest management, though these are not always easy to accomplish due to land ownership, cost and social issues (CILSS, 2004).

Around one-quarter of the 2.7 billion people who rely on biomass (and another 0.3 billion on coal) now use improved cook stoves (UNDP and WHO, 2009). This amounts to 166 million households, around $70 \%$ being in China. Lighting demands met by relatively costly kerosene lamps, torches and candles, are being slowly replaced by RE electricity technologies that can deliver cost-effective high-quality lighting. For example, around 1 million solar lanterns (REN21, 2010) have been installed worldwide along with over 1.5 million solar PV home systems (also used for radio, television, refrigeration, communications and mobile phone charging). Solar PV-powered water pumps, micro-hydro schemes and mini-grids, small bioenergy gasifiers and biogas plants are all being widely deployed, but reliable statistics are not available to indicate rates of deployment with any accuracy (REN21, 2010).

\section{Challenges and opportunities for RE integration}

Although a variety of financial, regulatory and infrastructure barriers pose real challenges, they do not preclude RE having useful applications for reducing energy poverty in off-grid rural areas. RE applications, such as from solar PV systems, can provide income-generating activities to stimulate development of small and medium enterprises. To increase energy access as well as grid expansion, innovative and affordable delivery mechanisms could be developed, such as concessions coupled with subsidies and public/private partnerships (Section 11.5.6).

Some of the energy-poor may receive grid electricity during the next few decades as extension of the distribution network reaches more rural and peri-urban people (Section 9.4.2). Others in rural areas may benefit from local distributed energy supplies and mini-grids. Distributed energy supply technologies for buildings are under development (Section 8.2.5). The term 'digital energy' has been used to describe incorporation of the latest information technologies to effectively control domestic peak demand, energy storage equipment and RE generation systems in or around buildings (Cheung and Wilshire, 2010). Buildings that have been passive energy consumers could become energy producers and building managers could become operators of an energy network in collaboration with the local utilities (USDOE, 2008b). Whether such technologies are appropriate for use in rural areas in less developed countries has not yet been determined.

A combination of RE technologies suitable for rural communities or urban dwellings could be employed where suitable finance is available (Figure 8.21). Obtaining sufficient funding to purchase the electricity regardless of source could be challenging for new consumers, even for small amounts just to meet their basic needs. Innovative finance mechanisms (UNDP, 2009) can help ensure that the energy-poor better utilize local RE technologies as the least cost option.

Case Study: RE in the Democratic Republic of Congo (DR Congo). A significant proportion of the rural population in the DR Congo, the largest and most populated country of the Congo Basin, has very limited access to modern energy services. Of its 70 million people, only around $5 \%$ have access to electricity compared with $12 \%$ in Angola, $18 \%$ in

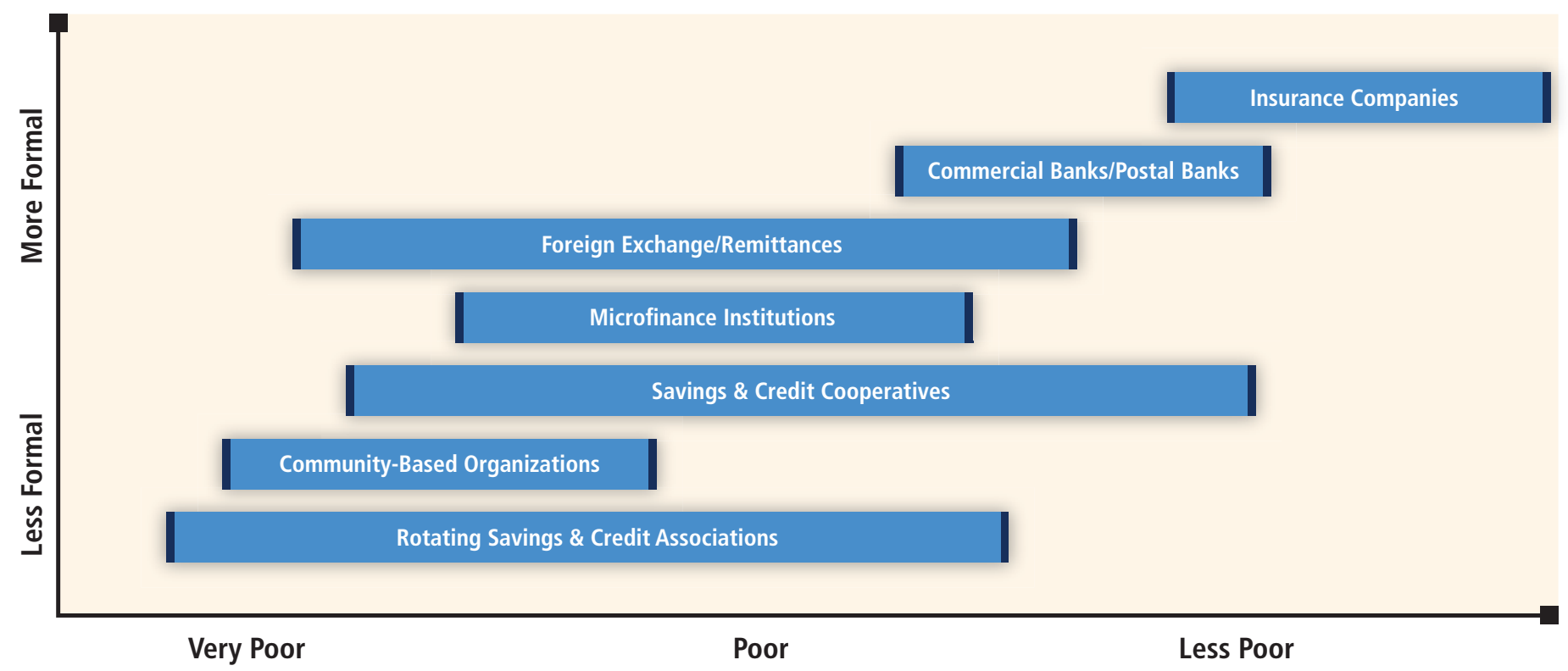

Figure 8.21 | Financing options to provide energy services for the poor, based on experiences in Burkina Faso, Kenya, Nepal and Tanzania (UNDP, 2009). 
Congo, $46 \%$ in Cameroon and $47 \%$ in Gabon (IEA, 2006). Despite the high hydro potential in the region, the rural electrification growth rate is comparatively low at less than $1 \%$ of population per year. In addition to a good solar resource, some 325 potential hydro schemes have been identified and preliminary data gathered (Khennas et al., 2009). Developing this mini- and micro-hydro potential could dramatically increase the rural electrification rate and ultimately improve the livelihood of many poor rural households. The implementation of such a programme would dramatically increase the supply of RE for rural people to meet their needs for basic energy services. The Congo Basin, with the second largest tropical rainforest area in the world, is experiencing some deforestation (de Wasseige et al., 2009). Developing local RE resources could contribute to limiting deforestation around the villages by reducing the demand for traditional biomass.

\subsubsection{Future trends for renewable energy in buildings}

In many developed countries, heating and cooling and to a lesser extent lighting, have the highest potential to reduce energy demand in buildings and thereby offer increased opportunities for the cost-effective integration of RE by having to meet a lower demand (Section 8.3.2.1). A study, Energy Efficiency in Buildings - Transforming the Market (WBCSD, 2009), included several case studies:

- For office buildings in Japan, in parallel with energy efficiency initiatives for heating and cooling equipment and lighting, solar PV was the major RE source projected to be used onsite in 2050, but to a limited degree especially in high-rise building designs.

- Energy consumption of single-family houses in France is dominated by space heating ( $\sim 60 \%$ of the total). Solar PV, along with solar water heaters, were projected to be integrated into improved energy efficient building designs by 2050 to meet a significant share of electricity demand.

Multi-family apartment blocks in China also have potential for numerous future energy efficiency improvements, especially for heating, ventilation and cooling. Only solar water heaters were projected to account for onsite RE potential in 2050. IEA scenario analysis (IEA, 2010c) forecast that there is potential for around $6 \mathrm{Gt} \mathrm{CO}_{2}$ emission reductions below the baseline scenario coming from the building sector by 2050, with 10 to $25 \%$ of the total (depending on assumptions about rates of technological improvements and cost reductions) coming from RE and the remainder from energy efficiency measures including heat pumps, building design, lighting and appliances.

In developed countries, the trend is for new building developments, as well as building refurbishments, to continue towards achieving zero-energy buildings or even 'energy-positive' buildings where RE technologies will meet the energy demand of the inhabitants and generate more energy than the building consumes (Figure 8.22). Investment in both RE and energy efficiency in buildings can produce costs and $\mathrm{CO}_{2}$ emissions reductions, but the comparative savings per unit of investment for either option will vary with the building type and location. In highdensity urban areas, the energy demand per hectare of built land area usually greatly exceeds the local flows of RE, which are typically below a $10 \mathrm{~kW} / \mathrm{ha}$ annual average. Therefore, RE integration to provide a high share of a building's total energy demand directly is more feasible in buildings located in rural and low-density urban areas. Therefore, compared with high-rise buildings, single-family homes could more easily become autonomous for their net energy needs (excluding transport) (Section 8.3.5). However, any savings in imported energy for such buildings located in rural or low-density urban areas could be partly offset by increased transport energy demands.

The market situation for RE integration during retrofitting of existing buildings is in the early development phase, as compared to integration into new buildings, but could strengthen in the near future as a result of policy attention shifting towards the existing building stock because of slow building stock turn-over.

In commercial buildings and urban and rural households in developing countries, the opportunities for integrating RE systems are considerable. To meet the future needs of the millions of people who currently rely on the inefficient combustion of traditional biomass (UN Energy, 2007), sustainable modern bioenergy systems, including small gasifiers, biogas engines, ethanol gels, pellet burners etc., coupled with efficient,

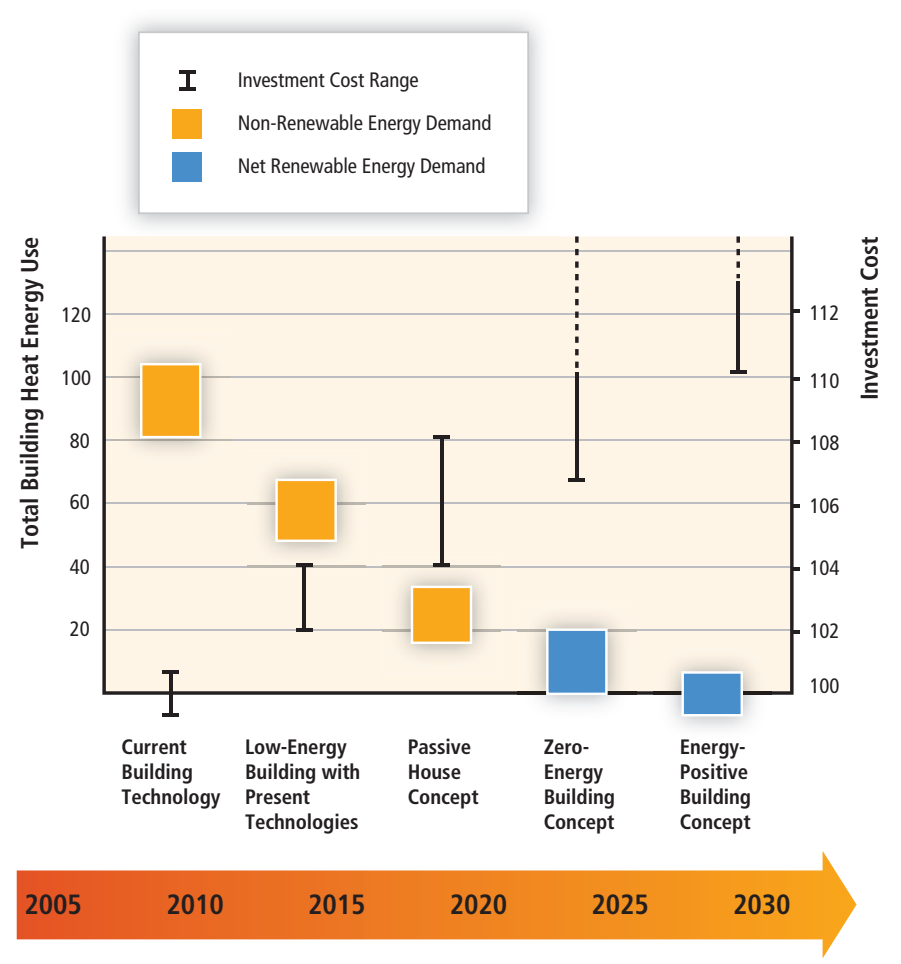

Figure 8.22 | Relative performance of current building technologies to meet heat energy demand compared with future designs of energy-efficient buildings with integrated RE systems and related investment costs (from base year $2005=100$ ), based on a full-scale demonstration project in Finland (VTT, 2009). 
affordable, well-designed and socially accepted appliances, particularly cooking stoves, could contribute significantly. The familiarity with the biomass resource could facilitate the transition. Poor access to modern energy services and the characteristics of energy demand in both urban and rural areas gives a comparative advantage to the integration of all forms of RE, which in the future could possibly be through decentralized RE supply options.

\subsubsection{Industry}

\subsubsection{Sector status}

Energy demand by manufacturing industries in 2008 was around 98 EJ of final energy (Figure 8.2), accounting for about one-third of total global consumer energy (IEA, 2010b), although the share differs markedly between countries. The industrial sector is highly diverse, ranging from 'heavy', very large, energy-intensive basic material manufacturers to small and medium sized enterprises (SMEs) with 'light' manufacturing. Energy-intensive iron and steel, non-ferrous metals, chemicals and fertilizers, petroleum refining, minerals, and pulp and paper industries account for approximately $85 \%$ of the sector's energy use (Bernstein et al., 2007). The production of these goods has grown strongly in the past 30 to 40 years and growth is projected to continue.

The sources of industrial $\mathrm{CO}_{2}$ emissions are from use of fossil fuels in energy carriers (such as grid electricity) or used directly on site (such as coal for process heat) as well as from non-energy uses of fossil fuels in chemicals processing, and from non-fossil fuel sources arising from the process, mainly through the decarbonation of calcium carbonate $\left(\mathrm{CaCO}_{3}\right)$ in cement manufacturing. In most countries, $\mathrm{CO}_{2}$ accounts for more than $90 \%$ of total industrial GHG emissions with the remainder coming from a range of gases including CFCs (IPCC, 2007). Direct and indirect $\mathrm{CO}_{2}$ emissions from industry in 2006 were 7.2 and $3.4 \mathrm{Gt}$ respectively, together equivalent to almost $40 \%$ of world energy and process $\mathrm{CO}_{2}$ emissions (IEA, 2009d).

Carbon dioxide emissions from industry can be reduced by:

- Energy efficiency measures that reduce specific energy use, which therefore, for some bio-based industries, can make any excess RE heat, electricity and biogas available for sale off-site;

- Materials recovery and recycling that eliminate the energyintensive primary extraction and conversion steps for many basic materials such as metals and paper pulp;

- RE integration and feedstock substitution to reduce the use of fossil fuels; and

- Carbon dioxide capture and storage (CCS) of emissions from both fossil and biomass fuels. Assuming that CCS becomes viable as a
GHG mitigation element in future energy systems, this could also be an option for $\mathrm{CO}_{2}$-producing industries and energy-intensive industries that consume biomass or fossil fuels for heating directly on-site.

Most of these measures are relevant also for integrating RE into present and future energy systems. The main opportunities for RE integration in industry, in no particular order, include:

- Direct use of process residues and biomass-derived fuels for on-site heat and CHP production and use as well as biogas and other biofuels, also used for transport applications (Sections 8.2.3, 8.3.1, and 2.3.3);

- Indirect use of RE through increased RE-based electricity demand, including for electro-thermal processes;

- Indirect use of RE through other purchased RE-based energy carriers including liquid fuels, biogas, heat and hydrogen (Section 8.2.3);

- Direct use of solar thermal energy for process heat and steam demands (Section 3.5.3); and

- Direct use of geothermal energy for process heat and steam demands (Section 4.3.5).

Other RE sources may also find industrial niche applications such as ocean energy for desalination (Section 6.3). There are no severe technical limits to increasing the direct and indirect use of RE in industry in the future. However, in the short term, integration may be limited by factors such as RE technology costs, capital turnover rates, space constraints or demands for high reliability and continuous operations.

The current direct use of RE by industry is dominated by biomass in the pulp and paper, sugar and ethanol industries where process by-products are important sources of cogenerated heat and electricity used mainly for the process but with potential to export off-site (Section 2.1). Thus, industry is not only a potential user of RE but also a potential supplier of RE as a co-product. Biomass is also an important fuel for many SMEs, such as the use of charcoal for brick making, notably in developing countries (Section 2.3.2). There is a growing interest in utilizing organic wastes and by-products for energy in, for example, the food industry through anaerobic digestion. Biogas production often replaces other forms of organic waste treatment due to waste and wastewater policies (Lantz et al., 2007). With the exception of biomass-based industries, the literature on $\mathrm{RE}$ in industry is relatively limited compared to other sectors.

Providing demand response services to enable electrical peak-load shifting as a form of load management is an important measure for industry. It is likely to achieve greater prominence in future electricity systems with increasing shares of variable RE generation (Section 8.2.1). It can 
also reduce the need for high marginal cost generation, offer low-cost system balancing and decrease grid reinforcement investment. The concept is already widely used to secure enough reserve- and peakingcapacity in many countries and is expected to become more important in the future. Existing programmes have mainly focused on industrial users that can shed relatively large loads through rescheduling, machinery interruption, and interruptible thermal energy storage, cool stores, electric boilers etc. Typically, industries are contracted to reduce or shut down load, sometimes remotely by the transmission system operator, according to pre-defined rules and with various means of financial compensation (Section 8.2.1.3). For industry, reduced production and risks of process equipment failure associated with demand response are important considerations. There are few published studies of the potential for demand response through industrial manageable power demand. In one example from Finland, the potential for demand response in the energy-intensive industries was estimated at 1,280 MW, equivalent to $9 \%$ of total system peak demand (Torriti et al., 2010).

\subsubsection{Energy-intensive industries}

The largest contributions of industry sector $\mathrm{CO}_{2}$ emissions in 2006 came from iron and steel $(29 \%)$, cement $(25 \%)$ and chemicals and petrochemicals (17\%) (IEA, 2009d). The pulp and paper industry accounted for only about $2 \%$ of industrial fossil fuel $\mathrm{CO}_{2}$ emissions since it uses large amounts of biomass for process energy (bioenergy systems generally being low carbon emitting).

Overall, possible pathways for increased direct integration of RE vary between different industrial sub-sectors. The main options are to replace fossil fuels in boilers, produce biogas from wastewater with high organic content and switch from oil and gas to biomass for industrial processes, for example by using bark powder in lime kilns that produce calcium oxide for the preparation of pulping liquor. Biomass can be co-fired with, or completely replace, fossil fuels in boilers, kilns and furnaces and there are alternatives for replacing petrochemicals through switching to biobased chemicals and materials.

Due to the scale of operations, access to sufficient volumes of biomass may be a constraint. Direct use of solar technologies can also be constrained by high energy demand and by the variability of the resource. Geothermal energy heat is suitable for use in industry due to its high capacity factors and energy densities but so far there are few applications in energy-intensive industries (Lund et al., 2010). Only around $500 \mathrm{MW}$ of geothermal capacity, corresponding to $2.7 \%$ of worldwide direct applications of geothermal energy, is currently used for industrial process heat. Current utilization is about $12 \mathrm{PJ} / \mathrm{yr}$ with applications in dairies, laundries, leather tanning, beverages and pulp mills. The Kawerau, New Zealand geothermal plant provides steam to the Norske Skog Tasman pulp mill that accounts for around half the present global geothermal industrial heat use (White, 2009). Geothermal energy could meet more industrial process heat demands if heat pumps are used to elevate temperatures. The potential is large (Section 4.2) and high capacity factors relative to solar thermal energy make it an attractive alternative for industry. However cost and constrained resource locations have been barriers to date.

For many energy-intensive processes, an important future option is indirect RE integration through switching to electricity and hydrogen. Electricity is already the main energy input for producing aluminium using the electro-chemical Hall-Héroult process. The broad range of options for producing carbon-neutral electricity, and its versatility of use, implies that electro-thermal processes could become more important in the future for replacing fuels in drying, heating, curing and melting operations. Plasma technologies can deliver heat at several thousand degrees Celsius and replace fossil fuel combustion for high-temperature applications. Electro-thermal processes include heat pumps, electric boilers, electric ovens, resistive heating, electric arcs, plasma induction, radio frequency and microwaves, infrared and ultraviolet radiation, laser and electron beams (EPRI, 2009). These technologies are presently used where they offer distinct advantages (such as energy savings, higher productivity or product quality), or where there are no viable alternatives (such as for electric-arc furnaces). Deployment has been limited since direct combustion of fossil fuels is generally less expensive than electricity. However, relative prices may change considerably if climate policies place a value on carbon emissions. Electro-thermal processes must compete against a portfolio of other low-carbon process options even if electricity supply is RE-based or otherwise decarbonized.

Energy-intensive industries are generally capital intensive and the resulting long capital asset cycles constitute one of the main barriers to energy transition in this sector. Cyclical markets and periods of low profit margins are common where management focus is usually on cutting costs and extending asset life rather than on making investments and taking risks with new technologies. In existing plants, retrofit options may be constrained by space limitations, risk aversion and reliability requirements. Green-field investments are mainly taking place in developing countries, although enabling energy and climate policies are less common than in developed countries.

Energy-intensive industries are often given favourable treatment in developed countries that have ambitious climate policies since they are subject to international competition and hence carry risks of carbon leakage. Exemptions from energy and carbon taxes, or free allocation of emission permits in trading schemes, are prevalent. Bio-based industries, such as the pulp and paper industry, can benefit from, and respond to, RE policy (Ericsson et al., 2010). Sectoral approaches are considered in international climate policy in order to reduce carbon leakage risks and facilitate technology transfer and the financing of mitigation measures (Schmidt et al., 2008).

Iron and steel. Production of iron and steel involves ore preparation, coke making, and iron making in blast furnaces and basic oxygen furnaces by reducing the iron ore. Primary energy inputs are 13 to $14 \mathrm{GJ} / \mathrm{t}$ 
of iron, usually from coal. Natural gas for direct reduction of iron ore is also an established technology. Using electric-arc furnaces to recycle scrap steel, these energy-intensive steps can be bypassed and primary energy use reduced to around 4 to $6 \mathrm{GJ} / \mathrm{t}$. However, the amount of scrap steel is limited and the increasing demand for primary steel is mainly met from iron ore. Various R\&D efforts, some of which involve RE uptake, focus on reducing $\mathrm{CO}_{2}$ emissions (Croezen and Korteland, 2010; Miwa and Okuda, 2010).

Charcoal was for a long time the main energy source for the iron and steel industry until coal and coke took over in the 1800s. During its traditional production, roughly only one-third of the total wood energy content is converted to charcoal, the rest being released as gases (Section 2.3.2). Higher efficiencies are attainable (Rossilo-Calle et al., 2000). Charcoal can provide the reducing agent in the production of iron in blast furnaces but coke has the advantage of higher heating value, purity and mechanical strength.

Present day steel mills mostly rely entirely on fossil fuels and electricity. Charcoal has not been able to compete, with the exception of use in a few blast furnaces in Brazil. Options for increasing the use of RE in the iron and steel industry in the near term include switching to RE electricity in electric-arc furnaces and substituting coal and coke with charcoal, subject to resource and sustainability constraints. Switching to biomethane is also an option. Research on electricity and hydrogen-based processes for reducing iron shows potential in the long term but CCS linked with coke combustion may be a less expensive option.

Cement. Production of cement involves extraction and grinding of limestone and heating to temperatures well above $950^{\circ} \mathrm{C}$. Decomposition of calcium carbonate into calcium oxide takes place in a rotary kiln, driving off $\mathrm{CO}_{2}$ in the process of producing the cement clinker. $\mathrm{CO}_{2}$ emissions from this reaction account for slightly more than half of the total emissions with the remainder coming from the combustion of fossil fuels. Hence, even a complete switch to RE fuels would reduce emissions by less than half.

The cement process is not particularly sensitive to the type of fuel but sufficiently high flame temperatures are needed to heat the materials. Different types of waste, including used tyres, wood and plastics are already co-combusted in some cement kilns. A variety of biomassderived fuels can be used to displace fossil fuels. Large reductions of $\mathrm{CO}_{2}$ emissions from carbonate-based feedstock are not possible without CCS, but emissions could also be reduced by using non-carbonate-based feedstock (Phair, 2006).

Chemicals and petrochemicals. This sector is large and highly diverse. High-volume chemical manufacture of olefins and aromatics, methanol and ammonia account for more than $70 \%$ of total sector energy use (IEA, 2008c). The main feedstocks for providing the building blocks of chemical products are oil, natural gas and coal which are also consumed for energy (Ren and Patel, 2009). Chemicals such as ethanol and methanol may be considered both as fuels and as platform chemicals for a range of products.

Steam-cracking is a key process step in the production of olefins and aromatics. Combustion of various biomass fuels and wastes could be used for steam production. Methanol production is mostly based on natural gas but it can also be produced from biomass or by reacting $\mathrm{CO}_{2}$ with hydrogen, possibly of renewable origin.

The potential for shifting to RE feedstocks in the chemicals sector is large (Hatti-Kaul et al., 2007). Many of the first man-made chemicals were derived from biomass through, for example, using ethanol as a platform chemical, before the shift was made to petroleum-based feedstocks. A shift back to bio-based chemicals would involve four principle approaches:

- Feedstocks converted using industrial biotechnology processes such as fermentation or enzymatic conversions (Section 2.3.3.3);

- Thermo-chemical conversion of biomass for the production of a range of chemicals, including methanol (Section 2.3.3.1);

- Naturally occurring polymers and other compounds extracted by various means; and

- Green biotechnology and plant breeding used to modify crops for non-food production.

In the fertilizer industry, ammonia production is an energy-intensive process that involves reacting hydrogen and nitrogen at high pressure. The energy embedded in fertilizer consumption by agriculture (Section 8.3.4) represents about $1 \%$ of global primary energy demand (Ramirez and Worrell, 2006). The nitrogen is obtained from the air and the source of hydrogen is typically natural gas, but also coal gasification, refinery gases and heavy oil products. Ammonia production gives a $\mathrm{CO}_{2}$-rich stream and lends itself to CCS. Hydrogen from RE sources could also be used for the reaction and other nitrogen fixation processes are possible, including biological nitrogen fixation (Ahlgren et al., 2008).

Forest products. Forest harvesting operations and the transport of logs to saw mills, pulp and paper mills and wood processing industries involve handling large volumes of woody biomass. Residues and by-products all along the value chain can be used to provide energy for internal use as well as for export. For example, the bark component stripped from the logs can be combusted in separate boilers. Enough high-pressure steam can often be produced for CHP generation onsite to meet all the steam and electricity needs of a modern pulp mill. The onsite use of biomass as a by-product for heat and power generation means that the GHG intensity of the forest industry can be relatively low.

There are many different pulping processes but the two main routes are mechanical and chemical. For electricity-intensive mechanical pulping, after debarking and chipping, the wood chips are processed in large grinders and nearly all the fibre ends up in the pulp, which is used for producing paper such as newsprint. Heat is recovered from the mechanical pulping process and the steam produced is used for 
drying the paper and other processes. Chemical pulping is used to produce stronger high-quality fibres and involves dissolving the lignin in a chemical cooking process. About half of the wood, mainly lignin, ends up in the spent pulping liquor that is concentrated in evaporators. This 'black liquor' can be combusted in chemical recovery boilers. Changing from the traditional recovery boiler to black liquor gasification in chemical pulping would increase the efficiency of energy recovery and facilitate higher electricity-to-heat ratios in the CHP system with the syngas used for fuel production (see case study below).

Continuous incremental improvements in energy end-use efficiency, higher steam pressure in boilers and use of condensing steam turbines are reducing the need for importing purchased energy in the pulp and paper industry and can also free up a portion of the heat and electricity generated to be sold as co-products (Axegård et al., 2002).

\section{Case study: Black liquor gasification for bio-DME production.}

As an alternative to producing heat from black liquor in chemical recovery boilers, gasification is a technology that has been subject to R\&D for more than 20 years and demonstrated in several pilot-scale plants (Kåberger and Kusar, 2008). The syngas produced (mainly CO and $\mathrm{H}_{2}$ ) can be used with high efficiency in combined cycle CHP plants or for the production of biofuels via, for example, the Fischer-Tropsch process (Section 8.2.4). The first pilot plant demonstrating pressurized gasification for producing DME (dimethyl ether) was inaugurated in Piteå, Sweden, in September 2010 with a rated capacity of about 4t/ day. Partner companies are Chemrec, Haldor Topsoe, Volvo, Preem, Total, Delphi and ETC with financial support from the Swedish Government and the European Commission. Compared to gasification of solid biomass, one advantage of black liquor is that it is easier to feed into a pressurized gasifier. Depending on the overall plant energy balance and layout there are often process integration advantages and potential for significant increases in energy efficiency. Energy that is tapped off for liquid or gaseous biofuel production (including DME) can be compensated for by using lower quality biomass to meet pulp and paper process energy demands. In addition to DME production, the project also involves four filling stations and $14 \mathrm{HDV}$ trucks using DME for fuel to assess the viability of bio-DME.

\subsubsection{Less energy-intensive industries and enterprises}

Non-energy-intensive industries, although numerous, account for a smaller share of total energy use than energy-intensive industries but are more flexible and offer greater opportunities for the integration of RE. They include food processing, textiles, light manufacturing of appliances and electronics, automotive assembly plants, wood processing etc. Much of the energy demand in these 'light' industries is similar to energy use in commercial buildings such as lighting, space heating, cooling, ventilation and office equipment. Most industrial heating and cooling demands are for moderate temperature ranges that facilitate the application of solar thermal energy, geothermal energy and solarpowered cooling systems with absorption chillers (IEA, 2007c; Schnitzer et al., 2007). Almost $150 \mathrm{GW}$ of solar thermal collector capacity was in operation worldwide in 2007 but less than $1 \%$ was used for industrial applications (IEA-SHC, 2010). Other than cost, part of the reason could be the variable nature of the solar resource providing insufficient reliability for an industrial process, although thermal storage, including for concentrating solar thermal systems (Section 3.2), could overcome the problem in some situations.

Typical process energy use is for low and medium temperature heating, cooking, cooling, washing, pumping and air-handling, coating, drying and dehydration, curing, grinding, preheating, product concentration, pasteurization and sterilization, and some chemical reactions. In addition, a range of mechanical operations use electric motors and compressed air to power tools and other equipment. Plants range in size from very small enterprises to larger-scale assembly plants and processing mills.

Many companies use hot water and steam for processes at temperatures between 50 and $120^{\circ} \mathrm{C}$ (Figure 8.23). When fossil fuels are used, installations that provide the heat are mostly run at temperatures

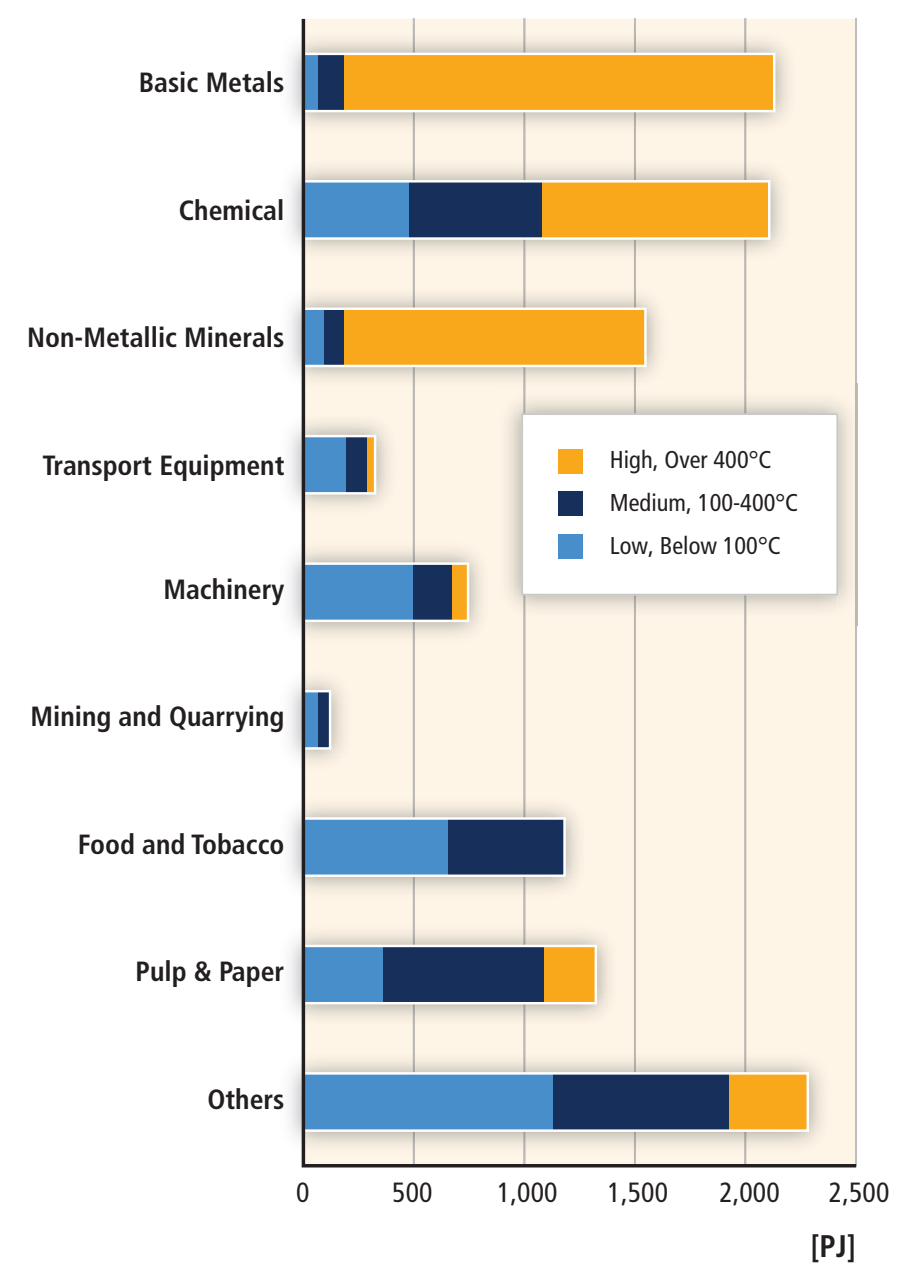

Figure 8.23 | Industrial heat demands by temperature quality and by manufacturing sector for 32 European countries (Werner, 2006b).

Note: Data created from German industry experiences and applied to the IEA energy database for the target region. 
between 120 and $180^{\circ} \mathrm{C}$ since these higher process heat temperatures enable smaller areas of heat exchangers and heating networks to be utilized. Solar energy opportunities focus more on engineering designs for operating at lower temperatures in order to optimize the whole system. For temperatures $<80^{\circ} \mathrm{C}$, solar thermal collectors are on the market, but there is limited experience for applications that require temperatures up to $250^{\circ} \mathrm{C}$ (Schnitzer et al., 2007). Such higher temperatures are possible using heat pumps or, in appropriate areas, concentrating solar thermal systems.

Industrial electro-technologies can save primary heat energy from coal and gas by using electricity. Industrial $\mathrm{CO}_{2}$ emissions can be reduced even if there are no primary energy savings, assuming electricity from RE resources replaces or saves fossil fuel-based thermal generation. Examples include freeze concentration instead of the thermal process of evaporation; dielectric heating (radio frequency and microwave heating) for drying; polymerization; and powder coatings using infra-red ovens for curing instead of solvent-based coatings and conventional convection ovens (Eurelectric, 2004). Other advantages include quick process startup, improved process control and higher productivity (EPRI, 2009). The conventional wisdom that high quality (high exergy) electricity should not be used to provide low quality (low exergy) thermal applications may be challenged in the future once electricity systems become decarbonized.

Many SMEs in developing countries use substantial amounts of crop residues in the form of husks, straw and shells from nuts, coffee, coconuts, rice etc. for heat and power generation. These residues are low cost and often used, together with fuelwood and charcoal, as fuels to supply heat for other local industries. In some food- and fibre-processing industries, wastewater with high organic content can also be used for biogas production but the resource currently tends to be poorly utilized.

In developed countries, waste policies are an important factor driving the increased utilization of biomass residues for energy. Bioenergy is most common in the food- and fibre-processing industries where, as for forest products (Section 8.3.3.4), on-site biomass residues are widely used to meet internal energy needs or the energy is exported off-site for use elsewhere, which therefore avoids waste disposal problems. For example, sugar and ethanol plants in Brazil use the bagasse by-product to produce heat and power and sell any surplus to the grid (see case study below). Any waste heat can be used by other industries and in district heating systems (Section 8.2.2). Heated greenhouses and fish farming are potential users of low-grade heat.

Industrial ecology and symbiosis are relatively new concepts used to denote inter-firm exchanges of energy, water, by-products etc., although these are not new phenomena. An inventory of the Swedish forest industry found several examples of such inter-firm exchanges, but typically between different entities within the same company group (Wolf and Petersson, 2007). The potential for increasing the indirect use of RE in such innovative ways is difficult to estimate.
Dehydration of agricultural and other products is an important application of solar energy. In many developing countries, the traditional method of dehydration in open air can result in food contamination, nutritional deterioration and large product losses. Solar dryer technologies that improve product quality and reduce drying times have been demonstrated. Examples include a solar tunnel dryer for hot chilli peppers (Hossain and Bala, 2007) and a solar dryer with thermal storage and biomass backup heater for pineapple (Madhlopa and Ngwalo, 2007).

The potential for increasing the direct use of RE in both heavy and light industries in general is poorly understood due to the complexity and diversity of the sector, and the varying geographical and climatic conditions of various locations. Aggregate mitigation and typical RE integration cost estimates cannot be made for similar reasons.

Direct use of RE in industry has difficulty competing at present due to the relatively low fossil fuel prices and low- or zero-energy and carbon taxes for industry. Improved utilization of processing residues in biomass-based industries to substitute for fossil fuels offers near-term opportunities, particularly where biomass residue disposal costs can be avoided. Solar thermal technologies are promising but further development of collectors, thermal storage, balancing systems and process adaptation and integration is needed. Direct use of geothermal heat is already used where industrial heat demands are nearby. Increased use of energy carriers such as electricity and natural gas that are clean and convenient at the point of end use is a general trend in industry. Indirect RE integration using electricity generated from RE sources, and facilitated through electro-technologies, may therefore have a large impact in the near and long term. RE support policies in different countries tend to focus more on the energy, transport and building sectors than on industry. Consequently the RE potential for the industry sector is relatively uncharted.

\section{Case studies}

Sugar industry and CHP. Limited grid access and low prices offered by monopoly buyers of electricity and independent power producers have provided disincentives for industries to increase overall energy efficiency and electricity-to-heat ratios in CHP production. Process electricity consumption in sugar and sugar/ethanol mills, for example, is typically in the range of 20 to $30 \mathrm{kWh}(72$ to $108 \mathrm{MJ}$ ) per tonne of fresh cane. Most sugar mills have been designed to be self-sufficient in heat and electricity using mainly bagasse as a fuel in inefficient, low pressure boilers. With higher rates of residue recovery and the introduction of high pressure boilers and condensing extraction steam turbines, more than $100 \mathrm{kWh} / \mathrm{t}(360 \mathrm{MJ} / \mathrm{t})$ can be produced for export. In Brazil, electricity generation is expected to increase from an average of about $9 \mathrm{kWh} / \mathrm{t}(32 \mathrm{MJ} / \mathrm{t})$ of sugarcane in 2005 to $135 \mathrm{kWh} / \mathrm{t}(486 \mathrm{MJ} / \mathrm{t})$ in 2020 (Macedo et al., 2008). However, sugar/ethanol mills provide opportunity for integrating a much higher level of biomass for energy in industry. The sugarcane tops and leaves are normally burned before harvest or left in the field after harvest. These could also be collected and brought 
to the mill to increase the potential export of electricity to more than $150 \mathrm{kWh} / \mathrm{t}(540 \mathrm{MJ} / \mathrm{t})$. This could be further increased to more than $300 \mathrm{kWh} / \mathrm{t}(1,080 \mathrm{MJ} / \mathrm{t})$ using gasification technology and combinedcycle power plants, or supercritical steam cycles (Larson et al., 2001). Integrating the utilization of biomass residues with feedstock logistics in sugar/ethanol mills offers cost and other advantages over separate handling and conversion of the residues.

Solar industrial process heat for industry. Solar thermal energy is well suited to many industrial processes. In 2003, the net industrial heat demand in Europe was estimated to be $8.7 \mathrm{EJ}$ and the electricity demand was 4.4 EJ (Werner, 2006b). Heat demands were estimated in 2003 at low, medium and high temperature levels for several industries in the EU 25 countries, four accession countries and three European Free Trade Association countries (Figure 8.23). Industrial process heat accounted for around $28 \%$ of total primary energy consumption by the sector with more than half of this demand for temperatures below $400^{\circ} \mathrm{C}$, which could be a suitable application for solar thermal energy (Vannoni et al., 2008).

Solar thermal energy technologies can be used to supply industrial heat, including concentrating solar thermal systems that can produce process steam directly in the collector. A pilot plant was inaugurated in 2010 in Ennepetal, Germany. This 'P3 project' demonstrated that direct steam generation from a small $100 \mathrm{~m}^{2}$ area of parabolic trough collectors can be suitable for industrial applications (Hennecke et al., 2008; Krüger et al., 2009). Another solar thermal example is the installation of about $5,000 \mathrm{~m}^{2}$ of solar collectors in 2008 by the Frito Lay food processing company at its plant in Modesto, California, to produce process steam and thereby reduce gas consumption and associated $\mathrm{CO}_{2}$ emissions (Krüger et al., 2008).

\subsubsection{Agriculture, forestry and fishing (primary production)}

\subsubsection{Sector status}

In OECD countries, the energy demand of the primary production sector is typically around $5 \%$ of total consumer energy, while the overall global average is $3 \%$ (Figure 8.2). Excluding land use change, currently primary production accounts for around $15 \%$ of total GHG emissions including methane and nitrous oxide (IPCC, 2007). Integration of RE into primary production systems, either as energy suppliers or end users, has been successfully achieved in a myriad of examples at both medium scale (such as bioenergy CHP plants and mini-hydro projects) and small scale (such as biogas plants and wind-powered water pumps).

Complex relationships exist between energy inputs and crop yields, sustainable practices (including tillage and fertilizer practices), water use, land use change, biodiversity, landscape and recreation, and soil carbon balances. Large regional differences occur due to climate, soils and land management (IPCC, 2007).
Low input subsistence farming and fishing rely mainly on human energy and animal power, with traditional biomass also used for drying and heating applications (Section 2.4.2). Intensive, industrialized agriculture, forest and fish production depend on significant energy inputs, usually from fossil fuels. These are either combusted directly for heating, drying and powering boats, tractors and machinery, or used indirectly to manufacture fertilizers and agricultural chemicals (Section 8.3.3), produce and transport purchased animal feed, construct buildings and fences and generate electricity for water pumping, lighting, cooling and operating fixed equipment. Typically twice as much energy is used directly on-farm compared with the indirect energy inputs (Schnepf, 2006), though this varies with the enterprise type. Energy efficiency measures are being implemented and future opportunities also exist to reduce fertilizer and agricultural chemical inputs by using precision farming application methods (USDA, 2009) and less intensive, organic farming systems.

Energy input versus energy output ratios vary with product and system. For example, the total energy inputs for growing potatoes can exceed the food energy output value of the harvested crop (giving a negative ratio as a result) (Haj Seyed Hadi, 2006). Energy ratios depend upon the local farm management system, the boundaries used in the energy analysis, and other assumptions. Hence a positive energy ratio for potatoes has also been reported (Mohammadi et al., 2008).

Primary producers can have a dual role as energy users and as suppliers of RE (Table 8.5) ${ }^{36}$ Landowners often have ready access to local RE resources including wind, biomass, solar radiation, the potential and kinetic energy in rivers and streams and biomass. Competition for land use to provide food, fibre, animal feed, energy crops for biofuels, recreation, biodiversity and conservation forests is growing and has come under close scrutiny (GMF, 2008; Fritsche et al., 2010).

Land investments have been made by some governments in countries other than their own in order to grow and export food such as wheat, rice and maize, but also energy crops for biofuels (Von Braun and Meizen-Dick, 2009). Possible exploitation of the existing rural communities has been a concern (WWICS, 2010), but benefits can accrue when the advantages of RE integration with land use are equitably shared, such as for sugar ethanol companies investing in Ghana (Sims, 2008). Developing a code of good conduct to share benefits, abide by national trade policies and respect customary rights of the family farm unit is being considered (UN Energy, 2007) as is the sustainable production of biomass (Section 2.5).

\subsubsection{Status and strategies}

The integration of RE with land use for primary production is well established. For example, wind turbines constructed on pasture and crop

36 Note that this section covers only on-farm and in-forest production and processing activities, including harvest and post-harvest operations up to the farm gate. Food and fibre processing operations are covered in Section 8.3.3. 
lands can provide additional revenue to the landowner since only 2 to $5 \%$ of the total land area is taken out of agricultural production by the access roads, turbine foundations and control centre buildings (Section 7.6.3). Similar opportunities exist for small- and mini-hydropower projects. Many sites of old water-powered grain mills could be utilized for run-of-river micro-hydropower generation schemes (Section 5.3.1). Lowhead turbines have been developed for operating in low-gradient water distribution channels to power irrigation pumps (EECA, 2008). Solar PV systems have been linked with water pumping and solar thermal systems have been commonly used for water heating and crop drying. Solar sorption technologies for air-conditioning, refrigeration, ice making and post-harvest chilling of fresh products remain at the development stage (Fan et al., 2007). Geothermal heat has been used for various applications including heating greenhouses, desiccation of fruit and vegetables, heating animal livestock houses, drying timber and heating water for fish and prawn farming (J. Lund, 2005).

Biomass resources produced in forests and on farms are commonly used to meet local agricultural and rural community heat energy demands but developing large-scale projects can be a challenge and possible removal of nutrients in the biomass a constraint for some soil types (IEA, 2007a). Returning some nutrients to the land as ash after combustion is feasible as is the production of biochar via pyrolysis, which can then be incorporated into the soil to improve the productivity as well as reduce atmospheric carbon concentrations if managed properly (Section 8.3.4.4).

Crop or forest residues are either collected and transported as a separate operation following the harvest of the primary product (grain or timber) or integrated as a harvesting operation of all co-products (Heikkilä et al., 2006). Privatization of the electricity industry in some countries has enabled sugar, rice and wood processing plant owners to invest in more efficient CHP plants that generate excess power for export (Section 8.3.3) and can also reduce local air pollution if the biomass is dry, combusted efficiently and displaces coal (Shanmukharadhya and Sudhakar, 2007).

Anaerobic digestion of animal manures, fish, food and fibre processing wastes, and green crops such as sorghum or maize is a well understood technology to produce biogas (Section 2.3.3). Gas storage is costly, so supply should be matched with demand where feasible (Section 8.2.3). The odourless, digested solid residues can be used for soil conditioning and nutrient replenishment. On-farm direct combustion of the biogas to supply heat is common practice, or after upgrading to biomethane (Section 8.2.3) it can be used in stationary gas engines for CHP or used as a transport fuel similar to compressed natural gas (Section 8.3.1).

\subsubsection{Pathways for renewable energy integration and adoption}

Much agricultural and forest land that produces food and fibre products could simultaneously be used for supplying RE, in many cases utilizing the heat and electricity on the property to displace the energy inputs purchased to run the enterprise (Table 8.5). Biofuels and biogas can also be produced on-farm, either for direct use on site (Section 8.2.3) or sold to the market. Market drivers for RE power generation on rural land and waterways include electrification of rural areas, a more secure energy supply and the avoidance of costly transmission line capacity upgrading in areas where demand loads are increasing (Section 8.2.1).

To meet the growing demands for primary products including biomass, increasing productivity of existing arable, pastoral and plantation forest lands by improving management and selecting higher yielding varieties is one option. (Changing diets to eat less animal products is another). Global average yields of staple crops have continued to increase over the past few decades (Figure 8.24). This trend could continue over the next few decades, with genetically modified crops possibly having a positive influence. Conversely, climate change trends including more frequent extreme weather events could offset some of the productivity gains expected from technological advances (Lobell and Field, 2007).

The primary production sector is making a slow transition to reducing its dependence on energy inputs as well as to better using its natural endowment of RE sources. Integration of land use for agriculture and energy purposes is growing but barriers to greater RE deployment in rural areas include high capital costs, lack of available financing, remoteness from energy demand (including access to electricity and gas grids), competition for land use, transport constraints, water supply limitations and lack of skills and knowledge in landowners and managers.

\subsubsection{Future trends for renewable energy in agriculture}

Distributed energy systems based on small-scale RE technologies (IEA, 2009b) have good potential in rural areas. The concept could also be applied to produce mini-power distribution grids (Section 8.2.1) in rural communities in developing countries where electricity services are not yet available.

A future opportunity for the agricultural sector is the concept of carbon sequestration in the soil as 'biochar' (Lehmann, 2007; Woolf et al.,

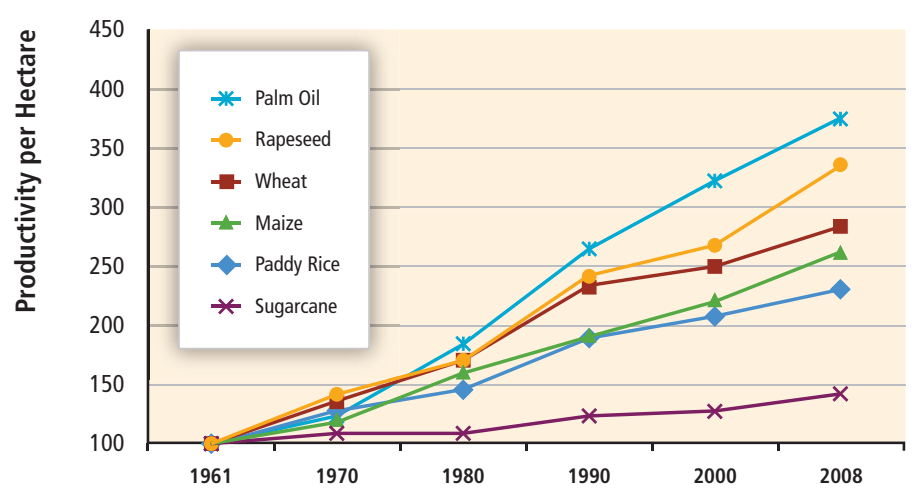

Figure $8.24 \mid$ Increased global productivity per hectare for a range of staple crops over the past few decades compared with average yields in base year 1961 shown at 100 (based on FAO (2009) data). 


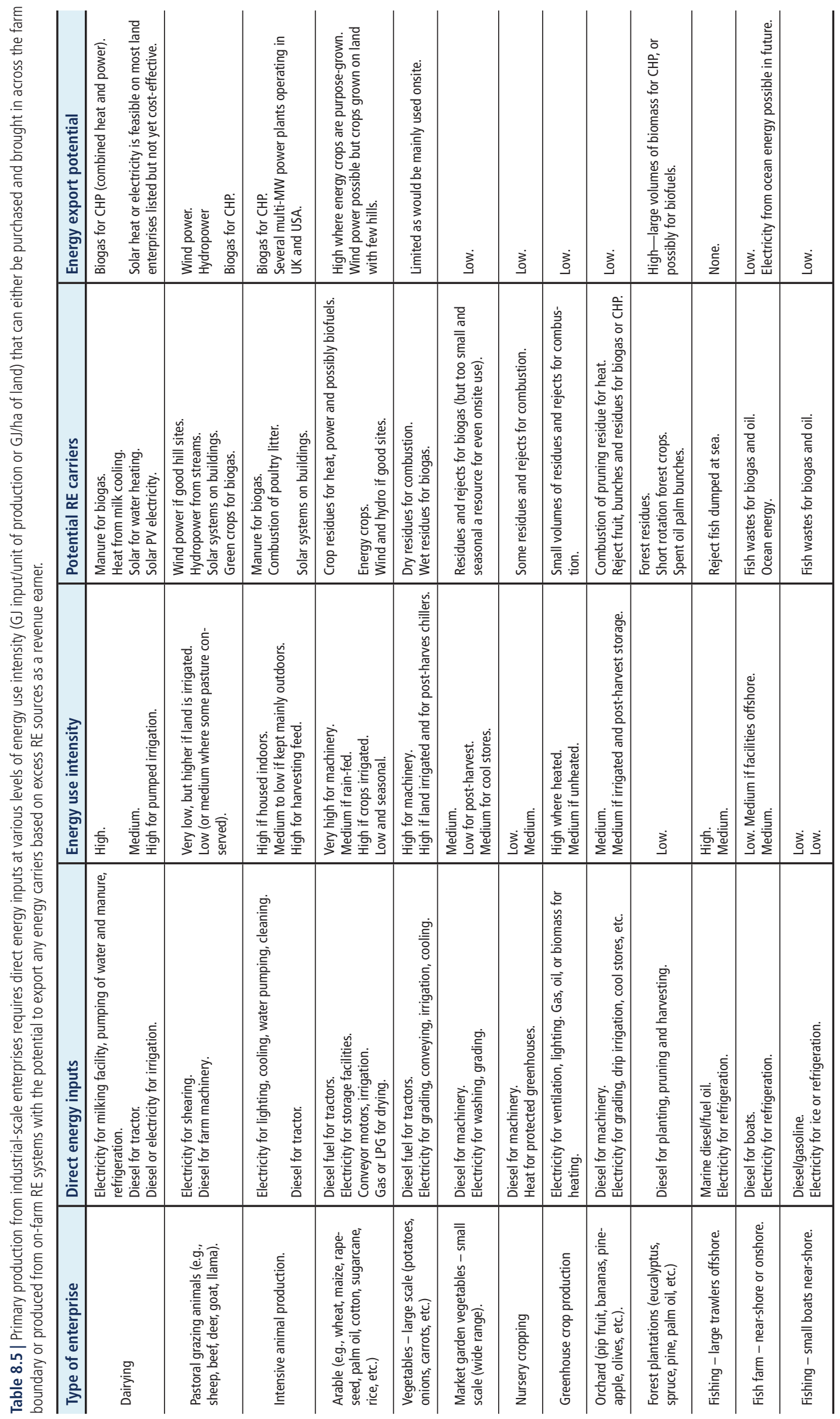


2010). When produced via gasification or pyrolysis using the controlled oxygen combustion of sustainably produced biomass, incorporation of the residual char into arable soils is claimed to enhance future plant growth and the carbon is removed from the atmosphere (Verheijen et al., 2010). Biochar properties vary with the biomass feedstock and various crops and soil types may respond in different ways in terms of their productivity. Further R\&D is required to address the net energy and nutrient balances for the various types of biochar.

\section{Case study: Distributed RE generation in a rural community.}

The small community of Totara Valley, New Zealand, illustrates how local RE resources can be utilized to meet local demands for heat and power and provide revenue and social benefits. The hydropower generation potential, wind speeds and solar radiation levels in the vicinity were monitored and a method developed to show seasonal and daily variations and match these with electricity demand (Murray, 2005) (Figure 8.25). An electricity generation and/or a lines distribution company could have strong business interests in such a scheme by becoming a joint venture partner, not only to buy and sell the surplus

(a)

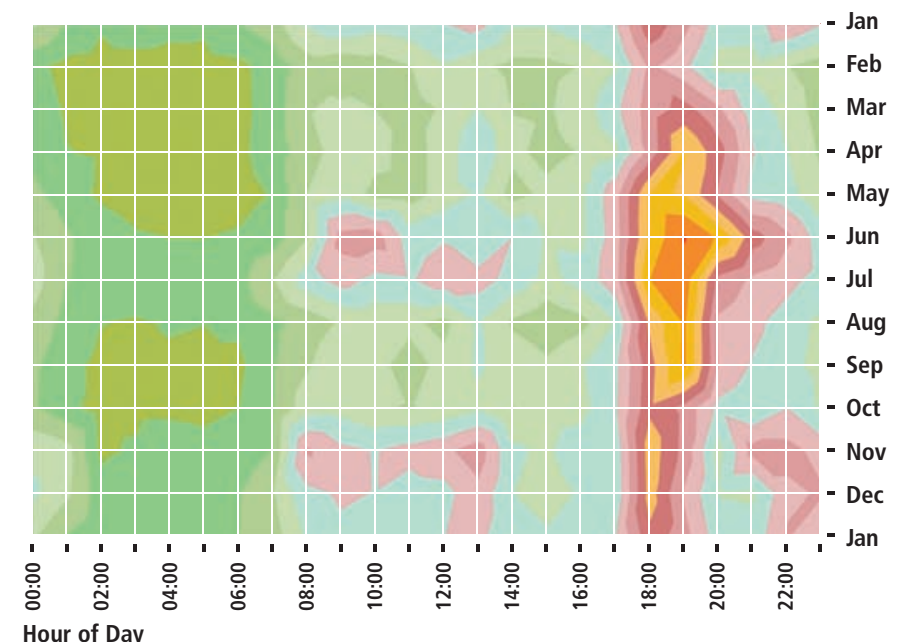

Hour of Day

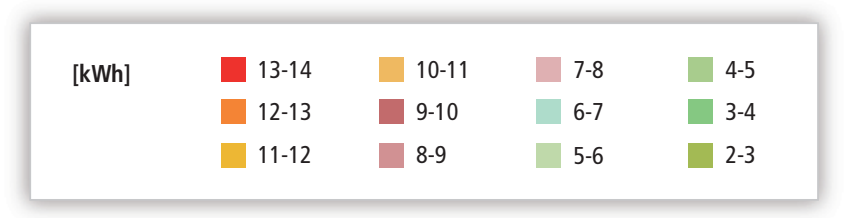

electricity, but also to sell, hire or lease the RE equipment to the landowners (Jayamaha, 2003).

The Totara Valley small-scale demonstration project consists of solar PV, solar thermal panels and heat pumps on some of the houses, a biodiesel generating set, a $1 \mathrm{~kW}$ Pelton micro-hydro turbine, and, on a hill site selected for its average wind speeds and proximity to load, a $2.2 \mathrm{~kW}$ wind turbine. Due to the USD 13,000 cost estimate for installing $1.5 \mathrm{~km}$ of copper cable to connect the hill site to the community buildings, the wind turbine is instead used to power an adjacent electrolyzer (Sudol, 2009). The hydrogen produced is carried in an underground alkathene pipe to a fuel cell housed in the farm buildings. Storage and transfer losses in the pipe are only around $1 \%$ of total hydrogen production (Gardiner et al., 2008). The overall efficiency of the hydrogen system is low but is partly offset by it acting as an energy store for the community system. The demonstration has shown that integration of a portfolio of RE technologies with existing heat and power supply systems is feasible for an agricultural community, but economic assessment of the options is recommended on a site-by-site basis. (b)
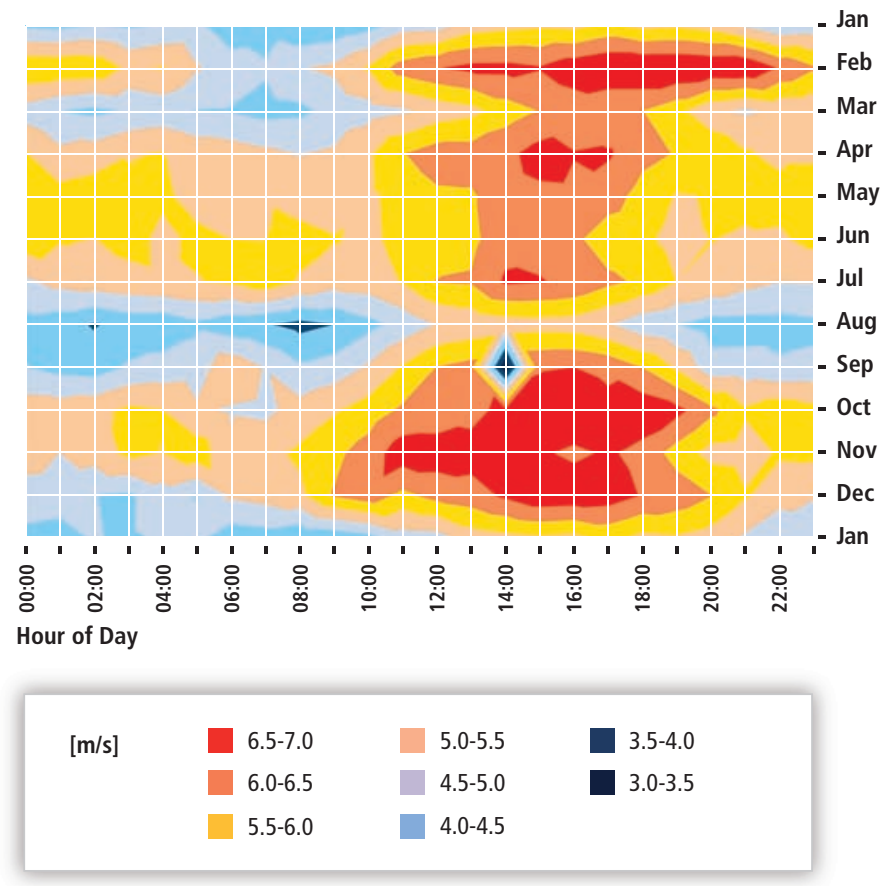

Figure 8.25 | (a) Average seasonal and daily electricity demand for the Totara Valley community (in kWh consumption per 30 minute periods), and (b) annual and daily wind data, showing some matching of wind power supply with evening and winter peak demands (Murray, 2005). 


\section{References}

Abdelkader, S., S. Abbott, J. Fu, L. McClean, D. Flynn, B. Fox, and L. Bryans (2009). Dynamic monitoring of overhead line ratings in wind intensive areas. In: European Wind Energy Conference (EWEC), Marseille, France, 16-19 March 2009.

Achilles, S., S. Schramm, and J. Bebic (2008). Transmission System Performance Analysis for High-Penetration Photovoltaics, Subcontract Report. National Renewable Energy Laboratory, Golden, CO, USA, 77 pp.

Ackermann, T., G. Ancell, L.D. Borup, P.B. Eriksen, B. Ernst, F. Groome, M. Lange, C. Mohrlen, A.G. Orths, J. O'Sullivan, and M. de la Torre (2009). Where the wind blows. IEEE Power and Energy Magazine, 7(6), pp. 65-75.

Ackermann, T., and P. Morthorst (2005). Economic aspects of wind power in power systems. In: Wind Power in Power Systems. T. Ackermann (ed.), John Wiley \& Sons, New York, NY, USA, pp. 383-410.

AEMO (2010). An Introduction to Australia's National Electricity Market. Australian Energy Market Operator, Melbourne, Australia, $28 \mathrm{pp}$.

Ahlgren, S., S. Bernesson, Å. Nordberg, and P.A. Hansson (2008). Nitrogen fertiliser production based on biogas - energy input, environmental impact and land use. Bioresource Technology, 101(18), pp. 7181-7184.

Åhman, M. (2010). Biomethane in the transport sector - An appraisal of the forgotten option. Energy Policy, 38(1), pp. 208-217.

AIGS (2008). All Island Grid Study, Workstream 4: Analysis of Impacts and Benefits. Department of Communications, Energy and Natural Resources, UK Department of Enterprise, Trade and Investment, Dublin, Ireland, 82 pp.

Akbari, H., S. Menon, and A. Rosenfeld (2009). Global cooling: increasing worldwide urban albedos to offset $\mathrm{CO}_{2}$. Climatic Change, 94(3-4), pp. 275-286.

Alakangas, E., and M. Flyktman (2001). Biomass CHP technologies. VTT Energy Reports 7/2001, VTT Energy, Jyvaskyla, Finland, 62 pp.

Aliabadi, A.A., J.M. Thomson, and J.S. Wallace (2010). Efficiency analysis of natural gas residential micro-cogeneration systems. Energy Fuels, 24(3), pp. 1704-1710.

Amigun, B., R. Sigamoney, and H. Blottnitz (2008). Commercialization of biofuel industry in Africa: A review. Renewable and Sustainable Energy Reviews, 12(3), pp. $690-711$.

Anant, S., D. Buddhi, and R.L. Sawhney (2008). Thermal cycling test of selected inorganic and organic phase change materials. Renewable Energy, 33(12), pp. 2606-2614.

Antvorskov, S. (2007). Introduction to integration of renewable energy in demand controlled hybrid ventilation systems for residential buildings. Building and Environment, 43(8), pp. 1350-1353.

ARE (2009). Hybrid Power Systems Based on Renewable Energies: A Suitable and Cost-Competitive Solution for Rural Electrification. Position Paper, Alliance for Rural Electrification, Brussels, Belgium, $7 \mathrm{pp}$.

Akershus Energi (2010). Skedsmo Kommune, Akershus Energi Varme AS. Ecoheat4EU.www.ecoheat4.eu/en/Country-by-country-db/Norway/ Local-Success-Stories/-print.

Arroyo, J.M., and F.D. Galiana (2005). Energy and reserve pricing in security and network-constrained electricity markets. IEEE Transactions on Power Systems, 20(2), pp. 634-643.

Avadikyan, A., and P. Llerenaa (2010). A real options reasoning approach to hybrid vehicle investments. Technological Forecasting and Social Change, 77(4), pp. 649-661.
Awerbuch, S. (2006). Portfolio-based electricity generation planning: policy implications for renewables and energy security. Mitigation and Adaptation Strategies for Global Change, 11(3), pp. 693-710.

Axegård, P., B. Backlund, and B. Warnquist (2002). The Eco-Cyclic pulp mill: Focus on closure, energy efficiency and chemical recovery development. Pulp \& Paper Canada, 103(5), pp. 26-29.

Azevedo, J.M., and F.D. Galiana (2009). The sugarcane ethanol power industry in Brazil: obstacles, success and perspectives. In: IEEE Electrical Power \& Energy Conference, Montreal, Canada, 22-23 October 2009.

Bajgain, S., and I.S. Shakya (2005). The Nepal Biogas Support Program: A Successful Model of Public Private Partnership for Rural Household. Netherlands Development Organisation and the Biogas Support Programme, The Hague, The Netherlands and Kathmandu, Nepal, 75 pp.

Bajnóczy, G., G. Palffy, E. Prépostffy, and A. Zöld (1999). Heat storage by twograde phase change material. Perodica Polytechnica Chemical Engineering, 43(2), pp. 137-147.

Bandivadekar, A., K. Bodek, L. Cheah, C. Evans, T. Groode, J. Heywood, E. Kasseris, M. Kromer, and M. Weiss (2008). On the Road in 2035: Reducing Transportation's Petroleum Consumption and GHG Emissions. Laboratory for Energy and the Environment, Massachusetts Institute of Technology, Cambridge, MA, USA

Barroso, L.A., S. Granville, J. Trinkenreich, M.V. Pereira, and P. Lino. (2003). Managing hydrological risks in hydro-based portfolios. IEEE Power Engineering Society General Meeting, 2(274).

Bauer, D., R. Marx, J. Nußbicker-Lux, F. Ochs, W. Heidemann, and H. MüllerSteinhagen (2010). German central solar heating plants with seasonal heat storage. Solar Energy, 84(4), pp. 612-623.

Bayem, H., L. Capely, F. Dufourd, and M. Petit (2009). Probabilistic study of the maximum penetration rate of renewable energy in an island network. In: IEEE PowerTech 2009, Bucharest, Romania, 28 June - 2 July 2009, pp. 1-5.

BDEW (2008). Technical Conditions for Connection to the Medium-Voltage Network. German Association of Energy and Water Industries, Berlin, Germany.

BEN (2010). Balanço Energetico Nacional (National Energy Balance Brazil). Ministry of Mines and Energy, Brazil. Available at: www.epe.gov.br/Estudos/Paginas/ Balan\%C3\%A70\%20Energ\%C3\%A9tico\%20Nacional\%20\%E2\%80\%93\%20 BEN/Estudos_13.aspx.

Bergen, A., and V. Vittal (2000). Power Systems Analysis. 2nd ed. Prentice-Hall Inc., NJ, USA, 619 pp.

Bernstein, L., J. Roy, K.C. Delhotal, J. Harnisch, R. Matsuhashi, L. Price, K. Tanaka, E. Worrell, F. Yamba, and Z. Fengqi (2007). Industry. In: Climate Change 2007: Mitigation of Climate Change. Contribution of Working Group III to the Fourth Assessment Report of the Intergovernmental Panel on Climate Change. B. Metz, O.R. Davidson, P.R. Bosch, R. Dave, and L.A. Meyer (eds.), Cambridge University Press, pp. 447-496.

Billinton, R. and R.N. Allan (1988). Concepts of power system reliability evaluation. International Journal of Electrical Power \& Energy Systems, 10(3), pp. 139-141.

Billinton, R., and P.G. Harrington (1978). Reliability evaluation in energy limited generating capacity studies. IEEE Transactions on Power Apparatus and Systems, 97(6), pp. 2076-2085.

Biogasmax (2009). European Biomethane Demonstration Project. Available at: www.biogasmax.co.uk.

Bloem, J.J. (2008). Evaluation of a PV-integrated building application in a well-controlled outdoor test environment. Building and Environment, 43(2), pp. 205 -216. 
BMU (2009). Richtlinien zur Förderung von Maßnahmen zur Nutzung erneuerbarer. Guidelines Energien im Wärmemarkt, German Federal Ministry for the Environment, Nature Conservation and Nuclear Safety (BMU), Berlin, Germany, 25 pp.

BMU (2010). Renewable Energy Sources in Figures. German Federal Ministry for the Environment, Nature Conservation and Nuclear Safety (BMU), Berlin, Germany, $76 \mathrm{pp}$.

Bodmann, M., D. Mangold, J. Nußbicker, S. Raab, A. Schenke, and T. Schmidt (2005). Solar unterstützte Nahwärme und Langzeit-Wärmespeicher (Februar 2003 bis Mai 2005). Report 0329607F, Forschungsbericht zum BMWA/BMUVorhaben, Stuttgart, Germany, 159 pp.

Bonhoff, K., N. Parker, S. Joest, M. Fichtner, M. Wietschel, U. Bünger, C. Stiller, P. Schmidt, and F. Merten (2009). Woher kommt der Wasserstoff in Deutschland bis 2050? [Where will the Hydrogen in Germany come from in 2050?]. Report GermanHy Study, Nationale Organisation Wasserstoff- und Brennstoffzellentechnologie (NOW), Berlin, Germany, 62 pp.

Börjesson, P., and G. Berndes (2006). The prospects for willow plantations for wastewater treatment in Sweden. Biomass \& Bioenergy, 30, pp. 428-436.

Börjesson, P., and B. Mattiasson (2008). Biogas as a resource-efficient vehicle fuel. Trends in Biotechnology, 26(1), pp. 7-13.

Bouzidi, B., M. Haddadi, and O. Belmokhtar (2009). Assessment of a photovoltaic pumping system in the areas of the Algerian Sahara. Renewable and Sustainable Energy Reviews, 13(4), pp. 879-886.

Brattle Group, Freeman Sullivan \& Co, and Global Energy Partners LLC (2009). A National Assessment of Demand Response Potential. Federal Energy Regulatory Commission, Washington, DC, USA, $254 \mathrm{pp}$.

Braun, T., T. Stetz, B. Reimann, G. Valov, and G. Arnold (2009). Optimal reactive power supply in distribution systems - Technological and economic assessment for PV systems. In: 24th European Photovoltaic Solar Energy Conference and Exhibition, Hamburg, Germany, 21-25 September 2009.

Breuer, W., V. Hartmann, D. Povh, D. Retzmann, and E. Teltsch (2004). Application of HVDC for large power system interconnections. In: International Council on Large Electric Systems, 2004 Session, Paris, France, 29 August - 3 September 2004.

Brinkman, N., M. Wang, T Weber, and T. Darlington (2005). Well-to-wheels analysis of advanced fuel/vehicle systems - a North American study of energy use. Greenhouse Gas Emissions and Criteria Pollutant Emissions, General Motors Report, May. 173 pp http://www.transportation.anl.gov/pdfs/TA/339.pdf

Bromley, C.J., L. Rybach, M.A. Mongillo, and I. Matsunaga (2006). Geothermal resource utilization strategies to promote beneficial environmental effects and to optimize sustainability. In: Proceedings RE 2006, Chiba, Japan, 9-13 October 2006, pp. 1-4.

Brown, D.W. (1996). The geothermal analog of pumped storage for electrical demand load following. In: Energy Conversion Engineering Conference (IECEC 96), Denver, Co, USA, 11-16 August 1996, pp. 1653-1656.

Brown, W. (2010). The National Grid - Building for the Future. Transpower New Zealand Ltd., Wellington, New Zealand, 48pp. Available at: www.transpower. co.nz/f1958,45849325/iet-wayne-11 may2010.pdf.

Bruus, F., and H. Kristjansson (2004). Principal design of heat distribution. Danish Board of District Heating Newsletter, 2/2004. See:http://dbdh.dk/images/ uploads/pdf-distribution/principal-design-of-heat-distribution.pdf.

Bryans, A.G., B. Fox, P.A. Crossley, and M. O'Malley (2005). Impact of tidal generation on power system operation in Ireland. IEEE Transactions on Power Systems, 20(4), pp. 2034-2040.
Buckingham, G.S. (1965). Remote control of electricity supplies to the domestic consumer. Electronics and Power, 11(3), p. 98.

Bueno, C., and J.A. Carta (2006). Wind powered pumped hydro storage systems, a means of increasing the penetration of renewable energy in the Canary Islands. Renewable and Sustainable Energy Reviews, 10(4), pp. 312-340.

Buijs, P., D. Bekaert, S. Cole, D. Van Hertem, and R. Belmans (2011). Transmission investment problems in Europe: Going beyond standard solutions. Energy Policy, 39(3), pp. 1794-1801

Burke, D., and M. O'Malley (2010). Maximizing firm wind connection to security constrained transmission networks. IEEE Transactions on Power Systems, 25(2), pp. 749-759.

Caamano-Martin, E., H. Laukamp, M. Jantsch, T. Erge, J. Thornycroft, H. De Moor, S. Cobben, D. Suna, and B. Gaiddon (2008). Interaction between photovoltaic distributed generation and electricity networks. Progress in Photovoltaics, 16(7), pp. 629-643.

CAFCP (2009). Hydrogen Fuel Cell Vehicle and Station Deployment Plan: A Strategy for Meeting the Challenge Ahead. Action Plan. California Fuel Cell Partnership (CAFCP), West Sacramento, CA, USA. Available at: www.fuelcellpartnership.org/ sites/files/Action\%20Plan\%20FINAL.pdf .

CAISO (2010). Fifth Replacement FERC Electric Tariff, Appendix V Large Generator Interconnection Agreement (LGIA). California Independent System Operator Corporation, Folsom, CA, USA, $68 \mathrm{pp}$.

Cappers, P., C. Goldman, and D. Kathan (2010). Demand response in US electricity markets: Empirical evidence. Energy, 35(4), pp. 1526-1535.

Caralis, G., and A. Zervos, (2007a): Analysis of wind power penetration in autonomous Greek islands. Wind Engineering, 31(6), pp. 487-502.

Caralis, G., and A. Zervos, (2007b): Analysis of the combined use of wind and pumped storage systems in autonomous Greek islands. Renewable Power Generation, 1(1), pp. 49-60.

Caralis, G., and A. Zervos (2010). Value of wind energy on the reliability of autonomous power systems. Renewable Power Generation, 4(2), pp. 186-197.

Carraretto, C. (2006). Power plant operation and management in a deregulated market. Energy, 31(6-7), pp. 1000-1016.

Castello, P., E. Tzimas, P. Moretto, and S.D. Peteves (2005). Techno-economic Assessment of Hydrogen Transmission and Distribution Systems in Europe in the Medium and Long Term. Report EUR 21586 EN, Institute for Energy, Petten, The Netherlands, 137 pp. (ISBN: 92-894-9292-9).

CEC (2006). Bioenergy Action Plan for California. Action Plan CEC-600-2006-01, Bioenergy Interagency Working Group, California Energy Commission (CEC), Sacramento, CA, USA.

Centolella, P. (2010). The integration of price responsive demand into Regional Transmission Organization (RTO) wholesale power markets and system operations. Energy, 35(4), pp. 1568-1574.

CEP (2010). Clean Energy Partnership. See: http://www.cleanenergypartnership.de/ fileadmin/pdf/20110519_CEP_\%20PM\%20Beitritt_AL\%20Honda_eng.pdf

Cerri, C.E.P., M. Easter, K. Paustian, K. Killian, K. Coleman, M. Bemoux, P. Falloon, D.S. Powlson, N.H. Batjes, E. Milne, and C.C. Cerri (2007). Predicted soil organic carbon stocks and changes in the Brazilian Amazon between 2000 and 2030. Agriculture, Ecosystems and Environment, 122, pp. 58-72.

CGEE (2009). Bioetanol como combustível: uma oportunidade para o Brasil. Report Document Number 389b, Centro de Gestão e Estudos Estratégicas em Ciência (CGEE), Tecnologia e Inovação, Sala, Brazil, 536 pp. 
Chan, H.-Y., B. Saffa, and J.Z. Riffat (2010). Review of passive solar heating and cooling technologies. Renewable and Sustainable Energy Reviews, 14, pp. 781-789.

Chen, H.S., T.N. Cong, W. Yang, C.Q. Tan, Y.L. Li, and Y.L. Ding (2009). Progress in electrical energy storage system: A critical review. Progress in Natural Science, 19(3), pp. 291-312.

Chen, Q., C. Kang, and Q. Xia (2010). Modeling flexible operation mechanism of $\mathrm{CO}_{2}$ capture power plant and its effects on power-system operation. IEEE Transactions on Energy Conversion, 25(3), pp. 853-861.

Chen, Z., J.M. Guerrero, and F. Blaabjerg (2009). A Review of the state of the art of power electronics for wind turbines. IEEE Transactions on Power Electronics, 24(8), pp. 1859-1875.

Cheung, A., and M. Wilshire (2010). White paper from Consortium on Digital Energy 2009-2010. Bloomberg New Energy Finance, London, UK, 40 pp.

Cheung, K. (2008). Ancillary service market design and implementation in North America: From theory to practice. In: Electric Utility Deregulation and Restructuring and Power Technologies, 2008 (DRPT 2008). Third International Conference, Nanjuing, China, 6-9 April 2008, pp. 66-73

Chowdhury, B.H., and A.W. Sawab (1996). Evaluating the value of distributed photovoltaic generations in radial distribution systems. IEEE Transactions on Energy Conversion, 11(3), pp. 595-600.

Christidis, P., I. Hidalgo, and A. Soria (2003). Dynamics of the Introduction of New Passenger Car Technologies: The IPTS Transport Technologies Model. Report EUR 20762 EN, European Commission, Brussels, Belgium.

Ciferno, J.P., and J.J. Marano (2002). Benchmarking Biomass Gasification Technologies for Fuels, Chemicals and Hydrogen Production. U.S. Department of Energy, National Energy Technology Laboratory, Pittsburgh, PA, USA, 58 pp.

CILSS (2004). Capitalisation of the Sahelian experience in natural forest management for wood energy production. Regional workshop. Comité Inter-Etate pour la Lutte contre la Sécheresse au Sahel (CILSS: Permanent Inter-State Committee for Drought Control in the Sahel), Niamey, Niger.

CILSS (2008). Réglemenation et fiscalité sur le bois énergie: situation comparée, contexte, enjeux et défis. Regional workshop. Comité Inter-Etate pour la Lutte contre la Sécheresse au Sahel (CILSS : Permanent Inter-State Committee for Drought Control in the Sahel), Niamey, Niger.

CONCAWE (2007). Well-to-wheels Analysis of Future Automotive Fuels and Powertrains in the European Context. Report Version 2c (March). Conservation of Clean Air and Water in Europe (CONCAWE), Brussels, Belgium. Available at: ies.jrc. ec.europa.eu/uploads/media/V3.1\%20TTW\%20Report\%2007102008.pdf.

Contreras, A.B., M. Thomson, and D.G. Infield (2007). Renewable energy powered desalination in Baja California Sur, Mexico. Desalination, 220(1-3), pp. 431-440.

Cornell (2005). Lake Source Cooling. Cornell University Facilities Services, Utilities and Energy Management, Ithaca, NY, USA. Available at: http://energyandsustainability.fs.cornell.edu/util/cooling/production/lsc/default.cfm.

CREZ (2010). CREZ Progress Report No. 1. Competitive Renewable Energy Zone (CREZ) Program Oversight, Public Utility Commission of Texas, Austin, TX, USA, $95 \mathrm{pp}$.

Croezen, H., and M. Korteland (2010). A Long-Term View of $\mathrm{CO}_{2}$ Efficient Manufacturing in the European Region. Report 107207 47, CE Delft, Delft, The Netherlands, $87 \mathrm{pp}$.

CSO (2010). Population and Migration Estimates. Central Statistics Office, Cork, Ireland, $9 \mathrm{pp}$.
Curtright, A.E., and J. Apt (2008). The character of power output from utility-scale photovoltaic systems. Progress in Photovoltaics, 16(3), pp. 241-247.

Dalenbäck, J.O. (2010). Success factors in solar district heating CIT Energy management AB, Project Report for Solar District Heating, (SDH) December. 62pp. http://www.solar-district-heating.eu/LinkClick.aspx?fileticket=c6-K2BVa2h $\mathrm{M} \% 3 \mathrm{~d} \&$ tabid $=69$

Dalton, G.J., D.A. Lockington, and T.E. Baldock (2008). Case study feasibility analysis of renewable energy supply options for small to medium-sized tourist accommodations. Renewable Energy, 34(4), pp. 1134 -1144.

Davis, S., S. Diegel, and R. Boundy (2010). Transportation Energy Data Book. ORNL-6985 (Edition 29 of ORNL-5198), Oak Ridge National Laboratory, Center for Transportation Analysis, Energy and Transportation Science Division, Oak Ridge, TN, USA.

de Angelis, F., G. Magnante, N. Rossi, and A. Siniscalchi (2010). Local governance and sustainable communities. European benchmarking and EU convergence regions in Southern Italy. In: MED3 Proceedings, Tunis, Tunisia, 7-8 October 2010, pp. 1-17. Available at: med-eu.org/documents/MED3/DE\%20ANGELISMAGNANTE-ROSSI-SINISCALCHI.pdf.

de Moraes, M.A.F.D., and L. Rodrigues (2006). Brazil Alcohol National Program. Relatório de pesquisa. No publisher specified, Piracicaba, Brazil, 54 pp. Available at: english.unica.com.br/multimedia/documentos/Default.asp?sqlPage=1.

de Wasseige, C., D. Devers, P. de Marcken, R. Eba'a Atyi, R. Nasi, and P. Mayaux (eds.) (2009). Etat des Forêts 2008. Congo Basin Forest Partnership, Publications Office of the European Union, 426 pp. (ISBN 978-92-79-132 11-7).

DEA (2009).Danish EnergyAgency. Danish Energy Agency, Copenhagen, Denmark. See: www.ens.dk/en-US/supply/Renewable-energy/WindPower/Facts-about-WindPower/Key-figures-statistics/Sider/Forside.aspx

Deane, J., B.Ò. Gallachòir, and E.J. McGeogh (2010). Techno-economic review of existing and new pumped hydro energy storage plant. Renewable and Sustainable Energy Reviews, 14(4), pp. 1293-1302.

DeCarolis, J., and D. Keith (2006). The economics of large-scale wind power in a carbon constrained world. Energy Policy, 34(4), pp. 395-410.

Delgado-Torres, A.M., and L. García-Rodríguez (2007). Comparison of solar technologies for driving a desalination system by means of an organic Rankine cycle. Desalination, 216(1-3), pp. 276-291.

Delille, G., B. François, and G. Malarange (2010). Dynamic frequency control support: A virtual inertia provided by distributed energy storage to isolated power systems. In: Innovative Smart Grid Technologies Conference Europe (ISGT Europe), IEEE PES, Gothenburg, Sweden, 11-13 October 2010.

Delucchi, M., and M. Jacobson (2009). A plan to power 100 percent of the planet with renewables. Scientific American, November 2009, pp. 58-65.

DENA (2005). Energiewirtschaftliche Planung für die Netzintegration von Windenergie in Deutschland an Land und Offshore bis zum Jahr 2020. Study by Energiewirtschaftliches Institut an der Universität zu Köln (EWI), DeutschesWindenergie-Institut (DEWI), E.ON Netz GmbH, RWE Transportnetz Strom GmbH, Vattenfall Europe Transmission GmbH. Report, Deutsche EnergieAgentur GmbH (DENA), Köln, Germany, 380 pp.

DENA (2010). Dena-Netzstudie II - Integration erneuerbarer Energien in die deutsche Stromversorgung im Zeitraum 2015-2020 mit Ausblick 2025. Deutsche EnergieAgentur GmbH (DENA), Berlin, Germany, 620 pp.

Denault, M., D. Dupuis, and S. Couture-Cardinal (2009). Complementarity of hydro and wind power: Improving the risk profile of energy inflows. Energy Policy, 37(12), pp. 5376-5384. 
Deng, Y., Z. Yu, and S. Liu (2011). A review on scale and siting of wind farms in China. Wind Energy, 14(3), pp. 463-470.

Denholm, P., and R.M. Margolis (2007). Evaluating the limits of solar photovoltaics (PV) in electric power systems utilizing energy storage and other enabling technologies. Energy Policy, 35(9), pp. 4424-4433.

Denholm, P., and R. Sioshansi (2009). The value of compressed air energy storage with wind in transmission-constrained electric power systems. Energy Policy, 37(8), pp. 3149-3158.

Denholm, P., R.M. Margolis, and J.M. Milford (2009). Quantifying avoided fuel use and emissions from solar photovoltaic generation in the western United States. Environmental Science \& Technology, 43(1), pp. 226-232.

Denholm, P., E. Ela, and B. Kirby (2010). The role of Energy Storage with Renewable Electricity Generation. Technical report, National Renewable Energy Laboratory, Golden, CO, USA, $61 \mathrm{pp}$.

Denny, E. (2009). The economics of tidal energy. Energy Policy, 37(5), pp. 1914-1924.

Denny, E., and M. O'Malley (2006). Wind generation, power system operation, and emissions reduction. IEEE Transactions on Power Systems, 21(1), pp. 341-347.

Denny, E., A. Tuohy, P. Meibom, A. Keane, D. Flynn, A. Mullane, and M. O'Malley (2010). The impact of increased interconnection on electricity systems with large penetrations of wind generation: A case study of Ireland and Great Britain. Energy Policy, 38(11), pp. 6946-6954.

DeValve, T., and B. Olsommer (2006). Micro-CHP Systems for Residential Applications Final Report. US DOE Report (Contract No. DE-FC26-04NT42217), United Technologies Research Center, East Hartford, CT, USA, 114 pp.

Devine-Wright, P., H. Devine-Wright, and F. Sherry-Brennan (2010). Visible technologies, invisible organisations: An empirical study of public beliefs about electricity supply networks. Energy Policy, 38(8), pp. 4127-4134.

DFID (2002). Energy for the Poor - Underpinning the Millennium Development Goals. UK Department for International Development (DFID), London, England. Available at: http://www.ecn.nl/fileadmin/ecn/units/bs/JEPP/energyforthepoor.pdf

Dimoudi, A., and P. Kostarela (2008). Energy monitoring and conservation potential in school buildings in the $C^{\prime}$ climatic zone of Greece. Renewable Energy, 34(1), pp. 289-296.

DiPippo, R. (2008). Geothermal Power Plants: Principles, Applications, Case Studies and Environmental Impact. 2nd ed. Elsevier Ltd., London, UK, 493 pp.

Doherty, R., H. Outhred, and M. O'Malley (2006). Establishing the role that wind generation may have in future generation portfolios. IEEE Transactions on Power Systems, 21(3), pp. 1415-1422.

Doherty, R., A. Mullane, G. Nolan, D.J. Burke, A. Bryson, and M. O'Malley (2010). An assessment of the impact of wind generation on system frequency control. IEEE Transactions on Power Systems, 25(1), pp. 452-460.

Doolla, S., and T.S. Bhatti (2006). Load frequency control of an isolated small-hydro power plant with reduced dump load. IEEE Transactions on Power Systems, 21(4), pp. 1912-1919.

Doukas, H., C. Nychtis, and J. Psarras (2008). Assessing energy-saving measures in buildings through an intelligent decision support model. Building and Environment, 44(2), pp. 290-298.

Dounis, A.I., and C. Caraiscos (2009). Advanced control systems engineering for energy and comfort management in a building environment: A review. Renewable and Sustainable Energy Reviews, 13(6-7), pp. 1246-1261.

DPG (2010). Elektrizitat: Schlüssel zu einem nachhaltigen und klimaverträglichen Energiesystem. Deutsch Physikalische Gesellshaft (DPG), Bad Honnef, Germany, $144 \mathrm{pp}$.
Droege, P., A. Radzi, N. Carlisle, and S. Lechtenböhmer (2010). 100\% Renewable Energy and Beyond for Cities. Report, HafenCity University Hamburg and World Future Council Foundation, Hamburg, Germany, $26 \mathrm{pp}$.

Dubey, S., and G.N. Tiwari (2010). Energy and exergy analysis of hybrid photovoltaic/thermal solar water heater considering with and without withdrawal from tank. Journal of Renewable and Sustainable Energy, 2(4), 043106.

Dudurych, I.M. (2010a). On-line assessment of secure level of wind on the Irish power system. In: Power and Energy Society General Meeting, IEEE, 25-29 July, Minneapolis, pp. 1-29.

Dudurych, I.M. (2010b). Statistical analysis of frequency response of island power system under increasing wind penetration. In: Power and Energy Society General Meeting, IEEE, Minneapolis, MN, USA, 25-29 July 2010, pp. 1-29.

Dunwoody, C. (2010). Progress and Next Steps in California. In: WHEC 2010 - 18th World Hydrogen Energy Conference. D. Stolten (ed.), International Association for Hydrogen Energy, Essen, Germany, 16-21 May 2010.

Duvall, M. (2010). Benefits and impacts of plug-in hybrid and battery electric vehicles. In: Electrification of the Transportation System: An MIT Energy Initiative Symposium, Cambridge, MA, USA, 8 April 2010, 32 pp. Available at: web.mit.edu/ mitei/docs/reports/electrification-transportation-system.pdf.

EA Energy Analyses (2007). 50\% Wind Power in Denmark in 2025. Energy Agency, Copenhagen, Denmark, $12 \mathrm{pp}$.

Earle, R., E.P. Kahn, and E. Macan (2009). Measuring the capacity impacts of demand response. The Electricity Journal, 22(6), pp. 47-58.

EASAC (2009). Transforming Europe's Electricity Supply - An Infrastructure Strategy for a Reliable, Renewable and Secure Power System. Policy report 11, European Academies Science Advisory Council (EASAC), Halle, Germany, 41 pp.

EC (2006). Spain's New Building Energy Standards Place the Country among the Leaders in Solar Energy in Europe. Action Plan, European Commission Environmental Technologies, Brussels, Belgium, 2 pp.

EC (2010). Energy Performance of Buildings Directive (Recast). Report 2010/31/EU, European Commission, Brussels, Belgium.

ECI (2006). Diversified Renewable Energy Resources: An Assessment of an Integrated Wind, Wave and Tidal Stream Electricity Generating System in the UK, and the Reliability of Wave Power Forecasting. The Carbon Trust and the Environmental Change Institute (ECI), London and Oxford, UK, 42 pp.

Ecofys (2008). Study on the Comparative Merits of Overhead Electricity Transmission Lines versus Underground Cables. Report prepared for the Department of Communications, Energy and Natural Resources, Dublin, Ireland, 234 pp.

EECA (2008). Hydro Energy on Your Farm, Technical Guide 5.0. Energy Efficiency and Conservation Authority (EECA) of New Zealand, Wellington, New Zealand.

Egeskog, A., J. Hansson, G. Berndes, and S. Werner (2009). Co-generation of biofuels for transportation and heat for district heating systems - an assessment of the national possibilities in the EU. Energy Policy, 37, pp. 5260-5272.

EIA (2007). About U.S. Natural Gas Pipelines - Transporting Natural Gas. Energy Information Administration, U.S. Department of Energy, Washington, DC, USA, $76 \mathrm{pp}$.

EIA (2010). International Energy Outlook 2010. Report DOE/EIA-0484(2010), Energy Information Administration, US Department of Energy, Washington, DC, USA, 338 pp. Available at: www.eia.doe.gov/oiaf/ieo/pdf/0484(2010).pdf.

EIGA (2004). Hydrogen Transportation Pipelines. Report IGC Doc 121/04, European Industrial Gases Association, Brussels, Belgium, 77 pp.

EirGrid (2008). Grid 25: A Strategy for the Development of Ireland's Electricity Grid for a Sustainable and Competitive Future. EirGrid, Dublin, Ireland, 47 pp. 
EirGrid (ed.) (2009). Grid Code Version 3.4. EirGrid, Dublin, Ireland, 316 pp.

EirGrid (2010a). Annual Renewable Report: Powering a Sustainable Future. EirGrid, Dublin, Ireland, $32 \mathrm{pp}$.

EirGrid (2010b). All Island TSO Facilitation of Renewable Studies. EirGrid, Dublin, Ireland, $77 \mathrm{pp}$.

Ekman, C.K., and S.H. Jensen (2010). Prospects for large scale electricity storage in Denmark. Energy Conversion and Management, 51(6), pp. 1140-1147.

El-Sharkawi, M.A. (2009). Electric Energy - An Introduction. CRC Press, Taylor \& Francis LLC, Oxford, UK, 472 pp.

Energinet.DK (2007). System Plan 2007. Energinet.DK, Fredericia, Denmark, 64 pp.

Energinet.DK (2008). Technical Report on the Future Expansion and Undergrounding of the Electricity Transmission Grid, Summary. Energinet.DK, Fredericia, Denmark, $28 \mathrm{pp}$.

EnerNex Corporation (2010). Eastern Wind Integration and Transmission study (EWITS). Subcontract Report National Renewable Energy Laboratory, Knoxville, TN, USA, $242 \mathrm{pp}$.

ENTSO-E (2010). Ten-Year Network Development Plan 2010-2020. European Network of Transmission System Operators for Electricity, Brussels, Belgium, 286 pp.

EPA (2007). Regulatory Impact Analysis: Renewable Fuel Standard Program: Estimated Costs of Renewable Fuels, Gasoline and Diesel (Chapter 7). Report EPA420-R-07-004, Office of Transportation and Air Quality, U.S. Environmental Protection Agency, Assessment and Standards Division, Washington, DC, USA, $62 \mathrm{pp}$.

EPA (2010). Renewable Fuel Standard Program (RFS-2) Regulatory Impact Analysis. Report EPA-420-R-10-006, Assessment and Standards Division, Office of Transportation and Air Quality, U.S. Environmental Protection Agency, Washington, DC, USA, $62 \mathrm{pp}$.

EPE (2009). Balanço Energético Nacional 2009: Ano base 2008. Empresa de Pesquisa Energética, Rio de Janeiro, Brazil.

Epp, B. (2009). Dänemark: Solare Nahwärme ist wirtschaftlich. Solarthemen, 17(2425 September), pp. 312.

EPRI (2007). Environmental Assessment of Plug-In Hybrid Electric Vehicles. Report 1015325, Electric Power Research Institute, Palo Alto, California, USA. Available at: miastrada.com/yahoo_site_admin/assets/docs/epriVolume1R2.36180810.pdf.

EPRI (2009). Program on Technology Innovation: Industrial Electrotechnology Development Opportunities. Electric Power Research Institute, Palo Alto, CA, USA.

EREC (2008). The Renewable Energy House. European Renewable Energy Council, Brussels, Belgium. Available at: www.erec.org/reh.html.

Ericsson, K. (2009). Introduction and Development of the Swedish District Heating Systems - Critical Factors and Lessons Learned (Policy Paper). Policy development for improving Renewable Energy Sources Heating and Cooling penetration in European Member States (Intelligent Energy Europe), CRES, Pikermi, Greece. Available at: www.res-h-policy.eu/downloads/Swedish_district_heating_casestudy_(D5)_final.pdf.

Ericsson, K., L.J. Nilsson, and M. Nilsson (2010). New energy strategies in the Swedish pulp and paper industry - The role of national and EU climate and energy policies. Energy Policy, 39, pp. 1439-1449.

Eriksen, P.B., and A.G. Orths (2008). The challenges and solutions of increasing from 20 to 50 percent of wind energy coverage in the Danish power system until 2025. In: 7th International Workshop on Large Scale Integration of Wind Power and on Transmission Networks for Offshore Wind Farms. T. Akermann (ed.), Enerynautics GmbH, Madrid, Spain, 26-27 May 2008, pp. 7.
Ernst, B., U. Schreier, F. Berster, J.H. Pease, C. Scholz, H.P. Erbring, S. Schlunke, and Y.V. Makarov (2010). Large-scale Wind and Solar Integration in Germany. Pacific Northwest National Laboratory, prepared for the U.S. Department of Energy, Oak Ridge, TN, USA, $52 \mathrm{pp}$.

Estanqueiro, A., C.B. Mateus, and R. Pestana (2010). Operational experience of extreme wind penetrations. In: 9th International Workshop on Large-Scale Integration of Wind Power into Power Systems as well as on Transmission Networks for Offshore Wind Power Plants, Quebec City, Canada, 18-19 October 2010, pp. 34-39.

Eto, J., J. Undrill, P. Mackin, R. Daschmans, B. Williams, B. Haney, R. Hunt, J. Ellis, H. Illian, C. Martinez, M. O'Malley, K. Coughlin, and K.H. LaCommare (2010). Use of Frequency Response Metrics to Assess the Planning and Operating Requirements for Reliable Integration of Variable Renewable Generation. Lawrence Berkeley National Laboratory, Berkeley, CA, USA, 141 pp.

Eurelectric (2004). Electricity for More Efficiency: Electric Technologies and Their Energy Savings Potential. Union of the Electricity Industry, Brussels, Belgium.

Eurogas (2008). Eurogas Annual Report 2007/2008. Eurogas, Brussels, Belgium, $43 \mathrm{pp}$.

Euroheat \& Power (2007). District Heating and Cooling - Country by Country 2007 survey. Report, Euroheat \& Power, Brussels, Belgium.

EWIS (2010). Towards a Successful Integration of Large Scale Wind Power into European Electricity Grids, Final Report. European Wind Integration Study, Brussels, Belgium, $182 \mathrm{pp}$.

Fan, Y., L. Luo, and B. Souyri (2007). Review of solar sorption refrigeration technologies: development and applications. Renewable and Sustainable Energy Reviews, 11(8), pp. 1758-1775.

FAO (2009). FAO Statistical Databases. UN Food and Agricultural Organization, Rome, Italy.

FERC (2005). Order 661-A. Federal Energy Regulatory Commission, Washington, DC, USA, $59 \mathrm{pp}$.

Fox, B., A.I. McCartney, and B.M. McCann (1998). Scheduling of radio-controlled heating load. IEE Proceedings: Generation, Transmission and Distribution, 145 pp. 641-646.

Fritsche, U.R., R.E.H. Sims, and A. Monti (2010). Direct and indirect land use competition issues for energy crops and their sustainable production - an overview. Biofuels, Bioproducts and Biorefining, 4, pp. 692-704.

Fusco, F., G. Nolan, and J.V. Ringwood (2010). Variability reduction through optimal combination of wind/wave resources - An Irish case study. Energy, 35(1), pp. 314-325.

Gardiner, A.I., E.N. Pilbrow, S.R. Broome, and A.E. McPherson (2008). Hylink a renewable distributed energy application for hydrogen. In: 3rd International Solar Energy Society Conference - Asia Pacific Region (ISES-AP-08), ISES, Sydney, Australia, 25-28 November 2008, pp. 11.

GE Energy (2010). Western Wind and Solar Integration Study Report (WWSIS). Subcontract Report NREL/SR-550-47781, National Renewable Energy Laboratory, Golden, CO, USA, 536 pp.

GE Energy Consulting (2007). Impact of Intermittent Generation on Operation of California Power Grid. Subcontract Report, California Energy Commission Public Interest Energy Research Program, Sacramento, CA, USA, 242 pp.

Giatrakos, G.P., T.D. Tsoutsos, and N. Zografakis (2009). Sustainable power planning for the island of Crete. Energy Policy, 37(4), pp. 1222-1238. 
Giebel, G., R. Brownsword, G. Kariniotakis, M. Denhard, and C. Draxl (2011). The State-Of-The-Art in Short-Term Prediction of Wind Power: A Literature Overview, 2nd Edition. ANEMOS. plus Deliverable D-1.2, ARMINES, France.

Gielen, D., and G. Simbolotti (2005). Prospects for Hydrogen and Fuel Cells. International Energy Agency Publications, Paris, France, $253 \mathrm{pp}$.

Gil, A., M.d.I. Torre, and R. Rivas (2010). Influence of wind energy forecast in deterministic and probabilistic sizing of reserves. In: 9th International Workshop on Large-Scale Integration of Wind Power into Power Systems as well as on Transmission Networks for Offshore Wind Power Plants, Quebec City, Canada, 18-19 October 2010.

Glanchant, J.M., and D. Finon (2010). Large-scale wind power in electricity markets. Energy Policy, 38(10), pp. 6384-6386.

GMF (2008). Feeding the world: are new global agricultural policies needed? German Marshall Fund report on Wilton Park Conference 927, Steyning, UK, 24-26 November 2008. Available at: cap2020.ieep.eu/2009/4/14/ feeding-the-world-are-new-global-agricultural-policies-needed.

Goldemberg, J. (2000). Rural energy in developing countries. In: World Energy Assessment: Energy and the Challenge of Sustainability. United Nations Development Programme, United Nations Department of Economic and Social Affairs, and World Energy Council, New York, NY, USA, pp. 367-389. Available at: www.undp.org/energy/activities/wea/drafts-frame.html.

Goldemberg, J. (2009). The Brazilian experience with biofuels. Innovations, 4(4), pp. 91-107.

Gorenstin, B.G., N.M. Campodonico, J.P. Costa, and M.V.F. Pereira, 1992: Stochastic optimization of a hydrothermal system including network constraints. IEEE Transactions on Power Systems, 7(2), pp. 791-797.

Grant, W., D. Edelson, J. Dumas, J. Zack, M. Ahlstrom, J. Kehler, P. Storck, J. Lerner, K. Parks, and C. Finley (2009). Change in the air. IEEE Power \& Energy Magazine, 7(6), pp. 47-58.

Graus, W., M. Voogt, and E. Worrell (2007). International comparison of energy efficiency of fossil power generation. Energy Policy, 35(7), pp. 3936-3951.

Greaves, B., J. Collins, J. Parkes, and A. Tindal (2009). Temporal forecast uncertainty for ramp events. Wind Engineering, 33(4), pp. 309-319.

Greene, D., P. Leiby, and D. Bowman (2007). Integrated Analysis of Market Transformation Scenarios with HyTrans. Report ORNL/TM-2007/094, Oak Ridge National Laboratory, Oak Ridge, TN, USA.

Grimsrud, G.P., L. Isaksen, M.L. Chan, and S.T.Y. Lee (1981). Marketability of lowhead hydropower. IEEE Transactions on Power Apparatus and Systems, 100(1), pp. 184-189.

Gronheit, P.E., and B.O.G. Mortensen (2003). Competition in the market for space heating. District heating as the infrastructure for competition among fuels and technologies. Energy Policy, 31, pp. 817-826.

Gronich, S. (2006). Hydrogen \& FCV implementation scenarios, 2010 - 2025. In: USDOE Hydrogen Transition Analysis Workshop. US Department of Energy, Washington, DC, USA, 26 January 2006. Available at: www1.eere.energy.gov/ hydrogenandfuelcells/pdfs/transition_wkshp_summ.pdf.

Hagen, M., E. Polman, J.K. Jensen, A. Myken, O. Joensson, and A. Dahl (2001). Adding Gas from Biomass to the Gas Grid. Technical Report ISSN 1102-7371, Swedish Gas Center, Malmö, Sweden, 142 pp.

Haj Seyed Hadi, M.R. (2006). Energy efficiency and ecological sustainability in conventional and integrated potato production. In: ATEF 2006 - Advanced Technology in the Environmental Field, L. Ubertini (ed.), Acta Press, Lanzarote, Spain, 6-8 February 2006, 501-034.
Haldane, T.G.N., and P.L. Blackstone (1955). Problems of hydro-electric design in mixed thermal hydro-electric systems Proceedings of the IEE - Part A: Power Engineering, 102(3), pp. 311-322.

Hara, R., H. Kita, T. Tanabe, H. Sugihara, A. Kuwayama, and S. Miwa (2009). Testing the technologies: Demonstration grid-connected photovoltaic projects in Japan. IEEE Power \& Energy Magazine, 7(3), pp. 77-85.

Harris, C. (2006). Electricity Markets, Pricing, Structures and Economics. John Wiley and Sons, Sussex, UK, $519 \mathrm{pp}$.

Hasche, B., A. Keane, and M. O'Malley (2010). Capacity credit of wind power, calculation and data requirements: The Irish power system case. IEEE Transactions on Power Systems, 26(1), pp. 1-11.

Hatti-Kaul, R., U. Törnvall, L. Gustafsson, and P. Börjesson (2007). Industrial biotechnology for the production of bio-based chemicals - a cradle-to-grave perspective. Trends in Biotechnology, 26, pp. 119-124.

Heidemann, W., and H. Müller-Steinhagen (2006). Central solar heating plants with seasonal heat storage. In: International Conference on Renewable Energies and Water Technologies, CIERTA, Almeria, Spain, 6-7 October 2006.

Heikkilä, J., J. Laitila, V. Tanttu, J. Lindblad, M. Sirén, and A. Asikainen (2006). Harvesting alternatives and cost factors of delimbed energy wood. Forestry Studies (Metsanduslikud Uurimused), 45, pp. 49-56.

Hennecke, K., T. Hirsch, D. Krüger, A. Lokurlu, and M. Walder (2008). Pilot plant for solar process steam supply. In: Eurosun 2008 - 1st International Congress on Heating, Cooling and Buildings, ISES Europe, Lisbon, Spain, 7-10 October 2008.

Henry, S., A.M. Denis, and P. Panciatici (2010). Feasibility study of off-shore HVDC grids. In: Power and Energy Society General Meeting, 2010 IEEE, Minneapolis, MN, USA, 25-29 July 2010, pp. 1-5, 25-29.

Herrmann, U., B. Kelly, and H. Price (2004). Two-tank molten salt storage for parabolic trough solar power plants. Energy, 29(5-6), pp. 883-893.

Himri, Y., A.B. Stambouli, B. Draoui, and S. Himri (2008). Techno-economical study of hybrid power system for a remote village in Algeria. Energy for Sustainable Development, 33(7), pp. 1128-1136.

Hingorani, N.G. (2007). FACTS technology - State of the art, current challenges and the future prospects. In: Power Engineering Society General Meeting, IEEE, Tampa, FL, USA, 24-28 June 2007, pp. 1-4, 24-28.

Hoekman, S.K. (2009). Biofuels in the U.S. - Challenges and opportunities. Renewable Energy, 34(1), pp. 14-22.

Hoff, T., and R. Perez (2010). Quantifying PV power output variability. Solar Energy, 84(10), pp. 1782-1793.

Holttinen, H., P. Meibom, A. Orths, F. van Hulle, B. Lange, M. O'Malley, J. Pierik, B. Ummels, J.O. Tande, A. Estanqueiro, M. Matos, E. Gomez, L. Söder, G. Strbac, A. Shakoor, J. Ricardo, J.C. Smith, M. Milligan, and E. Ela (2009). Design and Operation of Power Systems with Large Amounts of Wind Power. Final Report IEA Wind Task 25 (2006-2008), VTT, Vuorimiehentie, Finland, 229 pp. (ISBN 978-951-38-7308-0).

Holttinen, H., P. Meibom, A. Orths, B. Lange, M. O'Malley, J.O. Tande, A. Estanqueiro, E. Gomez, L. Söder, G. Strbac, J.C. Smith, and F. van Hulle (2011). Impacts of large amounts of wind power on design and operation of power systems, results of IEA collaboration. Wind Energy, 14(2), pp. 179-192.

Hossain, M.A., and B.K. Bala (2007). Drying of hot chilli using a solar tunnel drier. Solar Energy, 81(1), pp. 85-92.

Hotson, G.W. (1997). Utilisation of geothermal energy in a pulp and paper mill. Energy Sources, 19(1), pp. 49-54. 
Huang, S-H., Dumas, J., Gonzalez-Perez, C., Wei-Jen Lee (2009). Grid security through load reduction in the ERCOT market. IEEE Transactions on Industry Applications, 45(2), pp. 555-559.

Hughes, L. (2010). Meeting residential space heating demand with wind-generated electricity. Renewable Energy, 35(8), pp. 1765-1772.

Hur, K., M. Boddeti, N.D.R. Sarma, J. Dumas, J. Adams, and S.K. Chai (2010). High-wire act. IEEE Power \& Energy Magazine, 8(1), pp. 37-45.

Huttenrauch, J., and G. Muller-Syring (2006). Assessment of repair And Rehabilitation Technologies relating to the Transport of hythane (hydrogenmethane-mixture). Naturalhy Project Report No. R0016-WP4-P-0, DBI Gas- und Umwelttechnik GmbH, Leipzig, Germany, 63 pp.

IANGV (2009). International Association for Natural Gas Vehicles. International Association for Natural Gas Vehicles, Auckland, New Zealand. See: http://www. iangv.org/tools-resources/statistics.html

IBGE (2008). Perfil dos Municípios Brasileiros 2008. Instituto Brasileiro de Geografia e Estatística, Rio de Janeiro, Brazil (ISBN 978-85-240-4061-0 (CD-ROM)). Available at: www.ibge.gov.br/home/estatistica/economia/perfilmunic/2008/ munic2008.pdf.

ICA (2009). A um passo da cidadania: Projeto Piloto para Eletrificação de Favelas e Redução de Perdas. International Copper Association Ltd., São Paulo, Brazil, 94 pp. Available at: www.procobre.org/archivos/pdf/One_Step_Citizenship.pdf.

IEA (2006). Energy for cooking in developing countries. Chapter 15 in: World Energy Outlook 2006. International Energy Agency, Paris, France.

IEA (2007a). Bioenergy Project Development and Biomass Supply - Good Practice Guidelines. International Energy Agency, Paris, France, 66 pp.

IEA (2007b). Energy Statistics for Brazil (2007). International Energy Agency, Paris, France. Available at: www.iea.org/stats.

IEA (2007c). Mind the Gap - Quantifying Principal-Agent Problems in Energy Efficiency. International Energy Agency, Paris, France, 160 pp. (ISBN 978-92-64-03884-4).

IEA (2007d). Renewables for Heating And Cooling - Untapped Potential. International Energy Agency, Paris, France, 209 pp.

IEA (2008a). Combined Heat and Power: Evaluating the Benefits of Greater Global Investment. International Energy Agency, Paris, France.

IEA (2008b). Deploying Renewables: Principles for Effective Policies. International Energy Agency, Paris, France, 250 pp. (ISBN: 978-92-64-04220-9).

IEA (2008c). Energy Technology Perspectives 2008. Scenarios and Strategies to 2050. International Energy Agency, Paris, France, 646 pp.

IEA (2008d). World Energy Outlook 2008. International Energy Agency, Paris, France, $578 \mathrm{pp}$.

IEA (2009a). Cities, Towns and Renewable Energy - Yes In My Front Yard. International Energy Agency, Paris, France, 194 pp. (ISBN 978-92-64-07687-7).

IEA (2009b). Cogeneration and District Energy: Sustainable Energy Technologies for Today and Tomorrow. International Energy Agency, Paris, France, 24 pp.

IEA (2009c). Transport, Energy, and $\mathrm{CO}_{2}$ - Moving Towards Sustainability. International Energy Agency, Paris, France, 400 pp. (ISBN 978-92-64-07316-6).

IEA (2009d). World Energy Outlook 2009. International Energy Agency, Paris, France, $696 \mathrm{pp}$.

IEA (2010a). Energy Technology Perspectives 2010. Scenarios and Strategies to 2050. International Energy Agency, Paris, France, 708 pp.

IEA (2010b). Key World Energy Statistics 2010. International Energy Agency, Paris, France, $82 \mathrm{pp}$.

IEA (2010c). Technology Roadmap: Concentrating Solar Power. International Energy Agency, Paris, France, $52 \mathrm{pp}$.
IEA (2010d). World Energy Outlook 2010. International Energy Agency, Paris, France, $736 \mathrm{pp}$.

IEA Bioenergy (2010a). 100 \% Biogas for Urban Transport in Linköping, Sweden IEA Bioenergy Task 37, International Energy Agency, Svensk Biogas AB, Linköping, Sweden. Available at: www.iea-biogas.net/_download/linkoping_final.pdf.

IEA Bioenergy (2010b). Country report Sweden IEA Bioenergy Task 37, Energy from Biogas. IEA Bioenergy, International Energy Agency, Paris, France. See: http://www.iea-biogas.net/_download/publications/country-reports/april2011/ Sweden_Country_Report.pdf.

IEA-HIA (2006). Prospects for Hydrogen from Biomass. IEA Hydrogen Implementing Agreement Task 16, Subtask B, Final Report, International Energy Agency, Paris, France, 69 pp. Available at: ieahia.org/pdfs/finalreports/Task16BFinal.pdf.

IEA-SHC (2010). Solar Heating and Cooling Implementing Agreement. International Energy Agency, Paris, France. See: http://www.iea-shc.org/publications/downloads/Solar_Heat_Worldwide-2010.pdf.

Igarashi, Y., K. Mochidzuki, M. Takayama, and A. Sakoda (2009). Development of local fuel system for sustainable regional biomass utilization: Climate change: Global risks, challenges and decisions. In: IOP Conference Series: Earth and Environmental Science, 6(2009). IOP Publishing, Copenhagen, Denmark, doi:10.1088/1755-1315/6/1/001001.

Iglesias, G., and R. Carballo (2010). Wave resource in El Hierro - an island towards energy self-sufficiency. Renewable Energy, 36(2), pp. 689-698.

Insula (2010). El Hierro 100\% RES. International Scientific Council fo Island Development, Paris, France. Available at: www.insula.org/index. php?option=com_wrapper\&ltemid $=22$.

IPCC (2007). Climate Change 2007: Mitigation of Climate Change. Contribution of Working Group III to the Fourth Assessment Report of the Intergovernmental Panel on Climate Change. B. Metz, O.R. Davidson, P.R. Bosch, R. Dave, and L.A. Meyer (eds.), Cambridge University Press, 851 pp.

Ipsakis, D., S. Voutetakis, P. Seferlis, F. Stergiopoulos, and C. Elmasides (2009). Power management strategies for a stand-alone power system using renewable energy sources and hydrogen storage. International Journal of Hydrogen Energy, 34(16), pp. 7081-7095.

Jayamaha, N.P. (2003). Distributed Generation on Rural Electricity Networks - A Lines Company Perspective. Massey University, Massey, New Zealand, 243 pp.

Jenkins, N., G. Strbac, and J. Ekanayake (2010). Distributed Generation. Institution of Engineering and Technology, Stevenage, UK, 272 pp.

Jiang, B., and Y. Hai (2010). China's heat pumps technology review (in Chinese). China Construction, 2010(7), pp. 68-69.

Johansson, T.B., and J. Goldemberg (eds.) (2005). World Energy Assessment Overview: 2004 Update. United Nations Development Programme, United Nations Department of Economic and Social Affairs, and World Energy Council, New York, NY, USA, 85 pp. Available at: www.undp.org/energy/weaover2004. htm.

Johansson, T.B., H. Kelly, A. Reddy, R. Williams, and L. Burnham (1993). Renewable Energy: Sources for Fuels and Electricity. Island Press, Washington, DC, USA, 62 pp.

Johnston, R.A. (2007). Review of U.S. and European Regional Modeling Studies of Policies Intended to Reduce Highway Congestion, Fuel Use, and Emissions. Victoria Transport Policy Institute, Victoria, Canada, 9 pp.

Jónsson, T., P. Pinson, and H. Madsen (2010). On the market impact of wind energy forecasts. Energy Economics, 32, pp. 313-320. 
Jupe, S.C.E., and P.C. Taylor (2009). Distributed generation output control for network power flow management. IET Renewable Power Generation, 3(4), pp. 371-386.

Jupe, S.C.E., P.C. Taylor, and A. Michiorri (2010). Coordinated output control of multiple distributed generation schemes. IET Renewable Power Generation, 4(3), pp. 283-297.

Kåberger, T., and H. Kusar (2008). BioDME - beslut enskilt project, Volvo Powertrain Report, DNR 2008-000766, Project 31243-1 Swedish Energy Agency, Eskilstuna, Sweden. $10 \mathrm{pp}$.

Kaldellis, J.K., D. Zafirakis, and K. Kavadias (2009). Techno-economic comparison of energy storage systems for island autonomous electrical networks. Renewable and Sustainable Energy Reviews, 13(2), pp. 378-392.

Kalhammer, F.A., B.M. Kopf, D.H. Swan, V.P. Roan, and M.P. Walsh (2007). Status and Prospects for Zero Emission Vehicle Technology. Report ARB Independent Expert Panel, State of California Air Resources Board, Sacramento, CA, USA, 207 pp.

Kamakaté, F. and D. Gordon (2009). Managing Motorcycles: Opportunities to Reduce Pollution and Fuel Use from Two- and Three-Wheeled Vehicles. International Council on Clean Transportation, Washington, DC, USA. Available at: www.theicct.org/pubs/managing_motorcycles.pdf.

Kang, Y., and J. Zhang (2008). Study on current status, barriers and recommendations for China's CHP/DHC market development. Energy of China (In Chinese), 30(10), pp. 8-13.

Karapidakis, E. (2007). Transient analysis of Crete's power system with increased wind power penetration. In: International Conference on Power Engineering, Energy and Electrical Drives (POWERENG 2007), Setubal, Portugal, 12-14 April 2007, pp. 18-22.

Katsaprakakis, D.A., N. Papadakis, D.G. Christakis, and A. Zervos (2007). On the wind power rejection in the islands of Crete and Rhodes. Wind Energy, 10(5), pp. 415-434.

Kawasaki, N., T. Oozeki, K. Otani, and K. Kurokawa (2006). An evaluation method of the fluctuation characteristics of photovoltaic systems by using frequency analysis. Solar Energy Materials and Solar Cells, 90(18-19), pp. 3356-3363.

Keane, A., and M. O'Malley (2005). Optimal allocation of embedded generation on distribution networks. IEEE Transactions on Power Systems, 20(3), pp. 1640-1646.

Keane, A., M. Milligan, C.J. Dent, B. Hasche, C. D'Annunzio, K. Dragoon, H. Holttinen, N. Samaan, L. Söder, and M. O'Malley (2011a). Capacity value of wind power. IEEE Transactions on Power Systems, 26(2), pp. 564-572.

Keane, A., L.F. Ochoa, E. Vittal, C.J. Dent, and G.P. Harrison (2011b). Enhanced utilization of voltage control resources with distributed generation. IEEE Transactions on Power Systems, 26(1), pp. 252-260.

Kempton, W., and J. Tomic (2005). Vehicle-to-grid power implementation: From stabilizing the grid to supporting large-scale renewable energy. Journal of Power Sources, 144(1), pp. 280-294.

Khan, J., G. Bhuyan, and A. Moshref (2009). Potential Opportunities and Differences Associated with Integration of Ocean Wave and Marine Current Energy Plants in Comparison to Wind Energy. Report prepared by Powertech Labs for the IEA-OES Annex III, Powertech Labs Inc., Surrey, BC, Canada, 64 pp.

Khennas, S., C. Sepp, and S. Hunt (2009). Review and Appraisal of Potential Transformative Rural Energy Interventions in the Congo Basin. Final report by Practical Action Consulting and Eco Consulting, Department for International Development, London, UK.
KinderMorgan (2010). Pipeline Products: Central Florida Pipeline Co. Kinder Morgan, Dallas, Texas. Available at: www.kindermorgan.com/business/products_ pipelines/central_florida.cfm

Kirby, B.J. (2007). Load response fundamentally matches power system reliability requirements. In: Power Engineering Society General Meeting, IEEE, Tampa, $\mathrm{FL}$, USA, 24-28 June 2007, pp. 1-6.

Kirby, B., and M. Milligan (2010). Utilizing load response for wind and solar integration and power system reliability. In: WindPower 2010, Dallas, TX, 23-26 May 2010. Available at: www.nrel.gov/docs/fy10osti/48247.pdf.

Kiviluoma, J., and P. Meibom (2010). Influence of wind power, plug-in electric vehicles, and heat storages on power system investments. Energy, 35(3), pp. 1244-1255.

Kiviluoma, J., and P. Meibom (2011). Methodology for modelling plug-in electric vehicles in the power system and cost estimates for a system with either smart or dumb electric vehicles. Energy, 36(3), pp. 1758-1767.

Klobasa, M. (2010). Analysis of demand response and wind integration in Germany's electricity market. IET Renewable Power Generation, 4(1), pp. 55-63.

Kobayashi, H., and I. Kurihara (2009). Research and development of grid integration of distributed generation in Japan. In: IEEE Power and Energy Society General Meeting, Calgary, AB, Canada, 26-30 July 2009.

Kondoh, J. (2010). Autonomous frequency regulation by controllable loads to increase acceptable wind power generation. Wind Energy, 13(6), pp. 529-541.

Kromer, M.A., and J.B. Heywood (2007). Electric Powertrains: Opportunities and Challenges in the U.S. Light-Duty Vehicle Fleet. Report LFEE 2007-02 $\mathrm{RP}$, Laboratory for Energy and the Environment, Massachusetts Institute of Technology, Cambridge, MA, USA, 153 pp. Available at: web.mit.edu/sloan-autolab/research/beforeh2/files/kromer_electric_powertrains.pdf.

Krüger, D., A. Anthrakidis, S. Fischer, A. Lokurlu, M. Walder, R. Croy, and V. Quaschning (2009). Experiences with solar steam supply for an industrial steam network in the P3 Project. In: 15th International SolarPACES Symposium, Berlin, Germany, 18 September 2009, pp. 15.

Krüger, D.R., K. Hennecke, and S. Dathe (2008). Parabolrinnen für prozesswärme, Projekte und Entwicklungen 11. Kölner Sonnenkolloqium. German Aerospace Center (DLR) Solar Research, Köln, Germany. Available at: www.dlr.de/sf/en/ Portaldata/73/Resources/dokumente/Soko/Soko2008/Poster/5_Parabolrinnen_ fuer_Prozesswaerme.pdf.

Kundur, P., (2007). Power system stability. Chapter 7 in: Power System Stability and Control. L. Grigsby (ed.), CRC Press, Boca Raton, FL, USA.

Kurani, K.S., J. Axsen, N. Caperello, J. Davies, and T. Stillwater (2009). Learning from Consumers: Plug-In Hybrid Electric Vehicle (PHEV) Demonstration and Consumer Education, Outreach, Market Research Program. Research Report UCDITS-RR-09-21, Institute of Transportation Studies, University of California, Davis, CA, USA. Available at: pubs.its.ucdavis.edu/publication_detail.php?id=1310.

Lannoye, E., M. Milligan, J. Adams, A. Tuohy, H. Chandler, D. Flynn, and M. O'Malley (2010). Integration of variable generation: capacity value and evaluation of flexibility. In: IEEE Power and Energy Society General Meeting, Minneapolis, MN, 25-27 July 2010.

Lantz, M., M. Svensson, L. Björnsson, and P. Börjesson (2007). The prospects for an expansion of biogas systems in Sweden: incentives, barriers and potentials. Energy Policy, 35(3), pp. 1830-1843.

Larsen, S.F., C. Filippin, A. Beascochea, and G. Lesino (2008). An experience on integrating monitoring and simulation tools in the design of energy-saving buildings. Energy and Buildings, 40(6), pp. 987-997. 
Larsen, X.G., and J. Mann (2009). Extreme winds from the NCEP/NCAR reanalysis data. Wind Energy, 12(6), pp. 556-573.

Larson, E.D., R.H. Williams, M. Regis, and L.V. Leal (2001). A review of biomass integrated-gasifier/gas turbine combined cycle technology and its application in sugarcane industries, with an analysis for Cuba. Energy for Sustainable Development, 5(1), pp. 54-76.

Lazarewicz, M.L., and T.M. Ryan (2010). Integration of flywheel-based energy storage for frequency regulation in deregulated markets. In: IEEE Power and Energy Society General Meeting, Minneapolis, MN, $25-27$ July 2010, pp. 1-6, 25-29.

Lehmann, J. (2007). A handful of carbon. Nature, 447, pp. 143-144.

Leighty, W.C., J. Holloway, R. Merer, B. Somerday, C. Marchi, G. Keith, and D.E. White (2006). Compressorless hydrogen transmission pipelines deliver large-scale stranded renewable energy at competitive cost. In: 23rd World Gas Conference, Amsterdam, The Netherlands, 5-9 June 2006. Available at: www. leightyfoundation.org/files/WGC-Amsterdam/WGC-Abstract310.pdf.

Leilei, D., H. Liu, and S. Riffat (2009). Development of small-scale and micro-scale biomass-fuelled CHP systems - a literature review. Applied Thermal Engineering, 29(11-12), pp. 2119-2126.

Lemmini, F., and A. Errougani (2007). Experimentation of a solar adsorption refrigerator in Morocco. Renewable Energy, 32(15), pp. 2629-2641.

Levine, M., D. Ürge-Vorsatz, K. Blok, L. Geng, D. Harvey, S. Lang, G. Levermore, A. Mongameli Mehlwana, S. Mirasgedis, A. Novikova, J. Rilling, and H. Yoshion (2007). Residential and commercial buildings. In: Climate Change 2007: Mitigation of Climate Change. Contribution of Working Group III to the Fourth Assessment Report of the Intergovernmental Panel on Climate Change, B. Metz, O.R. Davidson, P.R. Bosch, R. Dave and L.A. Meyer (eds.), Cambridge University Press, pp. 387-446.

Li, J. (2009). From strong to smart: the Chinese Smart Grid and its relation with the globe. Asia Energy Platform News, September 2009, pp. 10.

Li, Z.S., G.Q. Zhang, D.M. Li, J. Zhou, L.J. Li, and L.X. Li (2007). Application and development of solar energy in building industry and its prospects in China. Energy Policy, 35(8), pp. 4121-4127.

Liao, C.P., E. Jochem, Y. Zhang, and N.R. Farid (2010). Wind power development and policies in China. Renewable Energy, 35(9), pp. 1879-1886.

Lighting Africa (2010). Lighting Africa - Catalyzing Markets for Modern Lighting. International Finance Corporation and World Bank Programme. See: www.lightingafrica.org/.

Liu, D.H., and S. Riffat (2009). Development of small-scale and micro-scale biomass-fuelled CHP systems - A literature review. Applied Thermal Engineering, 29(11-12), pp. 2119-2126.

Liu, E., and J. Bebic (2008). Distribution System Voltage Performance Analysis for High-Penetration Photovoltaics. Subcontract Report NREL/SR-581-42298, National Renewable Energy Laboratory, Golden, CO, USA.

Liu, Y.Q., and A. Kokko (2010). Wind power in China: Policy and development challenges. Energy Policy, 38(10), pp. 5520-5529.

Lobell, D.B., and C.B. Field (2007). Global scale climate - crop yield relationships and the impacts of recent warming. Environmental Research Letters, 2(1), pp. 1-7.

Loisel, R., A. Mercier, C. Gatzen, N. Elms, and H. Petric (2010). Valuation framework for large scale electricity storage in a case with wind curtailment. Energy Policy, 38(11), pp. 7323-7337.

Lone, S.A., and M.D. Mufti (2008). Modelling and simulation of a stand-alone hybrid power generation system incorporating redox flow battery storage system. International Journal of Modelling and Simulation, 28(3), pp. 337-346.
Longhetto, A., G. Elisei, and C. Giraud (1989). Effect of correlations in time and spatial extent on performance of very large solar conversion systems. Solar Energy, 43(2), pp. 77-84.

Lorenz, E., J. Hurka, D. Heinemann, and H.G. Beyer (2009). Irradiance forecasting for the power prediction of grid-connected photovoltaic systems. IEEE Journal of Selected Topics in Applied Earth Observations and Remote Sensing, 2(1), pp. 2-10.

Lorenz, E., T. Scheidsteger, J. Hurka, D. Heinemann, and C. Kurz (2010). Regional PV power prediction for improved grid integration. Progress in Photovoltaics: Research and Applications, doi:10.1002/pip.1033.

Lund, H. (2006). Large-scale integration of optimal combinations of PV, wind and wave power into the electricity supply. Renewable Energy, 31(4), pp. 503-515.

Lund, H., and E. Munster (2003). Management of surplus electricity-production from a fluctuating renewable-energy source. Applied Energy, 76(1-3), pp. 65-74.

Lund, H., and W. Kempton (2008). Integration of renewable energy into the transport and electricity sectors through V2G. Energy Policy, 36(9), pp. 3578-3587.

Lund, H., and G. Salgi (2009). The role of compressed air energy storage (CAES) in future sustainable energy systems. Energy Conversion and Management, 50(5), pp. 1172-1179.

Lund, J.W. (2005). Direct application of geothermal energy: 2005 worldwide review. Geothermics, 34, pp. 691-727.

Lund, J.W., D.H. Freeston, and T.L. Boyd (2010). Direct utilisation of geothermal energy 2010 worldwide review. In: Proceedings World Geothermal Congress 2010, Bali, Indonesia, 25-30 April 2010. Available at: www.geothermal-energy. org/pdf//GAstandard/WGC/2010/0007.pdf.

Lundsager, P., and I. Baring-Gould (2005). Isolated systems with wind power In: Wind Power in Power Systems. T. Ackermann (ed.), John Wiley \& Sons Ltd. London, UK, pp. 299-329.

Macedo, I.C., J.E.A. Seabra, and J.E.A.R. Silva (2008). Greenhouse gas emissions in the production and use of ethanol from sugarcane in Brazil: the 2005/2006 averages and a prediction for 2020. Biomass \& Bioenergy, 32, pp. 582-595.

MacGill, I. (2010). Electricity market design for facilitating the integration of wind energy: Experience and prospects with the Australian National Electricity Market. Energy Policy, 38(7), pp. 3180-3191.

MacLean, H.L., and L.B. Lave (2003). Evaluating automobile fuel/propulsion technologies. Progress in Energy and Combustion Science, 29, pp. 1-69.

Madhlopa, A., and G. Ngwalo (2007). Solar dryer with thermal storage and biomass-backup heater. Solar Energy, 81(4), pp. 449-462.

Mandle, K.T. (1988). Dinorwig pumped-storage scheme. Power Engineering Journal, 2(5), pp. 259-262.

Mangold, D., and T. Schmitt (2006). The new central solar heating plants with seasonal storage in Germany. In: EuroSun 2006, ISES (ed.), International Solar Energy Society, Glasgow, Scotland, 27-30 June 2006, pp. 6.

Mangold, D., M. Riegger, and T. Schmitt (2007). Solare Nahwärme und LangzeitWärmespeicher. Report 0329607L, Forschungsbericht zum BMU-Vorhaben, Stuttgart, Germany, $66 \mathrm{pp}$.

Marcos, J., L. Marroyo, E. Lorenzo, D. Alvira, and E. Izco (2011). From irradiance to output power fluctuations: the PV plant as a low pass filter. Progress in Photovoltaics: Research and Applications, doi:10.1002/pip.1063.

Margonelli, L. (2009). Clean energy's dirty little secret. The Atlantic Magazine, May 2009. Available at: www.theatlantic.com/magazine/archive/2009/05/ clean-energy-apos-s-dirty-little-secret/7377. 
Martinez, E., F. Sanza, J. Blanco, F. Daroca, and E. Jimenez (2008). Economic analysis of reactive power compensation in a wind farm: Influence of Spanish energy policy. Renewable Energy, 33(8), pp. 1880-1891.

Masters, C.L. (2002). Voltage rise - the big issue when connecting embedded generation to long $11 \mathrm{kV}$ overhead lines. Power Engineering Journal, 16(1), pp. 5-12.

Mathioulakis, E., V. Belessiotis, and E. Delyannis (2007). Desalination by using alternative energy: Review and state-of-the-art. Desalination, 203(1-3), pp. 346-365.

Matic, D. (2006). Global Opportunities for Natural Gas as a Transportation Fuel for Today and Tomorrow. Report from Working Committee 5 at the 23rd Word Gas Conference, Study Group 5.3 on Natural Gas for Vehicles (NGV), International Gas Union, Oslo, Norway, 144 pp.

McCarthy, R.W., J.M. Ogden, and D. Sperling (2007). Assessing reliability in energy supply systems. Energy Policy, 35(4), pp. 2151-2162.

McDonough, C., and R. Kraus (2007). Does dynamic pricing make sense for mass market customers? The Electricity Journal, 20(7), pp. 26-37.

McKormick, K., and T. Kåberger (2005). Exploring a pioneering bioenergy system: The case of Enköping in Sweden. Journal of Cleaner Production, 13, pp. 1003-1014.

McNutt, P., J. Hambrick, M. Keesee, and D. Brown (2009). Impact of SolarSmart Subdivisions on SMUD's Distribuion System. Technical report NREL/TP-55046093, National Renewable Energy Laboratory, Golden, CO, USA, 41 pp.

Meah, K., and S. Ula (2007). Comparative evaluation of HVDC and HVAC transmission systems. In: IEEE Power Engineering Society General Meeting, Tampa, FL, USA, 24-28 June 2007, pp. 1-5, 24-28.

Meah, K., S. Ula, and S. Barrett (2008). Solar photovoltaic water pumping - opportunities and challenges. Renewable and Sustainable Energy Reviews, 12(4), pp. $1162-1175$.

Meenual, T. (2010). Roadmapping the Provincial Electricity Authority (PEA) smart grids. In: 2010 Proceedings of the International Conference on Energy and Sustainable Development (ESD): Issues and Strategies, Chiang Mai, Thailand, 2-4 June 2010, 1-6pp. (ISBN: 978-1-4244-8563-5).

Meibom, P., R. Barth, B. Hasche, H. Brand, C. Weber, and M.J. O'Malley (2011). Stochastic optimisation model to study the operational impacts of high wind penetrations in Ireland. IEEE Transactions on Power Systems, doi:10.1109/ TPWRS.2010.2070848.

METI (2005). Energy Vision 2100, Strategic Technology Roadmap (Energy Sector). Ministry of Economy, Trade, and Industry, Tokyo, Japan, 42 pp. Available at: www. iae.or.jp/2100/main.pdf.

Miller, N., K. Clark, and M. Shao (2010). Impact of frequency responsive wind plant controls on grid performance. In: Proceedings of the 9th International Workshop on Large Scale Integration of Wind Power and on Transmission Networks for Offshore Wind Farms, Quebec City, Canada, 18-19 October 2010, pp. 371-382.

Milligan, M., B. Kirby, R. Gramlich, and M. Goggin (2009). Impact of Electric Industry Structure on High Wind Penetration Potential. Technical Report, National Renewable Energy Laboratory, Golden, CO, USA.

Mills, A., and R. Wiser (2010). Implications of Wide-Area Geographic Diversity for Short-Term Variability of Solar Power. LBNL-3884E, Environmental Energy
Technologies Division, Lawrence Berkeley National Laboratory, Berkeley, CA, USA, $48 \mathrm{pp}$.

Mills, A., M. Ahlstrom, M. Brower, A. Ellis, R. George, T. Hoff, B. Kroposki, C. Lenox, N. Miller, J. Stein, and Y. Wan (2009a). Understanding Variability and Uncertainty of Photovoltaics for Integration with the Electric Power System. Lawrence Berkeley National Laboratory, Berkeley, CA, USA.

Mills, A., R. Wiser, M. Milligan, and M. O'Malley (2009b). Comment on "Air Emissions Due to Wind and Solar Power". Environmental Science \& Technology, 43(15), pp. 6106-6107.

Mills, A., A.Phadke, and R. Wiser (2011). Exploration of resource and transmission expansion decisions in the Western Renewable Energy Zone initiative. Energy Policy, 39(3), pp. 1732-1745.

Ministry for Agriculture Livestock and Supply (2010). Sugar Cane and Ethanol Distilleries. Ministry for Agriculture Livestock and Supply, Brasilia, Brazil. (In Portuguese) Available at: http://www.agricultura.gov.br/arq_editor/file/1984_ posicao_04_2010.pdf

Mintzer, I. (2009). Look before you leap: Exploring the implications of advanced vehicles for import dependence and passenger safety. In: Plug-in Electric Vehicles: What Role for Washington? D.B. Sandalow (ed.), Brookings Institution Press, Washington, DC, USA, pp 107-126. Available at: www.potomacenergyfund.com/files/Potomac\%20Energy $\% 20$ Fund $\% 20-\% 20$ Look $\% 20$ Before $\% 20$ You\%20Leap.pdf.

Miwa, T., and $\mathrm{H}$. Okuda (2010). $\mathrm{CO}_{2}$ ultimate reduction in steelmaking process by innovative technology for Cool Earth 50. Journal of the Japan Institute of Energy, 89, pp. 28-35.

Modi, V., S. McDade, D. Lallement, and J. Saghir (2005). Energy Services for the Millennium Development Goals. Energy Sector Management Assistance Programme, United Nations Development Programme, UN Millennium Project, and World Bank, New York, NY, USA.

Mohammadi, A., A. Tabatabaeefar, S. Shahin, S. Rafiee, and A. Keyhani (2008). Energy use and economical analysis of potato production in Iran a case study: Ardabil province. Energy Conversion and Management, 49(12), pp. 3566-3570.

Mohitpour, M., and A. Murray (2000). Pipeline Design and Construction: A Practical Approach. ASME Press, New York, NY, USA.

MoP (2006). Rural electrification policy, Resolution 44/26/05-RE. Gazette of India, Ministry of Power, Vol. II (23 August), pp. 17.

Morales, A., X. Robe, M. Sala, P. Prats, C. Aguerri, and E. Torres (2008). Advanced grid requirements for the integration of wind farms into the Spanish transmission system. IET Renewable Power Generation, 2(1), pp. 47-59.

Morozumi, S., H. Nakama, and N. Inoue (2008). Demonstration projects for grid-connection issues in Japan. e \& i Elektrotechnik und Informationstechnik, 125(12), pp. 426-431.

Moura, P.S., and A.T. de Almeida (2010). The role of demand-side management in the grid integration of wind power. Applied Energy, 87(8), pp. 2581-2588.

Mpagalile, J.J., M.A. Hanna, and R. Weber (2005). Design and testing of a solar photovoltaic operated multi-seeds oil press. Renewable Energy, 31(12), pp. 1855-1866.

MTEP (2008). The Midwest ISO Transmission Expansion Plan; Growing the grid across the Heartland. Midwest ISO, Carmel, IN, USA, 402 pp. 
Mullane, A., and M. O'Malley (2005). The inertial response of induction-machinebased wind turbines. IEEE Transactions on Power Systems, 20(3), pp. 1496-1503.

Müller-Langer, F., F. Scholwin, and K Oehmichen (2009). Biomethane for transport: a worldwide overview. Presentation at IEA Bioenergy Task 39 Subtask Policy and Implementation Workshop: From today's to tomorrow's biofuels - From the Biofuels Directive to bio based transport systems in 2020; Dresden, Germany; June 3-5, 2009; adapted from: Possible European biogas supply strategies; Institute for Energy and Environment; Leipzig; 2007.

Munksgaard, J., and P.E. Morthorst (2008). Wind power in the Danish liberalised power market-Policy measures, price impact and investor incentives. Energy Policy, 36(10), pp. 3940-3947.

Murata, A., H. Yamaguchi, and K. Otani (2009). A method of estimating the output fluctuation of many photovoltaic power generation systems dispersed in a wide area. Electrical Engineering in Japan, 166(4), pp. 9-19.

Murray, P.E. (2005). Designing Sustainable Distributed Generation Systems for Rural Communities. Massey University, Palmerston North, New Zealand.

NAS (2009). Liquid Transportation Fuels from Coal and Biomass: Technological Status, Costs, and Environmental Impacts. National Academy of Sciences, National Academies Press, Washington, DC, USA, 388 pp. (ISBN-13: 978-0-309-13712-6).

National Bureau of Statistics China (2010). City District Heating (1990-1999, 2004-2008). (In Chinese). Available at: www.stats.gov.cn.

NationalGrid (2009). The Potential for Renewable Gas in the UK. Paper, National Grid, Media Relations, UK.

NATURALHY (2009). Strategic justification of the NATURALHY project. Project Report, NATURALHY, Groningen, The Netherlands, 19 pp. Available at: www. naturalhy.net/docs/Strategic_justification_NATURALHY.pdf.

NBB (2010). Automakers' and Engine Manufacturers' Positions of Support for Biodiesel Blends. National Biodiesel Board, Jefferson City, MO, USA. Available at: www.biodiesel.org/resources/oems/default.aspx.

NCEP (2007). Task Force on Biofuel Infrastructure. National Commission on Energy Policy, Washington, DC, USA. http://ourenergypolicy.org/docs/2/biofuels-taskforce.pdf

Nelson, P.A., D.J. Santini, and J. Barnes (2009). Factors determining the manufacturing costs of lithium- ion batteries for PHEVs. In: EVS-24 Conference. Stavanger, Norway, 13-16 May 2009, pp. 12. Available at: www.cars21.com/files/papers/ Nelson-Santini-Barnes-paper.pdf.

Nema, P., R.K. Nema, and S. Rangnekar (2009). A current and future state of art development of hybrid energy system using wind and PV-solar: A review. Renewable and Sustainable Energy Reviews, 13(8), pp. 2096-2103.

NERC (2009). Special Report: Accommodating High Levels of Variable Generation. North American Reliability Corporation, Princeton, NJ, USA, 95 pp.

NERC (2010a). NERC IVGTF Task 2.1 Report Variable Generation Power Forecasting for Operations. North American Electric Reliability Corporation, Princeton, NJ, USA, 35 pp. Available at: www.nerc.com/files/Varialbe\%20Generationn $\% 20$ Power\%20Forecasting\%20for\%200perations.pdf.

NERC (2010b). Special Report: Flexibility Requirements and Potential Metrics for Variable Generations: Implication for System Planning Studies. North American Electric Reliability Corporation, Princeton, NJ, USA, 63 pp.

NERC (2010c) Special Report: Potential Reliability Impacts of Emerging Flexible Resources. North American Electric Reliability Corporation, Princeton, NJ, USA, $57 \mathrm{pp}$.
NETL (2008). NETL Modern Grid Strategy - Powering Our 21st-Century Economy Advanced Metering Infrastructure. White Paper V1.0, National Energy Technology Laboratory, U.S. Department of Energy, Pittsburgh, PA, USA, 32 pp.

New Holland Information Center (2010). Biodiesel Support. New Holland Information Center, Racine, WI, USA. Available at: agriculture.newholland.com/ us/en/information-center/Biodiesel-Support/Pages/default.aspx.

Newbery, D.M. (2005). Electricity liberalisation in Britain: the quest for a satisfactory wholesale market design. Energy Journal, Special Issue on European Electricity Liberalisation, 26(Special I), pp. 43-70.

Newbery, D.M. (2010). Market design for a large share of wind power. Energy Policy, 38(7), pp. 3131-3134.

Nicholas, M., and J. Ogden (2010). An Analysis of Near-Term Hydrogen Vehicle Rollout Scenarios for Southern California. Report UCD-ITS-RR-10-03, University of California, Institute of Transportation Studies, Davis, CA, USA.

NISRA (2009). Northern Ireland Statistic \& Research Agency. Population and Migration Estimates Northern Ireland (2009) - Statistical Report. Northern Ireland Statistics \& Research Agency, National Statistics, Belfast, Ireland, 19 pp.

NIST (2007). White paper on Internationally Compatible Biofuel Standards (Tripartite task force: Brazil, European Union and United States of America). Report, National Institute of Standards and Technology, Gaithersburg, MD, USA, 93 pp.

Nordel (1996). Annual Report. Nordel, Helsinki, Finland, 64 pp.

Nordel (2000). Annual Report. Nordel, Helsinki, Finland, 70 pp.

Nordel (2008). Annual Report. Nordel, Helsinki, Finland, 23 pp.

Notholt, A. (2008). Fault Ride Through Capabilities of Inverter-Based Distributed Generation Connected to Low and Medium Voltage Distribution Networks. Kassel University, Kassel, Germany.

NRC (2008). Transitions to Alternative Transportation Technologies: A Focus on Hydrogen. The National Research Council, National Academies Press, Washington, DC, USA, 142 pp. (ISBN-13: 978-0-309-12100-2).

NRC (2010). Transitions to alternative transportation technologies: plug-in hybrid vehicles, The National Research Council, National Academies Press, Washington, DC, USA. 57pp. (ISBN-13: 978-0-309-14580-4).

NREL (2009). $H_{2}$ Production Cost vs. Process Composite Data Product (CDP \#15). National Renewable Energy Laboratory, Golden, CO, USA. Available at: www. nrel.gov/hydrogen/docs/cdp/cdp_15.jpg.

NREL (2010). Oahu Wind Integration and Transmission Study: Summary Report. National Renewable Energy Laboratory, Golden, CO, USA, 28 pp.

NSCA (2006). Biogas as transport fuel. Final Report, National Society for Clean Air and Environmental Protection, Brighton, UK, 46 pp. (ISBN 978090347461 1).

Nyamdash, B., E. Denny, and M. O'Malley (2010). The viability of balancing wind generation with large scale energy storage. Energy Policy, 38(11), pp. 7200-7208.

NZVCC (2008). University Research Commercialisation - Paying Dividends for New Zealand. Report, New Zealand Vice-Chancellors' Committee, Wellington, New Zealand, $11 \mathrm{pp}$.

Ochoa, P., and A. van Ackere (2009). Policy changes and the dynamics of capacity expansion in the Swiss electricity market. Energy Policy, 37(5), pp. 1983-1998.

Ogden, J.M., and C. Yang (2009). Build-up of a hydrogen infrastructure in the US. Chapter 15 in: The Hydrogen Economy: Opportunities and Challenges. M. Ball and M. Wietschel (eds.), Cambridge University Press, pp. 454-482.

Oleson, K.W., G.B. Bonan, and J. Feddema (2010). Effects of white roofs on urban temperature in a global climate model. Geophysical Research Letters, 37, L03701, doi:10.1029/2009GL042194. 
Oliver-Solà, J., X. Gabarrell, and J. Rieradevall (2009). Environmental impacts of the infrastructure for district heating in urban neighbourhoods. Energy Policy, 37(11), pp. 4711-4719.

Paatero, J.V., and P.D. Lund (2007). Effects of large-scale photovoltaic power integration on electricity distribution networks. Renewable Energy, 32(2), pp. 216-234.

Pacca, S., and J.R. Moreira (2009). Historical carbon budget of the Brazilian ethanol program. Energy Policy, 37(11), pp. 4863-4873.

Paish, 0. (2002). Small hydro power: technology and current status. Renewable and Sustainable Energy Reviews, 6(6), pp. 537-556.

Papaefthymiou, G., and D. Kurowicka (2009). Using copulas for modeling stochastic dependence in power system uncertainty analysis. IEEE Transactions on Power Systems, 24(1), pp. 40-49.

Papathanassiou, S.A., and N.G. Boulaxis (2006). Power limitations and energy yield evaluation for wind farms operating in island systems. Renewable Energy, 31(4), pp. 457-479.

Pastowski, A., and T. Grube (2009). Scope and perspectives of industrial hydrogen production and infrastructure for fuel cell vehicles in North Rhine-Westphalia. Energy Policy, 38(10), pp. 5382-5387.

PCGCC (2010). State and Local Net Greenhouse Gas Emissions Reduction Programs. Pew Center on Global Climate Change, Arlington, VA, USA. Available at: www. cleanairconstruction.org/content/legislative/AB1493\%20-\%20Greenhouse $\% 20$ Gas\%20Emissions\%20Reduction.pdf.

Pearmine, R., Y.H. Song, and A. Chebbo (2007). Influence of wind turbine behaviour on the primary frequency control of the British transmission grid. IET Renewable Power Generation, 1(2), pp. 142-150.

Pehnt, M., A. Paar, F. Merten, W. Irrek, and D. Schüwer (2009a). Intertwining renewable energy and energy efficiency: from distinctive policies to combined strategies. In: ECEEE 2009 Summer Study, ECEEE, La Colle sur Loup, Côte d'Azur, France, pp. 389-400.

Pehnt, M., A. Paar, P. Otter, F. Merten, T. Hanke, W. Irrek, D. Schüwer, N. Supersberger, and C. Zeiss (2009b). Energiebalance - Optimale Systemlösungen für erneuerbare Energien und Energieeffizienz (Energy Balance - Optimum System Solutions for Renewable Energy and Energy Efficiency). Report FKZ 0327614, Institut für Energie-und Umweltforschung Heidelberg GmbH, Heidelberg, Germany, $440 \mathrm{pp}$.

Pelland, S., and I. Abboud (2008). Comparing photovoltaic capacity value metrics: A case study for the City of Toronto. Progress in Photovoltaics, 16(8), pp. 715-724.

Perez, R., M. Taylor, T. Hoff, and J.P. Ross (2008). Reaching consensus in the definition of photovoltaics capacity credit in the USA: A practical application of satellite-derived solar resource data. IEEE Journal of Selected Topics in Applied Earth Observations and Remote Sensing, 1(1), pp. 28-33.

Pérez-Díaz, J.I., and J.R. Wilhelmi (2010). Assessment of the economic impact of environmental constraints on short-term hydropower plant operation. Energy Policy, 38(12), pp. 7960-7970.

Persson, M. (2003). Utvärdering av uppgraderingstekniker för biogas (Study of Biogas Upgrading Techniques). Report SGC 142, ISSN 1102-7371, Swedish Gas Centre, Malmö, Sweden, 69 pp.

Persson, M., O. Jönsson, and A. Wellinger (2006). Biogas Upgrading to Vehicle Fuel Standards and Grid Injection. IEA Report, Swedish Gas Center (SGC), Malmö, Sweden, $34 \mathrm{pp}$.
Phair, J.W. (2006). Green chemistry for sustainable cement production and use. Green Chemistry, 8, pp. 763-780.

Pihl, E. (2009). Concentrating Solar Power. Energy Committee of the Royal Swedish Academy of Sciences, Stockholm, Sweden, $32 \mathrm{pp}$.

Plotkin, S., and M. Singh (2009). Multi-Path Transportation Futures Study: Vehicle Characterization and Scenario Analyses. Report ANL/ESD/09-5, Argonne National Laboratory, Argonne, IL, USA, 310 pp. Available at: www.transportation.anl.gov/ pdfs/TA/613.PDF.

Power-Gen (2009). Cummins Approves B20 Biodiesel for 19- to 78-Litre High Horsepower Engines. Power Engineering International, PennWell Publishing, Tulsa, OK, USA.

PROINFA (2010). Programa de Incentivo às Fontes Alternativas de Energia Elétrica, Minas e Energia, Brasília, Brazil. Available at: www.mme.gov.br/programas/ proinfa.

Qadrdan, M., M. Chaudry, J.Z. Wu, N. Jenkins, and J. Ekanayake (2010). Impact of a large penetration of wind generation on the GB gas network. Energy Policy, 38(10), pp. 5684-5695.

Radtke, J., C.J. Dent, and S.J. Couch (2010). Capacity value of large tidal barrages. IEEE Transactions on Power Systems, doi:10.1109/TPWRS.2010.2095433.

RAE (2007). Decision 85/2007, 25th April 2007: "Adoption of a methodology for determining the growth potential of RES plants in saturated networks in accordance with the provisions of Article $4 \S 1$ of the Licensing Rules for electricity Production from RES and CHP" (in Greek). Regulatory Authority for Energy, Greece, Official Gazette B 448/3.4.2007.

Rajvanshi, A.K., S.M. Patil, and B. Mendonca (2007). Low-concentration ethanol stove for rural areas in India. Energy for Sustainable Development, 11(1), pp. 94-99.

Ramirez, C.A., and W. Worrell (2006). Feeding fossil fuels to the soil. An analysis of energy embedded and technological learning in the fertilizer industry. Resources Conservation and Recycling, 46, pp. 75-93.

Reikard, G. (2009). Forecasting ocean wave energy: Tests of time-series models. Ocean Engineering, 36(5), pp. 348-356.

REN (2008). Plano de investimento e desenvolvimento da rede de transporte 20092014 (2019). Rede Eléctrica Nacional, Lisbon, Spain, 26 pp.

REN21 (2010). Renewables 2010: Global Status Report. Renewable Energy Policy Network for the 21st Century Secretariat, Paris, France, $80 \mathrm{pp}$.

Ren, T., and M.K. Patel (2009). Basic petrochemicals from natural gas, coal and biomass: Energy use and $\mathrm{CO}_{2}$ emissions. Resources, Conservation and Recycling, 53, pp. 513-528.

Reynolds, R. (2000). The Current Fuel Ethanol Industry Transportation, Marketing, Distribution and Technical Considerations. Report Oak Ridge National Laboratory Ethanol Project, Subcontract No. 4500010570, Downstream Alternatives Inc., Bremen, IN, USA, 263 pp.

Riis, T.R., G. Sandrock, E.F. Hagen, Ø. Ulleberg, and P.J.S. Vie (2006). Hydrogen Production and Storage - R\&D Priorities and Gaps. Report (white paper), Hydrogen Implementing Agreement, International Energy Agency, Paris, France, $33 \mathrm{pp}$.

Rodrigues, M., A.P.C. Faaij, and A. Walter (2003). Techno-economic analysis of co-fired biomass integrated gasification/combined cycle systems with inclusion of economies of scale. Energy, 28(12), pp. 1229-1258. 
Rodriguez, G.D. (2010). A utility perspective of the role of energy storage in the smart grid. In: IEEE Power and Energy Society General Meeting, Minneapolis, MN, USA, 25-27 July 2010, pp. 1-2, 25-29.

Rodriguez, J.M., O. Alonso, M. Duvison, and T. Domingez (2008). The integration of renewable energy and the system operation: The Special Regime Control Centre (CECRE) in Spain. In: IEEE Power and Energy Society General Meeting Conversion and Delivery of Electrical Energy in the 21st Century, Pittsburgh, PA, USA, 20-24 July 2008, pp. 1-6, 20-24.

Rossilo-Calle, F., S.V. Bajay, and H. Rothman (2000). Industrial Uses of Biomass Energy: The Example of Brazil. Taylor \& Francis, London and New York.

Rousseau, A. And P. Sharer (2004). Comparing Apples To Apples: Well-to-Wheel Analysis of Current ICE and Fuel Cell Vehicle Technologies. Report No. 2004-011015, Argonne National Laboratory, Argonne, IL, USA.

Salter, S., J. Taylor, and N. Caldwell (2002). Power conversion mechanisms for wave energy. Proceedings of the Institution of Mechanical Engineers, Part M: Journal of Engineering for the Maritime Environment, 216(1), pp. 1-27.

Samaras, C., and K. Meisterling (2008). Life cycle assessment of greenhouse gas emissions from plug-in hybrid vehicles: implications for policy. Environmental Science \& Technology, 42(9), pp. 3170-3176.

Sandsmark, M., and B. Tennbakk (2010). Ex post monitoring of market power in hydro dominated electricity markets. Energy Policy, 38(3), pp. 1500-1509.

Scandiffio, M., and M.R.V. Leal (2008). Novo desenho logístico para exportação de etanol: uma visão de longo prazo. In: $7^{\circ}$ Congresso Internacional sobre Geração Distribuída e Energia no Meio Rural. L.B. Cortez (ed.), AGRENER, Fortaleza, Brazil, 23-26 September 2008. Available at: http://www.nipeunicamp.org.br/agrener/ anais/2008/Artigos/72.pdf.

Scania (2010). World's Largest Ethanol Bus Fleet Grows by 85 Scania Buses. Press release, 21 June 2010, Scania, Södertälje, Sweden. Available at: www.scania. com/media/pressreleases/N10018EN.aspx.

Schäfer, N., T. Degner, J. Jäger, T.Teil, and A. Shustov (2010). Adaptive protection system for distribution networks with distributed energy resources. In: 10th International Conference on Developments in Power System Protection, Manchester, UK, 29 March - 1 April 2010.

Schmidt, J., N. Helme, J. Lee, and M. Houdashelt (2008). Sector-based approach to the post-2012 climate change policy architecture. Climate Policy, 8, pp. 494-515.

Schnepf, R. (2006). Energy Use in Agriculture, Background And Issues - Updated. Congressional Research Service report, Order Code RL32712, Library of Congress, Washington, DC, USA, $40 \mathrm{pp}$.

Schnitzer, H., C. Brunner, and G. Gwehenberger (2007). Minimizing greenhouse gas emissions through the application of solar thermal energy in industrial processes. Journal of Cleaner Production, 15(13-14), pp. 1271-1286.

Schultz, R. (2007). HVDC options today [In my View]. IEEE Power and Energy Magazine, 5(2), pp. 94-96.

Schweppe, F.C., M.C. Caramanis, R.D. Tabors, and R.E. Bohn (1988). Spot Pricing of Electricity. Kluwer Academic Publishers, Boston, MA, USA, 355 pp.

Searchinger, T., R., R.A. Heimlich, F. Houghton, A. Dong, J. Elobeid, S. Fabiosa, D. Tokgoz, and T.-H. Hayes (2008). Use of U.S. croplands for biofuels increases greenhouse gases through emissions from land use change. Science, 319(5867), pp. 1238-1240.

Sebastian, M., J. Marti, and P. Lang (2008). Evolution of DSO control centre tool in order to maximize the value of aggregated distributed generation in smart grid. In: SmartGrids for Distribution. IET-CIRED. CIRED Seminar, Frankfurt, Germany, 23-24 June 2008, pp. 1-4, 23-24
Sensfuß, F., M. Ragwitz, and M. Genoese (2008). The merit-order effect: A detailed analysis of the price effect of renewable electricity generation on spot market prices in Germany. Energy Policy, 36(8), pp. 3076-3084.

Shanmukharadhya, K.S., and K.G. Sudhakar (2007). Effect of fuel moisture on combustion in a bagasse-fired furnace. Journal of Energy Resources Technology, 129(3), pp. 248-254.

Shenyang (2006). Guidance on Promoting the Development and Application of Heat Pumps. Document No.20 (in Chinese), Shenyang City Government, Shenyang, China.

Sherif, S.A., F. Barbir, and T.N. Veziroglu (2005). Towards a hydrogen economy. The Electricity Journal, 18(6), pp. 62-76.

Shiu, H., M. Milligan, B. Kirby, and K. Jackson (2006). California Renewables Portfolio Standard Renewable Generation Integration Cost Analysis: Multiyear analysis results and recommendations. California Energy Commission, Sacramento, CA, USA, 134pp.

Sims, R. (2008). Reaching consensus on sustainable biofuels. Renewable Energy World Magazine, July 2008. Available at: www.renewableenergyworld.com/rea/ news/article/2008/07/reaching-consensus-on-sustainable-biofuels-52692.

Sims, R., M. Taylor, J. Saddler, and W. Mabee (2008). From 1st- to 2nd-Generation Biofuel Technologies - An Overview of Current Industry and RD\&D Activities. IEA, Paris, France, $120 \mathrm{pp}$.

Sioshansi, R., and W. Short (2009). Evaluating the impacts of real-time pricing on the usage of wind generation. IEEE Transactions on Power Systems, 24(2), pp. 516-524.

Sjelvgren, D., S. Andersson, T. Andersson, U. Nyberg, and T.S. Dillon (1983). Optimal operations planning in a large hydrothermal power system. IEEE Transactions on Power Apparatus and Systems, 102(11), pp. 3644-3651.

Smith, J.C., M.R. Milligan, E.A. DeMeo, and B. Parsons (2007). Utility wind integration and operating impact state of the art. IEEE Transactions on Power Systems, 22(3), pp. 900-908.

Smith, J.C., S. Beuning, H. Durrwachter, E. Ela, D. Hawkins, B. Kirby, W. Lasher, J. Lowell, K. Porter, K. Schuyler, and P. Sotkiewicz (2010a). Impact of variable renewable energy on US electricity markets. In: IEEE Power and Energy Society General Meeting, Minneapolis, MN, USA, 25-27 July 2010, pp. 1-12, 25-29.

Smith, J.C., H. Holttinen, D. Osborn, R. Zavadil, W. Lasher, L. Gómez, T. Trötscher, J.O. Tande, M. Korpås, F. Van Hulle, A. Estanqueiro, and L. Dale (2010b). Transmission planning for wind energy: Status and prospects. In: EWEC 2010 European Wind Energy Conference, Warsaw, Poland, 20-23 April 2010.

Söder, L., and H. Holttinen (2008). On methodology for modelling power system impact on power systems. International Journal of Global Energy Issues, 29(1-2), pp. 181-198.

Söder, L., L. Hofmann, A. Orths, H. Holttinen, Y.H. Wan, and A. Tuohy (2007). Experience from wind integration in some high penetration areas. IEEE Transactions on Energy Conversion, 22(1), pp. 4-12.

Stadler, I. (2008). Power grid balancing of energy systems with high renewable energy penetration by demand response. Utilities Policy, 16(2), pp. 90-98.

Statistics Finland (2009). Production of Electricity and Heat 2009. Statistics Finland, Helsinki, Finland, $14 \mathrm{pp}$.

Sterner, M. (2009). Bioenergy and Renewable Power Methane in Integrated 100\% Renewable Energy Systems - Limiting Global Warming by Transforming Energy Systems. PhD Thesis, Kassel University, Kassel, Germany (ISBN: 978-3-89958-798-2). 
Stetz, T., W. Yan, and M. Braun (2010). Voltage control in distribution systems with high level PV-penetration - Improving absorption capacity for PV systems by reactive power supply. In: 25th European Photovoltaic Solar Energy Conference and Exhibition, Valencia, Spain, 6-10 September 2010, pp. 5000-5006.

Stoft, S. (2002). Power Systems Economics - Designing Markets for Electricity. IEE Press Editorial Board, Piscataway, NJ, USA, $496 \mathrm{pp}$.

Stoutenburg, E.D., N. Jenkins, and M.Z. Jacobson (2010). Power output variations of co-located offshore wind turbines and wave energy converters in California. Renewable Energy, 35(12), pp. 2781-2791.

Strauss, P. (2009). Einfluss des Frequenzverhaltens kleiner Generatoren und lasten auf Stromnetze unter besonderer Berücksichtigung großer Netzstörungen. Dissertation, University of Kassel, Kassel, Germany, 128 pp.

Strbac, G. (2008). Demand side management: Benefits and challenges. Energy Policy, 36(12), pp. 4419-4426.

Strunz, K., and H. Louie (2009). Cache energy control for storage: Power system integration and education based on analogies derived from computer engineering. IEEE Transactions on Power Systems, 24(1), pp. 12-19.

Sudol, P. (2009). Modelling and Analysis of Hydrogen Based Wind Energy Transmission and Storage Systems. Massey University, Palmerston North, New Zealand.

Swider, D.J., and C. Weber (2007). The costs of wind's intermittency in Germany: application of a stochastic electricity market model. European Transactions on Electrical Power, 17(2), pp. 151-172.

Takada, M., and N.A. Charles (2006). Energizing Poverty Reduction: A Review of the Energy-Poverty Nexus in Poverty Reduction Strategy Papers. United Nations Development Programme, New York, NY, USA, 117 pp. Available at: www.undp. org/environment/sustainable-energy-library.shtml.

Takada, M., and S. Fracchia (2007). A Review of Energy in National MDG Reports. United Nations Development Programme, New York, NY, USA, 48 pp. Available at: www.undp.org/environment/sustainable-energy-library.shtml.

Taylor, C. (1994). Power System Voltage Stability. McGraw Hill, 273 pp.

Tester, J.W., B.J. Anderson, A.S. Batchelor, D.D. Blackwell, R. DiPippo, and E.M. Drake (eds.) (2006). The Future of Geothermal Energy - Impact of Enhanced Geothermal Systems on the United States in the 21st Century. Prepared by the Massachusetts Institute of Technology, under Idaho National Laboratory Subcontract No. 6300019 for the U.S. Department of Energy, Assistant Secretary for Energy Efficiency and Renewable Energy, Office of Geothermal Technologies, Washington, DC, USA, 358 pp (ISBN-10: 0486477711, ISBN-13: 978-0486477718). Available at: geothermal.inel.gov/publications/future_of_ geothermal_energy.pdf.

Thomson, M., and D.G. Infield (2007). Impact of widespread photovoltaics generation on distribution systems. IET Renewable Power Generation, 1(1), pp. 33-40.

Thorsteinsson, H.H., and J.W. Tester (2010). Barriers and enablers to geothermal district heating development in the United States. Energy Policy, 38, pp. 803-813.

Thyholt, M., and A.G. Hestnes (2008). Heat supply to low-energy buildings in district heating areas: Analyses of $\mathrm{CO}_{2}$ emissions and electricity supply security. Energy and Buildings, 40(131-139)

TN Petróleo (2010). ANP propõe regulação para biocombustível. TN Petróleo, Brazil. Available at: www.tnpetroleo.com.br/clipping/4265/anp-propoe-regulacao-parabiocombustivel.

Torriti, J., M.G. Hassan, and M. Leach (2010). Demand response experience in Europe: Policies, programmes and implementation. Energy, 35(4), pp. 1575-1583.
TradeWind (2009). Integrating Wind. Developing Europe's Power Market for the Large Scale Integration of Wind Power. TradeWind, $104 \mathrm{pp}$.

Transmission Code (2007). Transmission Code: Netz- und Systemregeln der deutschen Übertragungsnetzbetreiber. Verband der Netzbetreiber, Berlin, Germany, 90pp.

TransPower (2008). Grid upgrade plan 2008 Instalment 1, part III: Wairakei Ring Investment proposal. Transpower New Zealand Ltd., Wellington, NZ, 43 pp.

TRB (2009). Modal Primer on Greenhouse Gas and Energy Issues for the Transportation Industry. Research Circular E-C143, Transportation Research Board, Washington, DC, USA (ISSN 0097-8515).

Troy, N., E. Denny, and M. O'Malley (2010). Base-load cycling on a system with significant wind penetration. IEEE Transactions on Power Systems, 25(2), pp. 1088-1097.

Tsikalakis, A.G., and N.D. Hatziargyriou (2008). Centralized control for optimizing microgrids operation. IEEE Transactions on Energy Conversion, 23(1), pp. 241-248.

Tsili, M., and S. Papathanassiou (2009). A review of grid code technical requirements for wind farms. IET Renewable Power Generation, 3(3), pp. 308-332.

Tuohy, A., and M. O'Malley (2011). Pumped storage in systems with very high wind penetration. Energy Policy, 39(4), pp. 1965-1974.

Tyll, H.K., and F. Schettler (2009). Power system problems solved by FACTS devices. In: Power Systems Conference and Exposition, Seattle, WA, USA, 16-18 March 2009, pp. 1-5, 15-18.

Uchida, H. (2010). Policy and action programs in Japan - Hydrogen energy as eco technology. In: WHEC 2010 - 18th World Hydrogen Energy Conference, International Association for Hydrogen Energy, Essen, Germany, 16-21 May 2010.

UCTE (2006). Final Report: System Disturbance on 4 November 2006. Union for the Co-Ordination of Transmission of Electricity, Brussels, Belgium, 85 pp.

Ueda, Y., K. Kurokawa, T. Tanabe, K. Kitamura, and H. Sugihara (2008). Analysis results of output power loss due to the grid voltage rise in grid-connected photovoltaic power generation systems. IEEE Transactions on Industrial Electronics, 55(7), pp. 2744-2751.

Ulleberg, Ø., T. Nakken, and A. Eté (2010). The wind/hydrogen demonstration system at Utsira in Norway: Evaluation of system performance using operational data and updated hydrogen energy system modeling tools. International Journal of Hydrogen Energy, 35(5), pp. 1841-1852.

Ummels, B.C., E. Pelgrum, and W.L. Kling (2008). Integration of large-scale wind power and use of energy storage in the Netherlands' electricity supply. IET Renewable Power Generation, 2(1), pp. 34-46.

UN Energy (2007). Sustainable Bioenergy: A Framework for Decision Makers. United Nations, New York, NY, USA, 64 pp. Available at: esa.un.org/un-energy/pdf/susdev.Biofuels.FAO.pdf.

UNEA (2009). Energy for Sustainable Development: Policy Options for Africa. United Nations Energy Africa, New York, NY, USA. Available at: www.uneca.org/eca_ resources/publications/unea-publication-tocsd15.pdf.

UNDP (2007). World Urbanization Prospects: The 2007 Revision. United Nations Population Division, United Nations, New York, NY, USA, 230 pp. Available at: www.un.org/esa/population/publications/wup2007/2007WUP_Highlights_web. pdf.

UNDP (2009). Small-Scale Finance for Modern Energy Services and the Role of Governments. United Nations Development Programme, New York, NY, USA, 43 pp. 
UNDP and WHO (2009). The Energy Access Situation in Developing Countries - A Review Focusing on the Least Developed Countries and Sub-Saharan Africa. United Nations Development Programme and World Health Organization, New York, NY, USA and Geneva, Switzerland. Available at: content.undp.org/go/newsroom/publications/environment-energy/www-ee-library/sustainable-energy/ undp-who-report-on-energy-access-in-developing-countries-review-of-Idcs--ssas.en.

University of Edinburgh (2006). Matching Renewable Electricity Generation with Demand: Academic study: Full report. University of Edinburgh, Edinburgh, Scotland, $77 \mathrm{pp}$.

US DOE (2004). Energy Information Administration Annual Energy Review 2003. U.S. Department of Energy, Washington, DC, USA, $428 \mathrm{pp}$.

US DOE (2008a). The Net-Zero Energy Commercial Building Initiative. U.S. Department of Energy, Washington, DC, USA. Available at: www1.eere.energy. gov/buildings/initiative.html.

US DOE (2008b). The Smart Grid: An Introduction. U.S. Department of Energy, Washington, DC, USA. Available at: www.oe.energy.gov/DocumentsandMedia/ DOE_SG_Book_Single_Pages(1).pdf.

US DOE and EPRI (1997). Renewable Energy Technology Characterizations. Topical Report, U.S. Department of Energy and EPRI, Washington, DC, USA and Palo Alto, CA, USA, 283 pp.

USDA (2009). Precision, Geospatial and Sensor Technologies. USDA Co-operative State Research Education and Extension Service, Washington, DC, USA. Available at: www.csrees.usda.gov/precisiongeospatialsensortechnologies.cfm.

U.S. Forest Service (2010). Record of Decision - San Diego Gas \& Electric Special Use Authorization for the Sunrise Powerlink Transmission Line Project. San Diego County, California, USA. Available at: http://www.sdge.com/sunrisepowerlink/ docs/ROD_SDGE_\%20SpecialUse.pdf

Utria, B.E. (2004). Ethanol and gelfuel: clean renewable cooking fuels for poverty alleviation in Africa. Energy for Sustainable Development, 8(3), pp. 107-114.

Vandezande, L., L. Meeus, R. Belmans, M. Saguan, and J.M. Glachant (2010). Well-functioning balancing markets: A prerequisite for wind power integration. Energy Policy, 38(7), pp. 3146-3154.

Vannoni, C., R. Battisti, and S. Drigo (2008). Potential for Solar Heat in Industrial Processes. Booklet IEA SHC Task 33 and SolarPACES, CIEMAT, Madrid, Spain, 17 pp.

Velasco, D., C.L. Trujillo, and R.A. Pena (2011). Power transmission in direct current. Future expectations for Colombia. Renewable \& Sustainable Energy Reviews, 15(1), pp. 759-765.

Verbruggen, A. (2006). Electricity intensity backstop level to meet sustainable backstop supply technologies. Energy Policy, 34, pp. 1310-1317.

Verheijen, F., I. Diafas, S. Jeffery, A.C. Bastos, and M. van der Velde (2010). Biochar Application to Soils: A Critical Scientific Review of Effects on Soil Properties, Processes and Functions. Science and Technical Report EUR 24099 EN - 2010, Joint Research Centre, Ispra, Italy, 166 pp.

Vittal, V., J. McCalley, V. Ajjarapu, and U. Shanbhag (2009). Impact of Increased DFIG Wind Penetration on Power Systems and Markets: Final Project Report. Power Systems Engineering Research Center, Tempe, AZ, USA, 221 pp.

Von Braun, J., and R. Meizen-Dick (2009). Land Grabbing by Foreign Investors in Developing Countries - Risks and Opportunities. IFPRI Policy Brief 13, International Food Policy Research Institute, Washington, DC, USA, 8 pp. Available at: www.ifpri.org/sites/default/files/publications/bp013all.pdf.
VTT (2009). Energy Visions 2050 - Summary. VTT Technical Research Centre of Finland, Helsinki, Finland.

Wagner, J. (2009). Nahwärmekonzept Hirtenwiesen II. In: Solarthermie 2009 - Heizen und Kühlen mit der Sonne. VDI Verlag GmbH, Düsseldorf, Germany, pp. 121-132. Available at: www.fachbuch-erneuerbare-energien.de/solarthermie_2010_vdi_ 2074.htm.

Walter, A. (2006). Is Brazilian biofuels experience a model for other developing countries? Entwicklung \& Ländlicher Raum, 40, pp. 22-24.

Wang, L. (2008). Contemporary issues in thermal gasification of biomass and its application to electricity and fuel production. Biomass and Bioenergy, 32(7), pp. 573-581.

Wang, M., H. Huo, L. Johnson, and D. He (2006). Projection of Chinese Motor Vehicle Growth, Oil Demand, and CO, Emissions through 2050. Report ANL/ESD/06-6, Argonne National Laboratory, Energy Systems Division, Argonne, IL, USA.

Wang, R.Z., T.S. Ge, C.J. Chen, Q. Ma, and Z.Q. Xiong (2009). Solar sorption cooling systems for residential applications: options and guidelines. International Journal of Refrigeration, 32, pp. 638-660.

Wangdee, W., W. Li, and R. Billinton (2010). Coordinating wind and hydro generation to increase the effective load carrying capability. In: IEEE 11th International Conference on Probabilistic Methods Applied to Power Systems (PMAPS), Singapore, 14-17 June 2010, pp. 337-342.

WBCSD (2008). Efficient Heat and Power for One Million People (ABB Case Study). World Business Council for Sustainable Development, Geneva, Switzerland, 5 pp WBCSD (2009). Transforming the Market - Energy Efficiency in Buildings. World Business Council for Sustainable Development, Geneva, Switzerland, 72 pp. Available at: www.wbcsd.org/DocRoot/Ge2Laeua8uu2rkodeu7q/91719_ EEBReport_WEB.pdf.

Weber, C. (2010). Adequate intraday market design to enable the integration of wind energy into the European power systems. Energy Policy, 38(7), pp. 3155-3163.

Wei, N., W. Yong, S. Yan, and D. Zhongcheng (2009). Government management and implementation of national real-time energy monitoring system for China large-scale public building. Energy Policy, 37(6), pp. 2087-2091.

Weiss, W., I. Bergmann, and R. Stelzer (2009). Solar Heat World Wide: Markets and Contribution to the Energy Supply 2007. IEA Solar Heating and Cooling Programme, International Energy Agency, Paris, France, 46 pp. Available at: www. energytech.at/pdf/SH_worldwide_2009.pdf.

Weisser, D., and R.S. Garcia (2005). Instantaneous wind energy penetration in isolated electricity grids: concepts and review. Renewable Energy, 30(8), pp. 1299-1308.

Wenger, H.J., T.E. Hoff, and B.K. Farmer (1994). Measuring the value of distributed photovoltaic generation: final results of the Kerman grid-support project. In: IEEE First World Conference on Photovoltaic Energy Conversion. Conference Record of the Twenty Fourth IEEE Photovoltaic Specialists Conference, 5-9 December 1994, Waikoloa, HI, USA, pp. 792-796.

Werner, S. (2004). District heating and cooling. In: Encyclopaedia of Energy, Vol. 1. C.J. Cleveland (ed.), Elsevier, New York, NY, USA, pp. 841-848.

Werner, S. (2006a). ECOHEATCOOL Work package 4 - The European Heat Market. Final report prepared for the EU Intelligent Energy Europe Programme, Euroheat \& Power, Brussels, Belgium, $73 \mathrm{pp}$.

Werner, S. (2006b). ECOHEATCOOL Work package 1 - The European Heat Market Final Report. Euroheat \& Power, Brussels, Belgium, $18 \mathrm{pp}$. 
White, B. (2009). An Updated Assessment of Geothermal Direct Heat Use in New Zealand. New Zealand Geothermal Association, Wellington, NZ, 36 pp.

Widén, J., E. Wäckelgård, and P.D. Lund (2009). Options for improving the load matching capability of distributed photovoltaics: Methodology and application to high-latitude data. Solar Energy, 83(11), pp. 1953-1966.

Wiemken, E., H.G. Beyer, W. Heydenreich, and K. Kiefer (2001). Power characteristics of PV ensembles: experiences from the combined power production of 100 grid connected PV systems distributed over the area of Germany. Solar Energy, 70(6), pp. 513-518.

Wilson, I.A.G., P.G. McGregor, and P.J. Hall (2010). Energy storage in the UK electrical network: Estimation of the scale and review of technology options. Energy Policy, 38(8), pp. 4099-4106.

Wiser, R., and M. Bolinger (2010). 2009 Wind Technologies Market Report. National Renewable Energy Laboratory, Golden, CO, USA, 88pp.

Wolf, A., and K. Petersson (2007). Industrial symbiosis in the Swedish forest industry. Progress in Industrial Ecology, 4(5), pp. 348-362.

Wood, A.J., and B.F. Wollenberg (1996). Power Generation Operation and Control. 2nd ed. John Wiley and Sons, New York, NY, USA, 569 pp.

Woolf, D., J.E. Amonette, F.A. Street-Perrott, J. Lehmann, and S. Joseph (2010). Sustainable biochar to mitigate global climate change. Nature Communications, doi:10.1038/ncomms1053.

Woyte, A., R. Belmans, and J. Nijs (2007). Fluctuations in instantaneous clearness index: Analysis and statistics. Solar Energy, 81(2), pp. 195-206.

Wu, C., W. Lee, C.L. Cheng, and H.-W. Lan (2008). Role and value of pumped storage units in an ancillary services market for isolated power systems - Simulation in the Taiwan power system. IEEE Transactions on Industry Applications, 44(6), pp. 1924-1929.

WWICS (2010). Land Grab: The Race for the World's Farmland (Event 5 May 2009). Woodrow Wilson International Centre for Scholars, Washington, DC, USA. Available at: www.wilsoncenter.org/index.cfm?fuseaction=events. event_summary\&event_id=517903.

Xcel Energy (2009). An Effective Load Carrying Capability Analysis for Estimating the Capacity Value of Solar Generation Resources on the Public Service Company of Colorado System. Xcel Energy Services, Inc., Denver, CO, USA, 13 pp.
Yang, C. (2008). Hydrogen and electricity: Parallels, interactions, and convergence. International Journal of Hydrogen Energy, 33, pp. 1977-1994.

Yang, X., Y. Song, G. Wang, and W. Wang (2010). A comprehensive review on the development of sustainable energy strategy and implementation in China. IEEE Transactions on Sustainable Energy, 1(2), pp. 57-65.

Yu, D., J. Liang, X. Han, and J. Zhao (2011). Profiling the regional wind power fluctuation in China. Energy Policy, 39(1), pp. 299-306.

Zabalza, I., A. Aranda, and M. Dolores de Gracia (2007). Feasibility analysis of fuel cells for combined heat and power systems in the tertiary sector. International Journal of Hydrogen Energy, 32, pp. 1396-1403.

Zah, R., H. Böni, M. Gauch, R. Hischier, M. Lehmann, and P. Wäger (2007). Life Cycle Assessment of Energy Products: Environmental Assessment of Biofuels. Federal Office for the Environment (BFE), Bern, Switzerland, 16 pp. Available at: http://www.bfe.admin.ch/themen/00490/00496/index. html? lang=en\&dossier_id=01273

Zgheib, E., and D. Clodic (2009). $\mathrm{CO}_{2}$ emission and energy reduction evaluations of plug-in hybrids (Paper 2009-01-1234). In: Advanced Hybrid Vehicle Powertrains. SAE International, Warrendale, pp. 399.

Zhang, P., F. Li, and N. Bhatt (2010). Next-generation monitoring, analysis, and control for the future smart control center. IEEE Transactions on Smart Grid, 1(2), pp. 186-192.

Zhang, X.-P., C. Rehtanz, and B. Pal (2006). Flexible AC Transmission Systems: Modelling and Control. Springer, Berlin, Germany, 383 pp.

Zinco, H., B. Bohm, H. Kristjansson, U. Ottosson, M. Rama, and K. Sipila (2008). District Heating Distribution in Areas with Low Heat Demand Density. IEA R\&D Programme on District Heating and Cooling, including the integration of CHP, 117 pp. Available at: www.iea-dhc.org/reports/pdf/Energiteknik_IEA-Finalreport-5.pdf.

Zogg, R., K. Roth, and J. Brodrick (2008). Lake-source district cooling systems. ASHRAE Journal, February 2008. Available at: findarticles.com/p/articles/ mi_m5PRB/is_2_50/ai_n25376339/?tag=content;col1.

Zuurbier, P., and J.V.D. Vooren (eds.) (2008). Sugarcane Ethanol:Contributions to Climate Change Mitigation and the Environment. Wageningen Academic Publishers, Wageningen, The Netherlands. 
